\title{
Palynologische Untersuchungen zur Geschichte von Umwelt und Besiedlung im südwestlichen Harzvorland
} (unter Einbeziehung geochemischer Befunde)

\author{
Dissertation \\ zur Erlangung des Doktorgrades \\ der Mathematisch-Naturwissenschaftlichen Fakultäten \\ der Georg-August-Universität zu Göttingen
}

vorgelegt von

Ina Begemann

aus Rinteln

Göttingen 2003 
Tag der mündlichen Prüfung: 06.11.2003

Referent: Prof. Dr. E. Grüger

Korreferent: Prof. Dr. H. Dierschke 


\section{Inhaltsverzeichnis}

Abbildungsverzeichnis

Seite 3

Abkürzungsverzeichnis

Seite 4

1 Einleitung

Seite 5

2 Das Untersuchungsgebiet

Seite 6

2.1 Naturräumliche Beschreibung

Seite 6

2.2 Böden

Seite 11

2.3 Klima

Seite 11

2.4 Vegetation

Seite 12

3 Siedlungsgeschichte

Seite 14

3.1 Paläolithikum (> 2 Mio. Jahre - 11.590 v. Chr.) ___ Seite 14

3.2 Mesolithikum (11.590-5.500) v.Chr.)

Seite 14

3.3 Neolithikum (5.500 - 2.000 v. Chr.)

Seite 15

3.4 Bronzezeit (2.000 - 700 v. Chr.)

Seite 16

3.5 Vorrömische Eisenzeit (700 v. Chr. - Christi Geburt)

Seite 18

3.6 Römische Kaiserzeit (Christi Geburt - 375 n. Chr.)

Seite 19

3.7 Völkerwanderungszeit (375 - $568 \mathrm{n}$. Chr.) und Merowingerzeit

Seite 22

3.8 Mittelalter und Neuzeit

Seite 22

3.8.1 Siedlungsgeschichte

Seite 23

3.8.2 Verkehrswege

Seite 31

3.8.3 Bergbaugeschichte

Seite 35

3.8.4 Wald- und Forstgeschichte

Seite 40

4 Umweltgeschichte

Seite 55

4.1 Aschenhütter Teich

Seite 55

4.1.1 Material und Methoden

Seite 56

4.1.2 Ergebnisse

Seite 61

4.1.3 Diskussion

Seite 75

4.2 Wittgerode

Seite 79

4.2.1 Material und Methoden

Seite 80

4.2.2 Ergebnisse

Seite 81

4.2.3 Diskussion

Seite 87

4.3 Moosloch

Seite 91

4.3.1 Material und Methoden

Seite 92

4.3.2 Ergebnisse

Seite 96

4.3.3 Diskussion

Seite 104

5 Zusammenfassende Diskussion der Ergebnisse

Seite 109

6 Literatur

Seite 115

7 Anhang

Seite 121 


\section{Abbildungsverzeichnis:}

Abbildung 1: Übersichtskarte des Untersuchungsgebietes und Lage der Untersuchungspunkte Seite 6

Abbildung 2: Naturräumliche Gliederung des Untersuchungsgebietes Seite 7

Abbildung 3: Die „Hohe Straße" im Fernwegenetz Seite 31

Abbildung 4: Die „Hohe Straße“ mit Nebenstrecke / älterer Route Seite 32

Abbildung 5: Der „Fastweg“ Seite 32

Abbildung 6: Die „Landstraße nach Nordhausen“ im Fernwegenetz Seite 33

Abbildung 7: Die „Landstraße nach Nordhausen“ mit Nebenstrecke / älterer Route_Seite 33 Abbildung 8: Die „Harzrandstraße“ im Fernwegenetz Seite 33

Abbildung 9: Verlauf der „Harzrandstraße“ Seite 34

Abbildung 10: Die Harzüberquerung auf dem „Harzweg“ im Fernwegenetz Seite 34

Abbildung 11: Die „Thüringer Heerstraße“ im Fernwegenetz Seite 35

Abbildung 12: Die „Thüringer Heerstraße“ mit Nebenstrecke / älterer Route Seite 35

Abbildung 13: Buchen / Fichtenmischbestände im Harz und ihre Verbreitung Seite 42 Abbildung 14: Lage des Aschenhütter Teiches Seite 55

Abbildung 15: Pollendiagramm des Profils Aschenhütter Teich (BP-Summe $=100 \%$ ) Beilage

Abbildung 16: Die Intensität und Datierung der Siedlungszeiten, zeitgleiche Verhüttungsaktivitäten sowie Bodenerosion im Diagramm vom Aschenhütter Teich (Altersangaben in Kalenderjahren). Seite 78

Abbildung 17: Lage der vermoorten Erdfallsenke Wittgerode Seite 79

Abbildung 18: Pollendiagramm des Profils von Wittgerode (BP-Summe $=100 \%$ ) Beilage

Abbildung 19: Vergleich der Pollenzonen-Datierungen Seite 87

Abbildung 20: Die Datierung der Pollenzonen (biostratigraphisch) und die Dauer des Hiatus (vermutet) im Diagramm Wittgerode Seite 90

Abbildung 21: Lage des Erdfallkessels Moosloch Seite 91

Abbildung 22: Pollendiagramm des Profils vom Moosloch (BP-Summe ohne Betula $=100 \%)$ Beilage

Abbildung 23: Intensität und Datierung der Siedlungszeiten, Verhüttungsaktivitäten und Bodenerosion im Diagramm vom Moosloch Seite 106

Abbildung 24: Datierungen der Pollenzonen, Darstellung der Siedlungszeiten und -intensitäten sowie geochemische Ergebnisse zu Verhüttung und Erosion für das südwestliche und südliche Harzvorland 


\section{Abkürzungsverzeichnis:}

$\begin{array}{ll}{ }^{14} \mathrm{C}(- \text { Datierung) } & \text { Radiokarbondatierung } \\ \text { Jahr / Jahre } \\ \text { AD } & \text { Anno Domini } \\ \text { AMS } & \text { Accelerator-Mass-Spectrometry } \\ \text { BC } & \text { before christ } \\ \text { BP } & \text { Baumpollen, before present } \\ \text { m ü. NN } & \text { Meter über Normal Null } \\ \text { Mio. } & \text { Million } \\ \text { NBP } & \text { Nichtbaumpollen } \\ \text { Pk } & \text { Pollenkorn / Pollenkörner } \\ \text { PZ } & \text { Pollenzone } \\ \text { Sz } & \text { Siedlungszeit } \\ \text { TK 25 } & \text { Topographische Karte, Maßstab 1:25.000 }\end{array}$




\section{Einleitung}

Die vorliegende Arbeit entstand als Teil des durch die Deutsche Forschungsgemeinschaft geförderten Projektes „Erdfallsedimente des südwestlichen Harzvorlandes als Zeugen der Umweltgeschichte der letzten 3000 Jahre unter besonderer Berücksichtigung der frühen Metallgewinnung“.

Ziel der Untersuchung war die Erforschung der regionalen und lokalen Vegetations-, Siedlungs- und Verhüttungsgeschichte anhand von Bohrkernen aus Erdfallsedimenten im Zechsteingürtel des südwestlichen und südlichen Harzvorlandes mit Hilfe pollenanalytischer und geochemischer Methoden. Die Kombination beider Untersuchungsmethoden an Material aus gleichen Beprobungshorizonten innerhalb eines Bohrprofils ermöglichte die unmittelbare Vergleichbarkeit der Ergebnisse zur Entwicklung der Landnutzung und der Metallgewinnung sowie deren wechselseitige Prüfung.

In der vorliegenden Arbeit werden die Ergebnisse der pollenanalytischen Untersuchungen von Sedimentproben aus den Erdfällen vom Aschenhütter Teich zwischen Herzberg und Osterode, von Wittgerode bei Bad Sachsa und vom Moosloch bei Nordhausen vorgestellt und diskutiert.

Die in dieser Arbeit erstellten Pollendiagramme wurden dabei unter besonderer Berücksichtigung der Ergebnisse der geochemischen Untersuchungen ausgewertet, die von Dipl. Geol. M. Deicke im Rahmen seiner Dissertation durchgeführt wurden (Deicke 2003).

Allen, die mir mit Rat und Tat zur Seite gestanden haben und damit zum Gelingen dieser Arbeit beigetragen haben, möchte ich an dieser Stelle meinen herzlichen Dank aussprechen.

Herrn Prof. E. Grüger sei ganz herzlich für die Betreuung meiner Dissertationsarbeit gedankt.

Herrn Prof. H. Ruppert danke ich für die Leitung des Projekts und Matthias Deicke für die lebendige Zusammenarbeit.

Herrn Prof. J. Schneider (Universität Göttingen) möchte ich für die Bereitstellung der Ausrüstung und seine tatkräftige Unterstützung der Bohraktion am Aschenhütter Teich herzlich danken.

Bei der Erstellung der Stratigraphie war die Unterstützung durch Herrn Dr. J. Wiethold (Universität Wiesbaden) sehr hilfreich, auch ihm sei an dieser Stelle sehr herzlich gedankt.

Frau Dr. R. Voigt möchte ich ebenfalls herzlich danken, sie stellte mir ihre unveröffentlichten Auswertungen zur Verfügung.

Für die Bereitstellung archäologischer Informationen danke ich Herrn Dr. L. Klappauf (Goslar) und Herrn Dr. J. Grönke (Nordhausen).

Für die anregenden Gespräche über fachliche Fragen und viele andere wichtige Themen danke ich Frau Dr. W. Kirleis (Göttingen).

Meiner guten Freundin Heike Uphoff danke ich für viele gute Gespräche, ermunternden Zuspruch, erheiternde Anekdoten und Apfelkuchen mit Schlag, der mir die allerletzte heißeste Phase versüßte.

Durch die Höhen und Tiefen der letzten und anstrengendsten Zeit meiner Dissertation begleiteten mich Frank Heilmann und Helge Knieriem, die mir mit viel Sachverstand und Überblick halfen, die letzten Hürden zu nehmen. Herzlichen Dank dafür.

Meine Familie insbesondere meine Eltern, Ursula und Wolfgang Begemann, haben mich in allen meinen Vorhaben unterstützt und mir den Rücken (nicht nur finanziell) gestärkt. Für ihr Vertrauen und ihre Liebe danke ich Ihnen von ganzem Herzen. 


\section{Das Untersuchungsgebiet}

In der vorliegenden Arbeit wird ein Teilbereich des südwestlichen und südlichen Harzvorlandes unter umweltgeschichtlichen Aspekten untersucht. Die wesentlichen Landschaftsmerkmale im südwestlichen und südlichen Teil des Harzvorlandes stimmen so gut überein, dass das gesamte Untersuchungsgebiet im folgenden Text grundsätzlich mit „Südwestliches Harzvorland" bezeichnet wird. In Kapitel 2.1 werden die geomorphologischen, geologischen und geographischen Verhältnisse beschrieben. Die Teillandschaften des Südwestlichen und des Südlichen Harzvorlandes werden dabei getrennt betrachtet.

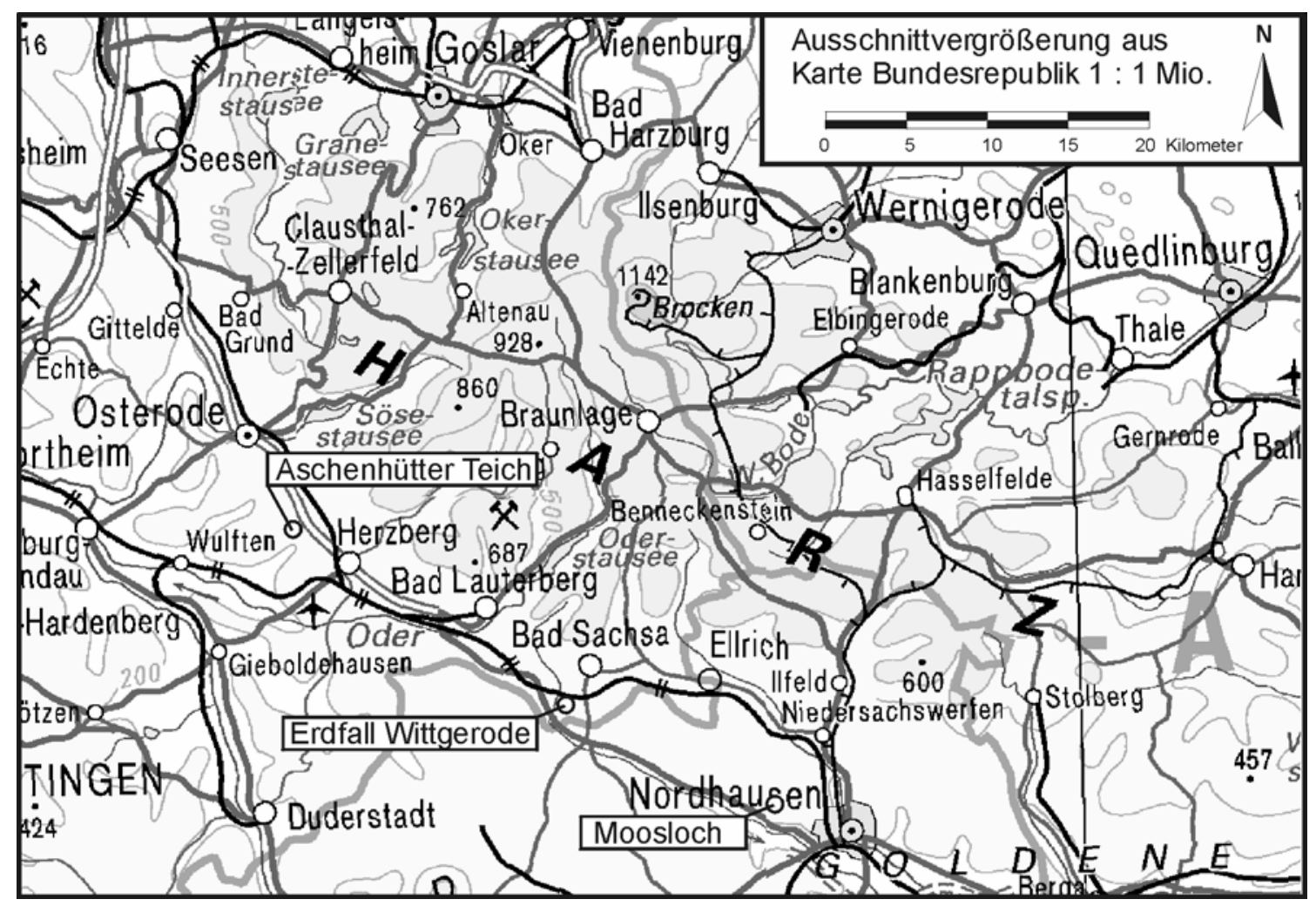

Abbildung 1: Übersichtskarte des Untersuchungsgebietes und Lage der Untersuchungspunkte.

\subsection{Naturräumliche Beschreibung ${ }^{1}$}

Die naturräumliche Gliederung des Untersuchungsgebietes sowie des sich nordöstlich anschließenden Harzgebirges folgt maßgeblich den Vorgaben der Untergrundgeologie. Vor diesem Hintergrund wird zunächst ein erdgeschichtlicher Überblick über die paläozoischen und mesozoischen Ereignisse vermittelt, die zur grundlegenden geomorphologischen Ausprägung des Harzgebirges und seines südwestlichen Vorlandes geführt haben. Auf känozoische Bildungen wie eiszeitliche Lössdecken oder die Ausbildung von Schotterfluren wird dann im Anschluss des (nach BRINKMANN 1976; HENNINGSEN 1981; HERRMANN 1981; WACHENDORF 1986) zusammengefassten erdgeschichtlichen Überblicks im Rahmen der Beschreibung der einzelnen Naturräume eingegangen.

Im Zuge der variszischen Orogenese, die vom Oberdevon bis zum Ende des Paläozoikums andauerte, wurden während der zweiten orogenen Hauptphase im Bereich des heutigen Harzgebirges marine Beckensedimente des variszischen Geosynklinalraumes in steilstehen-

\footnotetext{
${ }^{1}$ Im wesentlichen zitiert nach HÖVERMANN 1963; SPÖNEMANN 1970
} 
de, Nordwest vergente Falten gelegt. Gleichzeitig kam es zur Intrusion magmatischer Schmelzen (z.B. „Brockengranit“). Die mächtige devonisch-unterkarbonische Schichtenfolge der Rheno-Herzynischen Zone steht im Harzgebirge mit Nordost streichenden Faltenachsen und Schichtflächen („variszisches Streichen“) an der heutigen Geländeoberfläche an.

Nach der orogenen Heraushebung erfolgte unter ariden Klimabedingungen bei gleichzeitigem Rückzug des Meeres eine intensive Abtragung des Gebirges bis auf die permische Rumpffläche, die im obersten Perm dem aus nördlicher Richtung transgredierenden Zechsteinmeer als Sedimentationsraum diente. Zu dieser Zeit wurde der Harz mindestens einmal vollständig überflutet. Vor allem an seinem Südwestrand kam es schließlich unter nach wie vor ariden Klimabedingungen im Bereich der als Saturationsschelf dienenden Eichsfeldschwelle zu einer zyklischen Eindampfung des Zechsteinmeeres. So entstanden z.T. mehrere $100 \mathrm{~m}$ mächtige Evaporitfolgen aus Karbonaten, Sulfaten und Chloriden, die nach ihren Löslichkeitsprodukten ausgefällt wurden und heute die vier Serien der Zechsteinstratigraphie am südwestlichen Harzrand bilden.

In einem festländischen Becken, das sich über große Teile von Mitteleuropa erstreckte, erfolgte während der unteren Trias die ebenfalls zyklische Ablagerung der grobklastischen bis tonigen Buntsandstein-Sedimente. Diese wurden nach der Ausbildung eines Binnenmeeres von den mächtigen marinen Karbonatablagerungen des Muschelkalk überdeckt, in die - wie schon zur Zechsteinzeit - evaporitische Folgen eingeschaltet sind.

Im Zuge der Saxonischen Gebirgsbildung mit vorherrschend bruchhafter Tektonik entlang intrakontinentaler Schwächezonen erfolgte seit der Unteren Kreide eine in mehreren Schüben nach Nordosten gerichtete Heraushebung des Harzgebirges als Pultscholle entlang der Nordwest/Südost streichenden Harz-Nordrand-Aufschiebung des Grundgebirges über das Deckgebirge. Sowohl die Hebungsbeträge als auch die Verkippung nahmen nach Südwesten hin drastisch ab, so dass auch die Schichtflächen der Zechstein- und Buntsandsteinfolgen im Südwestlichen Harzvorland, die dort das Grundgebirge diskordant überlagern, nur leicht in diese Richtung einfallen. Ihr Streichen folgt dabei der herzynischen Richtung, die dem Harzgebirge seine äußere geographische Orientierung verleiht und nahezu senkrecht zur variszischen Hauptrichtung der paläozoischen Strukturen steht.

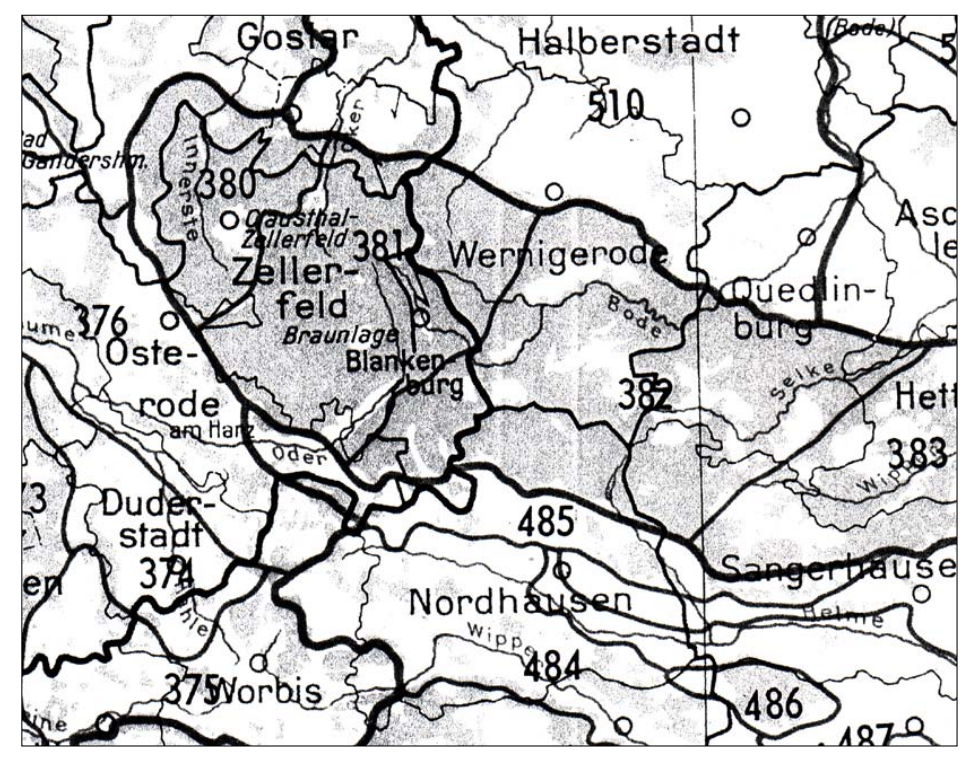

Abbildung 2: Naturräumliche Gliederung des Untersuchungsgebietes nach MEYNEN et al. (1962). Die mit Nummern versehenen Einheiten werden im folgenden Text beschrieben. 


\section{Südwestliches Harzvorland}

Das Südwestliche Harzvorland (376; Abb. 2) ist eine stark strukturierte Schichtstufenlandschaft, deren Relief maßgeblich durch die wechselhaften Verwitterungsresistenzen der im Untergrund anstehenden Schichtpakete des Zechstein (oberes Perm) und des Unteren Buntsandstein (untere Trias) geprägt wird. Lössbedeckte Becken und Platten bilden dabei mit Kuppen aus Sand- oder Kalkstein bzw. Dolomit ein kleinräumiges Mosaik. Das charakteristische Nebeneinander von Hochflächen und Senken wird mehrfach von breiten Schotterfluren aus drenthezeitlichen Niederterrassensedimenten der aus dem Harz kommenden Flüsse Söse, Sieber und Oder durchbrochen und so in einzelne Blöcke zerteilt. Fluviatile Mittelterrassensedimente sind aufgrund ihrer Lössbedeckung selten aufgeschlossen. Zwischen Osterode und Herzberg erstreckt sich entlang des unmittelbaren Harzrandes ein bedeutender Aufschluss der elsterzeitlichen Oberterrasse. Das Vorkommen breiter Schotterfluren auch im Auebereich stellt in Norddeutschland eine Eigenart des Nördlichen und Südwestlichen Harzvorlandes dar und ist auf die hohe Reliefenergie sowie die starke Wasserführung der Harzflüsse bis zum Bau der Talsperren zurückzuführen. So wurden im Rahmen holozäner Hochwasser der anthropogen unbeeinflussten Harzflüsse sowohl Niederterrassenschotter aufgearbeitet als auch Sand und Kies aus dem Harzgebirge ins Vorland verfrachtet. Die stark anthropogen beeinflusste Bildung von Auelehmen durch die Erosion der Lössdecken von den Hochlagen wurde somit in diesen Talbereichen stark erschwert (MENSCHING 1950; RICKEN 1982).

Im Bereich des Sösetals bestimmen Schotterablagerungen gänzlich das Landschaftsbild. Im südwestlich ausgerichteten Teil des Sösetals ist die Talsohle dabei mit Auelehm ausgekleidet, während im nordwestlich ausgerichteten, dem Harzrand näheren Abschnitt terrassenförmige Schotterablagerungen vorherrschen. Im Untergrund stehen Karbonatgesteine der Zechstein- sowie untergeordnet der Muschelkalkformation über unterkarbonischem Grundgebirge aus Grauwacken und Tonsteinen an. Die fast durchgängige quartäre Überdeckung lässt die unterschiedlichen Eigenschaften der Festgesteine in Hinblick auf Bodenbildung und Vegetation jedoch zurücktreten.

Weiter südlich steigen die Osteroder Kalkberge steil auf $300 \mathrm{~m}$ ü. NN an. Diese aus Zechsteindolomit bestehende Hochfläche ist in für Karstgebiete typischer Weise extrem trocken. Die rasch versickernden Niederschlagswässer und vor allem die Wasserführung des unterirdisch ausgebildeten Karstwasserleiters haben hier durch Auslaugung vergipster Anhydritvorkommen im Liegenden an der Oberfläche zur Bildung zahlreicher Karstformen (z.B. Erdfälle) geführt, von denen das gesamte Gebiet durchsetzt ist. Sowohl die Hochfläche als auch die dortigen Trockentäler sind mit einer geringmächtigen Lössschicht bedeckt. Nach Südwesten dacht die Hochfläche bis auf $250 \mathrm{~m}$ ü. NN ab.

Im Südwesten der Osteroder Kalkberge grenzen diese an die Osteroder Buntsandsteinberge als flacher Schichtstufe des Unteren Buntsandstein. Diese dacht unter Ausbildung mehrerer Terrassen nach Südwesten ab, wo die Hochfläche zum Teil von Löss überdeckt ist. In den bis zu 100 m tief eingeschnittenen Tälern fließt im Gegensatz zu den Trockentälern der Kalkberge regelmäßig Wasser. Dennoch kommt es auch in diesem Gebiet durch bis in die Gegenwart andauernde Auslaugungsprozesse im liegenden Zechstein zu Verkarstungserscheinungen und der damit verbundenen Bildung von Erdfällen durch Einsturz und Nachsacken der Buntsandsteinbedeckung über Hohlräumen. Das südwestliche Harzvorland und der südliche Zechsteingürtel, insbesondere die Gebiete um Osterode und Walkenried, gehören zu den bedeutendsten Gipskarstgebieten Deutschlands (MOHR 1982). Der Aschenhütter Teich, der Jues See bei Herzberg und die Jettenhöhle bei Düna gehen auf derartige Prozesse zurück.

Die Flussläufe der Harzflüsse Oder und Sieber werden von Schotterfluren mit einer das Landschaftsbild dominierenden Breite zwischen 1 und $4 \mathrm{~km}$ begleitet. Diese Fluren bestehen vorwiegend aus groben Harzgeröllen und erheben sich nur wenige Meter über die Flussbetten. Die „Aue“ südwestlich von Herzberg war noch bis zum Ende der letzten Eiszeit das Tal der Sieber. Hier herrschen meist grobe Schotterrohböden vor. 
Begünstigt durch die hohe Durchlässigkeit der Schotterfluren verlieren Oder und Sieber z.T. enorme Wassermengen an den unterirdischen Karstwasserleiter, der dem Ausbiss der Zechsteinformation parallel zum Harzrand sowie deren Abtauchen unter hangende Buntsandsteinschichten folgt und so eine der bekanntesten und ergiebigsten Karstquellen Deutschlands speist, die Rhumequelle 6 km südlich von Herzberg (HERRMANN 1981).

Eingeschlossen zwischen den Schotterfluren der „Aue“, der rezenten Sieber und der Oder befindet sich der Herzberger Burgberg Der nordöstliche Teil dieser nach Südwesten abfallenden, meist lössbedeckten Hochfläche besteht aus Zechsteindolomit, der im südwestlichen Teil von Gesteinen der Unteren Buntsandsteinfolge überlagert wird, die hier an der Oberfläche anstehen. Das Schloss Herzberg, dem der Berg seinen Namen verdankt, befindet sich auf der äußersten Nordostspitze des Plateaus.

Südwestlich der „Aue“ stehen die z.T. lössbedeckten Niederterrassensedimente der Oder an, die als Herzberger Vorlandterrassen bezeichnet werden.

Das Relief des sich östlich anschließenden Südharzrandes wird von Hügeln aus Zechsteindolomit geformt, welche die Talauen der Harzflüsse um 50 bis 80 m überragen. Die Scharzfelder und Bartolfelder Zechsteinhügel tragen häufig felsige Gipfelkuppen und sind durch Karstprozesse im Untergrund an der Geländeoberfläche mit Erdfällen übersät. Während die überwiegend flachen Südhänge mit Braunerden bedeckt sind, haben sich auf dem scharfkantig gebrochenen Dolomitschutt der steilen Nordhänge Rendzinaböden entwickelt.

\section{Südliches Harzvorland (485)}

Die Landschaftsmerkmale des südwestlichen Harzvorlandes setzen sich nach Osten im 1 bis $7 \mathrm{~km}$ breiten Südharzer Zechsteingürtel fort, der den südlichen Harzrand in nordwestsüdöstlicher Längserstreckung säumt. Neben den zum Teil schluchtartig eingetieften Tälern der Harzflüsse und größeren Erdfällen ragen hier die Härtlingsrücken aus Zechsteinsteindolomit schroff in die Höhe. Die Römersteine bei Bad Sachsa beispielsweise erreichen eine Höhe von 340-380 m ü. NN und erheben sich dabei 80-100 m über die Flusstäler. Eine durch Auslaugung von vergipstem Anhydrit des Zechstein entstandene Subrosionsrinne verläuft in der Mitte des Gebietes auf einer Höhe von 210-260 m ü. NN parallel zum Harzrand. Sie ist mit kiesig-sandigen Schottern der Harzflüsse bedeckt und trägt teilweise eine Lösslehmschicht (BAUER 1962c).

Die sich an das südwestliche Harzvorland anschließenden Walkenrieder und Petersdorfer Hügelländer als Teilbereiche des Südharzer Zechsteingürtels gleichen mit ihrem mosaikartigen Relief aus Zechsteinhügeln und Schotterfluren den nordöstlichen Scharzfelder und Bartolfelder Hügelländern. Unter der von Karsterscheinungen geformten Oberfläche befinden sich mächtige Dolomitdecken, die das Landschaftsbild durch Ausbildung zum Teil steilhängiger Plateaus und felsiger Kuppen prägen. Im Petersdorfer Zechsteinhügelland überwiegt Gips in den anstehenden Sedimentgesteinen, durch dessen Verwitterung nährstoffarme Gipsböden von pulvriger Konsistenz entstanden sind.

Am südöstlichen Harzrand schließt sich der nur wenige hundert Meter breite Uftrunger Zechsteingürtel an, der morphologisch betrachtet ebenfalls aus Erdfällen, Kuppen und Trockentälern zusammengesetzt ist.

Wie bereits für das südwestliche Harzvorland beschrieben, zerteilen auch die südlichen Harzflüsse wie Zorge, Bere und Thyra den Zechsteingürtel mit ihren Tälern. Diese bestehen aus schmalen, feuchten Auen und bis zu mehrere hundert Meter breiten Schotterterrassen, die teilweise lössbedeckt sind und sich bis zu $60 \mathrm{~m}$ über die Talsohlen erheben. Auf inrem Weg durch das Karstgebiet verlieren auch diese Flüsse erhebliche Wassermengen an die unterirdischen Karstwasserleiter, von denen wiederum stark schüttende Karstquellen gespeist werden (BAUER 1962c).

In südlicher Richtung schließt sich an den Südharzer Zechsteingürtel das Nordthüringische Hügelland (484) an. Dabei handelt es sich um ein Buntsandsteingebiet, dessen flach nach 
Süden einfallende Schichten in Platten und Hügel aufgelöst worden sind, deren ruhiges Relief lediglich durch einige Erdfälle unterbrochen wird (BAUER 1962b).

Im Bereich der ostwärts gerichteten Oberen Helmeniederung (mittlere Höhe 220-260 m ü. NN) verlaufen die Fließgewässer in flachen Muldentälern. Durch die Auslaugung von mächtigen Steinsalz- und Gipslagen des Zechstein wurde die Helmeniederung (487.0) gebildet. Diese südostwärts gerichtete Talniederung erfuhr eine starke pleistozäne Aufschotterung. Im Helmerieth am Südharzrand erreichen diese Schotter eine Mächtigkeit von $200 \mathrm{~m}$. So entstand ein breiter und ebener Talboden, der seit dem Mittelalter von Auelehm bedeckt ist (Goldene Aue) (BAUER 1962a).

Östlich von Nordhausen grenzt ein nordwestlicher Ausläufer des Unteren Unstrut-Berg- und Hügellandes an das Untersuchungsgebiet. Im Untergrund des Nordhausener Plattenlandes steht eine Kalk-Sandstein Wechselfolge des Unteren Buntsandstein an, die durch die Täler der Harzflüsse in einzelne Platten zerteilt wird. Das Gelände fällt von etwa $300 \mathrm{~m}$ ü. NN nach Süden auf etwa $200 \mathrm{~m}$ ü. NN ab.

\section{Harzgebirge}

Das maßgeblich an der Prägung des gesamten Harzvorlandes beteiligte und bergbaugeschichtlich so bedeutende Harzgebirge ist die nördlichste und mit der Brockenspitze zugleich auch die höchste Erhebung der Mittelgebirgsschwelle. Seine Gesamtausdehnung beläuft sich auf eine Länge von $90 \mathrm{~km}$ und eine Breite von $30 \mathrm{~km}$ (HÖVERMANN 1962).

Der geologische Untergrund des Hochharzes (381) besteht im Osten aus Intrusivgesteinen des Oberkarbon („Brockengranit“), die dem zweiten magmatischen Zyklus der variszischen Gebirgsbildung zuzuordnen sind. Im Westen dagegen, südlich von Altenau, stehen Quarzite des Unterkarbon mit Nordost streichenden Strukturen an (Kammquarzit des Acker-Bruchberges). Der Hochharz überragt die inn umschließende Hochfläche des Oberharzes. Mit dem Brockenmassiv (1142 $\mathrm{m}$ ) befindet sich hier die höchste Erhebung des gesamten Gebirges.

Der West- oder Oberharz (380), ein steil aufragendes Massiv aus paläozoischen Grauwacken, Tonschiefern, Quarziten, Graniten und Diabasen, erreicht Höhen von 600-700 m ü. NN. Sein Zentrum bilden unterschiedlich stark zertalte Hochflächen, die sich zum Rand hin in tief eingeschnittene Täler auflösen.

Die Hochfläche des Südlichen Oberharzes dacht nach Süden von 700 auf $500 \mathrm{~m}$ ü. NN ab und wurde von den Flussläufen der Wieda, Oder und Sieber in schmale, langgestreckte Riedel und einzelne Bergkuppen zerteilt. So entstand das am tiefsten zertalte Gebiet des Oberharzes.

Der Unterharz (382), eine ebene bis schwach wellige Hochfläche, die sich allmählich nach Osten hin abdacht, ist schwer gegen den Oberharz abzugrenzen. Als Grenzmarkierung wird daher die 1000 mm-Jahresisohyete herangezogen, die den gesamten Westharz einschließt.

Der Südrand des Unterharzes ist ein tief zerschnittenes, gestaffeltes Bergland. Seine Hochfläche wird fast ausschließlich nach Norden entwässert. In südlicher Richtung verlässt als einziges Tal die Bere das Plateau. Die übrigen nach Süden ausgerichteten Täler sind auf den stark zertalten Randbereich der Südabdachung beschränkt.

Abgesehen von ihren Randsäumen ist die Östliche Harzabdachung (383) schwach nach Osten geneigt. Die Geländeoberfläche liegt unter $400 \mathrm{~m}$ ü. NN, wobei die größeren Täler in der Regel weniger als $40 \mathrm{~m}$ eingetieft sind. Aufgrund des dichten Talsystems entsteht der Eindruck eines gewellten Hügellandes. 


\subsection{Böden}

Im Untersuchungsgebiet herrschen weitgehend unterschiedlich stark gebleichte Braunerden vor. Das räumliche Auftreten davon abweichender Bodentypen wurde bereits in Kapitel 2.1 in Hinblick auf die im Untergrund anstehenden Fest- und Lockergesteine erwähnt. In Tabelle 1 sind die wichtigsten Bodentypen in der Nähe der Untersuchungspunkte (nach HöVERMANN 1963; SPÖNEMANN 1970) zusammengestellt und den naturräumlichen Einheiten zugeordnet.

Tabelle 1: Wichtige Bodentypen in der Umgebung der Untersuchungspunkte, die Ziffern beziehen sich auf Untereinheiten der in Abb. 2 dargestellten naturräumlichen Einheiten (HöVERMANN 1963; SPÖNEMANN 1970)

\begin{tabular}{|c|c|c|c|}
\hline Naturräumliche Einheit & $\mathrm{Nr}$ & Bodentyp & Anmerkungen \\
\hline $\begin{array}{l}\text { Schotterfluren der Rhume, } \\
\text { Oder, Sieber }\end{array}$ & 376.23 & grobe Schotterrohböden & \\
\hline $\begin{array}{l}\text { Bartolfelder \& Scharzfelder } \\
\text { Zechsteinhügel }\end{array}$ & $376.26 \& 27$ & flachgründige Rendzinen & $\begin{array}{l}\text { meist an den nördlichen } \\
\text { Steilhängen der Hügel, } \\
\text { nährstoffarm }\end{array}$ \\
\hline $\begin{array}{l}\text { Liebenroder Hügelland \& } \\
\text { Trebraer Plattenland }\end{array}$ & $484.0 \& 1$ & $\begin{array}{l}\text { lehmige und sandig-lehmige } \\
\text { Braunerden, z.T. schwach } \\
\text { podsolig }\end{array}$ & \\
\hline Obere Helmeniederung & 484.2 & mineralische Nassböden & nährstoffreich \\
\hline \multirow{2}{*}{$\begin{array}{l}\text { Walkenrieder } \\
\text { Zechsteinhügelland }\end{array}$} & \multirow[t]{2}{*}{485.0} & flachgründige Rendzinen & nährstoffarm \\
\hline & & tonige Braunerden & schwer \\
\hline $\begin{array}{l}\text { Petersdorfer } \\
\text { Zechsteinhügelland }\end{array}$ & 485.1 & lockere, pulvrige Gipsböden & nährstoffarm \\
\hline Helme-Unstrut-Niederung & 487 & $\begin{array}{l}\text { schwach degradierte } \\
\text { Schwarzerdeböden }\end{array}$ & $\begin{array}{l}\text { auf lössbedeckten } \\
\text { Terrassenflächen, sehr gute } \\
\text { Ackerböden (nährstoffreich und } \\
\text { leicht) }\end{array}$ \\
\hline
\end{tabular}

\subsection{Klima ${ }^{2}$}

Die Jahresmitteltemperatur am gesamten westlichen Harzrand beträgt $7,5^{\circ} \mathrm{C}$ (z.B. Station Bad Sachsa, $324 \mathrm{~m}$ ü. NN). Im weiteren Harzvorland steigt sie bei geringerer Meereshöhe auf $8{ }^{\circ} \mathrm{C}$ an (z.B. Station Seesen, $200 \mathrm{~m}$ ü. NN). Die Hauptvegetationsperiode am Harzrand beträgt 185-189 Tage mit Tagesmitteltemperaturen über $10^{\circ} \mathrm{C}$ (PFLUME 1999). Ausgewählte Klimadaten für das westliche und südwestliche Harzvorland sind in Tabelle 2 zusammengestellt.

Die vorherrschenden Windrichtungen in der freien Atmosphäre sind aufgrund der Lage des Harzes in der Westwindzone der gemäßigten Breiten Südwest, West und Nordwest. In Tälern jedoch treten durch die Geländeform in Bodennähe beeinflusste Windrichtungen auf, die in der Regel dem Talverlauf folgen. Der Gebirgskörper des Harzes bewirkt am Südharzrand eine Abschirmung nach Norden, so dass hier Winde dieser Richtung fast vollständig ausbleiben. Dafür treten überdurchschnittlich häufig gebirgsrandparallele Westwinde auf, welche durch die Wirkung des Gebirgsrandes als Strömungsleitlinie begünstigt werden. Am Nordharzrand hingegen werden westliche bis südwestliche Winde aufgrund der Leelage abgelenkt und treten seltener in Erscheinung.

In den Tälern kommt es bei antizyklonalem Einfluß zur Ausbildung von Tal-Bergwindsystemen. Dabei strömt die Luft tagsüber tal- und hangaufwärts, während nachts Luftströmungen in entgegengesetzter Richtung vorherrschen. Zusätzlich entwickelt sich ein überlagerndes

\footnotetext{
${ }^{2}$ Im wesentlichen zitiert nach GLÄSSER 1994
} 
Vorland/Gebirgswindsystem. Die Luft strömt dabei am Tag vom Vorland zum Gebirge und von den Hochharzflächen zum Hochharz, was die Ausbildung einer dichten Bewölkung zur Folge hat. Nachts sinkt die Luft aus dem Hochharz zum Vorland hin ab und die Bewölkung löst sich wieder auf.

Tabelle 2: Ausgewählte Klimadaten für das westliche und südwestliche Harzvorland (GLÄSSER 1994; PFLUME 1999; SCHÖNFELDER 1978)

\begin{tabular}{|c|c|c|}
\hline \multirow{2}{*}{ Jahresmitteltemperatur } & Bad Sachsa (324 m ü. NN) & $7,5^{\circ} \mathrm{C}$ \\
\hline & Seesen (200 m ü. NN) & $8,0^{\circ} \mathrm{C}$ \\
\hline Hauptvegetationsperiode $\left(>10^{\circ} \mathrm{C}\right)$ & \multicolumn{2}{|c|}{ 185-189 Tage } \\
\hline Jahresniederschlagsmittel & Osterode & $913 \mathrm{~mm}$ \\
\hline & Herzberg & $783 \mathrm{~mm}$ \\
\hline & Bad Sachsa & $935 \mathrm{~mm}$ \\
\hline & Walkenried & $846 \mathrm{~mm}$ \\
\hline
\end{tabular}

Die durchschnittliche jährliche Niederschlagsmenge ist aufgrund der vorherrschenden Westwinde im westlichen und südwestlichen Harzvorland relativ hoch. Sie beträgt auf einer Höhe von $300 \mathrm{~m}$ ü. NN im Jahresmittel etwa $800-900 \mathrm{~mm}$. Die $800 \mathrm{~mm}$-Isohyete verläuft in $5 \mathrm{~km}$ Entfernung parallel zum Gebirgsrand, während die $700 \mathrm{~mm}$-lsohyete weitere $5 \mathrm{~km}$ außerhalb des Gebirgsrandes ebenfalls parallel zu diesem verläuft.

Direkt am westlichen und südwestlichen Harzrand wird ein mittlerer Jahresniederschlag von 800-900 mm erreicht, während in den Randtälern 1000-1200 mm Niederschlag überschritten werden. In den Tälern östlich des Odertals nehmen die Niederschläge mit zunehmend östlicher Lage ab (Wieda: $1050 \mathrm{~mm}$, Stolberg: $760 \mathrm{~mm}$ ). In gleicher Weise verringern sich die Niederschläge am direkten Südharzrand und im südlichen Harzvorland von Westen nach Osten von $900 \mathrm{~mm}$ (Bad Lauterberg: $915 \mathrm{~mm}$ ) bis auf $500 \mathrm{~mm}$ (östl. Teil der Helmeniederung) pro Jahr. Am nördlichen Harzrand nehmen die jährlichen Niederschläge von $800 \mathrm{~mm}$ im Westen auf etwa $560 \mathrm{~mm}$ im Osten ebenfalls ab, da sich die Leewirkung des Gebirges in östlicher Richtung verstärkt.

\subsection{Vegetation}

Im südwestlichen Harzvorland bilden auf den Standorten mit basenarmen Braunerden über Buntsandstein Hainsimsen-Buchenwälder (Luzulo-Fagetum) und kleinflächig trockene Buchen-Traubeneichenwälder (Luzulo-Quercetum petraeae) in der kollinen bis submontanen Höhenstufe (unter ca. $450 \mathrm{~m}$ ü. NN) die heutige Vegetation. Auf basenreichen Braunerden über Kalk sind es Perlgras-Buchenwälder (Melico-Fagetum). Besonders im submontanen Bereich wird ein großer Teil dieser Standorte heute von Fichtenforsten eingenommen (DRACHENFELS 1990).

In begrenztem Umfang treten auf Standorten mit mäßigem Grundwasser-Einfluss Sternmieren-Eichen-Hainbuchenwälder (Stellario-Carpinetum) auf. Auf eher flachgründigen, trockenen Standorten zumeist auf Kalkgesteinen tritt der Elsbeeren-Eichen-Hainbuchenwald (Galio-Carpinetum) auf, der durch Mittelwaldnutzung der natürlichen Buchenwaldgesellschaft anthropogen entstanden ist (DIERSCHKE 1986).

Die nährstoffreicheren Standorte werden fast vollständig von Ackerland, Wiesen und Weiden eingenommen. Auf ärmeren Standorten dagegen befinden sich häufig Fichtenforste.

Die wichtigsten natürlichen Waldgesellschaften im Bereich des Gipskarstes sind der Orchideen-Buchenwald (Carici-Fagetum) und der Frühlings-Platterbsen-Buchenwald (LathyroFagetum). An Steilhängen treten natürliche, waldfreie Reliktrasen-Gesellschaften auf (Cardaminopsio-Festucetum pallentis, Sesleria-Gesellschaften), die eine Besonderheit dieses Raumes darstellen (SCHÖNFELDER 1978). Durch die ehemalige Beweidung großer Teile dieses Gebietes vor allem durch Schafherden konnten sich Kalkmagerrasen (Festuco- 
Brometea) ausbreiten, die heute noch an vielen Stellen anzutreffen sind. Diese unter Naturschutz stehenden Gesellschaften sind aktuell stark durch den Gipsabbau und die weitgehende Aufgabe der Beweidung im Untersuchungsgebiet bedroht (JANDT 1999).

Die Schotterablagerungen entlang der Fließgewässer im kollinen Harzvorland bilden ein basen- und nährstoffarmes Ausgangssubstrat. Der Wasserdurchzug und die häufigen Überflutungen liefern jedoch ausreichend Nährstoffe, so dass hier Gesellschaften mit üppigem Pfanzenwuchs gedeihen können. Im Bereich des amphibischen Ufersaumes, der meist nur eine Breite von 1-2 m aufweist, handelt es sich dabei um verschiedene gehölzfreie Ufergesellschaften wie Spülsaum-Röhricht-Zwillingsgesellschaften (Bidentetea - Rumici-Phalaridion), artenarme Glanzgras-(Phalaris arundinacea-) Röhrichte, Staudensaum-RöhrichtZwillingsgesellschaften (Artemisietea-Rumici-Phalaridion) und Pestwurz-Uferfluren (Aegopodio-Petasitetum hybridi). Daran schließen sich schmale Ufer- und Auenwälder an, die eine üppige und hochwüchsige Krautschicht besitzen. Es handelt sich dabei um Erlen-Uferwälder (Stellario nemori-Alnetum aegopodietosum) und Eschen-Auenwälder.

Beide Waldgesellschaften sind nur fragmentarisch im Harzvorland erhalten, da der Bereich der Talaue in der Regel intensiv agrarisch genutzt wird. Häufig handelt es sich lediglich um sehr schmale, galerieartige Wälder entlang der Fließgewässer oder lockere Baumreihen, die durch ihre Freistellung und das eindringende Weidevieh stark anthropogen verändert sind. Es treten darüber hinaus häufig mehrstämmige Bäume auf, die als Überreste einer ehemaligen Niederwaldnutzung gewertet werden müssen (DIERSCHKE et al. 1983).

Die heutige Vegetation des südwestlichen Harzvorlandes ist stark anthropogen geprägt. Die fruchtbaren Lössgebiete werden als Ackerland bewirtschaftet, während feuchte und frische Bereiche der Auen als Wiesen und Weiden genutzt werden. Ungünstigere Standorte werden forstlich genutzt, wobei Braunerden häufig mit Fichtenforsten bestanden sind und Rendzinen in der Regel Buchenforste tragen.

Im Bereich der montanen Höhenstufe (ca. 450-750 m ü. NN) des Harzes sind auf den basenarmen Standorten als heutige potentiell natürliche Vegetation Hainsimsen-Buchenwälder (Luzulo-Fagetum) und Fichten-Buchenwälder (Calamagrostio villosae-Fagetum) beschrieben worden. Im hochmontanen Bereich bilden Wollreitgras-Fichtenwälder (Calamagrostio villosae-Piceetum), die nur teilweise Buchen enthalten, die heutige potentiell natürliche Vegetation. Die Fichte bildet schließlich die Waldgrenze, die großflächig nur am Brocken erreicht wird (DRACHENFELS 1990).

Als Folge des mittelalterlichen Bergbaus entstanden besonders entlang der Flüsse und Bäche im Harz und im Harzvorland zahlreiche schwermetallhaltige Schlackenplätze. Da die hohe Metallionen-Konzentration dieser Böden für die meisten Pflanzen toxisch ist, siedelt hier die Erzflechtengesellschaft (Acarosporetum sinopicae) und der Harzer SchwermetallGrasnelkenrasen (Armerietum halleri) (DIERSCHKE 1969). Auch die Ausbreitung des Heidekrautes (Calluna vulgaris) im Bereich ehemaliger Schlackenhalden und Verhüttungsplätze konnte im Harz mehrfach beobachtet werden. 


\section{Siedlungsgeschichte}

Die Siedlungsgeschichte des südwestlichen Harzvorlandes wird im folgenden Text chronologisch beschrieben. Zusätzlich werden die wichtigsten archäologischen Befunde in tabellarischer Form dargestellt.

\subsection{Paläolithikum (> 2 Mio. Jahre -11.590 v. Chr.)}

Die Altsteinzeit ist der älteste Abschnitt der Menschheitsgeschichte. Sie begann im Tertiär mit dem Erscheinen der Australopethicinen im östlichen Afrika vor mehr als 2 Millionen Jahren. Während des anschließenden Pleistozäns mit seinen Wechseln von Kalt- und Warmzeiten entwickelten sich zahlreiche Menschenformen, die sich seit dem Auftreten des Homo erectus auch nach Europa verbreiteten. Alle während des Paläolithikums auftretenden Kulturen waren Wildbeuter und nutzten somit als „Jäger und Sammler“ die Resourcen der in dieser Zeit starken Schwankungen unterworfenen Umwelt. Während der Kaltzeiten traten in den waldlosen Kältesteppen Mitteleuropas beispielsweise Mammut, Rentier und Wollnashorn auf. In den warmzeitlichen Wäldern dagegen lebten Waldelefant, Rothirsch und Flusspferd (HÄßLER 1991).

Die ältesten Funde, welche die Anwesenheit von Menschen im südwestlichen Harzvorland belegen, sind etwa 14.000-16.000 Jahre alt. Sie gehören dem Jungpaläolithikum an. Der Rastplatz einer Gruppe von Rentierjägern der späten Magdalénien-Kultur konnte 1926 vor dem Höhlenportal der „Steinkirche“, einer natürlichen Dolomithöhle im Steinberg nördlich von Scharzfeld, entdeckt werden. Neben Stein- und Knochengeräten sowie einer Feuerstelle konnten Knochen von Rentier, Mammut, Wisent, Wildpferd und wollhaarigem Nashorn sichergestellt werden (CLAUS 1978; FLINDT \& LEIBER 1998; VEIL 1988).

\subsection{Mesolithikum (11.590-5.500 v.Chr.)}

Die Mittlere Steinzeit fasst die Wildbeuterkulturen seit Beginn der letzten Warmzeit, des Holozäns, zusammen. Die Umweltbedingungen änderten sich durch die zunehmende Erwärmung und die Wiederbewaldung nach der Weichselkaltzeit noch einmal grundlegend. Mit der Vegetation veränderte sich auch die Tierwelt. Unter den neuen bejagten Arten befanden sich beispielsweise Reh und Wildschwein (HÄßLER 1991).

Im Südwestlichen Harzvorland zeigten Steingeräte einer weiteren Fundschicht vor dem Portal der "Steinkirche“ das Lager einer mesolithischen Gruppe an. Diese hatte einige tausend Jahre später denselben Rastplatz aufgesucht (Literatur wie oben). Weitere Funde dieser Zeit, beispielsweise von Pfeilen, Harpunen und anderen Arbeitsgeräten aus Knochen und Geweih, konnten in der Talniederung der Söse, um Scharzfeld, bei Tettenborn-Steina an den Dolomitfelsenkliffs der "Römersteine“ und im Bereich der zahlreichen Abris (Felsdächer) sichergestellt werden (CLAUS 1978). 
Tabelle 3: Neuere steinzeitliche Lesefunde im Untersuchungsgebiet

\begin{tabular}{|c|c|c|c|c|}
\hline Funde & Zeitstellung & $\begin{array}{l}\text { örtliche } \\
\text { Beschreibung }\end{array}$ & Landkreis & Literatur \\
\hline $\begin{array}{l}59 \text { geschlagene } \\
\text { Feuersteinartefakte }\end{array}$ & $\begin{array}{l}\text { jüngeres Mesolithikum } \\
\text { (jünger } 7000 \text { cal BP) }\end{array}$ & $\begin{array}{l}\text { westlich } \\
\text { Schwiegershausen }\end{array}$ & Osterode am Harz & MÖLLER 1999 \\
\hline $\begin{array}{l}\text { Specksteine, } \\
\text { Flintabschläge, } \\
\text { breite Pfeilspitze } \\
\text { aus Flint }\end{array}$ & Neolithikum & $\begin{array}{l}\text { östlich Hattorf, } \\
\text { nördlich der } \\
\text { Bahnlinie Hattorf- } \\
\text { Herzberg } \\
\end{array}$ & Osterode am Harz & MÖLLER 1999 \\
\hline $\begin{array}{l}30 \text { bearbeitete Flint- } \\
\text { und Kieselschiefer- } \\
\text { stücke }\end{array}$ & Neolithikum & $\begin{array}{l}\text { südöstlich } \\
\text { Elbingerode }\end{array}$ & Osterode am Harz & MÖLLER 1998 \\
\hline $\begin{array}{l}\text { Klingen, Bohrer, } \\
\text { eine Pfeilspitze aus } \\
\text { Flint }\end{array}$ & $\begin{array}{l}\text { spätes Neolithikum / } \\
\text { frühe Bronzezeit }\end{array}$ & östlich von Hattorf & Osterode am Harz & MÖLLER 1998 \\
\hline
\end{tabular}

\subsection{Neolithikum (5.500 - 2.000 v. Chr.)}

Die ersten sesshaften, Ackerbau und Viehzucht betreibenden Menschen im südwestlichen Harzvorland gehörten der linienbandkeramischen Kultur an. Diese Kultur, die sich durch die namengebende, linienverzierte Keramik auszeichnet, hatte sich zwischen 5500 und 4900 v. Chr. über weite Teile Mitteleuropas ausgebreitet (HÄßLER 1991).

Nördlich von Schwiegershausen konnte eine ausgedehnte Siedlung dieser Kultur mit mehreren Hausgrundrissen ergraben werden, die etwa 150-200 Jahre bestanden hat (tab. 4). Die Linienbandkeramiker besiedelten überwiegend die fruchtbaren Lössböden. In Südniedersachsen stellt die Siedlung bei Schwiegershausen den bisher nördlichsten Fundpunkt einer Siedlungskonzentration im westlichen Eichsfeld dar. Neben Keramikfragmenten, Feuersteinartefakten, Mahlsteinbruchstücken und einer Geröllkeule konnten auch Speisereste auf vier Gefäßböden sichergestellt werden. Die botanische Untersuchung der Makroreste ergab das Spektrum der typischen Kulturpflanzen der Linienbandkeramiker: Einkorn, Emmer, Gerste, Lein und Hülsenfrüchte (Tab. 4). Der Ackerbau wurde auf vermutlich kleinen, von Bäumen beschatteten Flächen als Feld-Gras-Wirtschaft betrieben. In Schwiegershausen wurden außerdem Knochenreste von Schweinen und Rindern gefunden (FLINDT \& GESCHWINDE 1997; KALTOFEN 1998).

Eine weitere Linienbandkeramische Siedlung konnte nordwestlich von Nordhausen in der Nähe der Ortschaft Klein Wechsungen lokalisiert werden ${ }^{3}$.

Eine bei Kalefeld gelegene neolithische Siedlung sowie der Fund einer importierten Pflugschar bei Dorste zeigten Einflüsse der Rössener Kultur im südwestlichen Harzvorland (FLINDT \& GESCHWINDE 1997). Darüber hinaus lassen sich zahlreiche Lesefunde nicht im Gebiet ansässigen neolithischen Kulturen wie der Michelsberger Kultur oder der Schnurkeramik zuordnen (CLAUS 1978).

Bei Auleben östlich von Nordhausen wurden aus der Zeit der Trichterbecher-Kultur stammende Kupferäxte gefunden. Sie gelangten aus dem Donauraum nach Thüringen. Es handelt sich um die ältesten bisher gefundenen Metallgegenstände im Untersuchungsgebiet (PESCHEL 1994). Ebenfalls aus dem Jungneolithikum stammt der Befund einer befestigten Siedlung bei Sundhausen südlich von Nordhausen. Im Fundgut konnten mit Hilfe von botanischen Makrorestanalysen Emmer (Triticum spelta), Gerste (Hordeum vulgare) und Haselnüsse (Corylus avellana) festgestellt werden (SCHULTZE-MOTEL \& GALL 1994; WALTER 1990).

\footnotetext{
${ }^{3}$ Freundliche Mitteilung von J. Grönke, Untere Denkmalschutzbehörde Nordhausen.
} 
Im Bereich der späteren Pipinsburg bei Osterode konnte eine Kulturschicht dem Mittel- bis Jungneolithikum zugewiesen werden (Tab. 4).

Tabelle 4: Steinzeitliche Siedlungen

\begin{tabular}{|c|c|c|c|c|}
\hline & Pipinsburg & $\begin{array}{l}\text { Linienbandkeramische } \\
\text { Siedlung }\end{array}$ & Sundhausen & Sundhausen \\
\hline bei & Osterode am Harz & Schwiegershausen & Nordhausen & Nordhausen \\
\hline Ldkr & Osterode am Harz & Osterode am Harz & Nordhausen & Nordhausen \\
\hline Zeitstellung & $\begin{array}{l}\text { Mittel- und } \\
\text { Jungneolithikum (5./4. } \\
\text { Jahrtsd.v. Chr. und } \\
\text { 2.H.3. Jahrtsd.v. Chr.) }\end{array}$ & $\begin{array}{l}\text { älteres Neolithikum ca. } \\
5200 \text { v. Chr. }\end{array}$ & $\begin{array}{l}\text { Bernburger } \\
\text { Kultur }\end{array}$ & $\begin{array}{l}\text { Salzmünder / } \\
\text { Bernburger } \\
\text { Kultur }\end{array}$ \\
\hline Beschreibung & $\begin{array}{l}\text { Kulturschicht mit } \\
\text { Funden, keine } \\
\text { Besiedlung }\end{array}$ & $\begin{array}{l}5 \text { Hausgrundrisse } \\
\text { (Großbau Typ 1a nach } \\
\text { Moddermann) in einem } \\
\text { größeren Siedlungs- } \\
\text { areal, Nutzungsdauer } \\
\text { etwa 150-200 Jahre } \\
\end{array}$ & $\begin{array}{l}\text { befestigte } \\
\text { Siedlung mit } \\
\text { Brunnen }\end{array}$ & $\begin{array}{l}\text { (Notbergung } \\
\text { aus } \\
\text { Kiesschächten) } \\
\text { Hinweise auf } \\
\text { Besiedlung }\end{array}$ \\
\hline Literatur & $\begin{array}{l}\text { CLAUS 1973; HEINE } \\
\text { 1991b; SCHLÜTER } \\
\text { 1975a; SCHLÜTER } \\
1987\end{array}$ & $\begin{array}{l}\text { FLINDT \& GESCHWINDE } \\
1997\end{array}$ & WALTER 1990 & WALTER 1990 \\
\hline $\begin{array}{l}\text { Botanische } \\
\text { Makrorest- } \\
\text { analyse }\end{array}$ & & $\begin{array}{l}\text { Emmer, Einkorn, } \\
\text { Gerste, Hirse, Lein }{ }^{4}, \\
\text { versch. Hülsenfrüchte, } \\
\text { Sammelfrüchte. } \\
\text { (KALTOFEN 1998) }\end{array}$ & $\begin{array}{l}\text { Triticum spelta, } \\
\text { Hordeum } \\
\text { vulgare, Corylus } \\
\text { avellana }\end{array}$ & $\begin{array}{l}\text { Triticum spelta } \\
\text { cf., Unkräuter, } \\
\text { Holzkohle }\end{array}$ \\
\hline
\end{tabular}

\subsection{Bronzezeit (2.000 - 700 v. Chr.)}

Aus der Bronzezeit liegen im Untersuchungsgebiet im wesentlichen Grab- und Hortfunde vor. Ein auf dem Rotenberg unweit der Wallburg „König Heinrichs Vogelherd“ gelegener Grabhügel konnte aufgrund der darin enthaltenen Beigaben in die frühe Bronzezeit (ca. 2000-1500 v. Chr.) datiert werden. Nordwestlich von Nordhausen, auf dem Starenberg bei Kleinwechsungen (ca. 1,5 km südlich der Lokalität Moosloch), wurde eine Fundkonzentration der Aunjetitzer Kultur zugeordnet ${ }^{5}$. Auch Siedlungsreste und typische Hockerbestattungen in Flachgräbern, die der hochentwickelten Aunjetitzer Kultur zugeordnet werden, stehen im nördlichen und südlichen Harzvorland an vielen Standorten an (CLAUS 1978; DUŠEK 1999).

Die Funde der mittleren Bronzezeit (ca. 1500-1200 v. Chr.) weisen häufig Verbindungen zur osthessischen Gruppe der süddeutschen Hügelgräberzeit auf. Es gab während dieser Periode vermutlich einen intensiven Nord-Süd gerichteten Kulturaustausch entlang des Leinetals, der sich bis ins Harzvorland ausgewirkt hat. Einzelfunde wie die Spiralplattenfibel aus der Einhornhöhle bei Scharzfeld oder der Fund eines Beiles am Pfaffentalskopf bei Bad Lauterberg belegen die Begehung auch dicht bewaldeter Gebiete am Harzrand. Größtenteils unbekannt sind die Siedlungsplätze der mittleren und auch der frühen Bronzezeit (CLAUS 1978).

Die jüngere Bronzezeit (1200-700 v. Chr.) oder Urnenfelderzeit ist durch eine großräumige

\footnotetext{
${ }^{4}$ Bei KALTOFEN (1998) sind nur die deutschen Pflanzennamen genannt, daher können leider keine genaueren Angaben zur Hirseart und zum Lein gemacht werden.

${ }^{5}$ Freundliche Mitteilung von J. Grönke, Untere Denkmalschutzbehörde Nordhausen.
} 
kulturelle Vereinheitlichung geprägt. Statt der bis dahin üblichen Körperbestattungen wurden die Toten nun verbrannt und in Urnen beigesetzt. Ost- und Mitteldeutschland wurden in dieser Zeit von der Lausitzer Kultur geprägt (JOCKENHÖVEL \& KUBACH 1994). Einflüsse einiger ihrer Untergruppen wie der Saalemündungsgruppe und der Unstrut-Gruppe lassen sich auch im Harzvorland feststellen. Im Untersuchungsgebiet wurde dieser Einfluss im Fundgut der Lichtensteinhöhle und der spätbronzezeitlichen Höhensiedlung auf der Pipinsburg greifbar (siehe unten).

Während der Frühen und Mittleren Bronzezeit war die Besiedlungsdichte im Harzvorland eher gering, sie nahm jedoch in der Jüngeren Bronzezeit zu (CLAUS 1978).

Der bronzezeitliche Ackerbau lässt sich als ortsgebundene, extensive Feld-Gras-Wirtschaft beschreiben. Auf den relativ kleinen Flächen fand ein Dauerfeldbau statt. Es gab jedoch noch keine nachhaltige Düngung, so dass die Böden schnell an Fruchtbarkeit verloren. Die Bodenbearbeitung erfolgte weiterhin mit dem Hakenpflug, der nun allerdings aus mehreren auswechselbaren Teilen bestand und von zwei Ochsen gezogen werden konnte (Jochsohlenhakenpflug). Da noch keine Schollenwende möglich war, blieb der Ackerbau ein Saatfurchenbau, der große Abstände zwischen den angebauten Pflanzen erzwang und so viel Raum für Unkräuter ließ (BEHRE 1998). Durch den Einsatz von Metallsicheln zur Ährenernte konnte seit der Mittelbronzezeit wesentlich effektiver geerntet werden. Seit der Jungbronzezeit läßt sich auch eine Strohgewinnung für den Hausbau fassen (HENNING 1997).

Das Spektrum der angebauten Kulturpflanzen wurde während der Bronzezeit zunehmend erweitert, so dass eine deutlich risikoärmere Ernährungssicherung möglich war. Neben den bereits bekannten Weizen- (Triticum spec.) und Gerstenarten (Hordeum spec.) wurden zunehmend auch Dinkel (Triticum spelta) und Rispenhirse (Panicum miliaceum) angebaut. Dazu kamen immer häufiger Hülsenfrüchte (Vicia faba) und Öl- bzw. Faserpflanzen (Papaver somniferum, Camelina sativa, Linum usitatissimum)(BEHRE 1998).

Bei den Nutztieren zeichneten sich landschaftsbedingte Unterschiede im Verhältnis der Arten zueinander ab. Während im nördlichen Teil Deutschlands die Rinderhaltung klar überwog, nahm zum Mittelgebirgsrand hin der Anteil der Kleintierherden aus Schwein, Schaf und Ziege immer weiter zu, bis im Raum Süddeutschlands Rinder und Kleintiere zu gleichen Anteilen gehalten wurden (HENNING 1997).

\begin{tabular}{|c|c|}
\hline $\begin{array}{l}\text { Lokalität } \\
\text { bei } \\
\text { Ldkr }\end{array}$ & $\begin{array}{l}\text { Lichtenstein Höhle } \\
\text { bei Dorste } \\
\text { Osterode am Harz }\end{array}$ \\
\hline \multirow[t]{2}{*}{ Zeitstellung } & Späte Bronzezeit (ca. 1000 - 700 v. Chr.) \\
\hline & Mittel- und Spätstufe der Unstrutgruppe \\
\hline Beschreibung & $\begin{array}{l}\text { sehr umfangreiches Fundgut bestehend aus mind. } 36 \text { menschl. Skeletten, } \\
\text { einfachem Bronzeschmuck, Keramik, Tierknochen, zahlreichen Feuerstellen uam. }\end{array}$ \\
\hline $\begin{array}{l}\text { Siedlungs- } \\
\text { geschehen }\end{array}$ & $\begin{array}{l}\text { Die Höhle wurde wahrscheinlich zu Bestattungsriten mit begleitenden } \\
\text { Kulthandlungen wiederholt aufgesucht. Für die meisten Individuen konnte mit Hilfe } \\
\text { der DNA-Analyse ein Verwandtschaftsverhältnis nachgewiesen werden. Die Funde } \\
\text { weisen auf Verbindungen der Menschen zum thüringer Raum hin. Ein direkter } \\
\text { Zusammenhang mit der nahegelegenen Höhensiedlung der Späten Bronzezeit im } \\
\text { Bereich der Pipinsburg scheint wahrscheinlich zu sein. }\end{array}$ \\
\hline Literatur & FLINDT 1996; FLINDT \& LEIBER 1998; MÖLLER 1999 \\
\hline Anthropologie & HERRMANN 1988; SCHULTES 2000 \\
\hline
\end{tabular}




\begin{tabular}{|c|c|}
\hline $\begin{array}{l}\text { Lokalität } \\
\text { bei } \\
\text { Ldkr }\end{array}$ & $\begin{array}{l}\text { Pipinsburg } \\
\text { Osterode am Harz } \\
\text { Osterode am Harz }\end{array}$ \\
\hline & (siehe auch Tab. 4) \\
\hline Zeitstellung & frühe Bronzezeit \\
\hline Beschreibung & Kulturschicht mit Funden \\
\hline Zeitstellung & $\begin{array}{l}\text { späte Bronzezeit (ca. } 1000-700 \text { v. Chr.) } \\
(\text { Per.IV=HaB } 1 \text { bis Per.V=HaB } 2 / 3)\end{array}$ \\
\hline Beschreibung & unbefestigte Höhensiedlung \\
\hline $\begin{array}{l}\text { Siedlungs- } \\
\text { geschehen }\end{array}$ & $\begin{array}{l}\text { Kulturell sind die Funde vermutlich an die Saalemündungsgruppe anzuschließen, } \\
\text { Beziehungen zur Unstrutgruppe und ein Einfluss der Urnenfelder-Kultur sind ebenfalls } \\
\text { fassbar. }\end{array}$ \\
\hline Zeitstellung & $\begin{array}{l}\text { Besiedlungslücke bis zum Beginn der Späthallstattzeit }\left(\mathrm{HaD}_{2}\right) \text {. } \\
\text { Eisenzeit (ca. } 450 \text { v. Chr. - 1. Hälfte 1. Jh. } \mathbf{n} \text {. Chr.) }\end{array}$ \\
\hline Beschreibung & $\begin{array}{l}\text { drei zeitlich aufeinander folgende Siedlungen in Spornlage, jeweils durch mind. } 2 \text { Holz- } \\
\text { Erde-Mauern befestigt }\end{array}$ \\
\hline $\begin{array}{l}\text { Siedlungs- } \\
\text { geschehen }\end{array}$ & $\begin{array}{l}\text { 1. Phase: Späthallstatt / Frühlatènezeit }\left(\mathrm{HaD}_{2} / \mathrm{LTA}\right) \text {, kulturell an die körperbestattende } \\
\text { Thüringische Kultur der älteren Eisenzeit anzuschließen. } \\
\text { kurze Besiedlungslücke während der frühesten Mittellatènezeit }\left(\mathrm{LTB}_{1}\right)\end{array}$ \\
\hline & $\begin{array}{l}\text { 2. Phase: Mittellatènezeit, das Formengut des frühen Abschnitts dieser Phase weist auf } \\
\text { eine enge Verbindung zum „mitteldeutschen Kontaktgebiet“ im Elbe-Saale-Raum } \\
\text { (Kontaktzone keltischer Latènekultur im Süden und germanischer Kultur im Norden). } \\
\text { 3. Phase: Im jüngsten Abschnitt (LTC } \text { LT }_{2} / \text { Beginn LTD) tritt ein starker Einfluss keltischer } \\
\text { Kultur Süddeutschlands hinzu. Eine unmittelbare Beziehung zur spätkeltischen } \\
\text { Oppidazivilisation wird erkennbar. Erstmals lässt sich auch ein direkter Einfluss des } \\
\text { elbgermanischen Kreises fassen (Gefäße mit Ripdorf-Profil). } \\
\text { Siedlungsabbruch am Übergang von der Mittel- zur Spätlatènezeit (LTC/D) } \\
\text { Die Pipinsburg hatte während der Eisenzeit die Funktion eines Herrensitzes mit } \\
\text { Wirtschafts- und Handelsfunktionen am Rande der keltischen Zivilisation. } \\
\text { (Fortsetzung siehe späte Kaiserzeit / frühe Völkerwanderungszeit, Kapitel } 3.6 \text { und } \\
\text { Mittelalter, Kapitel 3.8) }\end{array}$ \\
\hline Literatur & Claus 1958; HeIne 1991b; SCHLÜTER 1975a; SCHLÜTER 1987 \\
\hline $\begin{array}{l}\text { Botanische } \\
\text { Makrorest- } \\
\text { analyse }\end{array}$ & $\begin{array}{l}\text { untersucht wurde Material aus einer Kulturschicht und aus Gruben: } \\
\text { Triticum monococcum, Tr. dicoccum, Tr. spelta, Tr. aestivum, Tr. compactum, Hordeum } \\
\text { vulgare (Spelzgerste), Avena sativa, Panicum miliaceum, Pisum sativum, Vicia faba, } \\
\text { Linum usitatissimum, Camelina sativa, Nüsse, Obstarten, Unkräuter. } \\
\text { (Hopf in CLAUS 1958; WILLERDING 1974; WILLERDING 1979) }\end{array}$ \\
\hline
\end{tabular}

\subsection{Vorrömische Eisenzeit (700 v. Chr. - Christi Geburt)}

Das südwestliche Harzvorland war während der vorrömischen Eisenzeit relativ dicht besiedelt. Parallel zu der befestigten Höhensiedlung Pipinsburg bestanden zahlreiche kleinere, isoliert liegende Siedlungen zum Beispiel am heutigen südlichen Ortsrand von Herzberg am Harz, bei Badenhausen und nahe der Jettenhöhle bei Düna (siehe unten). Sie alle wiesen ein ähnliches Fundspektrum wie die Pipinsburg auf. Diese war im Unterschied zu vielen anderen Höhensiedlungen dieser Zeit permanent besiedelt. Das Fundgut belegt die weitreichenden Kontakte der damaligen Bewohner. Vermutlich hat die Pipinsburg eine wichtige Vermittlerposition bei Kontakten zwischen der Jastorfkultur im Norden und der südöstlich anschließenden keltischen Kultur eingenommen (HÄßLER 1991). Eine möglicherweise kultische Nutzung durch dieselbe Bevölkerungsgruppe konnte in der bereits erwähnten Einhornhöhle bei Scharzfeld nachgewiesen werden. Die verstreut gelagerten Knochen von insgesamt 13 Menschen weisen auf einen Bestattungs- oder Opferkult hin (FLINDT \& LEIBER 1998). Die 
Besiedlung aller bisher genannten Orte bricht einheitlich mit dem Beginn der Spätlatènezeit, im 1. Jh. v. Chr. ab. Die Siedlungsaufgabe im Kontaktgebiet war vermutlich eine Reaktion auf das stärkere Vordringen der Germanen nach Süden und den daraus resultierenden kriegerischen Auseinandersetzungen mit den Kelten (CLAUS 1978).

Der Ackerbau wurde während der Vorrömischen Eisenzeit in mehreren Punkten weiter entwickelt. Im Unterschied zur Bronzezeit lassen sich beispielsweise erste Bodenverbesserungsmaßnahmen wie die Umsetzung von Bodenmaterial und die Anreicherung mit Humus z.B. bei Nörten-Hardenberg fassen (KLAMM 1987). Während der mittleren und späten Latènezeit wurde ein schollenwendender Pfug entwickelt, der erstmals einen echten Feldbau mit einer Breitsaat im Saatbett ermöglichte. Der Hakenpflug verschwand jedoch nicht gänzlich, sondern blieb parallel im Einsatz. Bei der Ernte wurden die bereits üblichen Bronzesicheln durch Eisensicheln ersetzt.

Eiserne Sensen, deren raumgreifende, fast bodennahe Mahd eine nahezu revolutionäre Verbesserung darstellte, konnten erstmals in der älteren Latènezeit für die keltisch geprägten Gebiete nachgewiesen werden. Sie wurden vermutlich nicht zur Ernte des Getreides, sondern zur Grasmahd für Tierfutter eingesetzt (HENNING 1997).

Alle bereits aus der Bronzezeit bekannten Nutzpflanzen wurden während der Eisenzeit weiter etabliert. Die Spelzgerste (Hordeum vulgare) wurde besonders häufig angebaut und gilt daher als charakteristische Getreideart dieser Zeit (WILLERDING 1979). Aus der Kombination der während der Eisenzeit an den jeweiligen Untersuchungspunkten angebauten Taxa und dem verbreiteten Vorkommen des Dinkels, der einen Anbau als Wintergetreide ermöglicht, lässt sich außerdem der mögliche Beginn einer Fruchtwechselfolge ableiten (WILLERDING \& WOLF 1990). In Norddeutschland setzte sich der Lein (Linum usitatissimum) als eine der wichtigsten Anbaupflanzen durch (WILLERDING 1980).

Neben Hund, Rind, Schaf, Ziege und Schwein wurde die Haltung von Hühnern und Gänsen etabliert. Zunehmend setzte sich auch die Pferdehaltung durch.

\begin{tabular}{|ll|}
\hline $\begin{array}{l}\text { Lokalität } \\
\text { bei } \\
\text { Ldkr }\end{array}$ & $\begin{array}{l}\text { Jettenhöhle } \\
\text { bei Düna, im NSG Hainholz } \\
\text { Osterode am Harz }\end{array}$ \\
\hline $\begin{array}{l}\text { Zeitstellung } \\
\text { Beschreibung }\end{array}$ & $\begin{array}{l}\text { Mittel- und spätlatènezeitlich (LTC2 und LTD1) } \\
\text { hauptsächlich Keramikbruchstücke, Holzkohlen und verkohlte Pflanzenreste im } \\
\text { südöstlichen Raum der Karsthöhle }\end{array}$ \\
Siedlungs- & $\begin{array}{l}\text { 400 m südlich des heutigen Eingangs der Höhle konnten ausgedehnte eisenzeitliche } \\
\text { geschehen } \\
\text { Siedlungsspuren festgestellt werden. Vermutlich wurden die Funde von dieser nahe } \\
\text { gelegenen eisenzeitlichen Siedlung in die Höhle verlagert. Denkbar ist jedoch auch } \\
\text { eine bewusste Deponierung (Kultische Handlungen?). Der Siedlungsplatz lag }\end{array}$ \\
& $\begin{array}{l}\text { unmittelbar an der wichtigen Fernverbindung „Hohe Straße“ (siehe unten). } \\
\text { (BOTH 1987; CLAUS 1978; FLINDT \& LEIBER 1998; SCHLÜTER 1975b) }\end{array}$ \\
Botanische & $\begin{array}{l}\text { Hordeum vulgare (Spelzgerste), Panicum miliaceum, Linum usitatissimum, Unkräuter } \\
\text { Makrorest- } \\
\text { analyse }\end{array}$ \\
\hline (WILLERDING 1975)
\end{tabular}

\subsection{Römische Kaiserzeit (Christi Geburt - 375 n. Chr.)}

Der Übergang von der Vorrömischen Eisenzeit zur Römischen Kaiserzeit außerhalb der römischen Provinzen ist nicht durch einen kulturellen Umbruch gekennzeichnet. Die räumliche Nähe zum römischen Reich, äußert sich in Funden römischer Importwaren, die auf Handelsbeziehungen zwischen Germanen und Römern hinweisen. Darüber hinaus fanden zahlreiche römische Kriegszüge mit dem Ziel statt, die Grenze des Imperiums bis an die Elbe vorzuverlegen (HÄßLER 1991). 
Die ersten schriftlich dokumentierten Berichte dieser Zeit stammen aus der Feder römischer Schriftsteller wie Plinius und Tacitus, die ganz Germanien als von Wald und Sumpf bedeckt schilderten. Tacitus schrieb in seiner um die Zeitenwende erschienen „Germania“: „Das Land zeigt zwar, was das Aussehen angeht, beträchtliche Unterschiede, ist jedoch im großen und ganzen grauenerregend wegen seiner Wälder oder häßlich wegen seiner Moore."(LUND 1988). Diese Beschreibungen sind jedoch keinesfalls als objektive Schilderungen zu betrachten, da weder Tacitus noch andere römische Schriftsteller dieser Zeit (mit Ausnahme von Caesar) je selbst in dem Gebiet waren und die Ausführungen häufig politisch gefärbt wurden. Diese schriftlichen Überlieferungen lassen erstmals Gebiete und Namen einzelner Germanischer Stämme erkennen (HÄßLER 1991).

Zieht man die Befunde der Siedlungsarchäologie für die Römische Kaiserzeit heran, so wird deutlich, dass aufgrund der Siedlungsdichte zumindest in den ausgedehnten Zentren der Germanischen Siedelräume kein dichter Urwald bestanden haben kann. Vermutlich trennten unzugängliche Urwaldgebiete die Siedelräume voneinander, deren Waldbedeckung durch direkte Holzentnahme, Waldweide und Rodungen stark verringert war.

Im Bereich außerhalb des römischen Einflusses bestanden noch keine größeren Siedlungen. Lediglich Einzelhöfe oder kleine Dörfer sind archäologisch nachgewiesen. Sie wirtschafteten weitgehend als autarke Einheiten für den Eigenbedarf. Im wesentlichen wurden die landwirtschaftlichen Traditionen der Eisenzeit ohne Brüche fortgeführt. Eine Neuerung stellte die Bodenmelioration dar, die für den Zeitraum nach Christi Geburt häufiger nachweisbar ist. Der Ackerbau erfolgte auf sogenannten „celtic fields“, die auf leichten Lehm- oder Sandböden angelegt wurden. Angebaut wurden alle auch für die Eisenzeit nachgewiesenen Getreidearten. Die Funde von Ackerbohnen (Vicia faba) sind sehr häufig und die Bedeutung der Ölsaaten (Linum usitatissimum, Camelina sativa) nahm zu.

Als bevorzugte Nutztiere dieser Zeit gelten Rinder und Pferde. Außerdem von großer Bedeutung waren Schweine und Schafe, deren Anteile nach der naturräumlichen Ausstattung des Untersuchungsgebietes stark variierten. So überwog die Schweinezucht im Binnenland, wo Eichenmischwälder zur Mast zur Verfügung standen, während im Küstenbereich die Schafzucht deutlich höhere Anteile hatte. Alle diese Nutztierarten waren im Vergleich zu heutigen Rassen sehr kleinwüchsig und lieferten daher einen relativ geringen Fleischertrag. Außerdem hielt man Bienen, die Geflügel: Huhn, Gans und Ente, Hunde in verschieden Größen und vereinzelt bereits Katzen. Die Anteile der Sammelfrüchte und -pflanzen sowie die Erträge aus Jagd und Fischfang an der Ernährung müssen als gering angesehen werden (HENNING 1997).

\section{Germanische Besiedlung}

Während der Römischen Kaiserzeit schien das Harzvorland, aufgrund der geringen Zahl von archäologischen Befunden nur dünn besiedelt gewesen zu sein (CLAUS 1978). Neuere Untersuchungen hingegen weisen diesen „Siedlungsrückgang“, der von der Römischen Kaiserzeit bis zur Karolinger Zeit anzuhalten schien, als das Resultat einer Forschungslücke aus (KLAPPAUF 1986).

Die interdisziplinär untersuchte Siedlung bei Düna lässt eine Siedlungkontinuität von der Römischen Kaiserzeit bis ins späte Mittelalter erkennen (siehe unten). Am Zusammenlauf zweier Bäche wurde eine kleine kaiserzeitliche Gehöftgruppe ergraben. In den zur Siedlung gehörenden Rennfeueröfen konnte die Verhüttung von Erzen aus dem Rammelsberg bei Goslar im Harz seit dem ersten Jahrhundert nachgewiesen werden. Das Fundgut lässt sich der rheinwesergermanischen Kulturgruppe zuordnen, die im nordwestlichen Thüringen bis etwa 200 n. Chr. sehr häufig nachweisbar ist (KLAPPAUF \& LINKE 1990; KLAPPAUF \& LINKE 1996).

In Kontrast zu dem eher fundarmen Harzvorland stehen sowohl das benachbarte Leinetal als auch die Helme- und Unstrutniederung, wo sich die Befunde germanischer Siedlungen und Gräber häufen. Am südlichen Stadtrand von Nordhausen, am Beginn der Helmeniederung, wurde das bisher größte Brandgräberfeld der weserrheingermanischen Kulturgruppe er- 
graben (Tab. 5). Die beigabenarmen Bestattungsriten dieser Kultur lassen jedoch nur wenige Rückschlüsse auf die Lebensumstände der Menschen zu (PESCHEL 1994). Nordwestlich von Nordhausen, östlich von Kleinwechsungen, liegt ein Fundplatz der Oder/Warthe Gruppe, der ebenfalls in die Späte Latène-, bzw. Frühe Kaiserzeit datiert ${ }^{6}$.

Etwa am Übergang vom 2. zum 3. Jh. n. Chr. veränderten sich diese Bestattungsriten im westlichen Thüringen und im Harzgebiet drastisch. Körpergräber mit zum Teil sehr reicher Beigabenausstattung lassen sich aus dieser Zeit finden. Sie gehören dem Formenkreis der elbgermanischen Kultur an. Ein solches reich ausgestattetes Körpergrab konnte ebenfalls bei Nordhausen, in unmittelbarer Nähe des oben erwähnten Brandgräberfeldes, nachgewiesen werden (Tab. 5). Die aus dieser Zeit reichlich überlieferten Grabbeigaben lassen intensive Beziehungen zum römischen Reich bis hin zu einer Übernahme römischer Alltagsgewohnheiten erkennen (PESCHEL 1994).

\begin{tabular}{|c|c|}
\hline $\begin{array}{l}\text { Lokalität } \\
\text { bei } \\
\text { Ldkr }\end{array}$ & $\begin{array}{l}\text { Düna } \\
\text { Stadt Osterode am Harz } \\
\text { Osterode am Harz }\end{array}$ \\
\hline Zeitstellung & um Christi Geburt - erste Hälfte 14. Jh. \\
\hline Beschreibung & $\begin{array}{l}\text { Siedlung, später mit repräsentativem Gebäude bzw. Burg, in direktem Zusammenhang } \\
\text { mit dem Bergbau im Harz stehend (Verhüttung). }\end{array}$ \\
\hline $\begin{array}{l}\text { Siedlungs- } \\
\text { geschehen }\end{array}$ & $\begin{array}{l}\text { Düna wurde in der ausgehenden Spätlatènezeit bzw. am Beginn der römischen } \\
\text { Kaiserzeit von Menschen, die der rheinwesergermanischen Kulturgruppe zugeordnet } \\
\text { werden, besiedelt. Die Anlage bestand aus mehreren einfachen Gehöften, die durch } \\
\text { Zäune und Bachläufe abgegrenzt waren. Anhand eines Rennfeuerofens und zahl- } \\
\text { reicher Schlackenreste konnten Eisen-, Blei-, und Kupferverhüttung nachgewiesen } \\
\text { werden. Die dort verhütteten Buntmetallerze stammten überwiegend aus der Erz- } \\
\text { lagerstätte „Rammelsberg“ bei Goslar. Mehrere hundert Jahre entwickelt sich diese } \\
\text { Besiedlung kontinuierlich weiter. Auch während der Völkerwanderungszeit im 6. Jh., } \\
\text { verringerte sich lediglich die Siedlungsintensität. Eine Wüstungsphase dagegen konnte } \\
\text { nicht festgestellt werden. } \\
\text { (Fortsetzung siehe Mittelalter, Kapitel 3.8) }\end{array}$ \\
\hline Literatur & $\begin{array}{l}\text { HEINE } 1991 \text { b; KLAPPAUF 1983; KLAPPAUF \& LINKE 1990; KLAPPAUF \& LINKE 1996; } \\
\text { StEINAU } 1986\end{array}$ \\
\hline $\begin{array}{l}\text { Botanische } \\
\text { Makrorest- } \\
\text { analyse }\end{array}$ & $\begin{array}{l}\text { Für den Beginn der Besiedlung konnte ein bachbegleitendes Erlengehölz mit Feld- } \\
\text { ahorn, Schlehe und Hasel nachgewiesen werden, das durch die Holznutzung } \\
\text { zunehmend aufgelichtet wurde. Spätestens ab dem } 7 . / 8 \text {. Jh. war es vollständig ver- } \\
\text { schwunden. Neben der Holzentnahme diente die Bachrinne auch der Ablagerung von } \\
\text { Siedlungsabfällen. } \\
\text { (ANDRAE \& WILLERDING 1989; WILLERDING 1986; Andrae in: KLAPPAUF \& LINKE 1990) }\end{array}$ \\
\hline Metallurgie & Brockner et al. in: KLAPPAUF \& LINKE 1990 \\
\hline
\end{tabular}

\begin{tabular}{|ll|}
\hline $\begin{array}{l}\text { Lokalität } \\
\text { bei } \\
\text { Ldkr }\end{array}$ & $\begin{array}{l}\text { Pipinsburg } \\
\text { Osterode am Harz } \\
\text { Osterode am Harz }\end{array}$ \\
\hline Zeitstellung & $\begin{array}{l}\text { (siehe auch Kapitel 3.3, 3.4 und 3.5 ) } \\
\text { späte Kaiserzeit / frühe Völkerwanderungszeit }\end{array}$ \\
Beschreibung & $\begin{array}{l}\text { Die Funde verweisen auf eine Begehung im 4./5.Jh. es fand jedoch keine } \\
\text { Besiedlung statt. } \\
\text { (Fortsetzung siehe Kapitel 3.8) }\end{array}$
\end{tabular}

Literatur $\quad$ Claus 1978; HeINE 1991b; SCHLÜTER 1975a; SCHLÜTER 1987

\footnotetext{
${ }^{6}$ Freundliche Mitteilung von J. Grönke, Untere Denkmalschutzbehörde Nordhausen.
} 
Tabelle 5: Germanisches Brandgräberfeld und Einzelgräber bei Nordhausen

\begin{tabular}{|l|l|l|l|l|l|}
\hline Lokalität & bei & Ldkr & Zeitstellung & Beschreibung & Literatur \\
\hline $\begin{array}{l}\text { Brand- } \\
\text { gräberfeld }\end{array}$ & $\begin{array}{l}\text { südlicher Stadtrand } \\
\text { Nordhausens an der } \\
\text { Straße nach Sundhausen }\end{array}$ & $\begin{array}{l}\text { Nord- } \\
\text { hausen }\end{array}$ & $\begin{array}{l}\text { spätlatène- } \\
\text { frühkaiser- } \\
\text { zeitlich }\end{array}$ & $\begin{array}{l}\text { ausgedehntes } \\
\text { Brandgräberfeld } \\
\text { inmitten der } \\
\text { Helmeaue }\end{array}$ & $\begin{array}{l}\text { GoCKEL } \\
2000\end{array}$ \\
\hline $\begin{array}{l}\text { germanisches } \\
\text { Körpergrab }\end{array}$ & $\begin{array}{l}\text { am südlichen Stadtrand } \\
\text { Nordhausens }\end{array}$ & $\begin{array}{l}\text { Nord- } \\
\text { hausen }\end{array}$ & $\begin{array}{l}\text { letztes } \\
\text { Drittel 3. Jh. } \\
\text { n. Chr. }\end{array}$ & $\begin{array}{l}\text { Körpergrab mit sehr } \\
\text { reichen Beigaben, } \\
\text { (etwa 300 m } \\
\text { westlich des } \\
\text { Brandgräberfeldes) }\end{array}$ & $\begin{array}{l}\text { GoCKEL } \\
2000\end{array}$ \\
\hline $\begin{array}{l}\text { germanisches } \\
\text { Körpergrab }\end{array}$ & $\begin{array}{l}\text { am Holungshügel nahe } \\
\text { der Straße nach } \\
\text { Hesserode (Nordhausen) }\end{array}$ & $\begin{array}{l}\text { Nord- } \\
\text { hausen }\end{array}$ & $\begin{array}{lll}\text { 7. Jh. n. } \\
\text { Chr. }\end{array}$ & $\begin{array}{l}\text { vereinzeltes } \\
\text { germanisches } \\
\text { Körpergrab }\end{array}$ & $\begin{array}{l}\text { GoCKEL } \\
2000\end{array}$ \\
\hline
\end{tabular}

\subsection{Völkerwanderungszeit (375 - $568 \mathrm{n}$. Chr.) und Merowingerzeit}

Die wohl unruhigste Zeit der europäischen Frühzeit begann im Jahre $375 \mathrm{n}$. Chr. mit dem Einfall der Hunnen in nordpontisches Gebiet und endete 568 n. Chr. mit der Wanderung der Langobarden nach Oberitalien. Der Zusammenbruch des Römischen Reiches und der antiken Weltordnung wurde von außen durch den Ansturm der ehemals unterdrückten Völker hervorgerufen. Auch die germanischen Stämme gerieten in Bewegung. Aus dieser Zeit des Umbruchs liegen nur sehr wenige Überlieferungen vor (HÄßLER 1991; PESCHEL 1994).

Für das Harzvorland muss eine Verringerung der Siedlungsintensität in dieser Zeit angenommen werden. Eine Siedlungsleere hat es dagegen nicht gegeben, wie beispielsweise die anhaltende Besiedlung in Düna belegt (siehe oben).

Noch während der Völkerwanderungszeit bildeten sich nach dem Untergang des Römischen Reiches die germanischen Königreiche, die das Mittelalter entscheidend geprägt haben. In Westeuropa entstand unter der Führung des Merowingers Chlodwig das Reich der Fanken, dessen Grenzen immer weiter vorgetrieben wurden, bis sie schließlich über Hessen hinaus an den Südrand des niedersächsischen Berglandes reichten. Das südwestliche Harzvorland lag damit im Spannungsfeld der von Westen herandrängenden Franken, des Königreiches der Sachsen im Norden und des Thüringischen Königreiches im Osten und Südosten. Nachdem die Franken mit Hilfe der Sachsen das Thüringische Reich bereits $531 \mathrm{n}$. Chr. eingenommen hatten, gehörte das Harzgebiet zum Einflussbereich der Sachsen (HÄßLER 1991; PESCHEL 1994).

\subsection{Mittelalter und Neuzeit}

Im folgenden Kapitel werden neben politischen und siedlungsgeographischen Entwicklungen des Frühen, Hohen und Späten Mittelalters verstärkt auch landwirtschafts- und forstgeschichtliche Aspekte erläutert.

Den Ergebnissen der Auswertung schriftlicher Quellen zur Forstgeschichte seit dem Hohen Mittelalter ist ein eigenständiges Kapitel gewidmet. Ebenso gesondert behandelt werden die Ergebnisse der Holzkohlenanalysen zur Waldnutzung, die den gesamten Zeitraum vom Frühen Mittelalter bis zur Frühen Neuzeit abdecken. Die Geschichte des Bergbaus wird ebenfalls eigenständig behandelt. 
Zunächst werden die wichtigsten gut untersuchten mittelalterlichen Lokalitäten im Untersuchungsgebiet unter Aufbereitung des aktuellen Forschungsstandes beschrieben. Für diese Lokalitäten ist jeweils eine Auswahl an Quellen angegeben. Dabei wurden sowohl grundlegende Arbeiten als auch Publikationen jüngeren Datums berücksichtigt, die wiederum ihrerseits ältere Literatur zitieren.

Tabelle 6 enthält eine Auflistung von bisher wenig untersuchten Burgen im Untersuchungsgebiet unter Angabe der Zeitstellung, des Siedlungsgeschehens und der jeweiligen Quellen.

\subsubsection{Siedlungsgeschichte}

\section{Frühes Mittelalter (700 - 1000 n. Chr.)}

Nach der Machtübernahme durch die Karolinger im frühen 8. Jh. führte das fränkische Reich zahlreiche Heerzüge gegen die Sachsen. Die Pipinsburg bei Osterode (siehe unten) gehörte vermutlich zu den frühesten Angriffszielen Karls des Großen auf sächsischem Gebiet. Im Jahre 804 wurden schließlich sowohl die Sachsen als auch die Friesen in das Frankenreich eingegliedert und christianisiert (HÄßLER 1991).

Nachdem das thüringische Gebiet bereits durch die Einsetzung fränkischer Adeliger und die Gründung neuer Dörfer erschlossen war, erfolgte auch im Harzvorland und im Eichsfelder Becken eine schnelle und planmäßige Kolonisierung während des letzten Viertels des 8. Jhs. In diesem Zusammenhang wurde eine größere Anzahl von Straßendörfern angelegt, deren Namen die Endung -rode oder -ingerode tragen. Im Gegensatz dazu stehen die älteren Ortsnamen im Gebiet wie beispielsweise Palithi $=$ Pöhlde, Dorstide $=$ Dorste, Foresazi $=$ Förste, Wolfenni $=$ Wulften, Hörnde $=$ Hörden oder Dunede $=$ Düna .

Neben einem größeren Siedlungsschwerpunkt von -rode-Orten im Eichsfelder Becken lassen sich (nach NITZ 1983) zwei kleinere Gebiete im südwestlichen Harzvorland erkennen. Das eine umfasst drei Dorfgründungen bei Osterode (Osterode, Motlingerode, Bunenrode), während das zweite direkt am Harzrand zwischen Osterode und dem heutigen Herzberg etwa im Bereich von Aschenhütte liegt und von vier Dorfneugründungen gebildet wird (Hermelingerode, Elbingerode, Runigerodt, Evekenrode). Damit lässt sich der früheste mittelalterliche Landesausbau im Untersuchungsgebiet ungewöhnlich detailliert erfassen.

Die Einführung des Feudalsystems, die spätestens mit der fränkischen Machtübernahme im Untersuchungsgebiet stattgefunden hatte, erzwang die Zahlung von Abgaben an den Grundherren. Damit wurde erstmals eine wesentliche Produktionssteigerung der bäuerlichen Höfe über die Deckung ihres Eigenbedarfes hinaus nötig. Schätzungen zufolge waren bis ins 12. Jh. etwa $95 \%$ aller Menschen Angehörige bäuerlicher Gemeinschaften, die sich mit einer auf Subsistenz ausgerichteten Landwirtschaft selbst versorgten (HENNING 1994).

Nach der Teilung des Karolingischen Reiches im Jahre 843 bildete sich unter dem zunehmenden Druck durch die Angriffe von Slawen ein sächsisches Stammesherzogtum aus. Seit der Mitte des 9. Jhs. wurde es von dem Geschlecht der Liudolfinger geführt, deren Besitztümer am Harz und der Oberweser konzentriert waren. Im Jahre 918 wurde der Liudolfinger Heinrich von Sachsen zum fränkischen König ernannt. Heinrich I., genannt „der Vogler", regierte als deutscher König und Herzog von Sachsen bis 936. Bis zur Regentschaft Heinrich II. blieb die deutsche Königswürde in der Hand der Liudolfinger. Nach dessen Tod ging sie im Jahre 1024 an das fränkische Geschlecht der Salier über (HäßLER 1991). 


\begin{tabular}{|c|c|}
\hline $\begin{array}{l}\text { Lokalität } \\
\text { bei } \\
\text { Ldkr }\end{array}$ & $\begin{array}{l}\text { Pipinsburg } \\
\text { Osterode am Harz } \\
\text { Osterode am Harz }\end{array}$ \\
\hline & (siehe auch Kapitel 3.3, 3.4, 3.5 und 3.6) \\
\hline Zeitstellung & frühes bis spätes Mittelalter (ca. 8. Jh. - 1365) \\
\hline Beschreibung & Burganlage \\
\hline $\begin{array}{l}\text { Siedlungs- } \\
\text { geschehen }\end{array}$ & $\begin{array}{l}\text { 1. Phase: ca. 8. Jh. - Anfang des 9. Jh., zur Zeit der sächsisch-fränkischen } \\
\text { Auseinandersetzungen, Sicherung durch Holz-Erde-Mauer und eine } 2,5 \text { m starke } \\
\text { Trockenmauer. } \\
\text { 2. Phase: ca. 9./10. Jh., spätkarolingisch-ottonische Zeit, Verstärkung der } \\
\text { Befestigungsanlagen in der Zeit nach der Eingliederung Sachsens in das } \\
\text { fränkische Reich (Aufschüttung der Holz-Erde-Mauer, zusätzliche Wallanlagen, } \\
\text { evtl. Errichtung des Zangentores). Möglicherweise diente die Pipinsburg bis ins } 11 . \\
\text { Jh. als Fluchtburg des nahen, nordöstlich im Sösetal liegenden Königshofes } \\
\text { Lasfelde. } \\
\text { 3. Phase: Mitte des 12. Jh. Bau der Burganlage an der Nordspitze des Sporns, } \\
\text { vermutlich im Besitz der Welfen, } 1134 \text { ist der in welfischem Dienst stehende Ritter } \\
\text { Werner von Berkelfeld auf der Pipinsburg ansässig. } \\
1365 \text { wird die Burg in einer Fehde zwischen Herzog Albrecht I. von Grubenhagen } \\
\text { gegen den Mainzer Erzbischof und den Landgrafen von Thüringen zerstört und } \\
\text { endgültig verlassen. }\end{array}$ \\
\hline Literatur & $\begin{array}{l}\text { CLAUS 1978; CLAus \& SCHLÜTER 1975; HEINE 1997; SCHLÜTER 1975a; SCHLÜTER } \\
1987\end{array}$ \\
\hline
\end{tabular}

Im gesamten Harzgebiet lässt sich ein innerer Landesausbau nach der Machtübernahme durch die Liudolfinger erkennen. Neben der Anlage zahlreicher Befestigungen (siehe „Burg Lichtenstein" und weitere Tab. 6) erfolgte eine weitreichende Urbarmachung bewaldeter Gebiete durch die Gründung zahlreicher Dörfer. Die Namen dieser neu gegründeten Siedlungen enden in der Regel auf -hausen (NITZ 1983).

\begin{tabular}{|ll|}
\hline $\begin{array}{l}\text { Lokalität } \\
\text { bei } \\
\text { Ldkr }\end{array}$ & $\begin{array}{l}\text { Burg Lichtenstein } \\
\text { Dorste } \\
\text { Osterode am Harz }\end{array}$ \\
\hline $\begin{array}{l}\text { Zeitstellung } \\
\text { Beschreibung }\end{array}$ & $\begin{array}{l}\text { 10. Jh.(?) bis vor 1567 } \\
\text { gut befestigte Burg auf einem Bergkegel, nur durch einen Weg zugänglich }\end{array}$ \\
Siedlungs- & $\begin{array}{l}\text { Die Burg wurde vermutlich von Heinrich dem Vogler (919 Oberhaupt des Dt. } \\
\text { geschehen } \\
\text { Reiches) erbaut. 1143 wurden die Burg und das Land durch Vormünder von Heinrich } \\
\text { dem Löwen in Besitz genommen. In der Folgezeit tobten heftige Kämpfe um die }\end{array}$ \\
& $\begin{array}{l}\text { Burg. Diese blieb im 11. und 12. Jh. uneingenommen. Die Ernährung der } \\
\text { Burgbewohner wurde durch das zur Burg gehörende Landgut Foresazi, das heutige }\end{array}$ \\
& $\begin{array}{l}\text { Förste, sichergestellt. 1366 wurde die Burg durch Friedrich, Landgraf von Thüringen } \\
\text { und Markgraf von Meißen, zusammen mit den Burgen Windhausen, Hindenburg und }\end{array}$ \\
& $\begin{array}{l}\text { Pipinsburg zerstört. Sie wurde in der Folgezeit wieder aufgebaut und bewohnt, bevor } \\
\text { die Burg Lichtenstein 1567 als verlassen beschrieben wurde. Das genaue Ende der }\end{array}$ \\
& Besiedlung ist unbekannt. \\
KRECKMANN 1999
\end{tabular}

Die Oberschicht dieser feudalistisch organisierten Gesellschaft, die adligen Familien, lebten nicht in den zahlreichen ausgebauten Burgen der Region, sondern in herrschaftlichen Wirtschaftshöfen. In Düna wurde einer dieser ländlichen Herrensitze detailliert archäologisch untersucht (siehe unten). 


\begin{tabular}{|ll|}
\hline $\begin{array}{l}\text { Name } \\
\text { bei } \\
\text { Ldkr }\end{array}$ & $\begin{array}{l}\text { Düna } \\
\text { Stadt Osterode am Harz } \\
\text { Osterode am Harz }\end{array}$ \\
\hline Zeitstellung & um Christi Geburt - erste Hälfte 14. Jh. \\
Beschreibung & $\begin{array}{l}\text { Siedlung mit repräsentativem Gebäude bzw. Burg in direktem Zusammenhang mit } \\
\text { dem Bergbau im Harz. }\end{array}$
\end{tabular}

Siedlungs- $\quad$ (siehe auch Kapitel 3.6)

geschehen Nach dem historisch überlieferten Beginn des Silberbergbaus im Rammelsberg um 968 n. Chr. und der Machtübernahme durch die Liudolfinger kam es allgemein im Harzraum zu einer starken Zunahme der Besiedlungsintensität. Vermutlich im Zuge des folgenden Ausbaus befestigter Anlagen wurde in Düna während des 10. Jhs. ein repräsentatives Steinhaus errichtet. Nach einem Brand um 1100 errichtete man auf dessen Fundamenten einen wohnturmartigen Saalgeschossbau (Turmhaus), der von Bach und Graben geschützt wurde. Seit der Anlage des Steingebäudes muss Düna als Herrensitz und vermutlich ebenfalls als Reichsgut betrachtet werden. Die bereits für die Römische Kaiserzeit nachgewiesene Verhüttung in der Siedlung wurde im Mittelalter kontinuierlich weiterbetrieben.

Im Verlauf des ausgehenden 13. Jhs. bis zum Ende des 14. Jhs., wurde die Siedlung verlassen. Spätestens seit 1372 lag eine totale Ortswüstung vor. Vermutlich wurde die Flur zumindest teilweise weiter bewirtschaftet. Hierzu liegen jedoch keine historischen Angaben vor. Neuzeitlich erfolgte eine WiederBesiedlung des heutigen Dorfes Düna.

Düna lag verkehrstechnisch günstig an der „Hohen Straße“, die neben Düna auch Pöhlde tangierte. Im Frühen Mittelalter war sie Teil des wichtigsten Fernweges, der von Norden westlich um den Harz nach Thürigen und Sachsen führte. Aufgrund ihrer Beziehung zu etlichen sehr alten Orten wird für sie eine vormittelalterliche Benutzung und Bedeutung angenommen (siehe Kapitel 3.8.2, S. 31).

Literatur HeINE 1991b; KLAPPAUF 1983; KLAPPAUF \& LINKE 1990; KLAPPAUF \& LINKE 1996; STEINAU 1986

Botanische $\quad A b$ dem 8./9. Jh. lässt sich am Bachrand oder in der bereits verfüllten und planierten Makrorest- $\quad$ Rinne ein trittrasenartiger Bewuchs feststellen (Poa annua, Plantago major, Polygoanalyse

Metallurgie Brockner et al. In: KLAPPAUF \& LINKE 1990 


\section{Hohes Mittelalter (1000 - 1250 n. Chr.)}

Etwa um $1000 \mathrm{n}$. Chr. begann die erste große Bergbauperiode im Harz, die auch als Zeit des „Alten Mannes“ bezeichnet wird. Die Metallgewinnung und -verarbeitung im Harzraum war von großer Bedeutung für die Machthabenden. In der Folgezeit entstand im Untersuchungsgebiet eine Vielzahl von Königsgütern. Die Siedlungsgeschichte des Harzvorlandes ist daher eng verknüpft mit der Geschichte des Bergbaus (siehe Kapitel 3.8.3, S. 35).

Die Königspfalzen dienten dem umherziehenden Hof als Residenzen. Sie mussten die Versorgung des Königs sowie seines umfangreichen Gefolges sichern und einen repräsentativen Rahmen für die Regierungsgeschäfte aufweisen. Neben Goslar am nördlichen Harzrand und Grone bei Göttingen waren die im Untersuchungsgebiet liegenden Pfalzen Pöhlde und Nordhausen (siehe unten) zwei wichtige Aufenthaltsorte des königlichen Hofes im südlichen Niedersachsen und nordwestlichen Thüringen (GOCKEL 2000; HÄßLER 1991).

\begin{tabular}{|c|c|}
\hline $\begin{array}{l}\text { Lokalität } \\
\text { bei } \\
\text { Ldkr }\end{array}$ & $\begin{array}{l}\text { Burgwall „König Heinrichs Vogelherd“ } \\
\text { Pöhlde, Herzberg am Harz } \\
\text { Osterode am Harz }\end{array}$ \\
\hline Zeitstellung & Anfang 10.Jh. (Ende Burg / Beginn der Aktivitäten im Bereich der Pfalz) \\
\hline Beschreibung & $\begin{array}{l}\text { Befestigte Burganlage südöstlich und "oberhalb“ der Pfalz gelegen. In den Wall ist } \\
\text { der alte „Fastweg“ einbezogen (siehe Kapitel 3.8.2, S. 31). }\end{array}$ \\
\hline $\begin{array}{l}\text { Siedlungs- } \\
\text { geschehen }\end{array}$ & $\begin{array}{l}\text { Zwei zeitlich sehr eng beieinander liegende Burgbauphasen mit nur geringen Sied- } \\
\text { lungsspuren wurden gefunden. Es handelte sich vermutlich um ein Refugium mit } \\
\text { herrschaftlicher Funktion. Ein liudolfingischer Hof aus dem 9.Jh. wird als dazugehörig } \\
\text { vermutet, konnte aber bisher nicht gefunden werden. }\end{array}$ \\
\hline Lokalität & Pfalz Pöhlde \\
\hline bei & Pöhlde, Herzberg am Harz \\
\hline Ldkr & Osterode am Harz \\
\hline Zeitstellung & Anfang 10.Jh. (Ende Burg / Beginn der Aktivitäten im Bereich der Pfalz) \\
\hline Beschreibung & Pfalz mit Kirche und Kloster im Tal unterhalb des Burgwalls gelegen \\
\hline $\begin{array}{l}\text { Siedlungs- } \\
\text { geschehen }\end{array}$ & $\begin{array}{l}\text { In zwei Schenkungsurkunden aus den Jahren } 927 \text { bzw. } 929 \text { wird die Pfalz erstmals } \\
\text { erwähnt. } 950 \text { gründete die Königin Mathilde ein Benediktinerkloster in Pöhlde. Unter } \\
\text { Heinrich II. (1002-1024) war sie die wichtigste Pfalz und die bevorzugte Weihnachts- } \\
\text { pfalz, bis sie } 1017 \text { durch Brand zerstört wurde. Danach wieder aufgebaut blieb sie } \\
\text { Königspfalz. Der letzte königliche Besuch ist mit Heinrich IV. } 1059 \text { überliefert. } \\
\text { Friedrich Barbarossa gab den Hof Pöhlde } 1158 \text { zusammen mit Burgen in Scharzfeld } \\
\text { und Herzberg an Heinrich den Löwen. Der Königshof der ehemaligen Weihnachts- } \\
\text { pfalz lag nördlich der Klosterkirche und bestand aus mehreren Gebäuden, die min- } \\
\text { destens drei Bauphasen aufwiesen. Die Kirche war durch einen gedeckten Gang mit } \\
\text { den Saalbauten verbunden. }\end{array}$ \\
\hline Literatur & $\begin{array}{l}\text { BiNDING 1996; BRACHMANN 1994; Claus 1973; Claus 1992; Claus \& FANSA 1983; } \\
\text { HEINE } 1997\end{array}$ \\
\hline
\end{tabular}




\begin{tabular}{|c|c|}
\hline $\begin{array}{l}\text { Lokalität } \\
\text { bei } \\
\text { Ldkr }\end{array}$ & $\begin{array}{l}\text { Pfalz und Stadt Nordhausen } \\
\text { Nordhausen } \\
\text { Nordhausen }\end{array}$ \\
\hline Zeitstellung & $\begin{array}{l}\text { erste schriftliche Nennung der Pfalz } 927 \text { (Die planmäßige Anlage der Städte } \\
\text { Nordhausen und Sundhausen erfolgte vermutlich bereits um die Mitte des 8. Jhs.) }\end{array}$ \\
\hline Beschreibung & keine archäologischen Funde der Pfalz \\
\hline $\begin{array}{l}\text { Siedlungs- } \\
\text { geschehen }\end{array}$ & $\begin{array}{l}\text { Der Beginn der Siedlungsaktivität ist unklar. Wahrscheinlich wurde in der Mitte des } \\
\text { 8. Jhs. der karolingische Königshof in Nordhausen zusammen mit dem nur } 3 \text { km } \\
\text { süd-südöstlich liegenden Sundhausen angelegt. Die beiden Orte lagen im } \\
\text { Schnittpunkt wichtiger Verkehrswege. Zwischen Nord- und Sund(=süd)hausen } \\
\text { bestand bis zur Urbarmachung im hohen Mittelalter die einzige Möglichkeit, die } \\
\text { Helmeniederung (die heutige „Goldene Aue“) zu überqueren. Zusätzlich kreuzten } \\
\text { hier die Heerstraße nach Heiligenstadt, der Heerweg nach Duderstadt und die } \\
\text { Harzrandstraße nach Pöhlde. Seit } 909 \text { war Nordhausen ein luidolfingischer Platz. } \\
927 \text { wurde eine luidolfingische Burg, erbaut von Herzog Heinrich von Sachsen, in } \\
\text { den Quellen genannt. } 961 / 62 \text { wurde ein Nonnenkloster gegründet, das spätere Stift } \\
\text { zum Heiligen Kreuz, das bereits } 962 \text { Markt, Zoll und Münzrecht erhielt. } 1220 \text { wurde } \\
\text { Nordhausen Reichsgut. Um } 1230 \text { wurde das Zisterzienserinnenkloster Neuwerk } \\
\text { eingerichtet. Von 1430-1432 war die Stadt Nordhausen Mitglied der Hanse. }\end{array}$ \\
\hline Literatur & GOCKEL 2000 \\
\hline
\end{tabular}

Etwa um 1200, im Zuge der Städtegründungswelle, erhielt die Siedlung Osterode, die seit spätestens 1153 durch eine Burg befestigt war (vgl. Tab. 6), das wirtschaftlich bedeutende Marktrecht. Das Stadtrecht wurde Osterode 1239 verliehen. Aufgrund seiner besonders günstigen Verkehrslage im Kreuzungsbereich verschiedener wichtiger Straßen setzte in Osterode sehr früh eine bedeutende wirtschaftliche Entwicklung ein (KEYSER 1952).

Im Harzvorland lässt sich eine weitere Phase des inneren Landesausbaus fassen, die im ausgehenden Hohen Mittelalter erfolgte. Die Ortsnamen dieser Gründungsperiode enden auf -hagen (Bsp. Königshagen bei Barbis, siehe unten). Die Gründung des Zisterzienserklosters Walkenried datiert ebenfalls in diese Zeit. Durch die Kultivierung der Helmeniederung und die Anlage zahlreicher Wirtschaftshöfe trug der Konvent maßgeblich zum Landesausbau bei (siehe unten). 


\begin{tabular}{|c|c|}
\hline $\begin{array}{l}\text { Lokalität } \\
\text { bei } \\
\text { Ldkr }\end{array}$ & $\begin{array}{l}\text { Wüstung Königshagen } \\
\text { Barbis (Bad Lauterberg) } \\
\text { Osterode am Harz }\end{array}$ \\
\hline Zeitstellung & $\begin{array}{l}\text { ca. } 1130 \text { gegründet - zwischen 1413/1420 im Zuge einer Fehde zerstört und } \\
\text { verlassen }\end{array}$ \\
\hline Beschreibung & $\begin{array}{l}\text { befestigter, wohnturmartiger Saalgeschossbau (Turmhaus), umgeben von einem } \\
\text { kleinen Haufendorf (ca. } 13 \text { Höfe), Königsgut }\end{array}$ \\
\hline $\begin{array}{l}\text { Siedlungs- } \\
\text { geschehen }\end{array}$ & $\begin{array}{l}\text { Die Gründung erfolgte vermutlich durch die Grafen von Scharzfeld und Lauterbach. } \\
\text { Für die Befestigung und ihre Randbebauung lässt sich folgende zeitliche Abfolge } \\
\text { erkennen: } 1 \text {. Wohnturm, möglicherweise mehrgeschossig, auf schwachem } \\
\text { aufgeschütteten Hügel, befestigt durch doppelte Palisade und Graben - } \\
\text { 2. Wohnturm, statt Palisade umgeben von Ring aus kleineren Häusern und Graben - } \\
\text { 3. Etwa um die Mitte des 13. Jhs., nachdem Königshagen in den Besitz des Klosters } \\
\text { Pöhlde gekommen war, Umbau des Turmes zur Kirche, Bestattungen im Hof, kleine } \\
\text { Häuschen fungieren als Speicher oder Remisen. Unter den umliegenden Höfen } \\
\text { konnten auch solche von Handwerkern lokalisiert werden (z.B. Töpferei), im späten } \\
\text { 14./15. Jh. bestanden zu den Glashütten des benachbarten Waldes Beziehungen. } \\
\text { Unter den Funden sind zahlreiche bäuerliche Arbeitsgeräte. Große Teile der } \\
\text { ehemaligen Flur, langstreifige isohypsenparallele Terrassenäcker, konnten im } \\
\text { Bebertal lokalisiert und kartiert werden. }\end{array}$ \\
\hline Literatur & HEINE 1991a; HEINE 1991b; JANSSEN 1963; JANSSEN 1987 \\
\hline Pollenanalysen & $\begin{array}{l}\text { Untersuchungen der Sedimente aus dem immerfeuchten Befestigungsgraben } \\
\text { ergaben, dass die Getreideanbauflächen kurz vor dem Brand der Siedlung } \\
\text { zugunsten des Grünlandes verringert worden waren. Auf den Brand folgte zunächst } \\
\text { eine „Trümmervegetation“, bevor die Werte des Getreidepollens wieder ansteigen. } \\
\text { Die Anbauflächen wurden vermutlich von Barbis aus weiter bewirtschaftet. } \\
\text { (JANSSEN 1987) }\end{array}$ \\
\hline
\end{tabular}

\begin{tabular}{|c|c|}
\hline $\begin{array}{l}\text { Lokalität } \\
\text { bei } \\
\text { Ldkr }\end{array}$ & $\begin{array}{l}\text { Zisterzienserkloster Walkenried } \\
\text { Walkenried } \\
\text { Osterode am Harz }\end{array}$ \\
\hline Zeitstellung & $1129-1525$ \\
\hline Beschreibung & Klosterruine \\
\hline $\begin{array}{l}\text { Siedlungs- } \\
\text { geschehen }\end{array}$ & $\begin{array}{l}\text { Wirtschaftlich sehr aktives Zisterzienserkloster mit ausgedehnten Besitztümern und } \\
\text { zahlreichen bäuerlichen Betrieben in Eigenwirtschaft (1205 wurden } 11 \text { solcher } \\
\text { Grangien und } 3 \text { Weingüter gezählt). Es besaß Anteile am Erzbergbau im Rammels- } \\
\text { berg, Hüttenbesitz im Harz (u. a. am Brunnenbach und im Zorgetal) und } \\
\text { ausgedehnten Forstbesitz in den Harzwäldern (siehe Kapitel Der Wald im Spiegel } \\
\text { historischer Quellen). Eine Beteiligung des Klosters an der Mitte des 12. Jhs. von } \\
\text { flämischen Siedlern durchgeführten Kultivierung des Helmerieths (heute „Goldene } \\
\text { Aue“) ist sehr wahrscheinlich. } 1525 \text { wurde das Kloster während des Bauernkriegs } \\
\text { geplündert, die Kirche wurde zur Ruine. } \\
\text { Die umfangreichen Urkunden des Klosters stellen eine wichtige historische Quelle } \\
\text { dar (DoLLE 2002). }\end{array}$ \\
\hline Literatur & BRÜNNING \& SCHMIDT 1969; HEUTGER 1977; REINBOTH \& REINBOTH 1989 \\
\hline
\end{tabular}

Das Hohe Mittelalter wurde überregional von einem starken Bevölkerungswachstum bei etwa gleich bleibender Produktivität der Landwirtschaft geprägt. Die Ernährung einer größer werdenden Bevölkerung konnte daher nur durch eine Ausweitung der bestehenden Anbauflächen bzw. durch die Rodung und Urbarmachung neuer Flächen gesichert werden. Der innere Landesausbau in den Altsiedelgebieten und die sogenannte Ostkolonisation östlich der Elbe waren die Folgen. Sie wurden von den Landesherren geplant und durchgeführt. Diese erweiterten damit gleichzeitg ihre Macht durch die Ansiedlung weiterer abgabenpflichtiger Bauern. 
Im Zuge eines inneren Landesausbaus wurden durch gezielte Rodungen von Wäldern Anbau- und Siedlungsflächen geschaffen, auf denen neue Dörfer angesiedelt werden konnten. Im Untersuchungsgebiet wurden bereits mehrere solcher zeitlich aufeinander folgender Ausbauphasen unterschieden (siehe oben). Dabei wurden zunehmend schlechtere Böden urbar gemacht, da die Flächen mit guter Bodenfruchtbarkeit in der Regel frühzeitig besiedelt worden waren. Diese Grenzertragsflächen lieferten nur unter günstigen Witterungsbedingungen ausreichende Erträge, um sowohl die Bauernfamilien zu ernähren als auch die Abgaben an den Landesherren leisten zu können (HENNING 1994).

Als Grundnahrungsmittel wurde auf den Ackerflächen ausschließlich Getreide angebaut, das ca. $70 \%$ des Kalorienbedarfes der damaligen Menschen deckte. Die Bewirtschaftung des Ackerlandes erfolgte zunehmend in einer geregelten Mehrfelderwirtschaft, bei der etwa dreiviertel der gesamten Äcker bestellt wurden, während die übrigen Flächen brachlagen. Im Gegensatz zur älteren, ungeregelten Feld-Gras-Wirtschaft wurde die Nutzung der Brache als gemeinsames Weideland meist auf ein Jahr begrenzt. Der einseitige Getreideanbau mit kurzer Brachezeit wirkte sich im Laufe der Zeit zunehmend negativ auf die Fruchtbarkeit des Bodens aus. Die Gemengelage der Felder und die Notwendigkeit einer gemeinsamen Beweidung der Brache ließ den sogenannten „Flurzwang“ entstehen. Dieser besagte, dass alle Felder eines Abschnittes gleichsinnig bestellt oder brach liegen gelassen werden mussten. Der Anbau aller weiteren Kulturpflanzen erfolgte in umzäunten, hofnahen Gärten. Dort wurden Gemüse, Hülsenfrüchte, Obst und Flachs zur individuellen Versorgung der Familien angebaut (HENNING 1994).

Neben dem Anbau von Getreide hatte auch die Viehzucht einen bedeutenden Anteil an der Versorgung der Familien. Sie diente im wesentlichen der Fleischversorgung, lieferte jedoch darüber hinaus Milchprodukte, Eier, Kleidung in Form von Wolle und Leder sowie Knochen und Horn als Materialien für verschiedene Geräte. Darüber hinaus dienten Ochsen als Zugtiere. Mit dem Anstieg der Bevölkerungzahl wuchs auch die Anzahl der landwirtschaftlichen Nutztiere solange, bis sie durch die herrschaftliche Begrenzung der Waldweideflächen eingeschränkt wurde. Die Futterversorgung der Tiere war lediglich im Sommer und Herbst durch die Weidemöglichkeiten im Wald und auf den Bracheflächen sichergestellt. Im Winter und Frühjahr reichte das auf den wenigen Wiesen beispielsweise in Feuchtgebieten gewonnene Heu nicht aus, um die Versorgung der Tiere zu gewährleisten. Eine sehr geringe Leistung der Tiere und eine hohe Anfälligkeit für Krankheiten und Seuchen waren die Folge dieser Unterversorgung (HENNING 1994).

Die Zunahme der Städte und damit die Zunahme des Bevölkerungsanteils, der nicht in der Landwirtschaft tätig war, erhöhte den Anteil der Arbeitsteilung in der Gesellschaft. Damit wurde regional die Ausrichtung der auf Subsistenzwirtschaft ausgelegten bäuerlichen Höfe auf eine Überproduktion zur Versorgung der Menschen in den Städten nötig. Die Erträge aus dem Getreideanbau und aus der Viehzucht unterlagen starken Schwankungen, die regelmäßig zu Hungersnöten führten (HENNING 1994).

\section{Spätes Mittelalter (1250 - 1500 n. Chr.) und frühe Neuzeit (1500 - 1800 n. Chr.)}

Von 1347 bis 1383 zogen mehrere verheerende Pestwellen durch ganz Mitteleuropa. Die Bevölkerung besonders der Städte wurde dadurch so stark verringert, dass es in der Folgezeit zu einem drastischen Überangebot an Getreide kam, was wiederum einen starken Preisverfall nach sich zog. Aufgrund des allgemeinen Flurzwanges konnten die Bauern jedoch nicht auf den Anbau anderer Nutzpflanzen wie beispielsweise Leguminosen ausweichen. Während dieser als Spätmittelalterliche Agrarkrise bezeichneten Phase kam es im 14. Jh. zu einer größeren Wüstungsperiode. In Folge der Krise wurden viele Dörfer verlassen. Die ansässigen Bauern konnten aufgrund des Preisverfalls die grundherrlichen Abgaben nicht mehr zahlen und wanderten ab (HENNING 1994).

Zusätzlich litt die Landbevölkerung verstärkt unter den zahlreichen Fehden und Kriegen der Landesherren. Während des Spätmittelalters war man dazu übergegangen, die Existenz- 
grundlage des Kontrahenten zu zerstören. Anstatt die befestigten Burgen anzugreifen, wurden daher Dörfer niedergebrannt und Felder verwüstet (siehe oben Bsp. Königshagen). Selbst wenn die Bewohner Schutz in einer der zahlreichen Befestigungen finden konnten, war damit ihre Lebensgrundlage nachhaltig geschädigt. Nicht wenige wanderten in die Städte ab (HENNING 1994).

Auch die Wüstungsprozesse selbst waren äußerst vielfältig. Nur wenn Dorfstellen gänzlich aufgegeben wurden, spricht man von einer totalen Ortswüstung (im Gegensatz dazu steht die partielle Ortswüstung). Die Flur eines Ortes wurde häufig von benachbarten Dörfern weiter bestellt. Wo dies nicht der Fall war und es zu einer Wiederbewaldung der Äcker kam, handelt es sich um eine Flurwüstung. Wurde ein wüstgefallenes Dorf wie im Falle Dünas später erneut besiedelt, so handelt es sich um eine temporäre Wüstung.

Tabelle 6: Mittelalterliche Burgen im Untersuchungsgebiet, nicht archäologisch untersucht

\begin{tabular}{|c|c|c|c|}
\hline Lokalität & $\begin{array}{l}\text { Zeit- } \\
\text { stellung }\end{array}$ & Beschreibung & Siedlungsgeschehen \\
\hline $\begin{array}{l}\text { Turmburg } \\
\text { bei Wulften } \\
\text { Ldkr. Osterode am } \\
\text { Harz } \\
\text { (KüHLHORN 1970) } \\
\end{array}$ & $889(?)$ & $\begin{array}{l}\text { Kreuzung der Nordhäuser und } \\
\text { der Thüringer Heerstrase, } \\
\text { Steinfundamente }\end{array}$ & $\begin{array}{l}\text { möglicherweise der } 889 \text { im } \\
\text { Tafelgüterverzeichnis genannte } \\
\text { Königshof „Horenburg“ }\end{array}$ \\
\hline $\begin{array}{l}\text { Sachsenstein } \\
\text { bei Bad Sachsa } \\
\text { Ldkr. Osterode am } \\
\text { Harz } \\
\text { (CLAUS 1978; } \\
\text { HEINE 1991a) } \\
\end{array}$ & $\begin{array}{l}1074 \\
\text { zerstört } \\
(?)\end{array}$ & $\begin{array}{l}\text { große Burganlage in } \\
\text { Spornlage, keine Merkmale } \\
\text { einer Residenz, vermtl. } \\
\text { wehrhafte Repräsentanz, Burg } \\
\text { mit außergewöhnlichen } \\
\text { sechseckigen Türmen }\end{array}$ & $\begin{array}{l}\text { Von Heinrich IV. gegen die } \\
\text { aufständigen Sachsen errichtet. } \\
\text { Wahrscheinlich } 1074 \text { nach einer } \\
\text { kurzen Besiedlung zerstört. Seit dem } \\
\text { 12. Jh. nur noch als Grenzpunkt } \\
\text { gewisse Bedeutung. }\end{array}$ \\
\hline $\begin{array}{l}\text { Burg Osterode } \\
\text { Osterode am Harz } \\
\text { Ldkr. Osterode am } \\
\text { Harz } \\
\text { (KüHLHORN 1970) } \\
\end{array}$ & $\begin{array}{l}(1136 ?) \\
1153- \\
\text { Mitte } \\
\text { 16.Jh. }\end{array}$ & $\begin{array}{l}\text { auf Ausläufer des } \\
\text { Butterberges, seit Mitte des } \\
\text { 16. Jhs. verfallend, erhalten } \\
\text { sind Reste des Bergfrieds und } \\
\text { Mauerreste }\end{array}$ & $\begin{array}{l}\text { Erbauer unbekannt, zunächst in der } \\
\text { Hand Heinrich des Löwen, später } \\
\text { dessen Sohn König Otto IV., mit } \\
\text { Bildung des Fürstentums } \\
\text { Grubenhagen zu diesem gehörend. }\end{array}$ \\
\hline $\begin{array}{l}\text { Ebersburg } \\
\text { Hermannsacker } \\
\text { Ldkr. Nordhausen }\end{array}$ & ca.1180 & $\begin{array}{l}\text { auf Felskuppe am Südrand des } \\
\text { Harzes, runder } \\
\text { dreigeschossiger Bergfried }\end{array}$ & $\begin{array}{l}\text { 1183/89 dem Pfalzgraf Hermann von } \\
\text { Sachsen durch den Erzbischof } \\
\text { Konrad von Mainz zu Lehen gegeben } \\
\text { (Ludowinger), vermutlich lag die Burg } \\
\text { auf dem Boden des Bistums Mainz, } \\
1247 \text { Belagerung der Burg durch Graf } \\
\text { Siegfried von Anhalt }\end{array}$ \\
\hline $\begin{array}{l}\text { Geiersberg } \\
\text { nörd. Nordhausen } \\
\text { Ldkr. Nordhausen } \\
\text { (STRICKHAUSEN } \\
\text { 1998) } \\
\end{array}$ & $\begin{array}{l}1194- \\
1220\end{array}$ & $\begin{array}{l}\text { Wüstung eines } \\
\text { Ministerialensitzes der } \\
\text { Liudolfinger }\end{array}$ & unbekannt \\
\hline $\begin{array}{l}\text { Burg und } \\
\text { Schloss Herzberg } \\
\text { Herzberg am Harz } \\
\text { Ldkr. Osterode am } \\
\text { Harz } \\
\text { (KüHLHORN 1970) } \\
\end{array}$ & $\begin{array}{l}1157 \\
\text { erste } \\
\text { Erwäh- } \\
\text { nung }\end{array}$ & $\begin{array}{l}\text { in Spornlage, Sichtverbindung } \\
\text { über die „Halbe Warte“ zur } \\
\text { Osteroder Burg }\end{array}$ & $\begin{array}{l}1157 \text { erhielt Heinrich der Löwe die } \\
\text { Burg von Kaiser Friedrich I., } 1203 \text { an } \\
\text { Heinrichs Sohn, König Otto IV. damit } \\
\text { ab } 1286 \text { bis } 1596 \text { zum Fürstentum } \\
\text { Grubenhagen, anschließend Besitz } \\
\text { des Fürstentums Braunschweig- } \\
\text { Wolfenbüttel, } 1665 \text { Besitz des } \\
\text { Fürstentums Calenberg }\end{array}$ \\
\hline
\end{tabular}




\begin{tabular}{|c|c|c|c|}
\hline Lokalität & $\begin{array}{l}\text { Zeit- } \\
\text { stellung }\end{array}$ & Beschreibung & Siedlungsgeschehen \\
\hline $\begin{array}{l}\text { Niedersalza } \\
\text { nordwestl. } \\
\text { Nordhausen } \\
\text { Ldkr. Nordhausen } \\
\text { (STRICKHAUSEN } \\
\text { 1998) }\end{array}$ & $\begin{array}{l}\text { Ende } \\
\text { des } 12 . \\
\text { Jhs. }\end{array}$ & $\begin{array}{l}\text { Wüstung eines } \\
\text { Ministerialensitzes der } \\
\text { Ludolwinger }\end{array}$ & unbekannt \\
\hline $\begin{array}{l}\text { Turmburg } \\
\text { Kirchturm von } \\
\text { Hattorf } \\
\text { Ldkr. Osterode am } \\
\text { Harz } \\
\text { (KüHLHORN 1970) }\end{array}$ & $\begin{array}{l}13 / 14 . \\
\text { Jh.(?) }\end{array}$ & $\begin{array}{l}\text { in Spornlage an der } \\
\text { Siebermündung, wehrhafter } \\
\text { Rundbau, angebautes } \\
\text { Kirchenschiff aus Fachwerk } \\
\text { von } 1755 / 56 \text { hatte einen } \\
\text { Vorläufer des } 15 . J h s .\end{array}$ & $\begin{array}{l}\text { vermutlich Teil der Burganlage der } \\
\text { Herren von Hattorf (Pipesborg) }\end{array}$ \\
\hline $\begin{array}{l}\text { Kalkburg } \\
\text { auf dem Hausberg } \\
\text { bei Hörden } \\
\text { Ldkr. Osterode am } \\
\text { Harz } \\
\text { (KüHLHORN 1970) }\end{array}$ & $\begin{array}{l}\text { nach } \\
1337\end{array}$ & $\begin{array}{l}\text { auf dem Hausberg (244,1 m } \\
\text { ü. NN), dicht südwestlich der } \\
\text { Aschenhütte, keine } \\
\text { aufgehenden Mauern }\end{array}$ & $\begin{array}{l}1337 \text { verspricht Heinrich, Herzog von } \\
\text { Grubenhagen, in einer Urkunde } \\
\text { seinem Bruder bei dem Bau einer } \\
\text { Burg auf dem Hausberg zu helfen, } \\
\text { die Burg wird später nicht wieder } \\
\text { erwähnt, daher möglicherweise nur } \\
\text { kurz in Benutzung oder nie } \\
\text { fertiggestellt }\end{array}$ \\
\hline $\begin{array}{l}\text { Burg } \\
\text { Windhausen } \\
\text { bei Windhausen } \\
\text { Ldkr. Osterode am } \\
\text { Harz } \\
\text { (KüHLHORN 1970) }\end{array}$ & $\begin{array}{l}1338 \\
\text { erwähnt }\end{array}$ & $\begin{array}{l}\text { auf dem Knollen gelegen, } \\
\text { Mauerreste und die } \\
\text { Grundmauer eines runden } \\
\text { Bergfrieds erhalten }\end{array}$ & $\begin{array}{l}\text { Burg der Braunschweigischen } \\
\text { Herzöge, } 1478 \text { vermutlich bereits } \\
\text { verfallen }\end{array}$ \\
\hline
\end{tabular}

\subsubsection{Verkehrswege}

Dank der ausführlichen Untersuchung von DENECKE (1969) zum historischen Wegenetz zwischen Solling und Harz liegen für einen Teil des Untersuchungsgebietes sehr detaillierte Angaben über die Linienführung alter Wege und alter Fernwege vor. Darüber hinaus lassen sich aufgrund der Angaben zur Einbindung der Verkehrswege in ein größerräumiges Verkehrsnetz auch Hinweise zur Verkehrsanbindung der Stadt Nordhausen in früherer Zeit ablesen.

Im folgenden Abschnitt bezeichnen in Klammern stehende Ortsnamen heutige Wüstungen.

\section{„Hohe Straße“ (,Herzbergischer Weg“, „,Harter Weg“, „Rietstieg“)}

Während des Frühen und Hohen Mittelalter war die „Hohe Straße“ Teil des wichtigsten Fernweges, der aus nördlicher und westlicher Richtung kommend westlich um den Harz herum in den thüringischen und sächsischen Raum führte (Abb. 3).

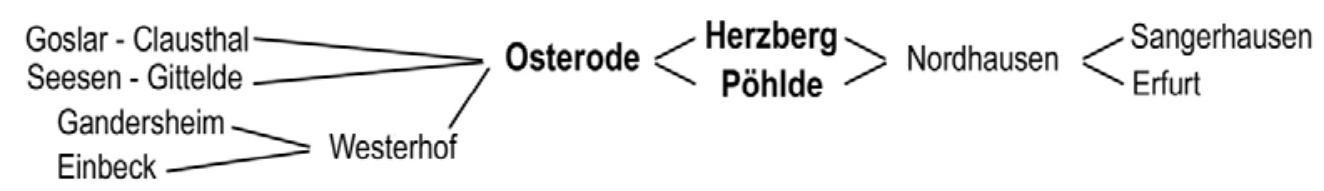

Abbildung 3: Die „Hohe Straße" im Fernwegenetz 
Die Strecke verlief nicht in der Harzrandsenke, sondern auf dem Zechsteinhöhenzug, der aufgrund der dort trockeneren Böden besser zu befahren war. In Abbildung 3 ist die Route wiedergegeben, die auffallend viele sehr alte Orte wie Düna = Dunede, Hörden, Elbingerode und Pöhlde beinhaltet (siehe Kapitel 3.8.1, S. 23). Die Platzwahl für bspw. Düna oder Pöhlde, die an landwirtschaftlich ungünstigen Standorten liegen, wurde vermutlich bereits durch die Verkehrslage an der „Hohen Straße“ beeinflusst. Die Bedeutung des Weges im 10. Jh. wird durch die Konzentration der Königsgüter am Wegesrand unterstrichen (Besitz des Königs z. B. in Bunenerode, Düna, Elbingerode, Pöhlde).

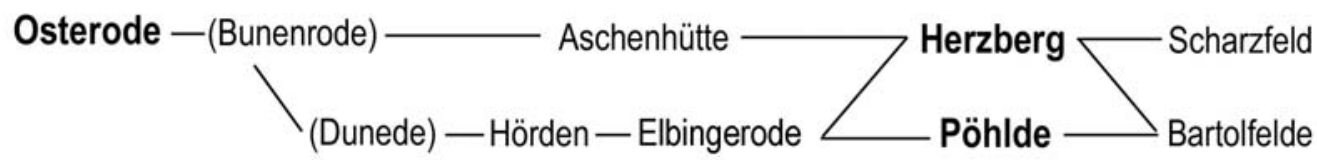

Abbildung 4: Die „Hohe Straße“ mit Nebenstrecke / älterer Route

Die Pfalz Pöhlde mit der etwas älteren Wallanlage „König Heinrichs Vogelherd“ war während des 10. Jhs. der wichtigste Ort entlang der Strecke. Pöhlde war bis zum Späten Mittelalter ein Verkehrsknotenpunkt mit Verbindungen nach Norden und Osten durch die beschriebene „Hohe Straße“, nach Süden durch die „Thüringer Heerstraße“ und nach Westen durch den „Fastweg“ (genannte Straßen werden im folgenden Text erläutert).

\section{„Fastweg“ (Teilstrecke auf dem Rotenberg)}

Der „Fastweg“ verläuft etwa von Lindau nach Pöhlde durchgehend auf dem RotenbergHöhenzug (Abb. 5). Die Benutzung dieser Teilstrecke wurde bereits im Frühen Mittelalter aufgegeben. Die „Landstraße nach Nordhausen“ wurde stattdessen befahren (siehe unten).

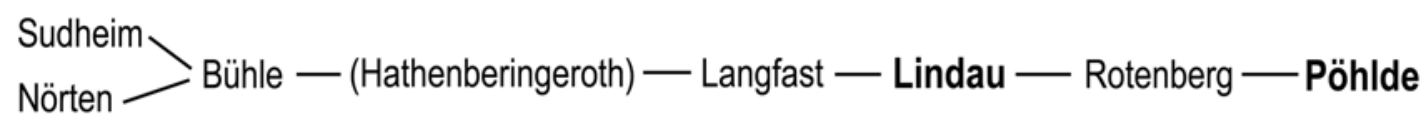

Abbildung 5: Der „Fastweg“

Die Bedeutung des Weges muss bis ins Frühe Mittelalter sehr hoch gewesen sein. Die Wallanlage „König Heinrichs Vogelherd“ bei Pöhlde, deren Nutzung im 10. Jh. endet, lag direkt auf dem Fahrweg. Entlang des gesamten Weges wurden darüber hinaus zahlreiche vorgeschichtliche Grabhügel lokalisiert. Da sie in direkter Beziehung zum Straßenverlauf angelegt wurden, erscheint eine sehr frühe Benutzung des Weges wahrscheinlich (siehe Kapitel 3.4, S. 16). 


\section{„Landstraße nach Nordhausen“ („Heerstraße“, „Hölle”, „Bierweg“)}

Die „Landstraße nach Nordhausen“ verband das südwestliche Harzvorland in westlicher Richtung mit dem Leinetal und weiteren wichtigen Fernwegen (Abb. 6).

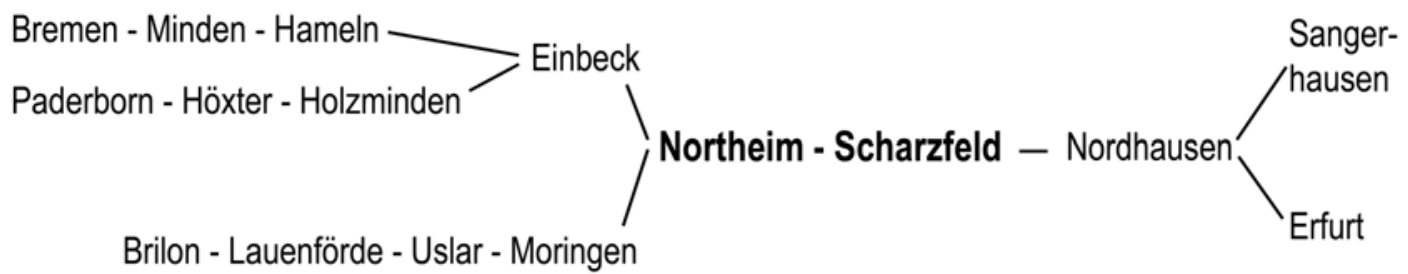

Abbildung 6: Die „Landstraße nach Nordhausen“ im Fernwegenetz

Die Bedeutung dieser Straße seit dem Frühen Mittelalter wird durch die vielen wichtigen Orte an ihrem Weg (Abb. 7) unterstrichen.

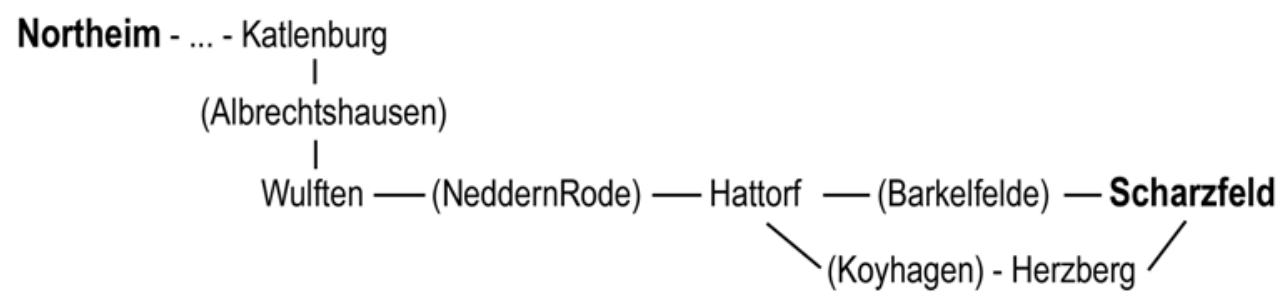

Abbildung 7: Die „Landstraße nach Nordhausen“ mit Nebenstrecke / älterer Route

Sowohl Katlenburg, Wulften, Hattorf, Herzberg als auch Scharzfeld besaßen während des Frühen und Hohen Mittelalters Befestigungen. Darüber hinaus kreuzen hier andere bedeutende Fernstraßen wie die „Hohe Straße“ und die „Thüringer Heerstraße“ den Verlauf der „Landstraße nach Nordhausen“.

\section{„Harzrandstraße“ (,,Thüringer Straße“, „Alte Heerstraße“, „Kaiserweg“")}

Die „Harzrandstraße" schließt ab Osterode in nördlicher Richtung an die „Hohe Straße" an (Abb. 8). Sie verläuft jedoch nicht auf dem Höhenzug, sondern bereits im 9./10. Jh. entlang der Harzrandsenke.

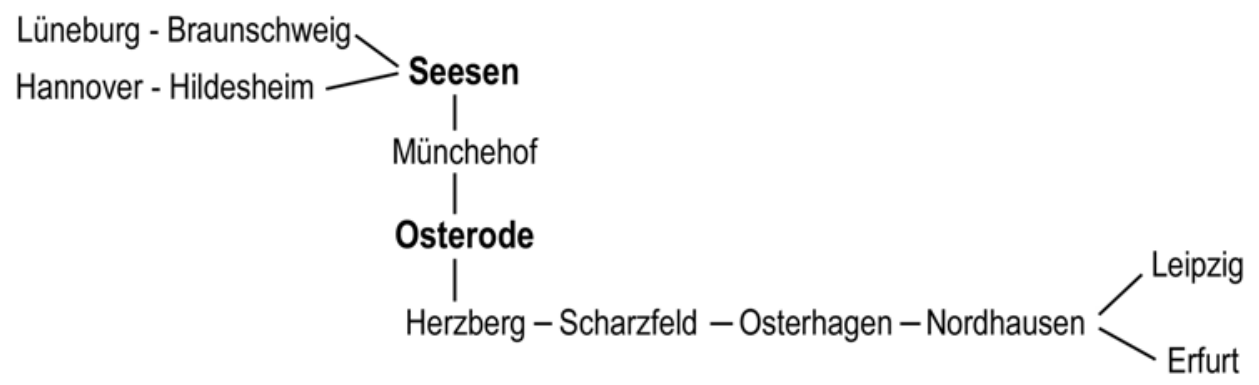

Abbildung 8: Die „Harzrandstraße“ im Fernwegenetz 
Zwischen Osterode und Badenhausen hält sich der Weg an die östliche Söseterrasse (Abb. 9):

\author{
Seesen - Heerhausen - Münchehof - Gittelde - Teichhütte - Badenhausen - Lasfelde - Petershütte - Osterode \\ Abbildung 9: Verlauf der "Harzrandstraße“
}

Die auf dem Höhenzug „Katzenstein“ oberhalb von Lasfelde liegende Pipinsburg war eindeutig auf den Verkehrsweg im Tal ausgerichtet und diente vermutlich zu dessen Kontrolle (siehe Kapitel 3.5, S. 18). Während der eisenzeitlichen Besiedlung der Pipinsburg verlief der Verkehrsweg vermutlich direkt auf dem Höhenzug in direkter Anbindung an die „Hohe Straße“, für die eine frühgeschichtliche Benutzung ebenfalls vermutet wird. Der Abschnitt zwischen Gittelde und Osterode ist auch neuzeitlich von großer Bedeutung. Er wurde zur heutigen Bundesstraße 243 ausgebaut.

\title{
„Harzweg“ (,Klausthaler Weg“, „Uuidukindes speckian“)
}

Der Aufstieg von Osterode (210 m ü. NN) bis zum Heiligenstock (570 m ü. NN) verlief auf dem First des schmalen Bergrückens zwischen der Großen bzw. der Kleinen Bremke und dem Lerbach. Die ältesten Nachweise einer Benutzung dieses Weges datieren in das 11. Jh. Vermutlich wurde diese Harzüberquerung jedoch bereits seit dem Frühen Mittelalter als Handelsroute begangen (Abb. 10).

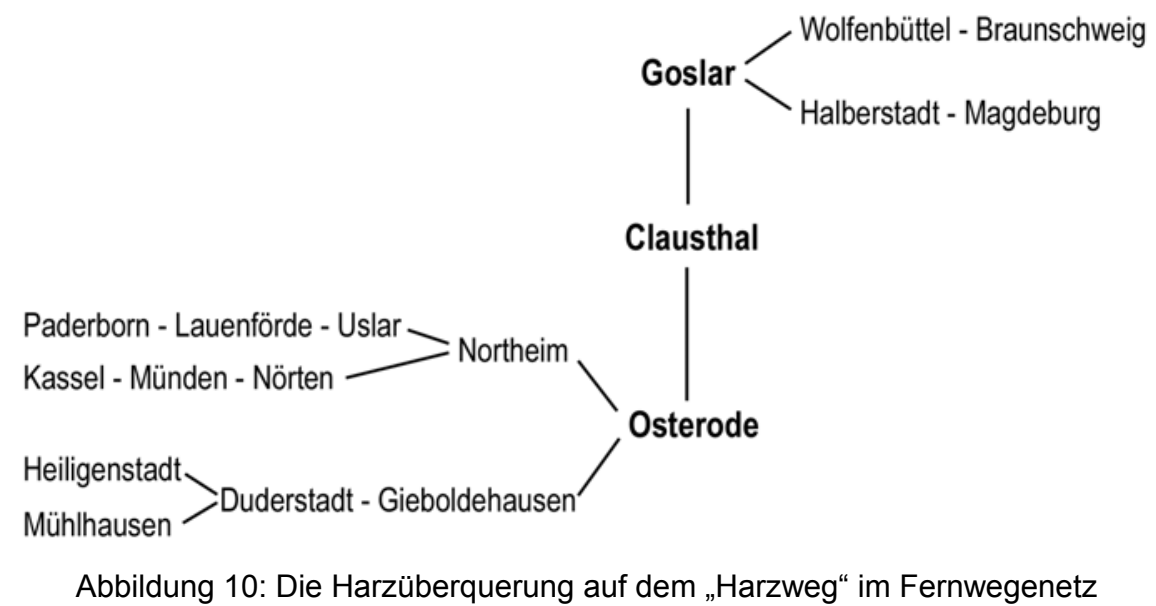

Der „Harzweg“ hatte bereits vor der Klostergründung in Clausthal im 12. Jh. als Pilgerstrecke eine Bedeutung. 


\section{„Thüringer Heerstraße“ („Nürnberger Heerstraße“, „Geleitsstraße“)}

Die „Thüringer Heerstraße“" war seit dem frühen Mittelalter von überregionaler Bedeutung. Während des Späten Mittelalters und der Frühen Neuzeit wurde sie ebenfalls stark frequentiert, da der Handelsverkehr in nord-südlicher Richtung hier verlief (Abb. 11).

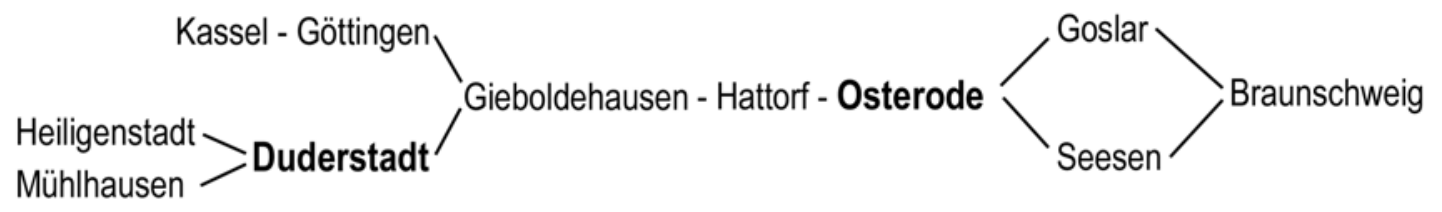

Abbildung 11: Die „Thüringer Heerstraße“ im Fernwegenetz

Die Straße verlief zum größten Teil in den Talsohlen der Hahle, der Rhume und der Söse (Abb. 12).

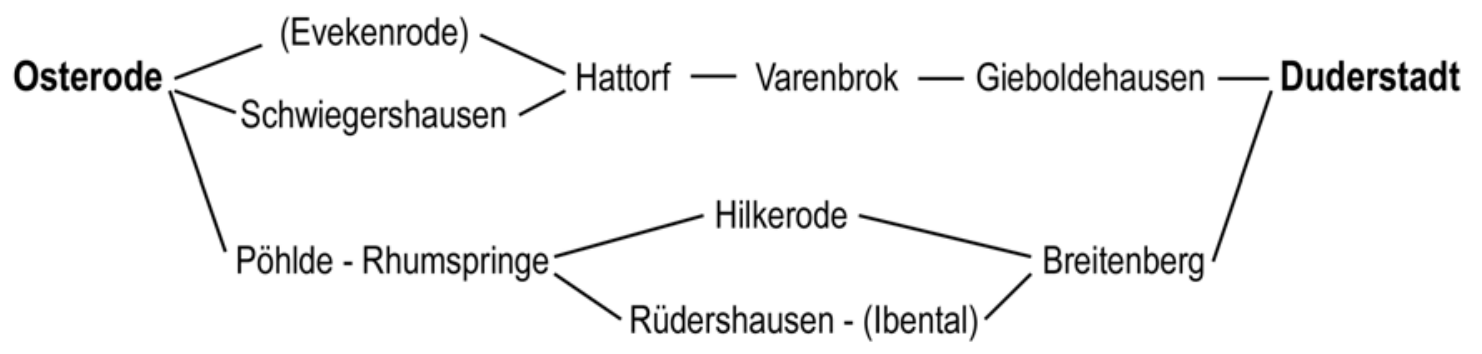

Abbildung 12: Die „Thüringer Heerstraße“ mit Nebenstrecke / älterer Route

Sie quert die Bergsporne des Sulberges, des Bilshäuser Kopfes und des Dutberges mit zum Teil sehr steilen Aufstiegen.

\subsubsection{Bergbaugeschichte}

Voraussetzungen für die Entwicklung eines Bergbaus sind das Vorhandensein und Auffinden abbauwürdiger Lagerstätten. Der Harz mit seinem oft oberflächennahen Aufschluss erzführender Gesteinsformationen und deren Verwitterungsprodukten bietet diese Voraussetzungen in idealer Weise, da sich hier auf relativ engem Raum eine große Anzahl unterschiedlichster Erzlagerstätten befindet.

\section{Älteste Spuren}

Erste Hinweise für eine Metallgewinnung im Harz deuten in die Eisenzeit. Im Silberhohl, einem vermoorten Erdfall bei Seesen, konnten technogene Anreicherungen von Schwermetallen nachgewiesen werden (HETTWER 1999). Desweiteren ergab die metallurgische Untersuchung eines Bronzenadelfragmentes von der Pipinsburg bei Osterode (siehe Kapitel 3.8.1) ein Bleiisotopenmuster, das Ähnlichkeit zu dem des Bleierzes der nahegelegenen Grube in Bad Grund aufweist (BROCKNER 1992).

Der älteste Nachweis einer Verhüttung von Erzen aus dem Harz datiert in die Römische 
Kaiserzeit. In der Siedlung Düna bei Osterode (siehe Kapitel 3.8.1) wurden unter anderem Rennfeueröfen und Schlackenreste nachgewiesen, die mit Hilfe von Keramik, ${ }^{14} \mathrm{C}$ Datierungen und dendrochronologischen Bestimmungen datiert wurden. Die Verhüttung von Eisenerzen aus dem Iberg bei Bad Grund und dem Lerbacher Revier bei Osterode konnte seit der Zeit um Christi Geburt nachgewiesen werden. Ab dem 3. Jh. n. Chr. setzte sowohl die Verhüttung von Oberharzer Gangerzen zur Silbergewinnung als auch die Verhüttung von Rammelsberger Erzen zur Kupfergewinnung ein (BROCKNER 2000; BROCKNER \& KOLB 1986). Der Hüttenbetrieb konnte in Düna mit Unterbrechungen bis in das 13. Jh. verfolgt werden (KLAPPAUF \& LINKE 1990).

Aus der besiedlungsschwachen Völkerwanderungszeit gibt es bisher keine Hinweise für eine Verhüttungstätigkeit im Harz oder Harzvorland. Dies änderte sich erst wieder ab $800 \mathrm{n}$. Chr. Im Frühen Mittelalter (700-1000 n. Chr.) traten im Oberharz erstmals Kohlenmeiler auf, die eine intensive Waldnutzung abseits der Siedlungen belegen (siehe Kapitel 3.8.4). Gleichzeitig stieg die Zahl kleiner Schlackenhalden in der Nähe von Bachläufen. Dort fand überwiegend eine Verhüttung von silberhaltigen Oberharzer Bleierzen statt. Das Silber wurde mittels eines Treibprozesses gewonnen, wie die Funde von Bleiglätte belegen (KLAPPAUF 2000).

\section{Die erste Bergbauphase oder die Zeit des „Alten Mannes“"7}

Ab 900 n. Chr. verbreitete sich die Kupfergewinnung durch Verhüttung der Rammelsberger Erze, wie das vermehrte Auftreten sogenannter Plattenschlackenhalden in windexponierten Lagen zeigt (KLAPPAUF 2000).

Tabelle 7: Lagerstätten im Oberharz, für die ein früher Abbau belegt ist

\begin{tabular}{|c|c|c|}
\hline Lagerstätte & Beschreibung & Abbauprodukte \\
\hline $\begin{array}{l}\text { Die Rammelsberger Lagerstätte } \\
\text { bei Goslar }\end{array}$ & $\begin{array}{l}2 \text { Massivsulfiderzkörper, das Alte- und das Neue } \\
\text { Lager, Hauptmetallanteile Zink, Blei, Kupfer, und } \\
\text { Silber, die z. T. stark verwachsenen Erzphasen } \\
\text { erschweren die Verarbeitung }\end{array}$ & $\begin{array}{l}\text { Kupfer, } \\
\text { silberhaltige } \\
\text { Fahlerze }\end{array}$ \\
\hline $\begin{array}{l}\text { Die Oberharzer } \\
\text { Gangvererzungen (insg. } 19 \\
\text { Gangzüge) }\end{array}$ & $\begin{array}{l}\text { nordwest-südost streichende Störungszonen, } \\
\text { Erzminerale: Zinkblende, silberhaltiger Bleiglanz, } \\
\text { untergeordnet Kupferkies, Trennung der } \\
\text { Erzphasen und Abscheidung der Gangart mit } \\
\text { einfachen Mitteln möglich }\end{array}$ & $\begin{array}{l}\text { silberhaltiges } \\
\text { Blei, Kupfer }\end{array}$ \\
\hline $\begin{array}{l}\text { Der Kupferschiefer entlang des } \\
\text { westlichen und südlichen } \\
\text { Harzrandes }\end{array}$ & $\begin{array}{l}\text { feinlaminierter bituminöser Mergel mit erhöhten } \\
\text { Buntmetallsulfidgehalten, enthält bis 3\% Kupfer, } \\
\text { Blei und Zink und in geringeren Anteilen } \\
\text { zahlreiche weitere Metalle }\end{array}$ & Kupfer, Silber \\
\hline $\begin{array}{l}\text { Die Roteisenerze des } \\
\text { Oberharzer Diabaszuges }\end{array}$ & $\begin{array}{l}\text { Eisengehalt z.T. 35-60 \%, erschwerter Abbau } \\
\text { und erschwerte Verhüttung durch erhöhte } \mathrm{SiO}_{2-} \\
\text { Gehalte }\end{array}$ & Eisen \\
\hline Die Iberger Eisenerze & $\begin{array}{l}\text { manganreicher Eisenspat (Siderit), durch dessen } \\
\text { Verwitterung bildeten sich Höhlen, dort stand das } \\
\text { Brauneisenerz als Lehm an, die hohen } \\
\text { Mangananteile wirkten als Stahlveredler in den } \\
\text { Eisenprodukten, relativ einfache Gewinnung und } \\
\text { Verhüttung }\end{array}$ & Eisen \\
\hline
\end{tabular}

\footnotetext{
7 Die Bezeichnung „Alter Mann“ wird im Montanwesen für verlassene Gruben oder ausgeerzte Gangbereiche verwendet. Am Beginn der „Zweiten Bergbauperiode“ im 16. Jh wurden mit diesem Begriff alle Spuren der in der Mitte des 14. Jhs. erloschenen "Ersten Bergbauperiode“ im Harz bezeichnet (LINKE 2000).
} 
Die Metall- und besonders die Silbergewinnung rückten den Harz und sein Vorland in das Interesse der deutschen Könige. Wie bereits in Kapitel 3.8.1 beschrieben wurde, entstand daraufhin im Harzvorland eine Vielzahl von Befestigungen und Königsgütern.

Eine wichtige schriftliche Überlieferung zum Bergbau im Harz stammt von dem Chronisten Widukind von Corvey, der zum Jahr 968 schrieb, dass von Otto dem Großen (936-973) Silberadern geöffnet worden seien: "terra saxonia venas argenti aperuerit“ (ZOTZ 1993). Diese Äußerung wurde von der Forschung lange Zeit auf die Ausbeutung der Rammelsberger Erze bezogen. Diese enthalten jedoch im wesentlichen Kupfer, während der geringe Silberanteil nur mit Hilfe komplexer Verhüttungsmethoden zu gewinnen ist. Es liegt daher näher, den Silberbergbau mit den bereits im 10. Jh. nachweislich ausgebeuteten Oberharzer Erzgängen in Verbindung zu bringen (STEUER 2000).

Die Einrichtung einer Münzstätte und eines Marktes durch Otto den Großen ist im Jahre 965 bei Gittelde nördlich von Osterode belegt. Verhüttungsanlagen aus dem 10. Jh. konnten im benachbarten Badenhausen nachgewiesen werden. Seit der Jahrtausendwende nahm auch die Bedeutung der Pfalz Goslar stark zu. Die in Goslar bestehende Münzstätte sowie das zur Stadt gehörende Bergdorf wurden 1024 um einen Markt und 1073 um eine Kaufmannsiedlung erweitert. Sämtliche Bergrechte waren zu dieser Zeit Eigentum der Könige und damit der Ottonen (HAUPTMEYER 1992). In den Münzstätten am Harz ließen die Ottonen die bekannten Sachsenpfennige und die Otto-Adelheid-Münzen prägen. Die Bedeutung des Silbergeldes nahm mit der Ausweitung des Handels und der Einrichtung von Märkten im Frühen und Hohen Mittelalter kontinuierlich zu (STEUER 2000).

Im Hohen Mittelalter (1000-1250 n. Chr.) wurde die Bergbauaktivität im Harz und in anderen Teilen Mitteleuropas stark ausgeweitet. Die Holzkohlenanalysen an Meilerplätzen im Harz zeigen, dass zur Deckung des enormen Energiebedarfs der Verhüttungsanlagen ganze Waldgebiete wahllos und unsystematisch abgeholzt wurden (siehe auch Kapitel 3.8.4). Dies führte schnell zu einer regelrechten Waldverwüstung und löste regionale Energiekrisen aus (HILLEBRECHT 1982). Das Erz musste über zunehmend größere Strecken zu den Orten der Holzkohlegewinnung transportiert werden, da wesentlich größere Volumina an Holzkohle zur Verhüttung einer bestimmten Menge Erz nötig waren. Die heute noch vielerorts erhaltenen Schlackenhalden sind daher über den gesamten Harz verteilt und befinden sich oft weit entfernt von den Lagerstätten. Allein im niedersächsischen Teil des Harzes wurden bisher ca. 800 Schmelzplätze lokalisiert (KLAPPAUF 2000).

Während des 12. Jhs. kam es auch im Bergbau, ähnlich wie in der Landwirtschaft, zu verschiedenen Innovationen. Im Harz ging man in den weniger ergiebigen Pingen (Gruben) zum Untertageabbau über, und der erste Stollen zur Ableitung des in der Tiefe austretenden Wassers, der Rathstiefste-Stollen, wurde ebenfalls im 12. Jh. angelegt. Die ersten permanenten Siedlungen im Gebirge entstanden ebenfalls im 12. Jh. (HAUPTMEYER 1992).

Der Bergbau im Harz und dort insbesondere am Rammelsberg unterlag sehr starken wirtschaftlichen Interessen. Als Heinrich der Löwe die Gruben 1181 im Rahmen einer Auseinandersetzung mit dem Kaiser und den Reichsständen zerstören ließ, wurde die Förderung bereits nach einer kurzen Zeit des Wiederaufbaus wieder aufgenommen (HAUPTMEYER 1992).

Mit der Reichsfürstenbelehnung Otto des Kindes im Jahre 1235, zu dem auch der Bergzehnt gehörte, endeten die königlichen Verfügungsrechte über den Bergbau im Harz. Durch Schenkungen und Verkäufe war darüber hinaus der Besitz der Gruben und Hütten im Lauf der Zeit an kirchliche Institutionen wie beispielsweise das Zisterzienser Kloster in Walkenried und adlige Familien vergeben worden (HAUPTMEYER 1992). 


\section{Die spätmittelalterliche Bergbaukrise}

Nach dem zuvor geschilderten stetigen Aufschwung der Metallgewinnung im Harz kam es während des Späten Mittelalters, in der Mitte des 14. Jhs., zur ersten schweren Krise des Bergbaus.

Verschiedene Faktoren bedingten in der Folgezeit den Niedergang des Bergbaus im Harz (HAUPTMEYER 1992; STEUER 2000):

- Der Aufwand und die Kosten für die Erzgewinnung waren mit der Zeit durch das Vordringen der Stollen in immer größere Tiefen stark angestiegen. Das eindringende Wasser konnte daher nicht mehr einfach abgeleitet werden, sondern musste gehoben werden.

- Es kam zu zahlreichen Grubeneinstürzen, da man die Stollen zu dicht nebeneinander in die Erde getrieben hatte.

- Die Wälder und damit die Energieressource Holzkohle wurde knapp. Ungeeignete Hölzer wurden infolgedessen für den Stollenbau eingesetzt (Hasel, Birke, Weide).

- Zahlreiche Arbeiter starben an den Folgen der Pest (1347 und 1349), 1360 standen die Stollen endgültig unter Wasser.

- Silber und andere Metalle waren weniger knapp, da die Bevölkerungszahlen aufgund der Pest drastisch gesunken waren. Das wirtschaftliche Interesse am Bergbau sank.

Die Bergbausiedlungen Clausthal, Zellerfeld, Braunlage und Andreasberg wurden als Folge der Krise verlassen (DENECKE 1978).

\section{Die zweite Bergbauphase}

Nach einer etwa 150jährigen Pause, in der die Wälder nachwuchsen und die Technologie entscheidend weiter entwickelt werden konnte, wurde der Bergbau im Harz in der Frühen Neuzeit erneut aufgenommen. Bereits Mitte des 15. Jhs. setzte der Abbau der oberflächennahen Erze wie der Eisenerze in den Osteroder Bergen wieder ein (HAUPTMEYER 1992; SCHUBART 1978).

Fraglich bleibt, wie umfassend das krisenbedingte Aussetzen des Bergbaus während des 14 . und 15. Jhs. im Harz war. Die Ergebnisse der Holzkohlenanalysen von HILLEBRECHT (1982) und Gerichtsprotokolle von Oberharzer Bergrechtsfällen sprechen gegen ein vollständiges Aussetzen der bergbaulichen Aktivitäten bis zur Mitte des 15. Jhs. (BORNHARDT 1931; BORNHARDT 1943; HILLEBRECHT 1982).

Überliefert ist weiterhin, dass die Bemühungen der Stadt Goslar, Investoren für eine Sümpfung der gefluteten Stollen am Rammelsberg zu finden, zwischen 1453-1456 erste Erfolge zeigten. Am Ende des 15. Jhs. hatten die Fördermengen bereits wieder alte Werte erreicht (BORNHARDT 1943). Im Gebiet um St. Andreasberg wurde die Erzförderung dagegen erst 1487 wieder aufgenommen (NIEMANN 1991). Ab 1520 veranlasste Herzog Heinrich der Jüngere die Aufnahme der Arbeiten in den Gruben Wildemann, Grund und Zellerfeld (BORNHARDT 1943). Nachdem zunächst die Silbergewinnung im Vordergrund der bergbaulichen Aktivitäten gestanden hatte, wurde die Gewinnung von Blei zunehmend wichtiger. Das Schwermetall spielte in gewerblichen Anwendungen eine immer größere Rolle (HAUPTMEYER 1992).

1521 wurde erstmals die sogenannte „Bergfreiheit“ erlassen. Diese Vergünstigungen beinhalteten den freien Handel, das freie Schlagen von Holz für Gruben und Häuser sowie das freie Roden von Wald für Ackerbau und Viehzucht für die Siedler. Auf diese Weise wurden der Bergbau und die Besiedlung in der unwirtlichen Umgebung des Oberharzes stark 
gefördert. Zusätzlich wurden die freien Bergstädte Clausthal, Zellerfeld, Wildemann, Grund, Lautenthal, Altenau und St. Andreasberg gegründet.

Auch das Problem des einströmenden Grundwassers konnte durch die effektivere Kraftübertragung bei der Nutzung der Wasserkraft zur Hebung des Grubenwassers bewältigt werden. Im 16. Jh. begann man mit der Anlage des „Oberharzer Wasserregals“, eines komplizierten Systems von Gräben und Teichen, um die Wassermengen zum Betrieb der Maschinen für Bergbau und Verhüttungsanlagen auch in trockenen Jahren bereitstellen zu können (BRÜNING 1928).

Nach diesem schnellen und umfassenden Aufschwung des Bergbaus wurden während des 15. Jhs. Fördermengen erreicht, die erst Ende des 19. Jhs. übertroffen werden konnten.

\section{Der 30jährige Krieg}

Der 30jährige Krieg (1618-1648) brachte die nächste längere Unterbrechung für den Harzbergbau. In St. Andreasberg standen die Anlagen von 1624-1654 still. Am Rammelsberg erfolgte nach 1625 in unregelmäßigen Abständen nur noch ein sehr geringer Abbau (BORNHARDT 1931; NIEMANN 1991).

\section{Die dritte Bergbauphase}

Nach dem Ende des 30jährigen Krieges wurden die Abbautätigkeiten nur langsam wieder aufgenommen. Ein erneuter Aufschwung des Harzer Bergbaus fand erst gegen Ende des 18. Jhs. statt. Bereits ab 1720 wurde das Holz wieder sehr knapp. Eine seit dem 17. Jh. überlieferte Ausbreitung des Borkenkäfers und die damit verbundene Schädigung der Wälder führte zunächst zu einem Überangebot an Holz und Holzkohle durch die häufigen Windbrüche der Bäume. Daraufhin wurde die Erzproduktion erhöht. Dies hatte die bereits erwähnte Holzknappheit zur Folge, woraufhin die Erzförderung gedrosselt werden musste (BORNHARDT 1931). Mitte des 17. Jhs. versuchte man, das Holzproblem durch gezieltes Aussäen von Fichten zu lösen. Während des 18. Jhs. wurden derartige Aussaaten wiederholt (SCHUBART 1978).

In den 80er Jahren des 18. Jhs. kam es zur nächsten Ausbreitung des Borkenkäfers mit ähnlichen Folgen für den Bergbau wie hundert Jahre zuvor. Eine Anhebung der Fördermenge hatte eine Holzverknappung zur Folge, die zur Senkung der Kapazitäten führte (BORNHARDT 1931; FIRBAS et al. 1939). Im 19. Jh. beendete schließlich der Einsatz von Steinkohle die Waldnutzung durch den Bergbau.

Mitte des 19. Jhs. erfuhr der Bergbau im Harz einen letzten Aufschwung durch die Verarbeitung der Zinkblende, die bis dato ungenutzt auf Schlackenhalden deponiert worden war. Die zunehmende Konkurrenz durch importierte Erze verschlechterte jedoch bereits seit dem 17. Jh. die wirtschaftliche Situation für den Harzbergbau. 1930 kam es, bedingt durch die Weltwirtschaftskrise, zur Schließung der meisten Harzer Gruben. 


\subsubsection{Wald- und Forstgeschichte}

\section{Waldbewirtschaftung}

Die Waldweide gehört zu den vermutlich ältesten menschlichen Nutzungen des Waldes. Sie kann pollenanalytisch im Harzvorland und Unteren Eichsfeld seit dem Neolithikum nachgewiesen werden (BEUG 1992; VOIGT 2003).

Der Eichenmast- oder Hudewald war bis zur Aufgabe der Waldweide in der zweiten Hälfte des 19. Jhs. ein wichtiger Bestandteil der bäuerlichen Subsistenzwirtschaft. Das Recht auf Waldweide wurde schon 1896 von dem Forsthistoriker August Seidensticker (SEIDENSTICKER 1896) als ein altes Recht beschrieben, das weder durch politische Umwälzungen noch durch Änderungen der Besitzverhältnisse eingeschränkt werden konnte.

Die durch Rinder, Schweine, Ziegen und Schafe beweideten Wälder wurden durch den Verbiss des Jungwuchses im Verlauf ihrer Nutzung zunehmend aufgelichtet. Durch den gleichzeitigen Einschlag der Eichen zur Bauholzgewinnung wurde dieser Prozess vielerorts beschleunigt. Weniger Eichen bedeuteten jedoch zugleich einen Rückgang der Eichelproduktion und damit eine schlechtere Versorgung der Schweine. Um dieser Verarmung entgegenzuwirken, wurden junge Eichen, sogenannte Eichheister, auf offenen Hudeflächen angepflanzt. Die ältesten schriftlichen Quellen für solche Pflanzungen stammen aus dem 12. und 13. Jh., wobei jedoch ein wesentlich früherer Beginn denkbar ist. Die anfänglich vermutlich freiwillige Hudewaldverbesserung durch die bäuerlichen Gemeinschaften entwickelte sich mit der Zeit zu einer Gegenleistung für den Bezug von Bauholz, das auch in bäuerlichen Nutzwäldern in herrschaftlichen Besitz übergegangen war (siehe unten). Schließlich wurde das Pflanzen von Eichheistern als Arbeitsdienst der Bauern eingefordert (KREMSER 1984).

Eine solche Eichenpflanzung zur Verbesserung eines alten Hudewaldes konnte Schubart am Krücker bei Schwiegershausen in ca. $5 \mathrm{~km}$ Entfernung zur Lokalität Aschenhütter Teich für den Zeitraum vor 1595 nachweisen (SCHUBART 1978).

Außerhalb der Hudewälder wurde das ursprüngliche Recht auf einen uneingeschränkten Holzeinschlag der Bauern, die sogenannte „freie Axt", im Laufe der Zeit von der jeweiligen Herrschaft auf das „Dust“- oder „Taubholz“ begrenzt. Wertvolle Hölzer wie Eichen und andere Harthölzer dagegen gehörten den Grundherren. Im Klosterforst von Walkenried wurde diese Trennung in ein Ober- (Baumholz) und ein Unterholz (Sträucher) spätestens 1254 eingeführt (SEIDENSTICKER 1896). Ausschließlich das Unterholz durfte demnach zur Brennholzgewinnung genutzt werden.

Diese Mittelwälder bestanden aus wertvollen älteren Bäumen, die sich als Bauhölzer eigneten, und Stangenholz oder Sträuchern in deren Unterwuchs, die regelmäßig zur Brennholzgewinnung geschlagen wurden. Auf diese Weise wurde im Gegensatz zu den Hudewäldern sowohl das Unter- als auch das Oberholz genutzt. Die Baumschicht wurde auch hier durch das Pflanzen von Setzlingen, den sogenannten Heistern oder Lassreisern, aufgefüllt (KREMSER 1984).

In der Nähe der holzintensiven Bergwerke und Hütten ging man schließlich zur Niederwaldwirtschaft über. Nach dem Einschlagen von Ober- und Unterholz auf einer bestimmten Fläche (Hai oder Schlaghai) wurde das nachwachsende Unterholz wiederholt genutzt. Eine Oberholzschicht mit höheren älteren Bäumen konnte sich aufgrund der relativ kurzen Umtriebszeiten (Regenerationszeiten zwischen zwei Einschlägen) nicht entwickeln. Nach SEIDENSTICKER (1896) wurde ein planmäßig rotierender Schlagholz- oder Niederwaldbetrieb im Harz bereits 1456 angeordnet.

Entlegene oder schwer zugängliche Waldgebiete wurden hingegen kaum genutzt. Im Buchen-Mischwald des inneren Harzes fand lediglich der sogenannte „Aushieb“ statt. Handwerker entnahmen dabei gezielt bestimmte für ihre Zwecke geeignete Baumarten wie 
den Bergahorn (siehe unten „Herzberger Forst“). Etwa seit dem 16. Jh. ging man dazu über, diese bis dahin kaum genutzten Wälder in einer frühen Form des heute verbreiteten Hochwaldbetriebes zu bewirtschaften (KREMSER 1984).

\section{Der Wald im Spiegel historischer Quellen}

Die umfangreiche Auswertung archivalischer Quellen unter forsthistorischen Gesichtspunkten durch Winfried Schubart (SCHUBART 1978) ermöglicht es, einen detaillierten Blick auf die Waldzusammensetzung des südwestlichen Harzes und seines Vorlandes in der Zeit des Hohen Mittelalters und der Frühen Neuzeit zu werfen. Ein Teil dieser Ergebnisse ist in Abbildung 13 dargestellt.

Im folgenden Abschnitt wird zunächst die aus der Quellenlage resultierende Waldzusammensetzung der Forstgebiete Osterode, Herzberg, Lauterberg und Walkenried überblickend beschrieben. Die zugeordneten Tabellen enthalten darüber hinaus detaillierte Angaben für kleine Forstorte oder Areale innerhalb dieser Forstgebiete.

Generell muss beachtet werden, dass sich die Quellen im Bereich des Harzrandes und des Harzvorlandes seit 1596 ausschließlich auf Laubwaldbestände in Mittelwaldnutzung bzw. auf Hudewälder beziehen. Bestände in größerer Entfernung vom Harzrand wurden dagegen zunehmend als ungleichaltrig und hochwaldartig beschrieben.

Im Osteroder Forst (bis zum Ackerbruchbergzug im Süden und einige vorgelagerte Landhölzer ${ }^{8}$ ) wurden die bestehenden Eichen- und Buchen-Mischwälder im 15. und 16. Jh., aufgrund ihrer Nutzung durch den Eisenbergbau zunehmend von natürlich angesamten Fichten durchsetzt. Die Namen mehrerer alter Forstorte weisen auf den ehemaligen Laubwaldcharakter dieser Bestände hin: der „Eichelnberg“, die „Eichelkappe“ (jeweils 1596), die zwei „Haseltäler“ (1730), das „Aller“- bzw. „Ellertal“ (1596, 1674) und der „Lindenbeck“ (1500) sind einige davon. Das 1596 erwähnte „Ibenthal“, das heutige „Ifental“, könnte darüber hinaus ein Hinweis auf ein ehemaliges Vorkommen der Eibe sein.

Der größte Teil der Waldgebiete um Osterode bestand im ausgehenden Mittelalter aus Buchen und Fichten in einem Mischwald mit unterschiedlichen Mengenanteilen. Schmale Bereiche in Randlage, die Waldränder von Badenhausen bis südlich des Ackerbruchbergzuges, enthielten dagegen bis ins 17. und teilweise bis ins 18. Jh. masttragende Eichen. Lediglich bei Riefensbeek-Kamschlacken befand sich ein Laubwaldgebiet. Hier stand Eichen-Mischwald, der von Buchen-Fichten-Wald umgeben war (vgl. Tab. 8).

Im Gegensatz dazu standen in den höheren Lagen wie den Kamm- und Schulterlagen des Ackerbruchbergzuges reine Fichtenwälder, die als Fichtenkerngebiete angesehen werden müssen (Erläuterung dazu siehe unten „Die Fichtenverbreitung“). Die für die Osteroder Forsten beschriebenen Laubwaldgebiete waren bis auf wenige in Tabelle 8 genannte Ausnahmen keine reinen Laubwälder, sondern enthielten bereits im 15. Jh. einen Fichtenanteil.

\footnotetext{
${ }^{8}$ Mit dem Begriff „Landhölzer" sind Waldgebiete gemeint, die abseits des eigentlichen Forstgebietes liegen, hier im Harzvorland.
} 


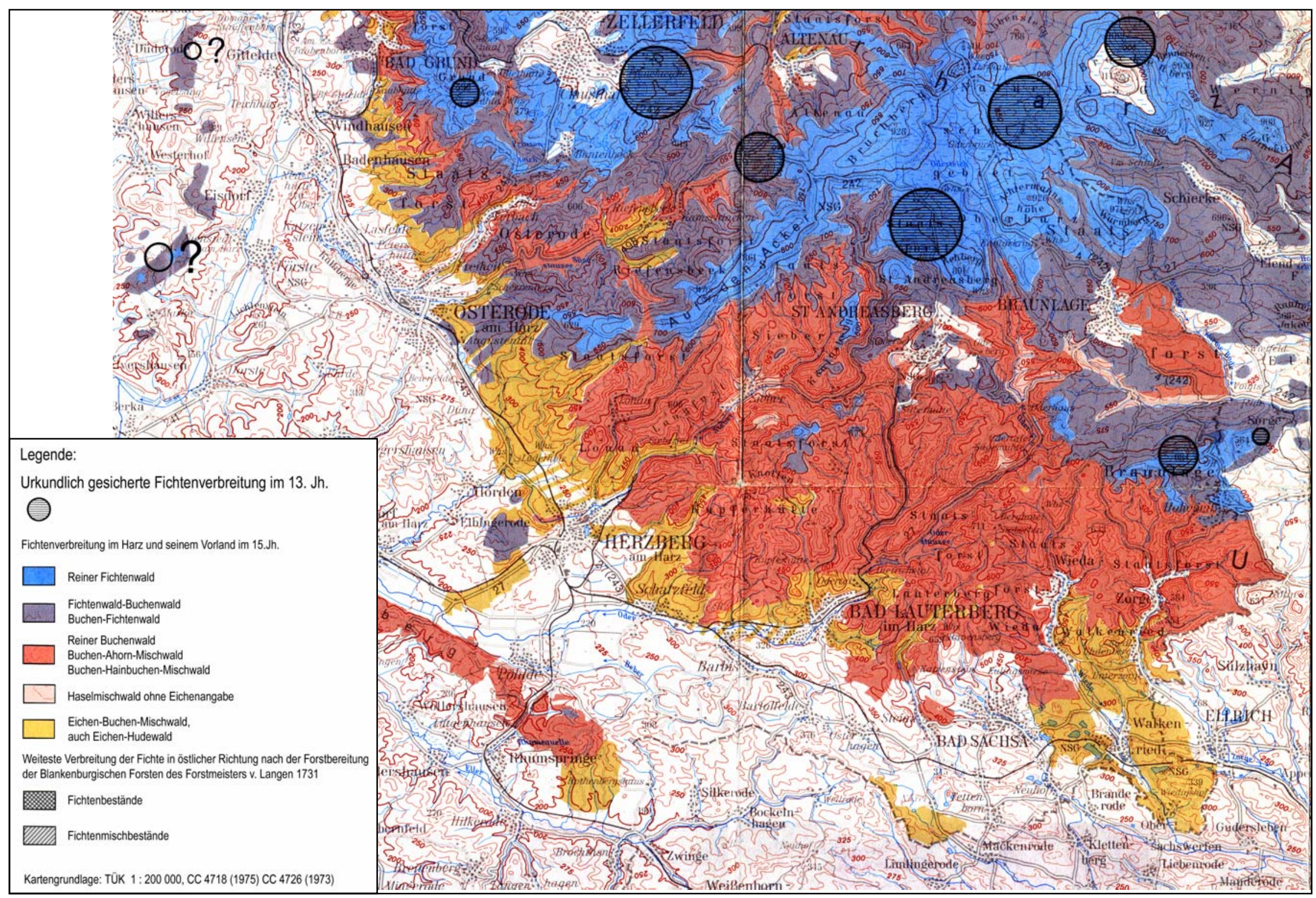

Abbildung 13: Buchen / Fichtenmischbestände im Harz und ihre Verbreitung nach SCHUBART (1978) 
Tabelle 8: Detaillierte Beschreibung des Osteroder Forstes für das 15. Jh. (ScHUBART 1978)

\begin{tabular}{|c|c|}
\hline Osteroder Forst (bis zum Ackerbruchbergzug im & den, Landhölzer) \\
\hline Ort/Lokalität & Waldbeschreibung \\
\hline $\begin{array}{l}\text { Schned- und Zimmerweg (etwa auf der Höhe von } \\
\text { Badenhausen) bis zum Stockweg }\end{array}$ & $\begin{array}{l}\text { masttragende Eichen, } 1630 \text { eine alte Linde am } \\
\text { Schnedweg }\end{array}$ \\
\hline Sonnenberg bis in den Eulenspiegel & masttragende Eichen \\
\hline Hengstrücken & masttragende Eichen \\
\hline Südosthang über Lerbach & masttragende Eichen \\
\hline $\begin{array}{l}\text { Scherenberg (auch auf seinem Ausläufer zwischen } \\
\text { Lerbach und Söse) }\end{array}$ & masttragende Eichen \\
\hline Osteröder Stadtwald & $\begin{array}{l}\text { masttragende Eichen, Ahorn-, Linden- und } \\
\text { Ilmenbäume (?) }\end{array}$ \\
\hline Lichtenstein & $\begin{array}{l}\text { Buche, wenig: Hainbuche, Zitterpappel, } \\
\text { Salweide und andere }\end{array}$ \\
\hline Beckerhau & $\begin{array}{l}\text { Buche, wenig: Hainbuche, Zitterpappel, } \\
\text { Salweide und andere }\end{array}$ \\
\hline Smachberg & $\begin{array}{l}\text { Buche, wenig: Hainbuche, Zitterpappel, } \\
\text { Salweide und andere }\end{array}$ \\
\hline Steinberg & $\begin{array}{l}\text { Buche, wenig: Hainbuche, Zitterpappel, } \\
\text { Salweide und andere }\end{array}$ \\
\hline Whilerstedte & $\begin{array}{l}\text { Rodungsblöße, Eichenpflanzung vorgesehen } \\
\text { (1622) }\end{array}$ \\
\hline am Nassen Weg & eine alte Linde \\
\hline zwischen Nassem Weg und Börweg & alte Eichen \\
\hline beidseitig die Hänge an der Söse bei Riefensbeek & Eichen, Buchen, Hasel \\
\hline Quitschenberg (Südlagen) & $\begin{array}{l}\text { Buche, Ahorn, Hasel, Birke, junge Fichten } \\
\text { (Laubholz stark überwiegend) }\end{array}$ \\
\hline Steinberg (Südlagen) & $\begin{array}{l}\text { Buche, Ahorn, Hasel, Birke, junge Fichten } \\
\text { (Laubholz stark überwiegend) }\end{array}$ \\
\hline Großer und Kleiner Egelnberg bis zur Voßemke & $\begin{array}{l}\text { Buche, Ahorn, Hasel, Birke, junge Fichten } \\
\text { (Laubholz stark überwiegend) }\end{array}$ \\
\hline Eichelnberg & $\begin{array}{l}\text { Eiche, Hasel, Ahorn, Birke abwechselnd mit } \\
\text { Buchen oder Fichten, Buchen (Laubholz stark } \\
\text { überwiegend) }\end{array}$ \\
\hline Großer Schacht am Breitenberg & $\begin{array}{l}\text { Eiche, Hasel, Ahorn, Birke abwechselnd mit } \\
\text { Buchen oder Fichten, Buchen }\end{array}$ \\
\hline Allertal & alte Buche, Ulme, Bergahorn \\
\hline unterhalb der Allerklippe & alte Buche, Ulme, Bergahorn \\
\hline Wolfstal & beidseitig, „vollständig“ Buche mit wenig Fichte \\
\hline Rauher Schacht & Buche mit wenig Fichte \\
\hline Breitenberg bis Stadtwald und Südhang & $\begin{array}{l}\text { Buche, Fichte, einzelne Eichen, Ahorne, } \\
\text { Bergulmen und Birken }\end{array}$ \\
\hline Kleines Haspeltal (heute Haspelloch) & Bergulmen \\
\hline Berge und Täler rechtsseitig des Lerbaches & überwiegend Fichte \\
\hline Schoenenberg & $\begin{array}{l}\text { überwiegend Buche, z.T. mit Zitterpappeln und } \\
\text { Salweiden in den Tälern, z.T. einzelne Eichen }\end{array}$ \\
\hline $\begin{array}{l}\text { Zusammentreffen der Kappen des Voßemke mit } \\
\text { dem Hundscherweg }\end{array}$ & reiner Buchenbestand \\
\hline Vaselstätte am Roten Sohl & reiner Buchenbestand \\
\hline Clausberg (Hochlagen) & reiner Buchenbestand \\
\hline Buchenberg (zwischen Rotries und Rumpelbrücke) & reiner Buchenbestand \\
\hline
\end{tabular}




\begin{tabular}{|l|l|}
\hline \multicolumn{2}{|l|}{ Osteroder Forst (bis zum Ackerbruchbergzug im Süden, Landhölzer) } \\
\hline Ort/Lokalität & Waldbeschreibung \\
\hline Kamm- und Schulterlagen des Ackers & reiner Fichtenbestand \\
\hline $\begin{array}{l}\text { Stieglitzecke (Acker) über Clausthaler Straße- } \\
\text { Hundscherweg-Rennstieg bis Heiligenstock- } \\
\text { Scharrenkreuz (Kaltenborn) }\end{array}$ & reiner Fichtenbestand \\
\hline
\end{tabular}

Die Auswertung der schriftlichen Quellen aus dem Zeitraum von 1596 bis 1732 ergab ein kleinräumig sehr differenziertes Bild für den Herzberger Forst vom Ackerbruchbergzug im Norden bis an die Sieber im Süden und die vorgelagerten Landhölzer (Tab. 9) sowie für den Lauterberger Forst, der sich südlich der Sieber anschließt (Tab. 10).

Am Harzrand in der Nähe der Dörfer befanden sich ausgedehnte Eichenhudewälder. Ebenfalls als sehr reich an Eichen und damit gut geeignet für die Eichelmast wurden die überwiegend südwestexponierten und damit sehr warmen Eichen-Buchenwald-Gebiete um Herzberg beschrieben. Die Eiche erreichte hier sogar die Hochflächen des Ackerbruchbergzuges. Bis ins 15. Jh. war ihre Verbreitung jedoch leicht rückläufig. Zwischen Herzberg und Bad Lauterberg beschränkten sich die Eichenvorkommen dagegen auf Standorte in der Nähe alter Burgen wie Scharzfeld und Lauterberg. Hier überwog ansonsten der Buchenwald. Bis in eine Höhe von 450 bis 500 m ü. NN erstreckte sich ein Gürtel aus BuchenHainbuchen-Wäldern in den Randlagen des Harzes, die überwiegend als Mittelwald bewirtschaftet wurden. Daran schloss sich Buchen-Bergahorn-Mischwald an, aus dem die größten Laubwaldgebiete des Harzes zusammengesetzt waren. Dieser war bis in hohe Lagen und innere Bereiche des Gebirges verbreitet. Häufig waren Eschen und/oder Birken mit größeren Anteilen am Aufbau dieser Wälder beteiligt. Der Buchen-Mischwald ging teilweise in einen reinen Buchenwald über.

Der Bergahorn hatte bis ins 15. und 16. Jh. sowohl im Südharz als auch im Nordwestharz hohe Anteile in den Buchenwäldern der höheren Lagen. Sein Rückgang wurde vermutlich durch die wiederholte, gezielte Entnahme dieser Bäume hervorgerufen und ist auf den sogenannten „Aushieb“ zurückzuführen, der von Drechslern und Drehern ausgeführt werden durfte (siehe oben „Waldbewirtschaftung“). Diese selektive Holzentnahme wird in den "Goslarer städtischen Statuten" aus dem Jahr 1456 und 1460 überliefert und lässt sich vermutlich auf weite Teile des Harzer Buchen-Mischwaldes übertragen.

Fichten-Buchen-Mischwald reichte im Gebiet um Osterode bis ins Sösetal hinab, während mit einem Fichtenanteil der Buchenwälder um Herzberg erst ab einer Höhe von $600 \mathrm{~m}$ ü. NN zu rechnen war. Reiner Fichtenwald war auf kleine Flächen im Anschluss an die sogenannten Kerngebiete beschränkt, die sich in den Hochlagen befanden (siehe unten „Die Fichtenverbreitung").

Tabelle 9: Detaillierte Beschreibung des Herzberger Forstes für die Zeit von 1596-1732 (SCHUBART 1978)

\begin{tabular}{|l|l|}
\hline \multicolumn{2}{|l|}{ Herzberger Forst (Ackerbruchbergzug im Norden bis zur Sieber im Süden, Landhölzer) } \\
\hline Forstort/Lokalität & Waldbeschreibung \\
\hline $\begin{array}{l}\text { Langfast (zwischen Großer } \\
\text { Lonau und Sieber) }\end{array}$ & $\begin{array}{l}\text { südlicher Teil (sog. Ecke über Herzberg): Eichen, Buchen, } \\
\text { Hainbuchen, Zitterpappeln - Ilmetäler: wenige Ulmen - in höheren } \\
\text { Lagen am Fastweg: überwiegend Buchen und Salweiden, wenig } \\
\text { Ahorn, Hainbuche, Zitterpappel und Esche - Ausbuschen der } \\
\text { überwiegend jungen Eichen }\end{array}$ \\
\hline Lüderholz & $\begin{array}{l}\text { Eichen (abständige), Buchen, Hainbuchen mit Zitterpappeln und } \\
\text { Birken, Fichten - geschontes Eichenmastholz ohne Unterholz }\end{array}$ \\
\hline Herzberg, östlich des Juessees & steiniger Anger mit wenigen alten Masteichen - Eichenhudewald \\
\hline
\end{tabular}




\begin{tabular}{|c|c|}
\hline \multicolumn{2}{|c|}{ Herzberger Forst (Ackerbruchbergzug im Norden bis zur Sieber im Süden, Landhölzer) } \\
\hline Ochsenberg bei Herzberg & Fichten \\
\hline Alter Krücker & altes Eichenmastholz (vor 1595 mit Eichheistern verjüngt) \\
\hline Recht Krücker & Buche, Hainbuche, wenig Zitterpappel \\
\hline Carstens Jägers Busch bei Düna & Dornsträucher, viel Hainbuche, viele ältere Eichen, wenig Buche \\
\hline Hainholz bei Düna & Dornsträucher, viel Hainbuche, viele ältere Eichen, wenig Buche \\
\hline Sackau & Dornsträucher, viel Hainbuche, viele ältere Eichen, wenig Buche \\
\hline Die Aue (sw vor Herzberg) & Eichen, Buchen mit viel Unterholz, besonders Dornsträucher \\
\hline Phillip (Berg bei Herzberg) & Eichen, Buchen mit viel Unterholz, besonders Dornsträucher \\
\hline Rotenberg & $\begin{array}{l}\text { Buchenwald, Hainbuche nur am Finnenkopf, Tannenberg und } \\
\text { Mittelberg bei Pöhlde }\end{array}$ \\
\hline Hans-Dietrichshai & $\begin{array}{l}\text { Eichen (abständige), Buchen, Hainbuchen mit Zitterpappeln und } \\
\text { Birken }\end{array}$ \\
\hline Neue Mahnte & viele junge und einige ältere Fichten \\
\hline Am Weinberg & $\begin{array}{l}\text { tiefere Bereiche: alte Fichten, Eichen und Buchen - höhere } \\
\text { Bereiche: alte Bergahorne und Eichen }\end{array}$ \\
\hline $\begin{array}{l}\text { Eichhalbe (mit Kastental und } \\
\text { Hunderücken) }\end{array}$ & Fichte, Buche, Hainbuche, Erle, Birke, Eiche \\
\hline Jährlingsberg & Fichten, alte Eichen und Buchen \\
\hline Schiefergrube & Fichten, alte Eichen und Buchen \\
\hline Keidelshagen & Fichten, alte Eichen und Buchen \\
\hline Rehhagen & $\begin{array}{l}\text { überwiegend Fichte, dazu alte Eichen, Feuchtstandorte mit } \\
\text { geringem Erlenanteil }\end{array}$ \\
\hline Schindelkopf & $\begin{array}{l}\text { überwiegend Fichte, dazu alte Eichen, Feuchtstandorte mit } \\
\text { geringem Erlenanteil }\end{array}$ \\
\hline $\begin{array}{l}\text { Die Heuer (unten vom } \\
\text { Bährenwinkel an den Bergzug } \\
\text { hinauf über Brakberg, Berglöcher } \\
\text { bis oben an Breite Ecke) }\end{array}$ & $\begin{array}{l}\text { Buche, Hainbuche, Zitterpappeln, Esche, Ahorn, Weide, Salweide; } \\
\text { Birke (in höheren Lagen), wenig Eiche (unten am Hägerfeld und } \\
\text { im Mühlberg), geringere Fichtenanteile am Clausschmidtskopf und } \\
\text { an der Breiten Ecke }\end{array}$ \\
\hline Heidelbeerkopf & erste Fichtenanteile im Buchenwald \\
\hline Schneiderhai & gesäte Fichtenbestände \\
\hline IImental & gesäte Fichtenbestände \\
\hline Kerbental & gesäte Fichtenbestände \\
\hline Sieber-Birkental & Buche, Ahorn mit Fichtenanteilen \\
\hline Wellbeckskopf & Buche, Ahorn mit Fichtenanteilen \\
\hline Kötischer Kopf & Buche, Ahorn mit Fichtenanteilen \\
\hline Mittelberge (höhere Lagen) & Buche, Ahorn mit Fichtenanteilen \\
\hline Jacobstal & Buche, Ahorn mit Fichtenanteilen \\
\hline Rohrtal & Buche, Ahorn mit Fichtenanteilen \\
\hline Gichtecke & Buche, Ahorn mit Fichtenanteilen \\
\hline Lilienbergecke (untere Lagen) & Buche, Ahorn mit Hasel \\
\hline
\end{tabular}




\begin{tabular}{|l|l|}
\hline \multicolumn{2}{|l|}{ Herzberger Forst (Ackerbruchbergzug im Norden bis zur Sieber im Süden, Landhölzer) } \\
\hline $\begin{array}{l}\text { entlang der Sieber und der } \\
\text { Großen Kulmke }\end{array}$ & Fichtenreinbestand \\
\hline Königsberg & $\begin{array}{l}\text { Buchen, Fichten, höhere Lagen: junger Fichtenbestand; } \\
\text { Förstertäler: Buchen, Fichten, mit Ahorn }\end{array}$ \\
\hline Mönchskappe & Fichte \\
\hline Kratzecke & Buche, Fichte in kleinräumig wechselnden Anteilen \\
\hline Großer und Kleiner Wurzelberg & Buche, Fichte in kleinräumig wechselnden Anteilen \\
\hline Verlorene Ecke & Buche, Ahorn, Salweide \\
\hline An der Schluft & $\begin{array}{l}\text { untere Lagen (Sonnenkopf, Schwarze Schluft, Steintäler): Buchen, } \\
\text { Fichten; höhere Lagen: Fichtenreinbestand }\end{array}$ \\
\hline Beckerhai & Fichtenreinbestand, teilweise mit Fichtensaat \\
\hline
\end{tabular}

Die Waldzusammensetzung des Herzberger und des Lauterberger Forstes war sehr ähnlich. Einen bereits angesprochenen wichtigen Unterschied stellten die deutlich geringeren Eichenvorkommen im Lauterberger Forst dar, während der Buchenwald hier überwog. Die als mit Eichenwald bestanden aufgeführten Forstorte Bünte, Crodenhagen und Steinberg bei Nüxei stellen Ausnahmen dar. Es handelt sich dabei um Landhölzer, die bereits im Vorland des Harzes liegen, aber zum Forst Lauterberg gehörten (Abb. 13).

Tabelle 10: Detaillierte Beschreibung des Lauterberger Forstes von 1596 (SCHUBART 1978)

\begin{tabular}{|l|l|}
\hline Lauterberger Forst (südlich der Sieber) & \\
\hline Ort/Lokalität & Waldbeschreibung \\
\hline linksseitig der Sieber & Buche \\
\hline Höhe über dem Gopenbornstal (685 m ü. NN) & Fichte \\
\hline Godeckenköpfe und -täler & Buche \\
\hline Schadenbeckskopf und -tal & Buche \\
\hline Großer und Kleiner Knollen & Buche (1630 mit mit Ahorn) \\
\hline Großetal & Buche \\
\hline beide Scheffeltäler & Buche \\
\hline Mittelberg & Buchenmischwald \\
\hline Übelsberg (650 m ü. NN) & $\begin{array}{l}\text { keine Angabe der Baumarten, gerodeter Hai, } \\
\text { gehegt (1630 mit Fichten) }\end{array}$ \\
\hline Mummental & Buche \\
\hline Steinautal (im Bramforst) & Buche \\
\hline Steinrücken & Buche \\
\hline Ahrendsberg & $\begin{array}{l}\text { Buche (Westseite), Birke (Ostseite) - 1630 mit } \\
\text { Hainbuchen }\end{array}$ \\
\hline Großer und Kleiner Heibeckskopf & alte und junge Buchen (einzeln abständig) \\
\hline Andreasbach & alte und junge Buchen (einzeln abständig) \\
\hline beiderseits der Bremke bis Eichelngraben & $\begin{array}{l}\text { Eichen-Buchen-Mischwald - freie } \\
\text { Feuerholznutzung durch die Bewohner des Dorfes } \\
\text { Schartzfeld }\end{array}$ \\
\hline Ruheberg & Buche (1630 mit Hainbuche) \\
\hline Hasental & Buche \\
\hline Himbeerental und -berg & Buche \\
\hline
\end{tabular}




\begin{tabular}{|c|c|}
\hline Lauterberger Forst (südlich der Sieber) & \\
\hline Ort/Lokalität & Waldbeschreibung \\
\hline $\begin{array}{l}\text { Grafenforst (Eichelbach bis Großer und Kleiner } \\
\text { Gründelken) }\end{array}$ & $\begin{array}{l}\text { - freie Feuerholz- und Bauholznutzung durch das } \\
\text { Haus Herzberg und die Bewohner der Dörfer } \\
\text { Herzberg und Scharzfeld (1730 - Buchenwald) }\end{array}$ \\
\hline Eichelkopf & Buche (1630 junge Eichen, Birken, Buchen) \\
\hline Remesberg & Buche \\
\hline Roter Sol & $\begin{array}{l}\text { Eichen-Buchen-Mischwald - Feuerholz- und } \\
\text { Bauholznutzung }\end{array}$ \\
\hline Bünte (Forstort bei Nüxei, westlich Mackenrode) & Eichenmastholz \\
\hline $\begin{array}{l}\text { Crodenhagen (Forstort bei Nüxei, westlich } \\
\text { Mackenrode) }\end{array}$ & $\begin{array}{l}\text { Eichen-Buchen-Mischwald, teilweise mit } \\
\text { Zitterpappel }\end{array}$ \\
\hline $\begin{array}{l}\text { Steinberg (Forstort bei Nüxei, westlich } \\
\text { Mackenrode) }\end{array}$ & $\begin{array}{l}\text { Eichen-Buchen-Mischwald, teilweise mit } \\
\text { Zitterpappel }\end{array}$ \\
\hline sieberaufwärts ab Dreibodetal & zusammenhängendes Fichtenareal \\
\hline
\end{tabular}

Das Gesamte Gebiet des Walkenrieder Klosterforstes am Harzrand bestand vermutlich bereits seit dem 12. Jh. überwiegend aus Eichenwald. Dieser wurde zum größten Teil als Kohlhai, das heißt als Niederwald zur Holzkohlegewinnung, genutzt. In einer Urkunde von 1320 wird ausdrücklich die Bewirtschaftung des Waldes für den Meilerbetrieb erwähnt. Der Eichenmischwald zog sich noch 1596 bis in die Zorgeaue bei Ellrich. In den Wäldern der weiter im Harzinneren gelegenen Gebiete setzte sich die Buche stärker durch und drängte die Eiche zurück, da diese Gebiete weniger stark bewirtschaftet wurden. Ähnliches wurde bereits für die Herzberger und Lauterberger Forsten beschrieben.

Sowohl der Eichen- als auch der Buchen-Mischwald enthielt eine Vielzahl anderer Laubholzarten wie Bergahorn, Esche, Hasel, Birke, Salweide, Zitterpappel, Ulme und verschiedene Sträucher. Fichten traten ausschließlich am Ebersberg bei Hohegeiß in Erscheinung, bei dem es sich um ein altes Fichtenkerngebiet handelt (siehe unten „Die Fichtenverbreitung").

Tabelle 11: Detaillierte Beschreibung des Walkenrieder Forstes von 1596 (SCHUBART 1978)

\begin{tabular}{|l|l|}
\hline Walkenrieder Forst & Waldbeschreibung \\
\hline Ort/Lokalität & große Eichen - kein Niederwald (!) \\
\hline Eichenberg & Eichenmastwald \\
\hline Moseberg & Eichen-Mischwald \\
\hline Zorgeaue & Eichen-Mischwald \\
\hline Steinborn & Eichen-Mischwald \\
\hline Illigesbach & Eichen-Mischwald \\
\hline Großer und Kleiner Eichelnbach & Eichen-Mischwald \\
\hline Herren-bzw. Junkernhölzlein bei Walkenried & Eichen-Mischwald \\
\hline Wieda bis zum Lauterberger Forst & Buche \\
\hline beiderseits der Wieda bei Möchesteigern & Kohlhaie ${ }^{9}$ unterschiedlichen Alters (Laubholz) \\
\hline zwischen Wieda und Zorge & Fichte \\
\hline Petersilienwasser am Ebersberg (Hohegeiß) &
\end{tabular}

Die östlich anschließenden Forstgebiete (Rothesütte, Huftal, Stolberg, Roßla, Wippra und Pölsfelde) konnten aus einem Mangel an Quellen leider nicht beschrieben werden. (SCHUBART 1978) hält jedoch ein Auftreten der Fichte vor 1700 in den meist dörflichen

\footnotetext{
${ }^{9}$ Kohlhaie sind Flächen, die niederwaldartig zur Herstellung von Holzkohle bewirtschaftet wurden.
} 
Gemeinwaldungen für unwahrscheinlich. Lediglich die an den Ebersberg grenzenden Hochlagen des Beneckensteiner Forstes trugen im 15. Jh. Fichten. Die übrigen Wälder waren vermutlich reine Eichen- und Buchen-Mischwälder in bunter Artenmischung, wie sie auch für den Walkenrieder Klosterforst beschrieben wurden.

\section{Die Fichtenverbreitung}

Die Fichte war bis in die Mitte des 13. Jhs. gänzlich auf den nordwestlichen Teil des Oberharzes beschränkt (Abb. 13). Mit der Ausnahme des $689 \mathrm{~m}$ ü. NN hohen Ebersberges bei Hohegeiß bildeten der Ackerbruchbergzug im Süden und das Brockenmassiv im Osten die Grenze ihrer Verbreitung. Die Fichte besiedelte ausschließlich die Hochlagen, Kuppen, Plateaus und Schulterlagen. Sie dominierte lediglich auf sehr kleinen Flächen mit besonders kühlen, feucht-nassen und basenarmen Standortbedingungen. Eine größere Verbreitung hatte sie in Mischbeständen mit Buchen und anderen Laubhölzern, die ebenfalls in den höheren Lagen vorkamen. Nach Norden und Nordwesten überschritt das Fichtenvorkommen möglicherweise den Harzrand.

Die sogenannten Fichtenkerngebiete befanden sich am Brocken, auf den Roten Brüchern (zwischen Brocken und Ackerbruchbergzug), auf dem Rammelsberg, auf dem Ebersberg bei Hohegeiß, auf dem Rennstieg zwischen der Innerste und dem westlichen Harzrand und im Harzvorland am Vogelberg sowie am Harzhorn bei Harriehausen. Für einige der Gebiete mit höherem Fichtenanteil sind mittelalterliche Namen wie „Schwarze Berge“, „Schwarzewald“ oder „Die Düsteren Tannen“ u.ä. überliefert. Der gesamte südöstliche Teil des Harzes sowie die Tallagen waren bis zu dieser Zeit fichtenfrei und blieben es weitgehend bis in die Mitte des 18. Jhs.

Eine erste Phase indirekt anthropogen geförderter Fichtenausbreitung im Harz erfolgte nach dem Ende der ersten Bergbauperiode im 14. und 15. Jh. im nordwestlichen Teil des Harzes in den ausgedehnten Niederwäldern entlang der Gewässer. Diese sogenannten Kohlhaie, die der Holzkohlegewinnung gedient hatten, wurden nicht weiter bewirtschaftet. Die angesamten Buchen, zwischen denen sich auch Fichten ausgebreitet hatten, wuchsen ungehindert weiter. Die so aufgewachsenen Fichten erhöhten den Anteil dieser Baumart in den vormals reinen Laubwäldern erheblich. Die Fichtenausbreitung blieb aufgrund der stärkeren Nutzung der Wälder auf den Nordwesten des Gebirges beschränkt. Das in Tabelle 9 genannte Fichtenvorkommen auf dem Ochsenberg bei Herzberg, das bereits 1596 erstmals erwähnt wurde, stellt eine weit nach Südwesten vorgeschobene Ausnahme dieser Regel dar.

Mit dem Beginn der Eisenerzgewinnung und -verhüttung im Osteroder und Elbingeroder Raum um die Mitte des 15. Jhs. und der Ansiedlung von Glashütten und Papiermühlen wurde schließlich auch südlich des Ackerbruchbergzuges der Laubwald durch Kohlhaie stärker beansprucht. Ende des 16. Jhs. war die Fichte in den Osteroder Forsten bereits bis in die Randbereiche vorgedrungen. Lediglich die Waldrandgebiete und Standorte mit besserer Basenversorgung in südexponierter Lage trugen zu dieser Zeit noch reinen Laubwald (Standorte siehe Tab. 8).

Auf den durch Rodung geschaffenen Flächen im bis dato geschlossenen Wald konnten sich erstmals auch im südlichen Oberharz Fichten ansiedeln. Durch die südwestliche Exposition und eine damit verbundene stärkere Erwärmung vieler Standorte in diesem Gebiet wurde die Ausbreitung der Fichten jedoch erschwert. Bis ins 18. Jh. stand daher im Bereich des südlichen Oberharzes auf vielen Flächen weiterhin Laubmischwald. Nach dem Ende des 30jährigen Krieges, noch vor 1674, wurde damit begonnen, die Fichte durch gezielte Aussaaten zu vermehren. Während des 18. Jhs. wurden derartige Aussaaten wiederholt. Sie trugen maßgeblich zur flächenhaften Verbreitung der Fichten bei. Heute ist der Fichtenwald ab einer Höhe von 500-600 m ü. NN die dominierende Waldgesellschaft im Harz. 


\section{Der Wald im Spiegel der Holzkohlenanalyse}

Im Harz, im Harzvorland und im Solling wurden von HILLEBRECHT (1982) an insgesamt 21 Lokalitäten zahlreiche Meilerplätze und Schlackenplätzen detailliert auf die Zusammensetzung der verkohlten Hölzer, die verwendeten Stamm- bzw. Ast-Durchmesser und die erzeugte Qualität der Kohlen untersucht. Ziel der Untersuchung war die Erfassung der frühesten Waldnutzungen und die Abfolge verschiedener Waldnutzungsformen und der durch sie hervorgerufenen Veränderungen in der Waldzusammensetzung.

Die Holzkohlenanalyse stellt eine wichtige Ergänzung zur Auswertung schriftlicher Quellen dar. Die ältesten Waldnutzungen setzen in der Regel vor dem Beginn schriftlicher Überlieferungen ein, so dass sie ausschließlich mit Hilfe der Holzkohlen-, Pollen- oder Makrorestanalyse fassbar werden. Darüber hinaus liefert das Holzkohlenspektrum einen relativen Querschnitt der lokalen Waldzusammensetzung, während in älteren Urkunden meist nur punktuelle Besonderheiten eines Gebietes verzeichnet sind, die keine Rückschlüsse auf das Vorkommen sonstiger Arten zulassen.

In den Tabellen 12 bis 17 sind die Ergebnisse der Holzkohlenanalyse von vier Lokalitäten am Harzrand nördlich von Osterode und zwei weiterer im Harzvorland dargestellt. Jede Tabelle enthält die detaillierten Ergebnisse der Holzkohlenanalyse von HILLEBRECHT (1982) und die daraus ablesbare lokale Waldentwicklung. Im Anschluss daran wird die regionale Waldentwicklung im Bereich des Harzrandes und des Harzvorlandes dargestellt. Die Altersangaben, die sich auf ${ }^{14} \mathrm{C}$-Datierungen beziehen, wurden nachträglich mit Hilfe des Kalibrierungsprogramms von STUIVER et al. (1998) von konventionellen Radiokarbonjahren in kalibrierte Kalenderjahre umgewandelt.

\section{Lokalitäten am Harzrand}

Tabelle 12

\begin{tabular}{|l|l|}
\hline $\begin{array}{l}\text { Lokalität } \\
\text { Höhe m ü. NN }\end{array}$ & $\begin{array}{l}\text { Schönenberg bei Osterode } \\
320 \\
\text { südwestlicher Harzrand, Südwest-exponiertes Tal, an einem Nebenbach zur } \\
\text { Großen Bremke }\end{array}$ \\
\hline $\begin{array}{l}\text { Art und Anzahl der } \\
\text { Fundplätze }\end{array}$ & 1 Schlackenplatz \\
\hline${ }^{14}$ C-Datierung & - \\
\hline sonstige Datierung & Neuzeit (17. Jh.?) \\
\hline Artenspektrum & Picea \\
\hline Waldbild & reiner Fichtenwald \\
\hline
\end{tabular}

Interpretation

Es zeichnet sich neuzeitlich ein reiner Fichtenbestand am Untersuchungsort ab. Eine Verzerrung der Ergebnisse durch eine bevorzugte Nutzung des Fichtenholzes ist dagegen unwahrscheinlich, da beispielsweise Buchenholz besser zur Verkohlung geeignet gewesen wäre. 
Tabelle 13

\begin{tabular}{|c|c|c|c|c|}
\hline $\begin{array}{l}\text { Lokalität } \\
\text { Höhe m ü. NN } \\
\text { Lage }\end{array}$ & $\begin{array}{l}\text { Rothries/Röddental } \\
260-400 \\
\text { Teil der südwestlichel }\end{array}$ & n Harzabdachung & & \\
\hline $\begin{array}{l}\text { Art und Anzahl } \\
\text { der Fundplätze }\end{array}$ & 2 Schlackenstellen & $\begin{array}{l}6 \text { Grubenmeiler, } 3 \text { kleine } \\
\text { Platzmeiler }\end{array}$ & $\begin{array}{l}15 \text { große } \\
\text { Platzmeiler }\end{array}$ & $\begin{array}{l}2 \\
\text { Schlackenstellen }\end{array}$ \\
\hline $\begin{array}{l}{ }^{14} \mathrm{C} \text {-Datierung } \\
\text { cal AD/BC }\end{array}$ & $\begin{array}{l}1280 \text { n. Chr, } \\
\text { ca.1010 n. Chr. }\end{array}$ & - & - & ca. 1570 n. Chr. \\
\hline $\begin{array}{l}\text { sonstige } \\
\text { Datierung }\end{array}$ & & & Neuzeit & \\
\hline Artenspektrum & $\begin{array}{l}\text { überwiegend Fagus, } \\
\text { verschiedene } \\
\text { Laubhölzer ( Alnus, } \\
\text { Tilia, Ulmus u.a.) }\end{array}$ & $\begin{array}{l}\text { Fagus, wenig Acer, } \\
\text { Quercus, } \\
\text { Destruktionsanzeiger } \\
\text { (Betula, Corylus u.a.), } \\
\text { verschiedene Laubhölzer } \\
\text { (Alnus, Tilia, Ulmus u.a.) }\end{array}$ & $\begin{array}{l}\text { Picea, wenig } \\
\text { Fagus, wenig } \\
\text { Acer, wenig } \\
\text { Quercus }\end{array}$ & Picea \\
\hline Waldbild & Buchen-Mischwald & $\begin{array}{l}\text { aufgelockerter } \\
\text { Laubmischwald, hohe } \\
\text { Anteile lichtbedürftiger und } \\
\text { ausschlagfähiger Arten }\end{array}$ & $\begin{array}{l}\text { überwiegend } \\
\text { Fichtenwald }\end{array}$ & $\begin{array}{l}\text { reiner } \\
\text { Fichtenwald }\end{array}$ \\
\hline
\end{tabular}

Der in den ältesten Schlackenstellen erfasste Buchen(misch)wald erscheint relativ unbeeinflusst von anthropogenen Eingriffen. Auf inn folgt ein Laubmischwald in

Interpretation Nieder- oder Mittelwaldbewirtschaftung. Dieses Waldbild blieb mindestens bis zum Ausgang des Mittelalters aufgrund der andauernden Nutzung im Untersuchungsgebiet konstant. Nach einem Hiatus werden neuzeitlich ganz überwiegend anthropogen bedingte Fichtenwälder angezeigt.

Tabelle 14

\begin{tabular}{|c|c|c|c|}
\hline $\begin{array}{l}\text { Lokalität } \\
\text { Höhe m ü. NN } \\
\text { Lage }\end{array}$ & \multicolumn{3}{|c|}{$\begin{array}{l}\text { Großes und Mittleres Lehmental, Steinbrücker Loch, Wäsche } \\
400-510 \\
\text { südwestlicher Harzrand, südlich bis südwestlich exponiert }\end{array}$} \\
\hline $\begin{array}{l}\text { Art und Anzahl } \\
\text { der Fundplätze }\end{array}$ & 3 Schlackenhalden & 9 Grubenmeiler & $\begin{array}{l}15 \text { große } \\
\text { Platzmeiler }\end{array}$ \\
\hline $\begin{array}{l}{ }^{14} \mathrm{C} \text {-Datierung } \\
\text { cal AD/BC }\end{array}$ & 1021 n. Chr., 1486 n. Chr. & $\begin{array}{l}689 \text { n. Chr., ca. } 750 \text { n. Chr., } \\
778 \text { n. Chr. }\end{array}$ & - \\
\hline $\begin{array}{l}\text { sonstige } \\
\text { Datierung }\end{array}$ & & & Neuzeit \\
\hline Artenspektrum & \multicolumn{2}{|c|}{$\begin{array}{l}\text { Fagus, verschiedene Laubhölzer (Acer, Tilia, Ulmus, Fraxinus u.a.), } \\
\text { wenig Destruktionsanzeiger (Betula, Corylus u.a.), teilweise mit } \\
\text { höheren Anteilen ausschlagfähiger Arten, mehr Quercus, weniger } \\
\text { Acer, teilweise mit hohen Picea-Anteilen }\end{array}$} & Picea \\
\hline Waldbild & \multicolumn{2}{|l|}{ Buchen-Mischwald } & $\begin{array}{l}\text { reiner } \\
\text { Fichtenwald }\end{array}$ \\
\hline
\end{tabular}

Der Buchen-Mischwald erscheint völlig unbeeinflusst von anthropogenen Eingriffen. Im Laufe der vermutlich mehrere 100 Jahre anhaltenden Nutzung traten Interpretation vermehrt ausschlagfähigere Arten und Destruktionszeiger auf. Die teilweise hohen Fichtenanteile beruhen vermutlich auf einem anthropogen geförderten Vorkommen von Picea auf weiter hangaufwärts gelegenen Flächen. Neuzeitlich erscheint ein anthropogen bedingter reiner Fichtenwald. 
Tabelle 15

\begin{tabular}{|l|l|}
\hline $\begin{array}{l}\text { Lokalität } \\
\text { Höhe m ü. NN } \\
\text { Lage }\end{array}$ & $\begin{array}{l}\text { Lattenkuhle } \\
560 \\
\text { südwestlicher Harzrand, nordöstlich exponiert am Rande einer vermoorten } \\
\text { Quellmulde }\end{array}$ \\
\hline $\begin{array}{l}\text { Art und Anzahl der } \\
\text { Fundplätze }\end{array}$ & 1 Schlackenhalde \\
\hline $\begin{array}{l}{ }^{14} \text { C-Datierung cal } \\
\text { AD/BC }\end{array}$ & 1025 n. Chr. \\
\hline Artenspektrum & $\begin{array}{l}\text { überwiegend Fagus und Acer, Destruktionsanzeiger (Betula, Corylus, Salix } \\
\text { u.a.) }\end{array}$ \\
\hline Waldbild & Buchen-Mischwald \\
\hline
\end{tabular}

Interpretation

Der Buchen-Mischwald erscheint völlig frei von anthropogenen Beeinflussungen. Vermutlich repräsentiert das Holzkohlenspektrum den ersten Eingriff in das Waldbild.

Im Oberharz beginnt die Nutzung von Holzkohle für den Bergbau bereits vor $1000 \mathrm{n}$. Chr. Die ältesten Holzkohlespektren datieren in die Zeit um $1000 \mathrm{n}$. Chr. und zeigen einen natürlichen Buchen-Ahorn-Mischwald an. Zum Harzrand hin treten verstärkt lichtbedürftige Hölzer wie Eichen hinzu. Vermutlich wurden sie bereits vor dem Einsetzen des Bergbaus durch eine Beweidung der Harzrandbereiche anthropogen gefördert. Fichtenholzkohle tritt in dieser frühen Phase ausschließlich in den höher gelegenen Lokalitäten auf, die hier nicht ausführlich dargestellt sind. Bedingt durch die mehrere hundert Jahre anhaltende Nutzung des Waldes während des Mittelalters kam es zu einer Degenerierung und starken Auflichtung des Buchen-Mischwaldes. Arten, die in der Lage sind, sich aus Stockausschlägen zu regenerieren, und lichtbedürftige, jedoch konkurrenzschwache Destruktionszeiger nahmen zu. Auch die Eiche wurde auf diese Weise gefördert. Es entstanden Nieder- oder Mittelwälder, deren Nutzung teilweise bis in die Frühe Neuzeit belegt ist. Die Spektren der neuzeitlichen Platzmeiler lassen dagegen auf einen reinen Fichtenwald schließen.

Holzkohlenanalytische Belege für den Übergang von Laubwäldern in Nieder- oder Mittelwaldwirtschaft zu Fichtenwäldern fehlen. Zudem besteht aus Mangel an Meilerplätzen ein Hiatus, der in die Zeit der ersten Bergbaukrise (14./15. Jh.) im Harz datiert.

Die Selektion oder der Schutz bestimmter Hölzer sind entgegen schriftlicher Überlieferungen im gesamten Untersuchungszeitraum nicht erkennbar. Nach (HILLEBRECHT 1982) hatte vielmehr der Holzbedarf der Bergwerke und Hütten Vorrang vor jeder anderen Nutzung des Waldes. Darüber hinaus erfolgte diese Nutzung ungeregelt und war nicht auf eine langfristige Sicherung der Ressource Holz ausgerichtet. Die geringen Durchmesser der verkohlten Hölzer weisen auf kurze Umtriebszeiten von etwa 10-20 Jahren hin, wodurch die Regeneration der Wälder stark eingeschränkt wurde. Die bewusste Förderung der schnellwüchsigen Fichten, die frühestens seit dem 17. Jh. erfolgte, stellt erstmalig eine Bewirtschaftung des Waldes dar, die über eine reine Entnahme hinausgeht. 


\section{Lokalitäten im Harzvorland}

Tabelle 16

\begin{tabular}{|l|l|}
\hline $\begin{array}{l}\text { Lokalität } \\
\text { Höhe m ü. NN } \\
\text { Lage }\end{array}$ & $\begin{array}{l}\text { Eisdorf } \\
155 \\
\text { südwestliches Harzvorland, Harzrandsenke zwischen Eisdorf und Nienstedt, } \\
\text { Westerhöfer Hügelland, an einem Nebenbach der Söse }\end{array}$ \\
\hline $\begin{array}{l}\text { Art und Anzahl } \\
\text { der Fundplätze }\end{array}$ & 1 Schlackenhalde \\
\hline $\begin{array}{l}{ }^{14} \text { C-Datierung cal } \\
\text { AD/BC }\end{array}$ & 1031 n. Chr. \\
\hline $\begin{array}{l}\text { sonstige } \\
\text { Datierung }\end{array}$ & Hohes bis Spätes Mittelalter \\
\hline Artenspektrum & $\begin{array}{l}\text { etwa gleiche Anteile: Fagus, verschiedene Laubhölzer (Tilia, Ulmus, Fraxinus } \\
\text { u. a.), Destruktionszeiger (Betula, Corylus u. a.), Quercus, Acer, mit höheren } \\
\text { Anteilen ausschlagfähiger Arten }\end{array}$ \\
\hline Waldbild & \begin{tabular}{l} 
Eichen-Mischwald mit Buchen-Anteil \\
\hline
\end{tabular}
\end{tabular}

Interpretation

Das Holz stammte vermutlich aus dem westlich gelegenen Westerhöfer Wald. In den Eichen-Mischwäldern wurde der Anteil der Buche durch die erkennbare Niederwald-Nutzung gering gehalten. Picea tritt in den Spektren nicht auf. Dennoch vorhandene Fichten könnten als Bauholz (Herrenholz) geschützt gewesen sein.

Tabelle 17

\begin{tabular}{|c|c|c|c|c|}
\hline $\begin{array}{l}\text { Lokalität } \\
\text { Höhe m ü. NN } \\
\text { Lage }\end{array}$ & \multicolumn{4}{|c|}{$\begin{array}{l}\text { Willershausen im Westerhöfer Hügelland } \\
\text { 200-300 } \\
\text { südwestliches Harzvorland, Teil des Westerhöfer Waldes, südexponierter Hang }\end{array}$} \\
\hline $\begin{array}{l}\text { Art und Anzahl } \\
\text { der Fundplätze }\end{array}$ & \multicolumn{4}{|c|}{12 Grubenmeiler, 43 Platzmeiler } \\
\hline $\begin{array}{l}{ }^{14} \mathrm{C} \text {-Datierung } \\
\text { cal AD/BC }\end{array}$ & ca. 1350 n. Chr. & $\begin{array}{l}\text { ca. } 1630 \text { n. Chr., } \\
1600 \text { n. Chr. }\end{array}$ & - & - \\
\hline $\begin{array}{l}\text { sonstige } \\
\text { Datierung }\end{array}$ & & & $1700-1760$ & $\begin{array}{l}\text { ab zweite Hälfte } \\
\text { 18. Jh. }\end{array}$ \\
\hline Artenspektrum & $\begin{array}{l}\text { überwiegend } \\
\text { Fagus, } \\
\text { verschiedene } \\
\text { Laubhölzer } \\
\text { (Tilia, Ulmus, } \\
\text { Fraxinus u.a.) }\end{array}$ & $\begin{array}{l}\text { überwiegend Fagus } \\
\text { und Picea, z.T. mit } \\
\text { verschiedenen Laub- } \\
\text { hölzern (Tilia, Ulmus, } \\
\text { Fraxinus u. a.), mit } \\
\text { Destruktionszeigern } \\
\text { (Betula, Corylus u.a.), } \\
\text { Quercus }\end{array}$ & $\begin{array}{l}\text { hohe Anteile an De- } \\
\text { struktionszeigern } \\
\text { (Betula, Corylus u. a.), } \\
\text { verschiedene Laub- } \\
\text { hölzer (Tilia, Ulmus, } \\
\text { Fraxinus u. a.), hohe } \\
\text { Anteile ausschlag- } \\
\text { fähiger Arten, wenig } \\
\text { Fagus, wenig Picea }\end{array}$ & $\begin{array}{l}\text { ganz über- } \\
\text { wiegend Fagus, } \\
\text { verschiedene } \\
\text { Laubhölzer (Tilia, } \\
\text { Ulmus, Fraxinus } \\
\text { u. a.), sehr wenig } \\
\text { Picea }\end{array}$ \\
\hline Waldbild & $\begin{array}{l}\text { Buchen- } \\
\text { Mischwald }\end{array}$ & $\begin{array}{l}\text { Buchen-Mischwald, } \\
\text { Fichten-Mischwald }\end{array}$ & $\begin{array}{l}\text { Nieder- bis Mittelwald } \\
\text { mit hohen Betula- } \\
\text { Anteilen }\end{array}$ & Buchenwald \\
\hline
\end{tabular}

Die Buchen- und Fichten-Mischwälder stellen die Vegetation ohne erkennbaren anthropogenen Einfluss dar. Diese Bestände wurden zunehmend stärker genutzt. Es entstand ein stark degenerierter, sich selbst verjüngender Nieder- oder Mittelwald. Die abgeholzten Flächen wurden schließlich mit Buchenwald aufgeforstet. 
Tabelle 18

\begin{tabular}{|l|l|}
\hline $\begin{array}{l}\text { Lokalität } \\
\text { Höhe m ü. NN }\end{array}$ & $\begin{array}{l}\text { Westerhof im Westerhöfer Wald } \\
\text { Lage-220 } \\
\text { südwestliches Harzvorland, Teil des Westerhöfer Waldes, mehrere Hanglagen } \\
\text { unterschiedlicher Exposition (Rehhagen / Bockwiese) }\end{array}$ \\
\hline $\begin{array}{l}\text { Art und Anzahl } \\
\text { der Fundplätze }\end{array}$ & 44 Platzmeiler \\
\hline $\begin{array}{l}\text { sonstige } \\
\text { Datierung }\end{array}$ & neuzeitlich \\
\hline Artenspektrum & $\begin{array}{l}\text { hohe Anteile an Destruktionszeigern (Betula, Corylus u. a.), verschiedene } \\
\text { Laubhölzer (Tilia, Ulmus, Fraxinus u. a.), Quercus, hohe Anteile lichtliebender und } \\
\text { ausschlagfähiger Arten, wenig Fagus, wenig Picea }\end{array}$ \\
\hline Waldbild & $\begin{array}{l}\text { Zwei Waldgenerationen nebeneinander: 1. Hudewald (Eichenüberhälter), 2. stark } \\
\text { degenerierter Nieder- oder Mittelwald }\end{array}$ \\
\hline
\end{tabular}

Interpretation

In der direkten Umgebung lag die noch heute durch Wölbäcker gekennzeichnete Flur der um 1500 n. Chr. wüst gefallenen Siedlung Bössekenhusen. Nach der Aufgabe des Ortes wurden die Äcker vermutlich vom Nachbarort Westerhof aus extensiv weiter bewirtschaftet, d. h. beweidet. Ein Hudewald mit geschonten Eichenüberhältern entwickelte sich. Durch die Verringerung oder Aufgabe der Beweidung kam zwischen den Eichen ein Niederwald auf. Im 17. Jh., nach etwa 10-40 Jahren wurde der gesamte Wald inklusive mehrerer Mastbäume radikal verkohlt.

Die Ergebnisse im Harzvorland zeigen, dass die Nutzung der Wälder in diesem Bereich sehr vielfältig war. Ebenso vielfältig waren die daraus resultierenden Waldentwicklungen. Für alle drei Lokalitäten muss ein sehr starker anthropogener Einfluss angenommen werden, der die Entwicklung des Waldes maßgeblich bestimmt hat. Klimatische und edaphische Einflüsse können aufgrund der Ähnlichkeit der Standortbedingungen ausgeschlossen werden.

Ein Nieder- oder Mittelwald konnte wenigstens für eine Phase der Waldentwicklung an jedem der drei Standorte nachgewiesen werden. Das Artenspektrum dieser erfassten Nutzwälder war nicht gleich, sondern unterschied sich durch die Art der vorhergehenden Nutzung des Waldes und die Dauer der Bewirtschaftung in Nieder- oder Mittelwaldwirtschaft.

Die Ergebnisse aus Eisdorf (Tab. 16) zeigen einen stark regenerativen Wald an, d. h. einen Wald mit einem hohen Anteil von Arten, die in der Lage sind, sich aus Stockausschlägen vegetativ zu regenerieren. Der Wald enthielt dagegen kaum Arten, die als Pionierhölzer einzustufen wären. Diese Waldzusammensetzung entwickelte sich durch den anhaltenden Niederwaldumtrieb, der vermutlich der Holzkohleherstellung diente.

In Westerhof (Tab. 18) hingegen war der Niederwald artenarm und besaß einen deutlichen Pionierwaldcharakter, was auf die vorhergehende Beweidung zurückzuführen ist. Die Eichenüberhälter in diesem Niederwald waren Relikte der vorhergehenden Hutewaldnutzung.

Bei Willershausen (Tab. 17) ging der Niederwald aus der Abholzung eines naturnahen Waldes hervor. Dort waren daher sowohl Pionierholzarten als auch stark regenerative Arten vertreten, die in der vorhergehenden Waldgesellschaft sehr geringe Anteile hatten und sich erst aufgrund der wiederholten Abholzung durchsetzen konnten. Im Anschluss an die Phase der Nieder- oder Mittelwaldwirtschaft kam es im Harzvorland zur Aufforstung der 
degenerierten Wälder. Eine solche Aufforstung, hier mit Buchen, konnte in Willershausen belegt werden. Die Entstehung der heute zahlreichen Fichtenforsten im Harzvorland konnte holzkohlenanalytisch nicht erfasst werden.

Im Gegensatz zur Nutzung der Wälder im Harz lässt sich in dessen Vorland der Schutz bestimmter wertvoller Hölzer wie Masteichen und vermutlich auch der Fichten erkennen (Willershausen Tab. 17). Deutlich tritt jedoch auch im Vorland das Vorrecht der Hütten in Erscheinung, für deren Energiebedarf z. B. im Falle von Westerhof auch mastfähige Eichen geopfert wurden (Tab. 18). Damit wird die enge Verknüpfung von Holzknappheit im Harz und der darauf folgenden Verlagerung der Holzkohleherstellung in das Vorland erkennbar, wie sie spätestens seit der frühen Neuzeit fassbar ist. Diese Entwicklung wird auch durch das geringere Alter der Meilerplätze im Harzvorland im Vergleich zu den wesentlich älteren Relikten der Holzkohlewirtschaft im Harz selbst bestätigt. 


\section{Umweltgeschichte}

\subsection{Aschenhütter Teich}

(R 3589 900, H 5727 700)

Der Aschenhütter Teich (Synomym: „Schwarzer Pfuhl“) befindet sich etwa $3 \mathrm{~km}$ nordwestlich der Stadt Herzberg im Landkreis Osterode/Harz und liegt auf einer Höhe von $217 \mathrm{~m}$ ü. NN. Der Teich hat eine ovale Oberfläche, die etwa $120 \mathrm{~m}$ lang und $50 \mathrm{~m}$ breit ist. Oberirdische Zu- oder Abläufe sind nicht erkennbar. Der Teich wird von einem Angelverein und als Badeteich genutzt. Die Vegetation in der Umgebung wird von Laubwald und Fichtenpflanzungen geprägt.

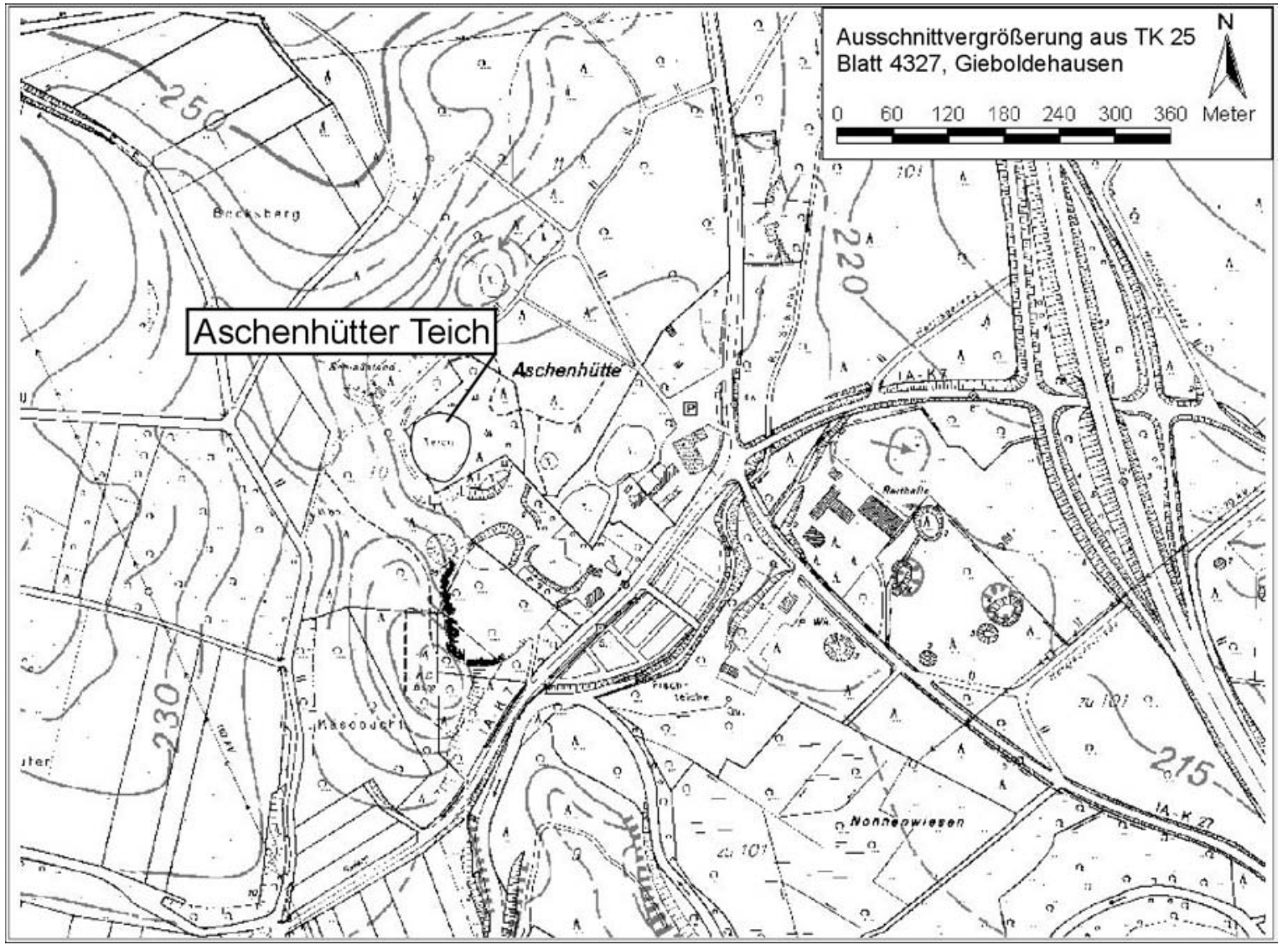

Abbildung 14: Lage des Aschenhütter Teiches (TK 25, Blatt 4327, Gieboldehausen)

Der Aschenhütter Teich, bei dem es sich um einen Erdfallsee handelt, liegt am westlichen Rand der breiten Talebene des Steinau-Baches am Fuß eines westlich angrenzenden, 20$25 \mathrm{~m}$ hohen Steilhanges aus vergipstem Werra-Anhydrit des unteren Zechstein. Der Untergrund der Talebene besteht aus weichselzeitlichen Niederterrassen-Schottern des SteinauBaches. Im Umfeld des Aschenhütter Teiches ist die Niederterrasse von zahlreichen Dolinen durchsetzt, was darauf schließen lässt, dass die Schotter verkarstungsfähige Gesteine des Zechstein überlagern (RICKEN 1980 zitiert nach DEICKE 2003). 


\subsubsection{Material und Methoden}

\section{Geländearbeit}

Am 17.5.2000 wurden von einem Schlauchboot aus erste Untersuchungen des Aschenhütter Teiches vorgenommen. Zunächst wurde die Höhe der Wassersäule mittels Echolot (Silva Echolot 320) vermessen. An der tiefsten Stelle des Teiches wurden daraufhin drei FallotKerne erbohrt. Der längste Kern erbrachte ungestörtes Sediment aus einer Tiefe von 35$72 \mathrm{~cm}$ unter Seegrund. Aus diesem Abschnitt wurden Proben für eine pollenanalytische Prüfung des Materials entnommen. Die mikroskopische Analyse der chemisch aufbereiteten Proben (s.a. Laborarbeiten) zeigte eine gute Pollenerhaltung und Pollenführung an.

Am 16.8.2000 erfolgte die eigentliche Bohrung. Zunächst wurde eine erneute Echolotmessung zur Bestimmung der Position mit der höchsten Wassersäule und damit der vermutlich mächtigsten Sedimentführung durchgeführt. Die Messung ergab eine maximale Wassertiefe von $5,30 \mathrm{~m}$. Von einer Bohrplattform aus wurde an dieser Stelle mit Hilfe eines Kolbenlot-Bohrers überlappend ein $778 \mathrm{~cm}$ langer Sedimentkern in fünf PVC-Rohren geborgen. Die Rohre wurden bis zur Weiterbearbeitung im Kühlraum des Instituts für Geologie und Dynamik der Lithosphäre (Universität Göttingen) senkrecht stehend gelagert.

Am 6. sowie am 9.10.2000 wurden die PVC-Rohre liegend der Länge nach mit einer Handkreissäge aufgesägt. Die so freigelegten Hälften der Sedimentkerne wurden daraufhin mit dünnen Kunststoffplatten vorsichtig durchteilt, aufgeklappt, vermessen und auf den PVCRohren beschriftet. Ein Halbkern aus jeder Tiefe wurde anschließend von M. Deicke geochemisch untersucht, während der jeweils andere Halbkern wie im Folgenden dargelegt stratigraphisch aufgenommen, abschnittsweise photographiert und im Rahmen der vorliegenden Arbeit pollenanalytisch untersucht wurde.

\section{Pollenanalysen}

\section{Probennahme}

Für die Pollenanalyse wurden die Kerne im Abstand von $4 \mathrm{~cm}$ nach einer oberflächlichen Säuberung mit einer abgeschnittenen Einweg-Spritze beprobt. Das entnommene Volumen wurde bestimmt. In jeder Tiefe wurde mindestens $1 \mathrm{ml}$ Material entnommen.

\section{Laborarbeiten}

Die Aufbereitung der Proben erfolgte nach der Methode von BEUG (1957). Anschließend wurde das Probenmaterial im Ultraschallbad unter Verwendung eines Gewebefilters der Maschenweite $6 \mu \mathrm{m}$ (PES6/5SR Polymon) gesiebt. Allen Proben wurde nach der Methode von STOCKMARR (1971) eine definierte Menge Lycopodium Sporen in Form industriell gefertigter Tabletten zugesetzt.

\section{Datenerhebung}

Aus dem Kern des Aschenhütter Teiches wurden 67 Proben pollenanalytisch ausgewertet. Es wurden je Probe mindestens 500 bzw. 1000 Pollenkörner von Baumarten ausgezählt. In einigen Proben konnte diese Zahl jedoch aufgrund der schlechten Pollenerhaltung und konzentration nicht erreicht werden.

Die Bestimmung und das Zählen der Pollentypen erfolgte mit einem Zeiss-Standard-Mikroskop bei 500 facher Vergrößerung (Apertur 0.75). Schwer bestimmbare Pollenkörner sowie alle Pollenkörner des Getreide-Typs wurden zusätzlich mit einem 100er Phasenkontrast-Öl- 
immersions-Objektiv (Apertur 1.25) bei 1250facher Vergrößerung untersucht. Bei der Bestimmung wurde folgende Literatur benutzt: BEUG (1961), FAEGRI \& IVERSEN (1989), JUNG et al. (1972), MOORE et al. (1991), PUNT (1976), PUNT et al. (1988), PUNT et al. (1991), PUNT \& CLARK (1980), PUNT \& CLARK (1981), PUNT \& CLARK (1984).

Darüber hinaus standen die Vergleichssammlung und die Fotokartei rezenter Pollenkörner und Sporen der Abteilung für Palynologie und Quartärwissenschaften des Albrecht-vonHaller-Institutes für Pflanzenwissenschaften der Universität Göttingen zur Verfügung. Die Nomenklatur folgt im allgemeinen MOORE et al. (1991). Die Bestimmung der Getreide-Typen erfolgte nach BEUG (1961). Demzufolge wurde im Phasenkontrast die Feinstruktur der Pollenkörner beurteilt und mit Hilfe eines Messokulars der größte Durchmesser des Pollenkorns, die Anulusbreite und -dicke sowie der Porendurchmesser bestimmt. Ebenfalls gemessen wurde der größte Durchmesser der Pollenkörner vom Humulus/Cannabis-Typ (PUNT \& MATOTEAUX 1984, DÖRFLER 1989) und vom Jasione/Campanula-Typ (FAEGRI \& IVERSEN 1989). Zusätzlich wurde die Anzahl der Holzkohlepartikel mit einem Durchmesser $>5 \mu \mathrm{m}$ in jeder Probe bestimmt.

\section{Auswertung und Darstellung}

Die Aufnahme der Rohdaten während des Mikroskopierens erfolgte mittels einer Computertastatur und dem Zähldatenprogramm „Count.Bas“. Alle Berechnungen wurden mit Hilfe des Programms „Microsoft Excel 2000“ durchgeführt. Die graphische Umsetzung erfolgte mit den Programmen „Tilia 1.12“, „Tilia graph 1.18“ und „Tilia graph view 1311“.

Die Ergebnisse der Pollenanalyse sind als Schattenrisskurven in einem Prozentwertediagramm dargestellt (Abb. 15, Beilage). Sofern nicht anders angegeben, beziehen sich alle dargestellten Werte auf die Baumpollensumme als Grundsumme (Baumpollensumme = $100 \%$ ). Im Vergleich zeigt das dargestellte Summendiagramm die Anteile der PollentaxaGruppen Bäume, Sträucher, Hasel und Krautige Pflanzen bezogen auf die Landpflanzenpollen-Summe. Konzentrationsangaben sowie Sporen- und Algenwerte sind als Balkendiagramme dargestellt.

Die Summenkurven fassen die Werte folgender Taxa zusammen:

- Eichenmischwald-Summe: Acer, Fraxinus, Quercus, Tilia cordata-Typ, Tilia platyphyllos-Typ, Ulmus.

- Baumpollen-Summe / Bäume: Abies, Acer, Alnus, Betula, Carpinus, Fagus, Fraxinus, Juglans, Picea, Pinus, Quercus, Salix, Tilia cordata-Typ, Tilia platyphyllos-Typ, Ulmus.

- Sträucher: Cornus mas, Cornus sanguinea-Typ, Crataegus-Typ, Frangula alnus, Rhamnus cathartica-Typ, Lonicera periclymenum-Typ, Lonicera xylosteum-Typ, Sambucus nigra-Typ, Sambucus ebulus-Typ, Viburnum-Typ.

- Nichtbaumpollen-Summe / Krautige Pflanzen: Alle Landpflanzenpollen-Typen außer Corylus und den oben genannten Baumpollen-Typen.

- Sek. Siedlungszeiger-Summe: Alchemilla-Typ, Agrostemma githago, Anthoceros punctatus, Artemisia, Brassicaceae, Centaurea cyanus, Chenopodiaceae, Fabaceae, Plantago lanceolata, Plantago major/media-Typ, Polygonum aviculare, Polygonum persicaria, Pteridium, Rumex, Urtica.

- Kulturpflanzen-Summe: Avena-Typ, Getreide indet., Hordeum-Typ, Linum usitatissimum, Secale, Triticum-Typ.

- Wasserpflanzen-Summe: Eupotamogeton, Lemna-Typ, Nymphaea alba-Typ, Myriophyllum spicatum-Typ, Myriophyllum verticillatum-Typ, Utricularia. 
Taxa mit sehr geringen Werten und/oder seltenem Auftreten sind nicht graphisch im Pollendiagramm dargestellt. Listen mit den Werten dieser Taxa befinden sich im Anhang in Tabelle 45 und Tabelle 46.

Die Berechnung des Polleninfluxes erfolgte nach folgender Formel:

$$
\frac{\frac{y}{\mathrm{~cm}^{3}}}{y_{g e z}} \times P k_{g e z} \times S\left[\frac{\mathrm{cm}}{a}\right]
$$

\section{Erläuterungen:}

$\begin{array}{lll}\frac{y}{c m^{3}} & = & \text { Anzahl der Lycopodium-Sporen, die einem Kubikzentimeter } \\ y_{g e z} & = & \text { Anzahenmaterial zugesetzt wurden. } \\ P k_{g e z} & = & \text { Anzahl der erfassten Pollenkörner eines Taxons. } \\ S\left[\frac{\mathrm{cm}}{a}\right] & = & \text { Sedimentationsrate, ausgedrückt in Zentimeter pro Jahr }\end{array}$

Die Influx-Werte sind in Tabelle 49, im Anhang dargestellt.

\section{Radiokarbondatierung}

\section{Probennahme}

Für die ${ }^{14} \mathrm{C}$-Bestimmung (AMS-Methode) wurden die Kerne nach der Entnahme der Proben für die Pollenananlyse auf terrestrische Makroreste hin untersucht. Dazu wurden sie in den für eine Datierung interessanten Bereichen in Scheiben von $1 \mathrm{~cm}$ Dicke zerschnitten. Das Material wurde anschließend gesiebt und verlesen. Geeignet erscheinende Reste wurden unter dem Binokular bestimmt und gezählt.

Die so gewonnenen Proben wurden anschließend an das Leibniz Labor für Altersbestimmung und Isotopenforschung unter der Leitung von Prof. Dr. P.M. Grootes an der Christian-Albrechts-Universität in Kiel geschickt.

In Tabelle 19 ist angegeben, in welchen Tiefen Material für AMS-Datierungen entnommen wurde und welcher Art diese botanischen Reste waren. Es handelt sich ausschließlich um Landpflanzenreste, um die Veränderung der Datierungsergebnisse durch einen „Hartwassereffekt" zu vermeiden (LANG 1994). Die Kalibrierung der Radiokarbondatierungen erfolgte nach STUIVER et al. (1998). Für die Berechnung der interpolierten Daten wurde der Mittelwert des Datierungsbereiches im $2 \sigma$-Bereich, der die höchste Wahrscheinlichkeit aufweist, verwendet (Tab. 19). 
Tabelle 19: Ergebnisse der ${ }^{14} \mathrm{C}$-Datierung des Kernes vom Aschenhütter Teich

\begin{tabular}{|c|c|}
\hline KIA16237 & Probentiefe $(\mathrm{cm}): 87-93$ \\
\hline \multirow[t]{4}{*}{ Material } & 1 Kätzchenschuppe Betula pubescens, \\
\hline & 1 Knospenschuppe Quercus, \\
\hline & 2 Knospenschuppen Fagus, \\
\hline & 2 frag. Knospenschuppen Fagus \\
\hline Radiokarbon Alter & BP $781 \pm 28$ \\
\hline Kalibriertes Alter & 1262 n. Chr. (2б-Bereich: 1216-1284) \\
\hline KIA16238 & Probentiefe (cm): 197-198 \\
\hline Material & 2 teiliges Holzfragment \\
\hline Radiokarbon Alter & BP $901 \pm 26$ \\
\hline Kalibriertes Alter & 1160 n. Chr. (2б-Bereich: 1039-1142) \\
\hline KIA16239 & Probentiefe $(\mathrm{cm}): \mathbf{2 1 0 - 2 1 1}$ \\
\hline \multirow[t]{2}{*}{ Material } & 1 Knospenschuppe Fagus, \\
\hline & Fagus Blattreste \\
\hline Radiokarbon Alter & BP $953 \pm 24$ \\
\hline Kalibriertes Alter & 1036, 1144, 1147 n. Chr. (2б-Bereich: 1022-1132) \\
\hline KIA16240 & Probentiefe $(\mathrm{cm}):$ 252-254 \\
\hline Material & 6 frag. Knospenschuppen Fagus \\
\hline Radiokarbon Alter & $1054 \pm 33$ \\
\hline Kalibriertes Alter & 996 n. Chr. (2б-Bereich:942-1025) \\
\hline KIA16241 & Probentiefe $(\mathrm{cm}): \mathbf{2 8 0 - 2 8 1}$ \\
\hline \multirow[t]{2}{*}{ Material } & 17 Knospenschuppen Fagus, \\
\hline & Blattreste Fagus \\
\hline Radiokarbon Alter & $1178 \pm 28$ \\
\hline Kalibriertes Alter & 886 n. Chr. (2б-Bereich:778-989) \\
\hline KIA16242 & Probentiefe $(\mathrm{cm}): 331-332$ \\
\hline \multirow[t]{2}{*}{ Material } & 14 Knospenschuppen Fagus, \\
\hline & 2-3 Blattreste Fagus \\
\hline Radiokarbon Alter & $1815 \pm 31$ \\
\hline Kalibriertes Alter & 229 n. Chr. (2б-Bereich:127-258) \\
\hline KIA16243 & Probentiefe $(\mathrm{cm}): \mathbf{3 8 0}-381$ \\
\hline \multirow[t]{2}{*}{ Material } & 7 Knospenschuppen Fagus, \\
\hline & Blattreste vermutlich Fagus \\
\hline Radiokarbon Alter & $2457 \pm 25$ \\
\hline Kalibriertes Alter & 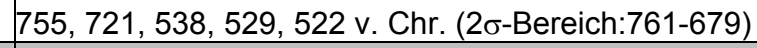 \\
\hline KIA16244 & Probentiefe $(\mathrm{cm}):$ :15-416 \\
\hline Material & 8 Knospenschuppen Fagus \\
\hline Radiokarbon Alter & $2509 \pm 27$ \\
\hline Kalibriertes Alter & $762,678,671,607,601$ v. Chr. $(2 \sigma$-Bereich:789-537) \\
\hline KIA16245 & Probentiefe $(\mathrm{cm}):$ 530-532 \\
\hline \multirow[t]{2}{*}{ Material } & Blattrest, \\
\hline & 1 kleines Stück Baumrinde (Bast) \\
\hline Radiokarbon Alter & $3280 \pm 25$ \\
\hline Kalibriertes Alter & 1524 v. Chr. (2б-Bereich:1624-1494) \\
\hline KIA16246 & Probentiefe $(\mathrm{cm}):$ 606-612 \\
\hline Material & 2 Holzstücke \\
\hline Radiokarbon Alter & $3794 \pm 27$ \\
\hline Kalibriertes Alter & 2266, 2264, 2202 v. Chr. (2б-Bereich:2301-2139) \\
\hline
\end{tabular}




\section{Interpolation}

Altersangaben für Tiefen, die nicht direkt datiert werden konnten, wurden entsprechend Formel 1 interpoliert:

Formel 1:

$$
T_{X}=T_{1}+\left(S_{X}-S_{1}\right) \times \frac{T_{2}-T_{1}}{S_{2}-S_{1}}
$$

wenn für $T$ (Alter) gilt: $T_{2}>T_{x}>T_{1}$ und für $S$ (Tiefe): $S_{2}>S_{x}>S_{1}$.

Die Standardabweichungen der interpolierten Altersangaben wurden gewonnen, indem die Mittelwerte aus den Standardabweichungen (die Hälfte des $2 \sigma$-Bereiches) der zur Interpolation herangezogenen Datierungen berechnet wurden (Tab. 20).

Tabelle 20: Mittlere Abweichungen der durch Interpolation am Diagramm vom Aschenhütter Teich gewonnenen Altersangaben (Angaben in Kalenderjahren)

\begin{tabular}{|r|c|c|r|r|r|r|r|r|}
\hline $\begin{array}{l}\text { Tiefen } \\
(\mathrm{cm})\end{array}$ & $\begin{array}{l}\text { Zonen n. } \\
\text { Firbas }\end{array}$ & $\begin{array}{l}\text { Interpolierte } \\
\text { Datierung }\end{array}$ & \pm & $\begin{array}{l}\text { Interpolierte } \\
\text { Strecke }(\mathrm{cm})\end{array}$ & 1.Datierung & \pm & 2.Datierung & \pm \\
\hline 277 & $\mathrm{IXb} / \mathrm{X}$ & $\mathbf{8 5 7}$ n. Chr. & $\mathbf{7 3 , 5}$ & 27,5 & 996 n. Chr. & 41,5 & 886 n. Chr. & 105,5 \\
\hline 333 & $\mathrm{IXa} / \mathrm{IXb}$ & $\mathbf{1 7 4}$ n. Chr. & $\mathbf{5 3 , 5}$ & 49,0 & 229 n. Chr. & 65,5 & 538 n. Chr. & 41,0 \\
\hline 433 & VIIIb/IXa & $\mathbf{7 9 9}$ v. Chr. & $\mathbf{9 5 , 5}$ & 115,5 & 671 v. Chr. & 126 & 1524 v. Chr. & 65,0 \\
\hline 529 & VIIla/VIIIb & $\mathbf{1 5 4 3}$ v. Chr. & $\mathbf{9 5 , 5}$ & 115,5 & 671 v. Chr. & 126 & 1524 v. Chr. & 65,0 \\
\hline
\end{tabular}


Tabelle 21: Alter der Pollenzonengrenzen des Diagramms vom Aschenhütter Teich $^{10}$

\begin{tabular}{|c|c|c|c|c|c|c|c|c|c|c|c|c|c|c|c|}
\hline \multirow{3}{*}{$\frac{\underset{N}{N}}{\alpha}$} & $g$ & 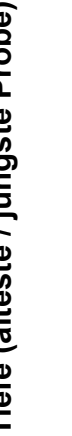 & \multicolumn{2}{|c|}{ 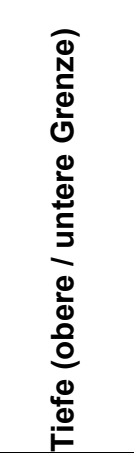 } & & Datie & ungen de & Zonengre & enzen & & \multirow[t]{2}{*}{ 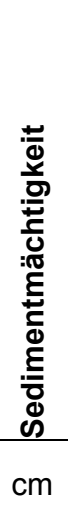 } & \multirow{2}{*}{ 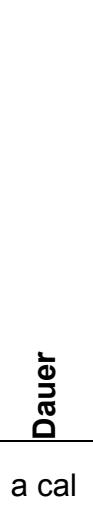 } & \multirow[t]{2}{*}{ 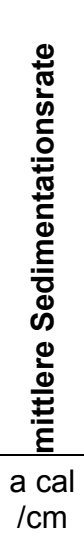 } & \multirow[t]{2}{*}{ 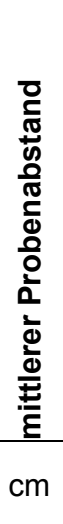 } & \multirow[t]{2}{*}{ 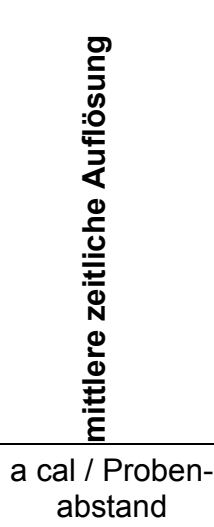 } \\
\hline & \multicolumn{2}{|c|}{$\mathrm{cm}$} & \multicolumn{2}{|c|}{$\mathrm{cm}$} & \multicolumn{2}{|c|}{ cal BP } & \multicolumn{2}{|c|}{$A D / B C$} & \multicolumn{2}{|c|}{ BP } & & & & & \\
\hline & 273 & 17 & 277 & 0 & 1093 & 0 & 857 AD & 1950 AD & 1162 & 0 & 277 & 1093 & 4 & 9 & 36 \\
\hline $2 d$ & & 9 & 17 & 0 & 132 & 0 & $1818 \mathrm{AD}$ & $1950 \mathrm{AD}$ & 148 & 0 & 17 & 132 & 8 & 16 & 128 \\
\hline 2c & 89 & 25 & 97 & 17 & 754 & 132 & 1196 AD & $1818 \mathrm{AD}$ & 842 & 148 & 80 & 622 & 5 & 16 & 80 \\
\hline $2 b$ & 201 & 105 & 203 & 97 & 866 & 754 & 1084 AD & $1196 \mathrm{AD}$ & 923 & 842 & 106 & 111,5 & 2 & 8 & 16 \\
\hline $2 a$ & 273 & 205 & 277 & 203 & 1093 & 866 & $857 \mathrm{AD}$ & $1084 \mathrm{AD}$ & 1162 & 923 & 74 & 227,5 & 3 & 8 & 24 \\
\hline $\mathbf{I X b}$ & 329 & 281 & 333 & 277 & 1776 & 1093 & $174 \mathrm{AD}$ & $857 \mathrm{AD}$ & 1834 & 1162 & 56 & 683 & 11 & 8 & 88 \\
\hline IXa & 425 & 327 & 433 & 333 & 2749 & 1776 & 799 BC & $174 \mathrm{AD}$ & 2626 & 1834 & 100 & 973 & 9 & 9 & 81 \\
\hline $1 b$ & 425 & 329 & 433 & 325 & 2749 & 1675 & 799 BC & 275 AD & 2626 & 1734 & 108 & 1074 & 10 & 9 & 90 \\
\hline VIIIb & 521 & 441 & 529 & 433 & 3493 & 2749 & $1543 \mathrm{BC}$ & 799 BC & 3267 & 2626 & 96 & 744 & 8 & 16 & 128 \\
\hline $1 a$ & 553 & 441 & 561 & 433 & 3763 & 2749 & $1813 \mathrm{BC}$ & 799 BC & 3478 & 2626 & 128 & 1014 & 8 & 16 & 128 \\
\hline VIIla & 777 & 537 & 777 & 529 & 5477 & 3493 & $3527 \mathrm{BC}$ & $1543 \mathrm{BC}$ & 4901 & 3267 & 248 & 1984 & 8 & 20 & 160 \\
\hline
\end{tabular}

\subsubsection{Ergebnisse}

\section{Stratigraphie}

Tabelle 22 enthält eine ausführliche Beschreibung der Stratigraphie des Kernes aus dem Aschenhütter Teich sowie die wichtigsten Ergebnisse der geochemischen Untersuchungen durch M. Deicke (DEICKE 2003). Die Teilkerne konnten anhand von Markerlagen eindeutig konnektiert werden. Lediglich Marker a (Farbumschlag) ergab keine sichere Konnektierung. In diesem Bereich wurde mit Hilfe paralleler geochemischer und pollenanalytischer Ergebnisse die Zuordnung überprüft. Der Masterscale gibt die Probentiefe vor und wurde nach der Konnektierung der Teilkerne angelegt. Im folgenden Text beziehen sich alle Tiefenangaben auf den Masterscale.

Die Stratigraphie ist sehr wechselhaft. Insbesondere die häufigen Blattlagen in den Teilkernen II3, II4 und I5 bedingen eine stark schwankende Sedimentationsrate.

Die Lemna-Reste in den Tiefen: 427,5-464 cm und 480-488 cm waren sehr gut erhalten und konnten als Dreifurchige Wasserlinse (Lemna trisulca) bestimmt werden.

\footnotetext{
${ }^{10}$ Die bei DEICKE (2003) genannten Jahreszahlen zum kalibrierten Alter und zur Dauer der Zonen weichen auf grund einer unterschiedlichen Interpretation der Kalibrierungsergebnisse leicht von den hier genannten Werten ab. Die unkalibrierten Ausgangsdaten sind identisch.
} 
Tabelle 22: Stratigraphische Beschreibung des Kernes aus dem Aschenhütter Teich

\begin{tabular}{|c|c|c|c|c|c|}
\hline 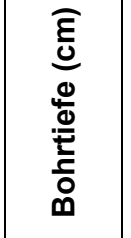 & 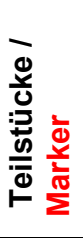 & 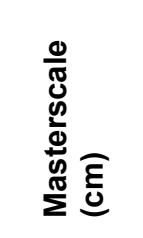 & Optische Beschreibung & 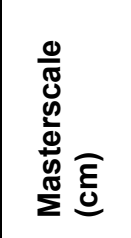 & $\begin{array}{l}\text { Ergebnisse der geochemischen Analysen } \\
\text { (DEICKE 2003) }\end{array}$ \\
\hline \multirow[t]{4}{*}{$0-100$} & 11 & $0-100$ & & \multirow[b]{2}{*}{$0-17$} & \multirow{2}{*}{$\begin{array}{l}\text { Eintrag von Schwermetallen (Fortsetzung } \\
\text { des kontinuierlichen Rückgangs vor der } \\
\text { Störung), Eintrag industrieller Schadstoffe } \\
\text { etwa ab } 11 \mathrm{~cm}\end{array}$} \\
\hline & & & & & \\
\hline & & $0-37$ & $\begin{array}{l}\text { Mischsediment aus } \\
\text { Feindetritusmudde und } \\
\text { Kalkmudde (fleckig) }\end{array}$ & $17-31$ & $\begin{array}{l}\text { Störung: sehr geringe Schwermetall- } \\
\text { Konzentration, erhöhter Dolomitanteil und } \\
\text { Gipsresidual -> möglw. Ablagerung eines } \\
\text { Trübestroms nach Verkippung von Abraum } \\
\text { aus dem benachbarten Steinbruch }\end{array}$ \\
\hline & & $37-100$ & $\begin{array}{l}\text { Feindetritusmudde } \\
\text { (braun-schwarz), etwas } \\
\text { fleckig }\end{array}$ & $31-90$ & $\begin{array}{l}\text { Eintrag von Schwermetallen (aufwärts } \\
\text { kontinuierlich zurückgehend), sinkende } \\
\text { Sedimentationsrate, Eintrag von zunehmend } \\
\text { Kalium-reichem Bodenmaterial (Nachlassen } \\
\text { der Bodendegradation) }\end{array}$ \\
\hline \multirow[t]{4}{*}{$100-200$} & 12 & $100-189$ & & $90-191$ & $\begin{array}{l}\text { starke Einträge von Kalium-verarmtem } \\
\text { Bodenmaterial (Löss, anstehende } \\
\text { Residualböden) ->Erosion, Bildung } \\
\text { authigenen Calcits }\end{array}$ \\
\hline & & $100-189$ & $\begin{array}{l}\text { Feindetritusmudde } \\
\text { (braun-schwarz) }\end{array}$ & \multirow{4}{*}{$177-189$} & \multirow{4}{*}{$\begin{array}{l}\text { stärkste } \mathrm{Cu} \text { - und } \mathrm{Zn} \text { - Anreicherung des } \\
\text { gesamten Kernes, vermutlich Eintrag von } \\
\text { belastetem Bodenmaterial, Schwermetall- } \\
\text { Gehalte sehr hoch, aufwärts abnehmend. }\end{array}$} \\
\hline & a & 189 & $\begin{array}{l}\text { Farbumschlag } \\
\text { (unsichere } \\
\text { Konnektierung) }\end{array}$ & & \\
\hline & & & $\begin{array}{l}\text { außerhalb des } \\
\text { Masterscales doppelte } \\
\text { Beprobung }\end{array}$ & & \\
\hline \multirow[t]{6}{*}{$170-246$} & 113 & 189-245 & & & \\
\hline & a & 189 & Farbumschlag & \multirow[b]{2}{*}{$191-282$} & \multirow{2}{*}{$\begin{array}{l}\text { „ruhige“ Sedimentation ( } 86 \% \text { organische } \\
\text { Komponente, } 7 \% \text { überwiegend authigene } \\
\text { Karbonate, ca. } 6 \% \text { eingetragene Silikate) }\end{array}$} \\
\hline & & & $\begin{array}{l}\text { außerhalb des } \\
\text { Masterscales doppelte } \\
\text { Beprobung }\end{array}$ & & \\
\hline & & $189-222$ & $\begin{array}{l}\text { Feindetritusmudde } \\
\text { (braun), Übergang zu } \\
\text { Algenmudde }\end{array}$ & $191-210$ & $\begin{array}{l}\text { extrem hohe Schwermetall-Konzentra- } \\
\text { tionen }(\max . \mathrm{Pb})\end{array}$ \\
\hline & & $222-245$ & Algenmudde (braun), & ab 226 & $\begin{array}{l}\text { Beginn der Verhüttung von polymetallischen } \\
\text { Erzen (aufwärts) }\end{array}$ \\
\hline & & & Kalkgehalt gering & ab 236 & $\begin{array}{l}\text { Beginn der Verhüttung von Kupfererzen } \\
\text { (aufwärts) }\end{array}$ \\
\hline \multirow[t]{6}{*}{$246-329$} & 114 & $245-323$ & & & \\
\hline & & $245-256$ & $\begin{array}{l}\text { Algenmudde (braun), } \\
\text { stark elastisch, } \\
\text { Kalkgehalt gering }\end{array}$ & & \\
\hline & & $256-266$ & $\begin{array}{l}\text { Feindetritusmudde } \\
\text { (braun-schwarz) }\end{array}$ & & \\
\hline & & $266-279$ & $\begin{array}{l}\text { Feindetritusmudde (grau- } \\
\text { braun) mit Blattlagen }\end{array}$ & & \\
\hline & & $279-300$ & $\begin{array}{l}\text { Feindetritusmudde (grau- } \\
\text { braun) }\end{array}$ & ab 282 & $\begin{array}{l}\text { Beginn der Verhüttung von Bleierzen zur } \\
\text { Silbergewinnung (aufwärts) }\end{array}$ \\
\hline & & $300-323$ & $\begin{array}{l}\text { Feindetritusmudde (grau- } \\
\text { braun) mit Blattlagen } \\
\text { (311: feines Kalkband, } \\
\text { ca. } 2 \mathrm{~mm} \text { ) }\end{array}$ & $282-317$ & $\begin{array}{l}\text { „ruhige Sedimentation“ (hauptsächlich } \\
\text { organische Komponente und authigener Calcit } \\
\text { = Seekreide, kaum Eintrag minerogenen } \\
\text { Materials) }\end{array}$ \\
\hline
\end{tabular}

Fortsetzung der Tabelle auf den folgenden Seiten. 


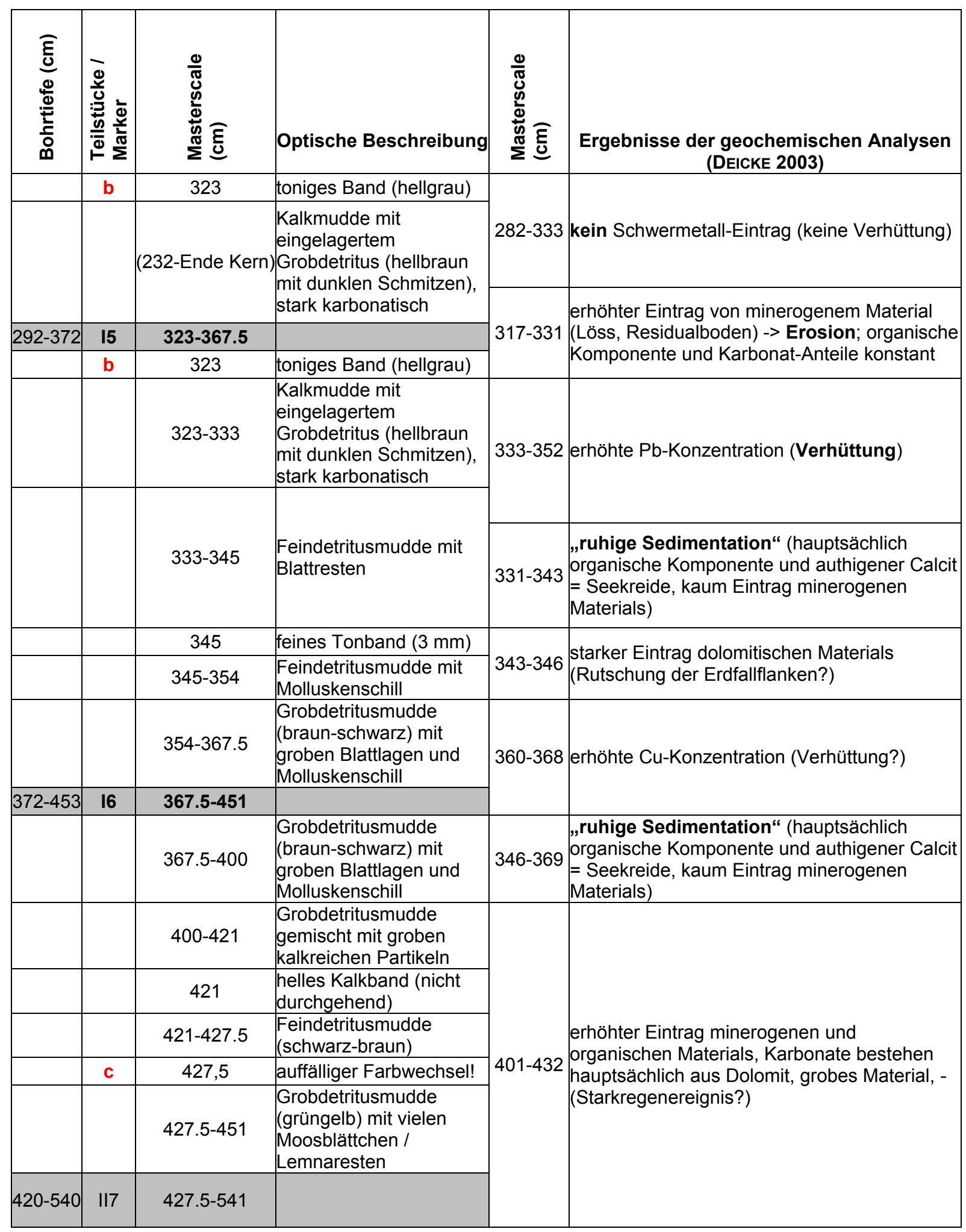

Fortsetzung der Tabelle auf den folgenden Seiten. 


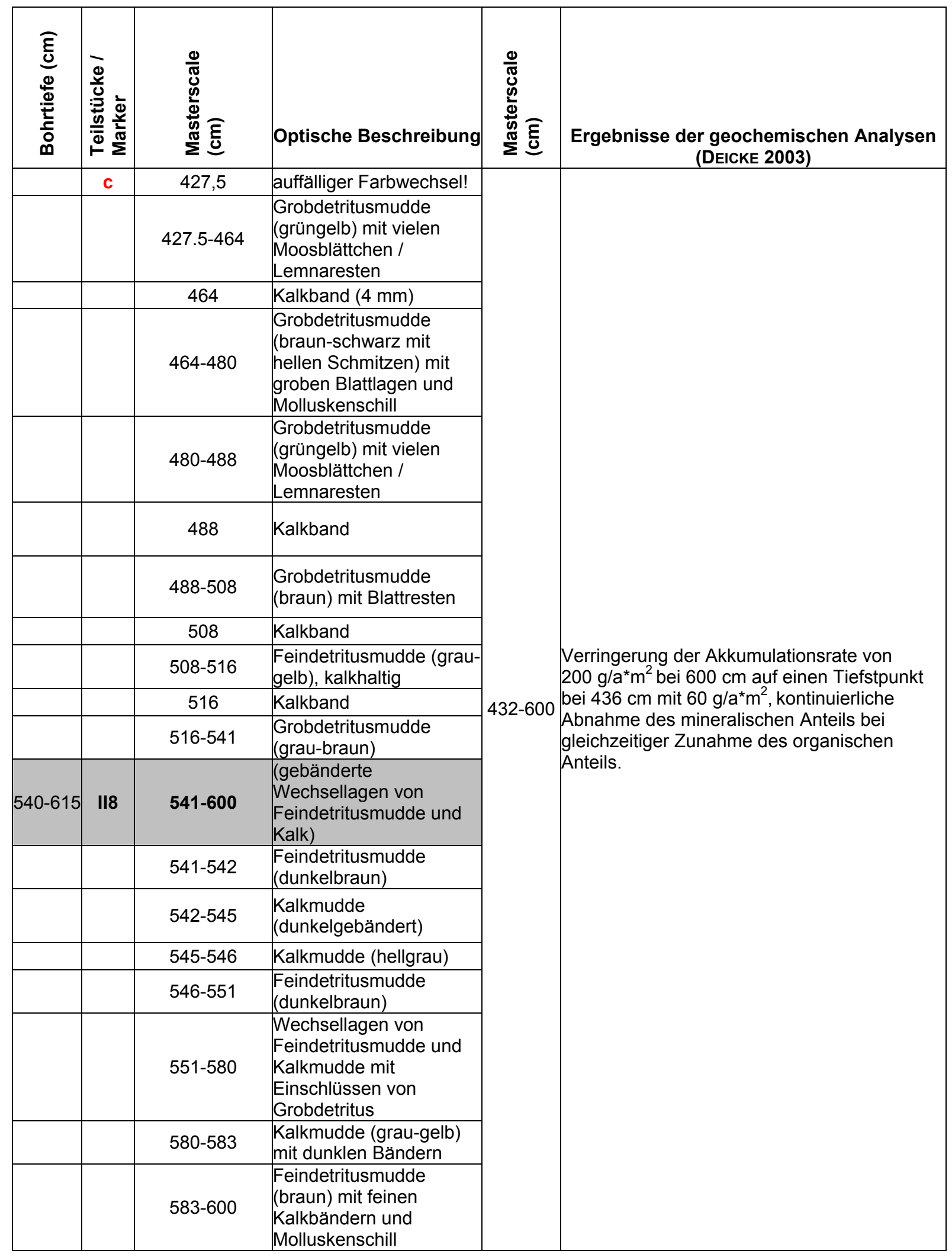

Fortsetzung der Tabelle auf der folgenden Seite. 


\begin{tabular}{|c|c|c|c|c|c|}
\hline 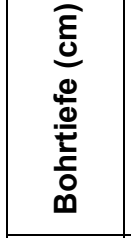 & 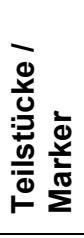 & 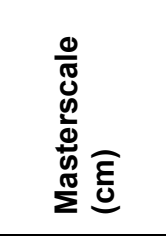 & Optische Beschreibung & 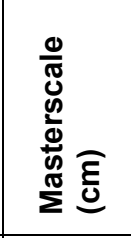 & $\begin{array}{l}\text { Ergebnisse der geochemischen Analysen } \\
\text { (DEICKE 2003) }\end{array}$ \\
\hline & d & 600 & Kalkband & \multirow{24}{*}{$600-778$} & \multirow{24}{*}{$\begin{array}{l}\text { Die sehr hohe Akkumulationsrate von } 1300 \\
\text { g/a*m² verringert sich aufwärts kontinuierlich. } \\
\text { Dabei nimmt der mineralische Anteil bei } \\
\text { gleichzeitiger Zunahme des organischen } \\
\text { Anteils ab. Das Material im tiefsten Abschnitt } \\
\text { des Kerns setzt sich aus Ton, Löss und } \\
\text { Dolomit zusammen. Geringe Mengen } \\
\text { unvollständig aufgelösten Gipses treten auf. } \\
\text { Sie könnten von der eingestürzten } \\
\text { Höhlendecke stammen. Das Kernende hat } \\
\text { daher vermutlich die Erdfallbasis erreicht. }\end{array}$} \\
\hline & & $600-615$ & $\begin{array}{l}\text { Feindetritusmudde } \\
\text { (braun) mit feinen } \\
\text { Kalkbändern und } \\
\text { Molluskenschill } \\
\end{array}$ & & \\
\hline & & 615-616 & $\begin{array}{l}\text { tonige Schluffmudde } \\
\text { (grau-gelb), stark } \\
\text { kalkhaltig }\end{array}$ & & \\
\hline \multirow[t]{12}{*}{$570-666$} & 19 & $600-682$ & & & \\
\hline & d & 600 & Kalkband & & \\
\hline & & $600-615$ & $\begin{array}{l}\text { Feindetritusmudde } \\
\text { (braun) mit feinen } \\
\text { Kalkbändern und } \\
\text { Molluskenschill } \\
\end{array}$ & & \\
\hline & & $615-617$ & $\begin{array}{l}\text { tonige Schluffmudde } \\
\text { (grau-gelb), stark } \\
\text { kalkhaltig }\end{array}$ & & \\
\hline & & $617-630$ & $\begin{array}{l}\text { Grobdetritusmudde } \\
\text { (grau), stark kalkhaltig } \\
\text { mit Molluskenschill }\end{array}$ & & \\
\hline & & $630-635$ & $\begin{array}{l}\text { tonige Kalkmudde mit } \\
\text { humosen Anteilen }\end{array}$ & & \\
\hline & & $630-646$ & $\begin{array}{l}\text { Feindetritusmudde } \\
\text { (grau), stark kalkhaltig }\end{array}$ & & \\
\hline & & $646-647$ & Kalkmudde & & \\
\hline & & $647-660$ & $\begin{array}{l}\text { Grobdetritusmudde } \\
\text { (grau-braun) }\end{array}$ & & \\
\hline & & $660-663$ & Kalkmudde (grau-gelb) & & \\
\hline & & $663-674$ & $\begin{array}{l}\text { stark humose } \\
\text { Kalkmudde (grau) }\end{array}$ & & \\
\hline & & 674-682 & $\begin{array}{l}\text { Kalkmudde mit } \\
\text { Schluffanteil (dunkel } \\
\text { gebändert) }\end{array}$ & & \\
\hline \multirow[t]{9}{*}{$666-763$} & 110 & $682-778$ & & & \\
\hline & & $682-700$ & $\begin{array}{l}\text { Kalkmudde mit } \\
\text { Schluffanteil (dunkel } \\
\text { gebändert) }\end{array}$ & & \\
\hline & & 700-716 & $\begin{array}{l}\text { Schluffmudde (grau), } \\
\text { etwas gebändert }\end{array}$ & & \\
\hline & & 716-730 & $\begin{array}{l}\text { Schluffmudde (grau) mit } \\
\text { deutlichen } \\
\text { Feindetritusbändern }\end{array}$ & & \\
\hline & & 730-738 & $\begin{array}{l}\text { Schluffmudde (grau), } \\
\text { etwas gebändert }\end{array}$ & & \\
\hline & & 738-749 & $\begin{array}{l}\text { Schluffmudde (grau), } \\
\text { nicht gebändert }\end{array}$ & & \\
\hline & & 749-760 & $\begin{array}{l}\text { Schluffmudde (grau), } \\
\text { etwas gebändert }\end{array}$ & & \\
\hline & & $760-762.5$ & $\begin{array}{l}\text { humoses Sandband } \\
\text { (grau) }\end{array}$ & & \\
\hline & & $762.5-778$ & $\begin{array}{l}\text { Schluffmudde (grau), } \\
\text { etwas gebändert }\end{array}$ & & \\
\hline
\end{tabular}




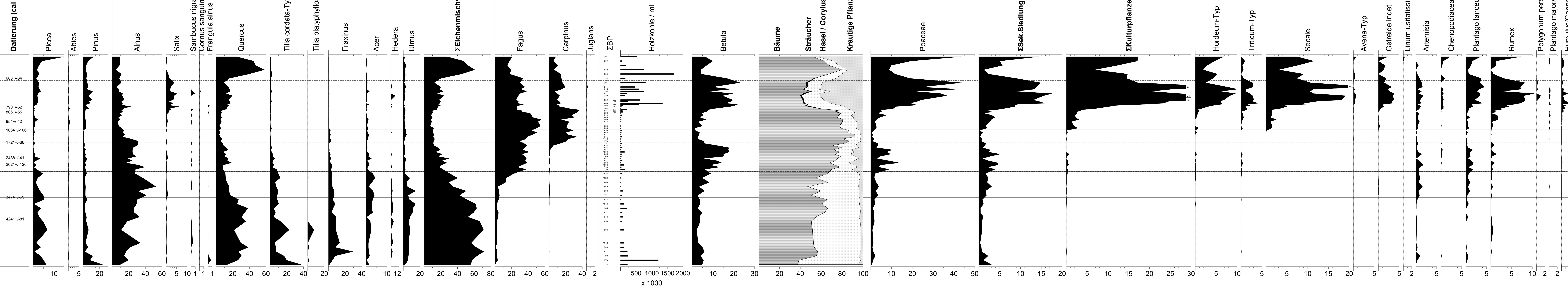

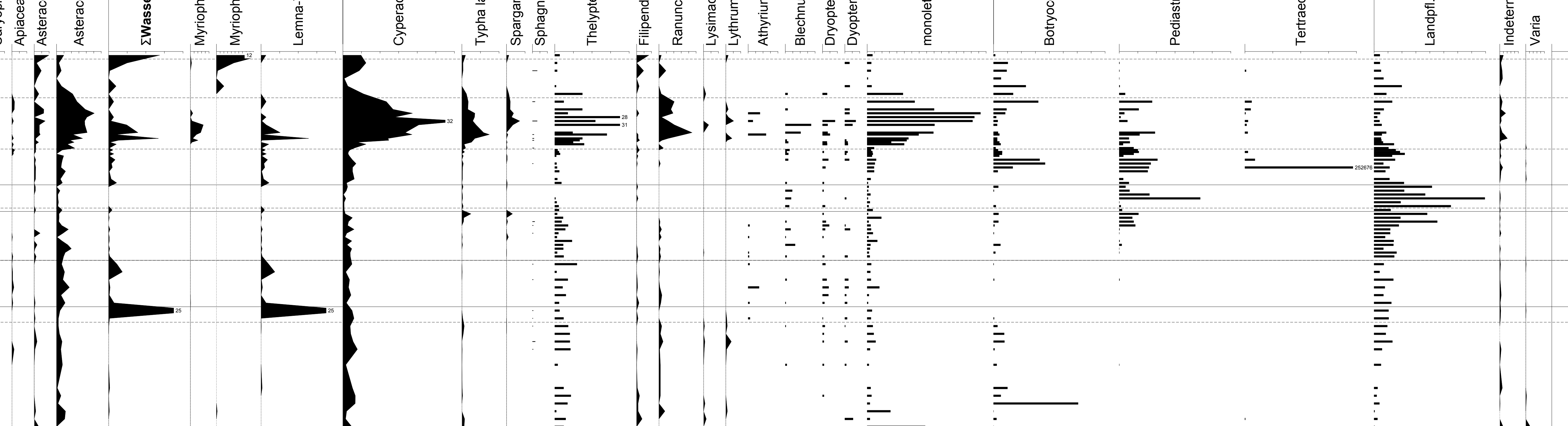




\section{Diagrammbeschreibung und Auswertung}

\begin{tabular}{|ll|}
\hline \multicolumn{2}{|l|}{ Liste der im Text beschriebenen Abbildung und der Tabellen: } \\
Abbildung 15: & Pollendiagramm des Profils Aschenhütter Teich (BP-Summe = 100\%), \\
& Beilage \\
Tabelle 45: & Zählwerte selten auftretender Taxa, 1. Teil, Anhang \\
Tabelle 46: & Zählwerte selten auftretender Taxa, 2. Teil, Anhang \\
Tabelle 49: & Pollen-Influx ausgewählter Taxa des Diagramms Aschenhütter Teich, \\
& Anhang \\
\hline
\end{tabular}

Die Pollendiagramme wurden in biostratigraphische Zonen nach Firbas (1949) eingeteilt. Die Kriterien für die Grenzziehungen wurden aus (BEUG 1992) übernommen (vgl. Tab. 23). Auf diese Weise wird eine gute Vergleichbarkeit mit den Standarddiagrammen vom Luttersee (BEUG 1992) und Jues-See (VOIGT 2003) aus dem Harzvorland ermöglicht.

Tabelle 23: Zur Zonierung des Pollendiagramms herangezogene Grenzkriterien nach (BEUG 1992)

\begin{tabular}{|c|c|}
\hline Zonen n. Firbas & Grenzkriterien \\
\hline $\mathbf{I X b} / \mathbf{X}$ & $\begin{array}{c}\text { Getreide-Werte }>1 \% \\
\text { Rückgang der Fagus- und Carpinus-Werte }\end{array}$ \\
\hline IXa / IXb & Anstieg der Carpinus-Werte \\
\hline VIIIb / IXa & Fagus-Kurve erreicht Maximalwerte $>30 \%$ \\
\hline VIIIa / VIIIb & Fagus-Werte $>5 \%$ \\
\hline VII / VIIIa & Fagus-Werte $>1 \%$ \\
\hline
\end{tabular}

Der folgenden Beschreibung jeder Pollen- und Siedlungszone ist ein Datenkopf vorangestellt, der angibt, in welcher Tiefe die jeweilige Zone beginnt und endet. Ferner sind Grenztiefen angegeben, die zwischen zwei untersuchten Proben liegen. Gleiches gilt auch für die angegebene Sedimentmächtigkeit. Dem folgt eine Zusammenstellung der Datierungen für die jeweilige Zone und der archäologischen Kulturstufen für die Region. Außerdem sind die wichtigsten sedimentologischen und geochemischen Ergebnisse angegeben, die aus den Untersuchungen von M. Deicke abgeleitet werden konnten (DEICKE 2003).

\section{Subboreal VIII}

VIIla $(777-529 \mathrm{~cm})$

$3527^{11}-1543$ v. Chr. (5477-3493 cal BP; 4901-3267 BP)

Dauer: 1984 a; mittlere Sedimentationsrate: $8 \mathrm{a} / \mathrm{cm}$; mittlerer Probenabstand: $20 \mathrm{~cm}=160 \mathrm{a}$.

Sediment: vorwiegend Karbonat- und Schluffmudden, untergeordnet Fein- und Grobdetritusmudden Jungneolithikum, Endneolithikum, Frühbronzezeit.

Die Fagus -Kurve beginnt in Zone VIIla mit Werten, die bereits deutlich über $1 \%$ liegen. Die Rotbuche war demnach im Gebiet um den Aschenhütter Teich anwesend. Es dominieren mit hohen Werten die Arten des Eichenmischwaldes: Quercus, Tilia cordata-Typ, Ulmus, Fraxinus und Acer. Obwohl die Prozentwerte der Eiche die der anderen Taxa in den meisten Spektren deutlich übertreffen, war zumindest die Linde (Tilia cordata-Typ) ebenfalls stark am Aufbau des Waldes beteiligt. Sie setzt relativ wenig Pollen frei und erscheint daher in

\footnotetext{
${ }^{11}$ Es handelt sich nicht um das Alter der unteren Grenze der Pollenzone VIIla, sondern um das Alter des unteren Kernendes.
} 
Diagrammen gegenüber windblütigen Gehölzen unterrepäsentiert (ANDERSEN 1973).

In diesen lichten Eichenmischwäldern, für die es keine rezente Entsprechung gibt, war die Hasel stark vertreten. Sie ist im Pollendiagramm mit sehr hohen Werten erfasst. Auch Hedera helix und Viscum album waren Bestandteile dieser Waldgesellschaft.

In Anbetracht der geringen Höhe des Bohrpunktes über NN sind die Picea-Werte sehr hoch. Die Fichte war jedoch vermutlich in der Umgebung des Aschenhütter Teiches nicht anwesend. Ihr Pollen wurde aus den höher gelegenen Bereichen des Harzes eingeweht. Die Werte der Kiefer, die ein sehr starker Pollenproduzent ist, sind zu gering, um die Anwesenheit von Pinus zu belegen.

Es treten bereits Hinweise auf Siedlungsaktivitäten auf: Die Werte von Plantago lanceolata, Artemisia und Pteridium sind in einigen Pollenspektren erhöht (z.B. $745 \mathrm{~cm})$. Parallel sind höhere Poaceae-Werte feststellbar. Die Holzkohle-Konzentration ist in einigen Spektren deutlich erhöht. Ein Getreide-Pollenkorn des Triticum-Typs wurde in $729 \mathrm{~cm}$ Tiefe nachgewiesen. Eine Siedlungsphase kann jedoch aufgrund des weitgehend fehlenden Kulturpflanzenpollens nicht ausgewiesen werden. Eine detaillierte Klärung der Siedlungsgeschichte in diesem frühen Abschnitt des Diagramms ist aufgrund der zeitlichen Auflösung von etwa 160 Jahren nicht möglich. Besonders während des Neolithikums war die Siedlungskontinuität häufig gering. Die Acker- und Siedlungsflächen dieser Zeit waren im Verhältnis zur ungestörten Waldfläche zudem meist klein, so dass nur durch hochauflösende pollenanalytische Untersuchungen neolithische Besiedlung nachgewiesen werden kann.

Auch anhand der geochemischen Befunde kann kein anthropogener Einfluss festgestellt werden. Die natürlichen Grundgehalte an silikatischem Detritus (Al, K, Ti, u.a.) sind im gesamten Sedimentabschnitt so hoch, dass ein durch Erosion verursachter Bodeneintrag in den See geochemisch nicht erkennbar wäre. Technogene Schwermetallanomalien liegen nicht vor (DEICKE 2003).

\section{VIIIb $(529-433 \mathrm{~cm})$}

1543-799 v.Chr. (3493-2749 cal BP; 3267-2626 BP)

Sediment: überwiegend Grob- und Feindetritusmudden

Dauer: 744 a; mittlere Sedimentationsrate: 8 a/cm, mittlerer Probenabstand: 16 cm=128 a.

Der Abschnitt VIIlb beginnt definitionsgemäß mit dem Anstieg der Fagus-Kurve auf Werte über 5\% (vgl. Tab. 23). Dieser Beginn der Massenausbreitung von Rotbuchen in den Wäldern wurde am Aschenhütter Teich auf 3500 cal BP datiert. Mit dem fortschreitenden Anstieg der Fagus-Kurve sinken im Pollendiagramm die Kurven der Eichenmischwaldarten ab. Die inn repräsentierenden Baumarten wurden zunehmend von der konkurrenzkräftigeren Rotbuche zurückgedrängt. Besonders stark ist die Quercus-Kurve betroffen. Sie fällt von etwa $30 \%$ auf $10 \%$ zurück. Gleiches gilt auch für die Hasel, deren Kurve unter starken Schwankungen ebenfalls abfällt.

In diesem Bereich ist die Carpinus-Kurve bereits geschlossen.

\section{SZ 1 a $(561-433 \mathrm{~cm})$}

1813-799 v. Chr. (3763-2749 cal BP; 3478-2626 BP)

Dauer: $1014 \mathrm{a}$; mittlere Sedimentationsrate: $8 \mathrm{a} / \mathrm{cm}$, mittlerer Probenabstand: $16 \mathrm{~cm}=128 \mathrm{a}$.

Frühe Bronzezeit, Mittlere Bronzezeit, Jüngere Bronzezeit.

Der Abschnitt a der SZ 1 erstreckt sich über $128 \mathrm{~cm}$ des Kernes und umfasst damit die gesamte Zone VIIIb. Die Initialphase zeichnet sich in den Proben $553 \mathrm{~cm} \& 537 \mathrm{~cm}$ ab. Sie sind Zone VIIla zugeordnet.

Die geschlossene Kurve der Getreide-Typen beginnt erst in der Tiefe $473 \mathrm{~cm}$. Die Kurven von Artemisia, Plantago lanceolata, Rumex, der Fabaceae und anderer sekundärer Sied- 
lungszeiger sind jedoch im gesamten Abschnitt erhöht. Parallel dazu zeigen auch die Kurven der Poaceae sowie der Nichtbaumpollen erhöhte Werte. Die Calluna-Werte sind ebenfalls erhöht.

Die Betula-Kurve steigt an. Die Birken profitierten als Pioniergehölze von den anthropogenen Eingriffen in die Waldgesellschaften und besiedelten ehemalige Rodungsflächen. Sie blieben jedoch relativ unbedeutend.

Aufgrund der weiterhin hohen Konzentration siliziklastischen Materials im Sediment ist es nicht möglich, Bodeneinträge aufgrund von Erosion zu erkennen. Technogene Schwermetallanomalien liegen nicht vor (DEICKE 2003).

Die bronzezeitliche Besiedlung im weiteren Umfeld des Aschenhütter Teiches zeichnet sich deutlich im Pollendiagramm ab. Die Siedlungsflächen und besonders die Ackerflächen lagen jedoch nicht in der unmittelbaren Nähe des Untersuchungspunktes.

\section{Älteres Subatlantikum IX}

IXa $(433-333 \mathrm{~cm})$

799 v.Chr.-174 n.Chr. (2749-1776 cal BP; 2626-1834 BP)

Sediment: überwiegend karbonatische Grobdetritusmudden, silikatische Zwischenlagen

Dauer: 973 a; mittlere Sedimentationsrate: $9 \mathrm{a} / \mathrm{cm}$, mittlerer Probenabstand: $9 \mathrm{~cm}=81 \mathrm{a}$.

Die Fagus-Kurve erreicht ihr erstes Maximum. Gegen Ende des Abschnittes beginnt der Anstieg der Carpinus-Kurve. Die Quercus-Werte steigen an. Alle anderen Eichenmischwaldarten gehen weiter zurück.

\section{SZ 1 b $(433-325 \mathrm{~cm})$}

799 v.Chr.-275 n.Chr. (2749-1675 cal BP; 2626-1734 BP)

Dauer: 1074 a; mittlere Sedimentationsrate: $10 \mathrm{a} / \mathrm{cm}$, mittlerer Probenabstand: $9 \mathrm{~cm}=90 \mathrm{a}$. Jüngere Bronzezeit, vorrömische Eisenzeit, Römische Kaiserzeit.

Die SZ 1 setzt sich in diesem jüngeren Abschnitt b intensiviert fort.

Die Kurve der Getreide-Typen ist bis zur Tiefe $393 \mathrm{~cm}$ geschlossen. Die Nichtbaumpollenund sekundären Siedlungszeiger-Kurven sowie die Poaceae-Kurve erreichen höhere Werte als im vorhergehenden Abschnitt a. Die Quercus-Kurve steigt an. Die Eichen wurden vermutlich als wertvolle Mastbäume gefördert.

Für die Zeit der Vorrömischen Eisenzeit wird im südwestlichen Harzvorland anhand archäologischer Funde eine relativ dichte Besiedlung angenommen. Diese Zunahme der Besiedlungsdichte zeichnet sich auch im Pollendiagramm ab. Darüber hinaus wurden etwa $1,5 \mathrm{~km}$ nordwestlich des Aschenhütter Teiches nahe der Jettenhöhle ausgedehnte Siedlungsspuren dieser Zeitstellung lokalisiert. In der Karsthöhle selbst wurden Keramikbruchstücke und verkohlte Pflanzenreste gefunden. Die Makrorestanalyse durch U. Willerding (WILLERDING 1975) ergab: Hordeum vulgare (Spelzgerste), Panicum miliaceum, Linum usitatissimum und Unkräuter (siehe Kapitel 3.5, S. 18). Möglicherweise zeichnet sich im Diagramm der Pollenniederschlag der Äcker dieser Siedlung ab.

Der Abschnitt $b$ der Siedlungszeit 1 läßt sich aufgrund des zweigipfligen Verlaufs der Siedlungszeiger-Typen-Kurve, der Poaceae-Kurve und der Betula-Kurve in eine jüngere und eine ältere Phase teilen. Sie werden durch einen deutlichen Rückgang aller genannten Kurven voneinander getrennt.

In der jüngeren Phase setzt nach dem erneuten Anstieg der Kurven im Unterschied zur älteren Phase die Kurve der Getreide-Typen aus. Dies könnte die Folge einer Verlagerung der Getreideanbauflächen in eine größere Entfernung vom Aschenhütter Teich sein. 
Getreidepollen (Ausnahme Roggenpollen) wird nur in geringen Mengen von den blühenden Pflanzen freigesetzt. Daher kann eine geringfügige Verlagerung der Äcker vom See weg dazu führen, daß die Kurve der Getreide-Typen im Pollendiagramm aussetzt. Eine Verringerung der Siedlungsintensität muss nicht zwangsläufig damit verbunden sein.

Das Untersuchungsgebiet lag während der Vorrömischen Eisenzeit in der Kontaktzone zwischen Keltischer und Germanischer Besiedlung. Die auf Auseinandersetzungen der beiden Kulturgruppen zurückgeführte zeitgleiche Aufgabe vieler Siedlungen im Untersuchungsgebiet während des 1 . Jhs. v. Chr. spiegelt sich im Pollendiagramm jedoch nicht wider (siehe Kapitel 3.5, S. 18). Lediglich das Aussetzen der Getreidepollen-Typen-Kurve im 1. Jh. v. Chr. ist erkennbar. Da die Anteile der Siedlungszeiger-Typen-Kurve, der PoaceaeKurve und der Betula-Kurve jedoch auf erhöhtem Niveau verlaufen, lässt sich weiterhin ein deutlicher Siedlungseinffluss erkennen. Desweiteren beginnt in dieser Zeit eine Verhüttungsphase, die ebenfalls gegen eine umfassende Siedlungsaufgabe spricht.

Die technogene Schwermetallanreicherung befindet sich im Bereich zwischen $352 \mathrm{~cm}$ (interpoliertes Alter $22+/-85,5 \mathrm{v}$. Chr.) und etwa $333 \mathrm{~cm}$. Die stärkste Bleiakkumulation wurde in $342 \mathrm{~cm}$ Tiefe $(103+/-85,5 \mathrm{n}$. Chr.) gemessen und datiert damit in die Römische Kaiserzeit. Der Beginn der technogenen Anreicherungen bei $352 \mathrm{~cm}$ datiert jedoch in die ausgehende Spätlatènezeit (interpoliertes Alter 22 +/- 85,5 v. Chr.). Die technogenen Metallanreicherungen decken sich demnach zeitlich nicht genau mit den frühesten Verhüttungsaktivitäten der Lokalität Düna, die im 3. Jh. n. Chr. einsetzten (DEICKE 2003). Der bisher unbekannte Verhüttungsort könnte möglicherweise südöstlich des Sudberges in ca. $1 \mathrm{~km}$ Entfernung zum Aschenhütter Teich liegen. Dort wurden Keramik, Hüttenlehm und Schlacken in einem als vorchristlich eingestuften Lesefund lokalisiert ${ }^{12}$.

Der bisher für das Harzvorland angenommene Siedlungsrückgang während der Römischen Kaiserzeit (z.B. ClAUS 1978) kann aufgrund der pollenanalytischen und geochemischen Ergebnisse im Umkreis des Aschenhütter Teiches nicht bestätigt werden. In der 1,5 km nordnordwestlich des Aschenhütter Teiches gelegenen Siedlung Düna konnte auch archäologisch eine kontinuierliche Besiedlung seit Christi Geburt nachgewiesen werden (siehe Kapitel 3.6, S. 19). Wie bereits dargelegt, war die Annahme eines Siedlungsrückgangs während der Römischen Kaiserzeit vermutlich aufgrund einer Forschungslücke entstanden (KLAPPAUF 1986).

Die Siedlungsaktivitäten der nahegelegenen Gehöftgruppe Düna spiegeln sich nicht im Pollenniederschlag des Untersuchungsortes wider. Getreideanbau ist nur über kurze Distanzen pollenanalytisch nachweisbar (vgl. BEHRE \& KUČAN 1986). Darüber hinaus lässt sich während der PZ IXb keine Siedlungsaktivität feststellen, obwohl für Düna lediglich ein vorübergehendes Nachlassen der Siedlungsintensität im 6. Jh. n. Chr. festgestellt wurde.

Das Vorhandensein eines weiteren Verhüttungsplatzes mindestens im 1. Jh. n. Chr. könnte ein Hinweis für die Existenz einer unentdeckten Siedlung sein. Für das Ende der Siedlungszeit $1 \mathrm{~b}$ und der Verhüttungsphase wurde ein Alter von $275+/-73,5 \mathrm{n}$. Chr. errechnet.

\section{IXb $(333-277 \mathrm{~cm})$}

174-857 n. Chr. (1776-1093 cal BP; 1834-1162 BP)

Dauer: 683 a; mittlere Sedimentationsrate: $11 \mathrm{a} / \mathrm{cm}$, mittlerer Probenabstand: $8 \mathrm{~cm}=88 \mathrm{a}$.

Sediment: überwiegend schwach karbonatische Mudden

Römische Kaiserzeit, Völkerwanderungszeit, Frühmittelalter.

Der Rückgang der sekundären Siedlungszeiger- und der Nichtbaumpollen-Kurven zeigt ein deutliches Nachlassen der Besiedlungsintensität in der Nähe des Untersuchungspunktes an. Der Baumpollenanteil steigt im Summendiagramm wieder auf Werte über $80 \%$ an, während

${ }^{12}$ Freundliche Mitteilung von Dr. L. Klappauf, Niedersächsisches Landesamt für Denkmalpflege, Arbeitsstelle Montanarchäologie, Goslar. 
der Nichtbaumpollenanteil deutlich unter $5 \%$ fällt. Eine umfassende Wiederbewaldung zeichnet sich ab.

Die Hainbuche profitierte besonders stark von den veränderten Bedingungen. Sie vermochte sich auf den verlassenen Wirtschaftsflächen auszubreiten. In Folge dessen steigt ihre Kurve auf Maximal-Werte an. Auch die Rotbuche konnte ihren Anteil weiter erhöhen. Die FagusKurve erreicht schließlich in der folgenden Zone mit $60 \%$ ihr absolutes Maximum in diesem Pollendiagramm.

Im Gegensatz dazu gehen die Werte von Quercus, Betula, Corylus und Alnus zurück. Sowohl Eichen als auch Birken und Haselsträucher sind in der vorhergehenden Siedlungsphase durch die menschliche Wirtschaftsweise gefördert worden. Mit dem Ausbleiben dieser Eingriffe werden sie von konkurrenzstärkeren Arten wie Rotbuche und Hainbuche zurückgedrängt. Der Rückgang der Erlen-Kurve dagegen hängt vermutlich nicht mit dem Nachlassen der Besiedlungsintensität zusammen, sondern muss andere Gründe haben, die aus dem Pollendiagramm nicht ablesbar sind.

Für diesen Abschnitt wurde die niedrigste Sedimentationsrate des gesamten Kernes festgestellt. Mit dem Ende der Siedlungszeit $1 \mathrm{~b}$ endet zeitgleich $(322 \mathrm{~cm})$ die zuvor beschriebene frühe Verhüttungsphase. In Zone IX lassen sich keine weiteren technogenen Anreicherungen feststellen (DEICKE 2003).

Die während der Völkerwanderungszeit anhaltende Besiedlung in Düna (siehe oben) zeichnet sich nicht im Pollendiagramm ab.

\section{Jüngeres Subatlantikum X}

\section{$X(277-0 \mathrm{~cm})$}

857 n.Chr.-heute (1093-0 cal BP; 1162-0 BP)

Sediment: schwach karbonatische Feindetritus- und Algenmudden

Dauer: $1093 \mathrm{a}$; mittlere Sedimentationsrate: $4 \mathrm{a} / \mathrm{cm}$, mittlerer Probenabstand: $9 \mathrm{~cm}=36 \mathrm{a}$.

\section{SZ 2a (277 - 203cm)}

857-1084 n.Chr. (1093-866 cal BP; 1162-923 BP)

Dauer: 227 a; mittlere Sedimentationsrate: $3 \mathrm{a} / \mathrm{cm}$, mittlerer Probenabstand: $8 \mathrm{~cm}=24 \mathrm{a}$.

Frühmittelalter.

Der dauerhafte Anstieg der Getreide-Kurve auf Werte über 1\% markiert definitionsgemäß den Beginn der PZ X (BEUG 1992). Dem gehen zwei Proben mit geringen Getreide-Werten voraus (289 cm: 0,3\% \& $281 \mathrm{~cm}: 0,2 \%$ ), die der PZ IXb zugeordnet sind. Sie stellen eine Initialphase der Siedlungszeit dar. Die Getreide-Werte nehmen nach dieser kurzen Initialphase rasch zu. Besonders deutlich steigen die Secale-Werte an, aber auch die Triticumund Hordeum-Typ-Kurven setzen ein. Die Summenkurve der Sek. Siedlungszeiger verläuft auf deutlich erhöhtem Niveau. Bemerkenswert ist das Auftreten von Pollenkörnern der Kornblume (Centaurea cyanus) in $249 \mathrm{~cm}$ Tiefe. Demnach wurde der Roggen bereits als Wintergetreide angebaut.

Die botanischen Makrorestanalysen an Fundmaterial des frühmittelalterlichen Herrensitzes im nahen Düna weisen ebenfalls deutlich auf einen Winterroggenanbau hin (siehe Kapitel 3.8.1, S. 23).

Das Summendiagramm zeigt einen Rückgang des Baumpollenanteils auf weniger als $70 \%$, während die Nichtbaumpollenwerte auf zum Teil über 10\% steigen. Der zuvor geschlossene Wald wurde erneut zur Schaffung von Acker- und Siedlungsflächen aufgelichtet. Gerodet wurden vermutlich Bereiche in dem von Rotbuchen dominierten Mischwald, so dass alle Baumarten in etwa gleichmäßig von der Dezimierung betroffen waren. Im Pollendiagramm 
lässt sich daher keine bedeutende Veränderung im Verhältnis der Baumpollenanteile feststellen. Auch die Influx-Werte bleiben konstant.

Geringfügige Anstiege der Pollenanteile lassen sich jedoch bei Betula, Corylus und Quercus feststellen. Sowohl Betula als auch Corylus profitierten von den Rodungen, da sie offengelassene Bereiche sehr schnell neu besiedeln konnten. Die Haselsträucher wurden außerdem als Art der Waldsäume häufiger. Auch eine Förderung durch den Menschen ist möglich, da Haselnüsse eine sehr wertvolle Nahrungsergänzung darstellen, die mindestens seit dem Mesolithikum genutzt wurde.

Der Eichenanteil ist ebenfalls etwas erhöht. In den darauffolgenden, jüngeren Abschnitten der SZ (2b \& c) nimmt der Eichenanteil weiter zu. Eine deutliche Förderung der Eichen durch den Menschen lässt sich fassen. Möglicherweise zeichnet sich in SZ 2a ein noch schwacher Beginn dieser Entwicklung ab. Aufgrund des wesentlich höheren Polleneintrags der Rot- und Hainbuchen wird im Pollenprozentdiagramm die Dynamik der Eichenkurve in diesem Abschnitt überlagert und erscheint daher gestaucht. Die Zunahme der Eichen begann bereits in SZ 2a, wie die Influx-Werte zeigen (Tab. 49).

Die Zunahme des Pinus- und Picea-Pollenanteils wird durch die Auflichtung der Landschaft verursacht. Der Rückgang der Bewaldung insgesamt verringert den Pollenanteil der lokalen und regionalen Gehölze. Daher steigt der relative Anteil des ferntransportierten Pollens im Prozent-Diagramm an, obwohl die absoluten Werte nur einen geringen Zuwachs zeigen (Influx-Werte). Der angetroffene Kiefern- und Fichtenpollen stammt wahrscheinlich von den benachbarten Hochlagen des Harzes. Der vereinzelt auftretende Tannenpollen stammt aus dem Thüringer Wald, dem nächstgelegenen natürlichen Standort der Weißtanne. Auch die Ergebnisse der Holzkohlenanalyse und der schriftlichen Quellen sprechen gegen ein Fichtenvorkommen in der Umgebung des Aschenhütter Teiches. Nach schriftlichen Quellen war die Fichte bis zur Mitte des 13. Jhs. ausschließlich auf den nordwestlichen Teil des Oberharzes beschränkt (siehe Kapitel 3.8.4, S. 41). Die Holzkohlenspektren vergleichbarer Lokalitäten aus der Zeit des frühen Mittelalters enthalten ebenfalls keinen Hinweis auf das Vorkommen von Fichten (siehe Kapitel 3.8.4, S. 49).

Von den erfassten Siedlungsaktivitäten scheinbar unbeeinflusst steigen die Fagus- und Carpinus-Werte weiter an. Die Carpinus-Kurve erreicht zum Ende des Abschnitts a der SZ 2 Werte über $30 \%$. Der Rückgang der Fagus-Kurve im jüngsten Teil des Abschnitts wird bei der Berechnung des Diagramms durch den starken Anstieg der Carpinus-Kurve in diesem Bereich hervorgerufen (siehe Influx).

Die technogenen Schwermetallgehalte steigen im Sediment der Siedlungszeit 2a kontinuierlich an. Am Übergang zur Siedlungszeit 2b $(205 \mathrm{~cm})$ erreichen sie ein erstes mittelalterliches Maximum. Die besonders hohen Schwermetallgehalte dieses Abschnitts deuten auf eine Erzverhüttung in unmittelbarer Nähe des Aschenhütter Teiches hin. Ein frühmittelalterlicher Schmelzplatz in der näheren Umgebung ist bisher nicht bekannt. Verhüttet wurden polymetallische Erze wie bspw. Rammelsberger Erze oder Kupferschiefer (DEICKE 2003).

Gegen Ende des Abschnitts a verstärkt sich die Siedlungsphase: Die Werte der GetreideTypen, Sekundären Siedlungszeiger und des Nichtbaumpollens steigen an.

Der frühmittelalterliche Landesausbau (-ingerode Orte) wurde von NITZ (1983) in das letzte Viertel des 8. Jhs. datiert (siehe Kapitel 3.8.1, S. 23). Die Anlage der vier bei Aschenhütte lokalisierten Dörfer zeichnet sich mit Beginn der Sz 2a im Diagramm ab (interpolierte Datierung $857+/-73,5$ n. Chr.). 
1084-1196 n.Chr. (866-754 cal BP; 923-842 BP)

Dauer: 112 a; mittlere Sedimentationsrate: $2 \mathrm{a} / \mathrm{cm}$, mittlerer Probenabstand: $8 \mathrm{~cm}=16$ a.

Sediment: Feindetritusmudden

Hochmittelalter.

Die Getreidesummenkurve erreicht in dieser Phase etwa 40\%. Der Secale Anteil liegt bei maximal 26\%; während gleichzeitig Pollenkörner von Centaurea cyanus häufiger werden. In zwei Proben $(185 \& 145 \mathrm{~cm}$ ) treten Sporen des Lebermooses Anthoceros punctatus auf, dessen Standort der offene Boden ist. Seine Sporen gelangten vermutlich mit oberflächig abfließendem Wasser in den Aschenhütter Teich, wie es bei Bodenerosion der Fall ist. Nach (DEICKE 2003) kann ein starker Anstieg des silikatischen Detritus zwischen 191-188 cm ebenfalls als Folge von Erosionsvorgängen gewertet werden. Aufgrund der Erosionsvorgänge, aber auch als Folge einer zunehmenden Eutrophierung des Sees wird während der Sz 2b die höchste Sedimentationsrate des gesamten Kernes erreicht.

In der SZ 2b wurde großflächig und intensiv Ackerbau in der Umgebung des Aschenhütter Teiches betrieben. Das Ausmaß des damaligen Getreideanbaus war dem der heutigen Agrarlandschaft ähnlich, wie Vergleiche mit Untersuchungen an Oberflächenproben aus dem Bereich des Seeburger Sees zeigen (STEINBERG 1944, zitiert nach BEUG 1992). Infolgedessen kam es zu Bodenerosion.

Hauptgetreide war Roggen, der als Winterfrucht angebaut wurde. Die Weizen- und Gersteanteile waren ebenfalls hoch. Diese autogamen Getreidesorten setzen weniger Pollen frei und sind daher im Diagramm gegenüber dem allogamen Roggen zum Teil stark unterrepräsentiert. Der Anteil des Hafers scheint dagegen gering gewesen zu sein.

Während der Sz 2b erfolgte der kontinuierliche Eintrag von stark kaliumverarmtem Material, das als Hinweis für eine starke Bodendegradierung gilt. Gleichzeitig zeichnet sich eine Anreicherung von Eisen ab, die darüber hinaus auf eine Versauerung des Bodens hindeutet (DEICKE 2003).

Alle Siedlungszeiger-Kurven sind stark erhöht und erreichen in SZ $2 b$ maximale Werte. Besonders hoch sind die Werte der Chenopodiaceae, von Rumex-, Plantago lanceolata- und Artemisia. Es hat demnach neben dem Getreideanbau eine ausgedehnte Grünlandwirtschaft und eine starke Zunahme ruderaler Standorte gegeben. Die Nutzung der Landschaft weitete sich auch auf ärmere Böden aus, wie die Zunahme der Calluna- und der Pteridium- Werte erkennen lässt. Es handelte sich dabei wahrscheinlich um die Schotterböden der östlich an den Aschenhütter Teich grenzenden Niederterrasse. Vermutlich wurde in diesem Bereich der Wald beweidet und auf diese Weise aufgelichtet.

Eine Ausbreitung von Calluna könnte ebenfalls auf versauerten bzw. durch eine erhöhte Schwermetallbelastung kontaminierten Böden stattgefunden haben, wie sie in der Nähe von Verhüttungsplätzen vorkommen.

Der Abschnitt $b$ ist von intensiven Rodungstätigkeiten geprägt. Infolgedessen gehen die Kurven von Fagus und Carpinus zurück. Die Kurven fast aller übrigen Gehölze, insbesondere die von Betula, Corylus und Quercus, steigen erneut an. Die Birken und Haselsträucher wurden weiterhin indirekt durch die Rodungen gefördert. Sie breiten sich auf den gerodeten Flächen, an den zahlreicher werdenden Waldrändern und an Wegen aus. Während die Zunahme im vorhergehenden Abschnitt 2a gering war, verdoppeln sich die Werte beider Taxa in SZ $2 b$.

Der Quercus-Anteil nimmt ebenfalls zu (Prozentwerte und Influx). Eichen sind langsam wachsende Bäume und daher nicht in der Lage, schnell auf entstandenen Freiflächen zur Ausbreitung zu kommen. Vermutlich wurden sie von den Rodungen ausgenommen und als Mastbäume geschont und gefördert. 
Auf einem Teil der gerodeten Flächen setzte eine Wiederbewaldung mit Hasel und Birke ein. Diese Rodungen dienten folglich nicht der Urbarmachung von Wald, sondern überwiegend der Holzgewinnung. Dieses Holz wurde dann vermutlich zu Holzkohle weiterverarbeitet, wie die besonders hohen Holzkohlekonzentrationen im Sediment nahelegen. Die Holzkohle lieferte die für die Verhüttung und Metallverarbeitung benötigte thermische Energie.

Aufgrund der starken Entwaldungen verdoppeln sich die Nichtbaumpollen-Werte. Sie erreichen im Summendiagramm über $40 \%$. Die zuvor dicht bewaldete Landschaft wurde demnach ganz erheblich aufgelichtet. Zu dieser Zeit ist in der Umgebung des Aschenhütter Teiches eher mit einer parkähnlichen Offenlandschaft zu rechnen als mit einem geschlossenen Wald.

Wie bereits in Abschnitt a der Siedlungszeit 2 beschrieben, hängt der Anstieg der Picea- und der Pinus-Kurve mit der Auflichtung der Landschaft und dem geringeren Polleneintrag der lokalen und regionalen Gehölze zusammen. Der relative Anteil des ferntransportierten Pollens steigt daher stärker an als die Influx-Werte.

In einer Tiefe von 190-175 cm wird das zweite Maximum technogener Schwermetalleinträge erreicht. Nach (DEICKE 2003) handelt es dabei nicht mehr um den Niederschlag eines Verhüttungsplatzes. Er vermutet, dass die Kontaminationen durch die Weiterverarbeitung eines Zwischenproduktes wie Kupferstein hervorgerufen wurden. Der Eintrag technogener Schwermetalle bleibt während des gesamten Abschnitts b der Siedlungszeit 2 auf sehr hohem Niveau.

Gegen Ende des Abschnitts b der Siedlungszeit 2 kommt es zu einem deutlichen Rückgang aller siedlungszeigenden Kurven. Parallel dazu sinken die Gehalte technogener Schwermetalle ab.

\section{SZ 2c (97-17cm)}

1196-1818 n.Chr. (754-132 cal BP; 842-148 BP)

Dauer: $622 \mathrm{a}$; mittlere Sedimentationsrate: $5 \mathrm{a} / \mathrm{cm}$, mittlerer Probenabstand: $16 \mathrm{~cm}=80 \mathrm{a}$.

Sediment: Feindetritusmudden

Spätmittelalter, Neuzeit.

Die SZ 2c wird von einem Rückgang der Siedlungsintensität gekennzeichnet, wobei jedoch keine Siedlungslücke vorliegt. Der zeitweilige Rückgang betrifft alle Siedlungszeiger-, die Getreide-Typen- und die Nichtbaumpollensummen-Kurve. Auch die indirekt anthropogen geförderten Gehölze Betula und Corylus gehen zurück.

Es kam nicht zu einer Wiederbewaldung durch Rot- und Hainbuchen, wie dies in PZ IXb zu beobachten war. Im Gegenteil die Fagus- und die Carpinus-Kurven sinken ab. Quercus dagegen profitierte als einzige Baumart von der offensichtlich veränderten Situation. Die Eichen-Werte steigen von weniger als $10 \%$ ausgehend rasant auf etwa $60 \%$ an. Sie erreichen damit den höchsten Wert ihrer Kurve. Auch die Holzkohlekonzentration erreicht in einzelnen Proben hohe Werte.

Die SZ 2c zeigt eine Verminderung und einen Wechsel der Bewirtschaftung im engeren Untersuchungsgebiet an: Der zuvor sehr intensive Getreideanbau ging stark zurück. Angezeigt vom starken Abfall der Kurven von Rumex und Plantago lanceolata zeichnet sich ein Rückgang der Grünlandbewirtschaftung ebenso deutlich im Diagramm ab.

Intensiviert wurde dagegen die Holzwirtschaft. Die extrem hohen Eichenanteile sprechen für eine intensive Förderung dieser wertvollen Nutzholzart. Als Mastbäume wurden die Eichen weiterhin als Überhälter in Mittelwäldern verschont. Der höhere Lichtgenuß dieser einzeln stehenden Eichen förderte ihre Blüte und somit ihre Pollenproduktion, was letztendlich im Pollendiagramm zu einer Erhöhung der Quercus-Werte führt. Eine Verdreifachung der Anteile wie im vorliegenden Diagramm läßt sich jedoch auf diese Weise nicht ausreichend erklären. Vermutlich wurden im Untersuchungsgebiet zusätzlich Eichen angepflanzt, wie dies nach KREMSER (1984) in Niedersachsen spätestens seit dem 12. Jh. auf offenen Hude- 
flächen und wüstgefallenen Ackerfluren der Fall war.

In der Umgebung des Aschenhütter Teiches nennt SCHUBART (1978) zwei Eichenmasthölzer: Das „Lüderholz“ in unmittelbarer Nähe und den „Alten Krücker“, der etwa 3 km westlich des Untersuchungspunktes liegt. Für den „Krücker“ wird darüber hinaus die Pflanzung von Eichen zur Verjüngung des Bestandes überliefert, die vor 1595 stattgefunden hat (siehe Kapitel 3.8.4, S. 41).

Der Einbruch des Getreideanbaus fällt vermutlich in die Zeit der spätmittelalterlichen Wüstungsperiode, die im 14. Jh. durch die Bevölkerungsverluste während der Pestwellen einsetzte und schließlich auch den Harzbergbau zurückgehen ließ.

Parallel zur nachlassenden Siedlungsintensität in der Sz 2c geht der Anteil technogener Elementgehalte kontinuierlich zurück (DEICKE 2003).

Am Übergang zu Sz 2d, zwischen 31-17 cm weisen deutlich erhöhte Silikat- und Dolomitgehalte auf eine Veränderung des Sedimentes in diesem Abschnitt hin. Möglicherweise wurde der natürliche Sedimentationsprozess durch einen Abraumeintrag aus dem benachbarten Steinbruch gestört. Die Pollenspektren aus $25 \mathrm{~cm}$ Tiefe lassen jedoch weder einen Hiatus noch den Eintrag alter Sedimente in den See erkennen. Da die liegenden Sedimente noch keine industriell erhöhten Schwermetallgehalte aufweisen, erfolgte der Eingriff vermutlich vorindustriell (DEICKE 2003).

\section{SZ 2d (17 - 0cm)}

1818 n.Chr.-heute (132-0 cal BP; 148-0 BP)

Dauer: $132 \mathrm{a}$; mittlere Sedimentationsrate: $8 \mathrm{a} / \mathrm{cm}$, mittlerer Probenabstand: $16 \mathrm{~cm}=128 \mathrm{a}$.

Sediment: Feindetritusmudde

Neuzeit.

Die SZ 2d wurde nur in einer Probe erfasst. Da sich jedoch deutliche Änderungen in den Pollenanteilen zeigen, scheint eine Abtrennung dieses einzelnen Spektrums als Zone gerechtfertigt zu sein.

Insgesamt läßt sich ein erneuter Anstieg der siedlungszeigenden Kurven feststellen. Die Werte der Nichtbaumpollensumme und der sekundären Siedlungszeiger erreichen dasselbe hohe Niveau wie in SZ 2b. Besonders die Werte der "Grünlandzeiger" Rumex und Plantago lanceolata steigen stark an. Gleichzeitig findet ein vergleichsweise schwacher Anstieg der Getreide-Summe statt.

Bemerkenswert ist der sprunghafte Anstieg der Picea-Kurve auf 15\%. Erstmals stockten Fichten im Untersuchungsgebiet. Die Quercus-Kurve fält auf $25 \%$ ab. Die Fagus- und die Carpinus-Werte steigen leicht an.

Ein erneuter Wechsel der Wirtschaftsform im Untersuchungsgebiet wird hier erkennbar: Die Waldweidewirtschaft, in deren Folge lange Zeit die Eichen gefördert wurden, wurde in der zweiten Hälfte des 19. Jhs. zugunsten einer Grünlandbewirtschaftung aufgegeben (siehe Kapitel 3.8.4, S. 40).

Darüber hinaus zeichnet sich erstmals die forstwirtschaftlich gezielte Vermehrung von Fichten durch Säen oder Anpflanzungen im Untersuchungsgebiet ab, die seit dem 17. Jh. im Harzraum betrieben wurde (siehe Kapitel 3.8.4, S. 48).

Die Gehalte sämtlicher Schwermetalle im Sediment steigen ab $23 \mathrm{~cm}$ kontinuierlich an, da seit dem Beginn der Industrialisierung ein zunehmender Eintrag industrieller Schadstoffe aus der Luft stattfand (DEICKE 2003). 


\subsubsection{Diskussion}

Die Ergebnisse zur Vegetations- und Siedlungsgeschichte des Pollendiagramms vom Aschenhütter Teich werden zunächst mit den pollenanalytischen Ergebnissen aus dem benachbarten Lüderholz (R 3590 300, H 5728 500) verglichen und anhand dieses Vergleiches diskutiert. Anschließend werden in Abbildung 16 die Ergebnisse zur Siedlungsgeschichte und zu den Verhüttungsvorgängen zusammenfassend dargestellt.

Der Name Lüderholz bezeichnet ein kleines bewaldetes Gebiet mit mehreren Erdfällen etwa $1 \mathrm{~km}$ östlich der Aschenhütte. Sedimente aus zwei dieser Erdfälle wurden 1982 von Chen im Rahmen ihrer Dissertation bearbeitet (CHEN 1982). Es handelt sich wie im Fall des Aschenhütter Teiches um kleine Ablagerungsstätten, in denen überwiegend der Pollen der lokalen Vegetation überliefert ist ${ }^{13}$ (vgl. BEHRE \& KUČAN 1986). Beide Profile wurden in gleicher Weise bearbeitet (Auszählung aller Proben auf mind. 500 Baumpollen, Berechnung als Prozentwert-Diagramm bezogen auf die Baumpollensumme), so dass ein detaillierter Vergleich der Ergebnisse möglich ist. Aufgrund der räumlichen Nähe des Lüderholzes zum Aschenhütter Teich können Abweichungen der Pollenanteile bspw. von siedlungszeigenden Taxa oder von Kulturpflanzen Aufschluss über die Lage der Felder oder Siedlungen geben. Die Anteile der regionalen Vegetation spiegeln an beiden Lokalitäten die Vegetationsgeschichte wider.

Die Ablagerungen am Lüderholz sind wesentlich älter als am Aschenhütter Teich. Sie ermöglichen daher eine genauere vegetationsgeschichtliche Einordnung des Sedimentationsbeginns am Aschenhütter Teich.

CHEN unterteilt die Pollenzone VIIla in einen älteren Teil mit Eichendominanz und einen jüngeren Teil, in der die Linde überwiegt. Der Beginn der Ablagerung im Aschenhütter Teich fällt aufgrund der niedrigeren Quercus-Werte in den jüngeren Abschnitt des Älteren Subboreals (Tab. 24). Die Werte der Tilia-Kurve schwanken dagegen stark und liegen insgesamt auf einem etwas geringeren Niveau als im Diagramm vom Lüderholz.

Nahezu identisch sind die Werte der ferntransportierten Baumpollentaxa Picea, Pinus und Abies beider Diagramme in PZ VIIla. Deutliche Abweichungen weisen dagegen die Fraxinusund die Ulmus-Kurven auf. Die Fraxinus-Kurve im Diagramm vom Aschenhütter Teich fällt ausgehend von Werten $>10 \%$ in PZ VIlla langsam ab. Erst mit Beginn der PZ X bleibt sie dauerhaft auf einem Niveau unter 1\%. Am Lüderholz dagegen erreicht die Fraxinus-Kurve maximal 5\% (in PZ VII). Die Kurve fällt bereits am Ende der Zone VIIla auf Werte unter 1\% ab und setzt teilweise ganz aus. Die Ulmus-Kurve fällt im Diagramm vom Lüderholz am Beginn der PZ VIIla dauerhaft auf Werte unter 5\% ab, während sie im Diagramm vom Aschenhütter Teich im selben Abschnitt zunächst ansteigt und Werte $>10 \%$ erreicht.

Tabelle 24: Vergleich ausgewählter Pollenspektren der PZ VIIla aus den Diagrammen vom Aschenhütter Teich und vom Lüderholz (CHEN 1982). Dargestellt sind die Minimal- und die Maximal-Werte bezogen auf die BPSumme, einmalige Extremwerte stehen in Klammern.

\begin{tabular}{|c|c|c|c|c|c|c|c|}
\hline BP-Prozentwerte & PZ VIIla & Picea & Quercus & Tilia & Ulmus & Fraxinus & $\Sigma$ Getreide-Typ \\
\hline Aschenhütter Teich & VIIla & $0,4-6,9$ & $21,5-38,7$ & $4,3-30,4$ & $5,5-14,4$ & $3,6-13,4(29,4)$ & 0,1 \\
\hline \multirow{2}{*}{ Lüderholz } & jünger & bis 7 & $<30$ & $>40$ & $<5$ & $<1$ & bis 1,4 \\
\cline { 2 - 8 } & älter & & $>40$ & $<30$ & & & \\
\hline
\end{tabular}

\footnotetext{
${ }^{13}$ Die Erdfälle am Lüderholz sind unmittelbar benachbart. Die beiden Pollendiagramme werden nach Chen (1982) daher gemeinsam ausgewertet und im folgenden Text als Pollendiagramm „Lüderholz“ bezeichnet.
} 
Während der PZ VIIla treten im Diagramm vom Aschenhütter Teich nur in drei Proben Pollenkörner des Getreide-Typs auf. Im Diagramm vom Lüderholz dagegen fand Chen (1982) „in fast allen Proben“ Pollenkörner des Triticum- und Hordeum-Typs. Die Kurve ist zwar nicht geschlossen, es werden jedoch Werte bis zu 1,4\% erreicht. Die GetreidePollenkörner stammen vermutlich von nahegelegenen Äckern, da im nur etwa $1 \mathrm{~km}$ entfernten Aschenhütter Teich entsprechnede Befunde fehlen. Das Lüderholz gehörte daher wahrscheinlich zum Nutzungsbereich der neolithischen Ackerbauern. Sowohl Ulmen als auch Eschen waren während des Subboreals als Arten der Eichenmischwälder Teil der vorherrschenden Waldgesellschaften. Darüber hinaus hatten sie entsprechend ihrer rezenten Verbreitung Standorte im Randbereich der vernässten Erdfallsenken. Die Werte des Diagramms vom Aschenhütter Teich sind den Ergebnissen der Pollenanlysen aus dem Jues-See in Herzberg am Harz sehr ähnlich (HERKING 1998; VOIGT 2003). Dieser 4 km südöstlich des Aschenhütter Teiches gelegene See besitzt eine relativ grosse Wasserfläche $\left(78.800 \mathrm{~m}^{2}\right)$ und reflektiert daher zu einem grösseren Teil den regionalen Pollenflug.

Im Bereich des Lüderholzes kam es dagegen zu einer lokal abweichenden Entwicklung der Vegetation, die sich in den Pollenspektren spiegelt. Möglicherweise wurden die Eschen- und Ulmenbestände am Lüderholz anthropogen zurückgedrängt. Denkbar ist eine Schneitelung der Taxa zur Laubfuttergewinnung, wie es seit dem Neolithikum nachgewiesen werden konnte (LANG 1994 und dort zitierte Autoren).

Das Diagramm vom Lüderholz weist nach CHEN (1982) eine Schichtlücke im Bereich der PZ VIIIb/IX auf. Die anschliessende Zone Xa beginnt mit sehr hohen Quercus-Werten (>60\%), die Fagus- und Carpinus-Kurven erreichen dagegen maximal 15\% (Tab. 25). Mit 5\% ist der Anteil der Getreide-Typ Pollenkörner sehr gering. Die Pollenspektren der Zone Xa vom Lüderholz entsprechen damit den Pollenanteilen der spätmittelalterlich-frühneuzeitlichen Siedlungszeit 2c am Aschenhütter Teich. Die Schichtlücke im Diagramm vom Lüderholz umfasst demnach mindestens die PZ VIIIb-IXa-IXb und Teile der PZ X. Sie ist damit wesentlich umfangreicher als von CHEN (1982) ursprünglich angenommen wurde.

Tabelle 25: Vergleich ausgewählter Pollenspektren der PZ X aus den Diagrammen vom Aschenhütter Teich und vom Lüderholz (CHEN 1982). Dargestellt sind die Minimal- und die Maximal-Werte bezogen auf die BP-Summe.

\begin{tabular}{|c|c|c|c|c|c|c|}
\hline BP-Prozentwerte & PZ X & Picea & Fagus & Carpinus & Quercus & $\Sigma$ Getreide-Typ \\
\hline \multirow{4}{*}{ Aschenhütter Teich } & 2d & 15 & 20,8 & 8,1 & 25,1 & 17,3 \\
\cline { 2 - 7 } & 2c & $1,5-4,3$ & $14,8-34$ & $5-14,8$ & $58,1-15,7$ & $6,8-17,1$ \\
\cline { 2 - 7 } & 2b & $0,2-3,7$ & $25,3-38,1$ & $7,1-25,4$ & $9,3-19,4$ & $6,9-39,5$ \\
\cline { 2 - 7 } & 2a & $0,2-2,2$ & $26,7-55,3$ & $14,2-35,8$ & $3,8-10,3$ & $1,2-3,6$ \\
\hline \multirow{2}{*}{ Lüderholz } & $\mathrm{Xb}$ & $<60$ & $<20$ & $<5$ & $5-50$ & $5-13$ \\
\cline { 2 - 7 } & $\mathrm{Xa}$ & $<5$ & 10 & $<10$ & $<70$ & $1,6-5$ \\
\hline
\end{tabular}

Die im Lüderholz-Diagramm anschließend ausgewiesene PZ Xb wird von Picea-Werten über $50 \%$ charakterisiert und datiert damit in die Neuzeit. Vermutlich wird im Pollendiagramm das Vorkommen von Fichten im geschonten Eichenmastholz des Herzberger Landholzes Lüderholz reflektiert, das für die Zeit von 1596-1732 schriftlich überliefert ist (vgl. Tab. 9). Im Diagramm vom Aschenhütter Teich erreicht die Picea-Kurve lediglich $15 \%$ im jüngsten Spektrum. Vermutlich wurde nur der Beginn der neuzeitlichen Siedlungsphase erfasst. Die Datierung des Beginns der Siedlungszeit 2d auf $1818 \mathrm{n}$. Chr. erscheint daher um mindestens 100 Jahre zu jung. Die Datierung liegt im Minimumbereich der Radiokarbon-DatierungsMethode (LANG 1994) und kann damit eine größere Abweichung aufweisen. 
Die sehr hohen Quercus-Werte in den Abschnitten 2c und Xa der Diagramme vom Aschenhütter Teich und vom Lüderholz (Tab. 25) reflektieren einen Polleneintrag aus den anthropogen geförderten Eichenhudewälder, die aus schriftlichen Quellen bekannt sind (siehe Kapitel 3.8.4). Das Gebiet Lüderholz selbst wurde zwischen 1596-1732 als "geschontes Eichenmastholz ohne Unterwuchs" beschrieben, in dem auch Fichten vorkamen (SCHUBART 1978). Für den Beginn des starken Eichenanstiegs (Sz 2c) im Diagramm vom Aschenhütter Teich konnte ein interpoliertes Alter von $1196+/-47,5 \mathrm{n}$. Chr. errechnet werden. Die Nutzung des Lüderholzes als Eichenhudewald hat daher sehr wahrscheinlich spätestens im 13. Jh. begonnen.

Tabelle 26: Die Intensität der Siedlungszeiten im Diagramm vom Aschenhütter Teich (Mittlere Baumpollenprozentwerte, $x=$ Präsenz)

\begin{tabular}{|c|c|c|c|c|c|c|c|c|c|c|c|c|c|c|c|c|c|c|}
\hline$\frac{N}{N}$ & $\begin{array}{l}\frac{0}{7} \\
\frac{0}{0} \\
\stackrel{0}{2} \\
0\end{array}$ & $\begin{array}{l}\stackrel{\infty}{\vec{D}} \\
\stackrel{\mathbb{D}}{\mathscr{W}}\end{array}$ & 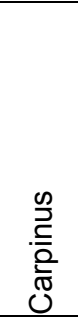 & $\begin{array}{l}0 \\
\mathbb{D} \\
\mathbb{d} \\
0 \\
0 \\
0 \\
0\end{array}$ & 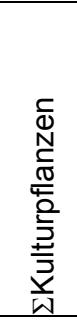 & 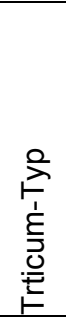 & $\begin{array}{l}\stackrel{2}{7} \\
\frac{1}{\pi} \\
\frac{1}{0} \\
\frac{1}{2} \\
\frac{1}{2}\end{array}$ & 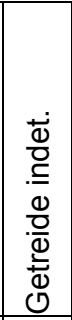 & $\begin{array}{l}\stackrel{2}{7} \\
\stackrel{1}{1} \\
\frac{1}{2} \\
\frac{0}{0} \\
\frac{0}{0} \\
\text { 운 }\end{array}$ & $\begin{array}{l}\frac{0}{\mathbb{N}} \\
\text { D } \\
\text { ஸ }\end{array}$ & 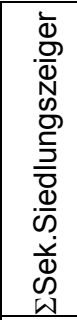 & $\begin{array}{l}\frac{\pi}{\pi} \\
\frac{\pi}{0} \\
0 \\
0 \\
\frac{1}{\pi} \\
\frac{\pi}{0} \\
\frac{\pi}{\pi} \\
\frac{\pi}{0} \\
\frac{\pi}{0}\end{array}$ & 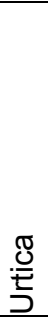 & 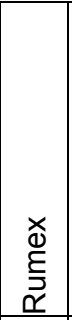 & 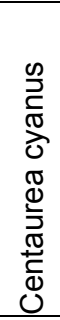 & $\begin{array}{c}\mathbb{0} \\
\stackrel{5}{5} \\
\overline{\bar{N}} \\
\mathcal{O} \\
\end{array}$ & 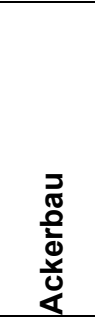 & 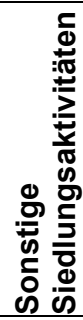 \\
\hline $2 d$ & 25,1 & 20,8 & 8,1 & 43,3 & 17,3 & & 0,7 & 2,3 & 6,8 & 7,5 & 14,3 & 3,6 & & 7,2 & & 0,7 & $(+)++$ & +++ \\
\hline $2 c$ & 41,1 & 20,7 & 10,1 & 13,7 & 13,1 & 0,5 & 0,1 & 0,9 & 3,8 & 7,7 & 4,6 & 1,6 & & 1,3 & & 0,6 & $(+)++$ & +++ \\
\hline $2 b$ & 14,7 & 30,1 & 13,4 & 25,6 & 22,5 & 2,2 & 0,2 & 2,4 & 6,1 & 11,6 & 12,3 & 2,7 & $x$ & 6,4 & 0,2 & 1,6 & +++ & +++ \\
\hline $2 a$ & 6,2 & 43,5 & 27,5 & 4,1 & 2,5 & 0,4 & $x$ & 0,1 & 0,4 & 1,5 & 2,6 & 0,5 & $x$ & 1,1 & $x$ & 0,4 & ++ & + \\
\hline $\mathbf{I X b}$ & 5,4 & 39,9 & 23,5 & 1,4 & 0,1 & & $x$ & & $x$ & $x$ & 0,7 & 0,2 & & 0,1 & & 0,2 & $(+)$ & - \\
\hline $1 b$ & 11,5 & 35,6 & 1,3 & 6,7 & 0,2 & 0,1 & & & 0,1 & & 2,8 & 1,1 & $x$ & 0,5 & & 0,1 & $(+)+$ & + \\
\hline $1 a$ & 16,9 & 8,6 & 0,5 & 2,5 & 0,1 & $x$ & & $x$ & $x$ & & 1,8 & 0,6 & $x$ & 0,2 & & 0,3 & + & + \\
\hline VIIIa & 29,6 & 2,4 & 0,1 & 1,3 & $x$ & $x$ & & & & & 1,0 & 0,2 & & 0,1 & & 0,1 & - & - \\
\hline
\end{tabular}

In Tabelle 26 wurde die Intensität der Siedlungszeiten im Diagramm vom Aschenhütter Teich bewertet (siehe auch Abb. 16). Während des Neolithikums (VIIIa) kann keine Siedlungsaktivität festgestellt werden, obwohl zeitgleich Getreide-Werte bis zu 1,4\% im Diagramm vom Lüderholz auftreten (siehe oben). Sowohl die bronzezeitliche Besiedlung (1a) als auch die anschließenden eisenzeitlichen Siedlungsaktivitäten (1b) sind von sehr geringer Intensität. Es lässt sich jedoch in der Siedlungszeit $1 \mathrm{~b}$ eine leichte Zunahme der Kulturpflanzen-Summe und einiger sekundärer Siedlungszeiger feststellen. Die Intensität der Siedlungsaktivitäten nahm in der Eisenzeit leicht zu. Während der Römischen Kaiserzeit (Ende 1b) wurde erstmals in der Nähe des Aschenhütter Teiches Verhüttung betrieben. Die Siedlungsaktivitäten während der folgenden siedlungsarmen Zeit (IXb) entsprechen den niedrigen Werten während des Neolithikums. Das gelegentliche Auftreten einzelner KulturpflanzenPollenkörner ist der einzige Hinweis auf menschliches Wirtschaften. Ein Einfluss aus der archäologisch bekannten Siedlung Düna, die in nur 1,5 km Entfernung vom Aschenhütter Teich liegt, lässt sich pollenanalytisch nicht nachweisen. 


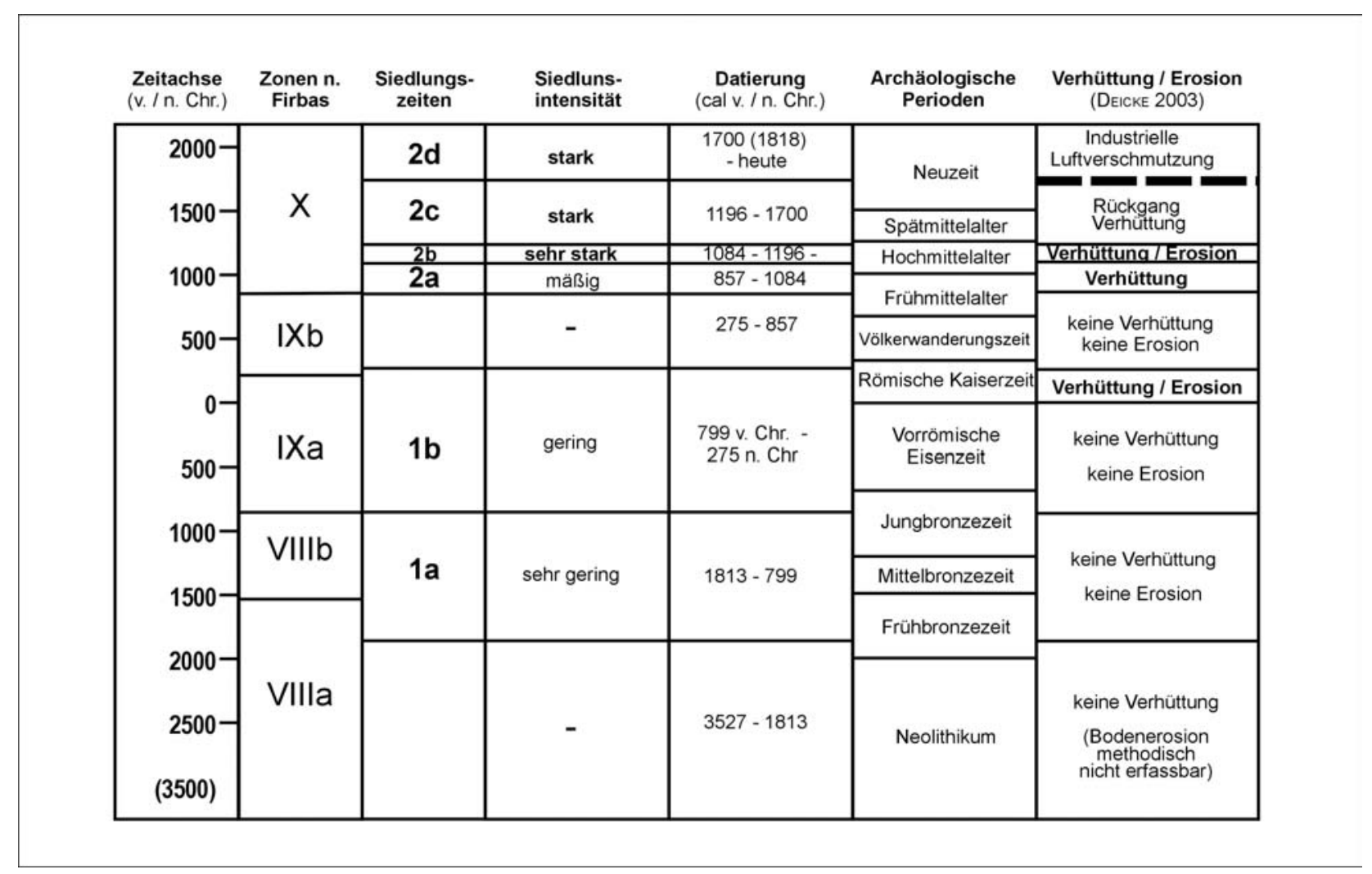

Abbildung 16: Die Intensität und Datierung der Siedlungszeiten, zeitgleiche Verhüttungsaktivitäten sowie Bodenerosion im Diagramm vom Aschenhütter Teich (Altersangaben in Kalenderjahren).

Die mittelalterlichen und neuzeitlichen Siedlungszeiten (2a-d) zeichnen sich im Diagramm vom Aschenhütter Teich durch eine hohe Intensität aus. Erstmals wird der Anbau von Getreide im Pollendiagramm stark reflektiert. Die Rodungsaktivität ist eng mit den Verhüttungsaktivitäten verknüpft und stieg erst mit Beginn des Hochmittelalters (2b) sehr stark an. In diesem Zeitraum wurde das erste mittelalterliche Verhüttungsmaximum festgestellt. Während des Hochmittelalters stiegen die Siedlungs- und die Verhüttungsintensität in der Umgebung des Aschenhütter Teiches auf höchste Werte an. Infolgedessen kommt es zu Bodenversauerung und -erosion. Während des Spätmittelalters und der Frühen Neuzeit wurden die Siedlungsaktivitäten dagegen extensiver. Die Intensität des Ackerbaus ging zurück und Eichen(hude)wälder wurden pollenanalytisch sichtbar. Im neuzeitlichen Abschnitt der Siedlungszeit (2d) wurde die Nutzung von Grünland erkennbar, die Eichenwälder gingen zurück.

Die Ergebnisse zur Siedlungsintensität sowie zu Verhüttungs- und Bodenerosionsvorgängen am Aschenhütter Teich sind in Abbildung 16 zusammenfassend dargestellt. 


\subsection{Wittgerode}

(R 3604 550, H 5716 700)

Die Erdfallsenke Wittgerode liegt etwa $2 \mathrm{~km}$ südsüdwestlich der Ortschaft Steina im Landkreis Osterode/Harz auf einer Höhe von 285 m ü. NN.

Der vermoorte Bereich, bei dem es sich um zwei ineinander übergehende Vermoorungen handelt, die in der Aufsicht die Form einer Acht beschreiben, ist etwa $200 \mathrm{~m}$ lang und bis zu $50 \mathrm{~m}$ breit.

Der Quellhorizont der Vermoorung befindet sich vermutlich im westlichen Teil der Erdfallsenke. Ein überirdischer Zulauf existiert nicht. Entwässert wird die Senke über einen Graben in östlicher Richtung zum Steina-Bach.

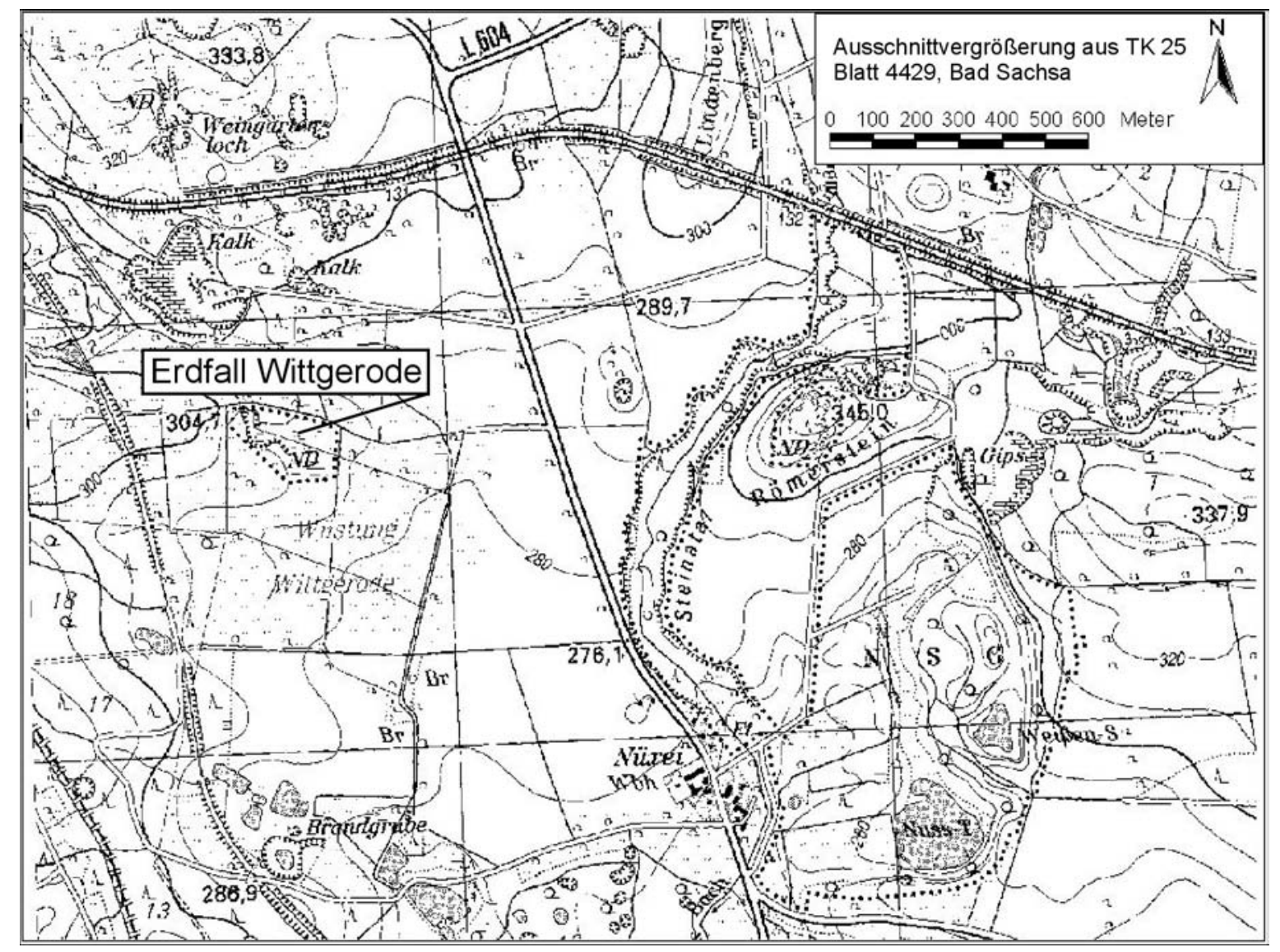

Abbildung 17: Lage der vermoorten Erdfallsenke Wittgerode (TK 25, Blatt 4429, Bad Sachsa)

Geologisch gesehen befindet sich der Erdfall in Sedimentgesteinen des Unteren Buntsandstein, der hier den liegenden Zechstein mit einer nur geringen Mächtigkeit überlagert. Bereits $200 \mathrm{~m}$ in nördlicher bzw. $100 \mathrm{~m}$ in südwestlicher Richtung stehen Zechsteindolomite an. Während die von Dolinen geprägte Umgebung der Senke als Grünland genutzt wird, befinden sich Äcker auf der östlich angrenzenden Schotterflur, die ein Teil der weichselzeitlichen Niederterrasse des Steina-Baches ist (Deicke 2003).

Die vermoorte Erdfallsenke Wittgerode ist als Naturdenkmal geschützt. 


\subsubsection{Material und Methoden}

\section{Geländearbeit}

Voruntersuchungen hatten erkennen lassen, dass die vermoorte Senke bei Wittgerode günstige Bedingungen für geochemische Untersuchungen bot. Der pH-Wert des Oberflächenwassers lag bei 6,3 und zeigte damit annähernd neutrale Bedingungen an. Bei einer ersten Bohrung im Jahre 1999 wurde eine Torfmächtigkeit von $500 \mathrm{~cm}$ festgestellt. Aus diesen Kernen (Wg 1/2 \& 3/4) entnommene Übersichtsproben ließen eine ausreichende Pollenführung und -erhaltung erwarten. Am 23.03.2000 wurde die Lokalität Wittgerode bei Bad Sachsa erneut mit Hilfe des projekteigenen russischen Kammerbohrers erbohrt. Diese Bohrung (Wg 5/6) erbrachte einen Kern von insgesamt $635 \mathrm{~cm}$ Länge. Die Bohrung wurde im Zentrum der Vermoorung etwa $5 \mathrm{~m}$ von der ersten Bohrstelle entfernt niedergebracht. Es wurde überlappend gebohrt, wobei die Bohrlöcher in etwa $80 \mathrm{~cm}$ Abstand zueinander lagen. Die Aufbewahrung der luftdicht in PVC-Halbschalen verpackten Kernstücke erfolgte liegend im Kühlraum des Instituts für Geologie und Dynamik der Lithosphäre (Universität Göttingen).

Tabelle 27: Bohrprotokoll des Kerns von Wittgerode

\begin{tabular}{|c|c|c|}
\hline & \multicolumn{2}{|c|}{\begin{tabular}{|l|l|} 
Bohrloch 5 & Bohrloch 6 \\
\end{tabular}} \\
\hline & a & b \\
\hline \multirow[t]{7}{*}{ Bohrtiefe (cm) } & $0-50$ & $45-95$ \\
\hline & $90-140$ & $135-185$ \\
\hline & $180-230$ & $225-275$ \\
\hline & $270-320$ & $315-365$ \\
\hline & $360-410$ & $405-455$ \\
\hline & $450-500$ & $495-545$ \\
\hline & $540-590$ & $585-635$ \\
\hline
\end{tabular}

\section{Pollenanalysen}

\section{Probennahme}

Die gefrorenen Halbkerne wurden mit einer handelsüblichen Handsäge in $1 \mathrm{~cm}$ dicke Scheiben zerteilt. Aus der Mitte jeder dieser Scheiben wurde anschließend mit einem skalierten Probenstecher Material für die Pollenanalyse entnommen. Mit Hilfe dieser Skalierung wurde das genaue Volumen der Probe bestimmt und notiert. Das restliche Material wurde für die geochemischen Analysen gesichert. Auf diese Weise konnte die pollenanalytische und geochemische Untersuchung direkt benachbarter Proben eines Kerns sichergestellt werden.

\section{Laborarbeiten \& Datenerhebung}

Die chemische Aufbereitung der Proben aus dem Profil von Wittgerode erfolgte nach der für das Material aus dem Aschenhütter Teich beschriebenen Methode (siehe Kapitel 4.1.1).

Aus dem Kern von Wittgerode wurden 36 Proben pollenanalytisch ausgewertet. Je Probe wurden mindestens 500 bzw. 1000 Baumpollenkörner ausgezählt. In einigen Proben konnte diese Zahl jedoch nicht erreicht werden, da wegen der schlechten Pollenerhaltung bzw. geringen Pollenkonzentration ein höheres Auszählen mit einem unverhältnismäßig hohen Zeitaufwand verbunden gewesen wäre.

Die Daten wurden ebenfalls nach der bereits für den Aschenhütter Teich beschriebenen Vorgehensweise ermittelt (siehe Kapitel 4.1.1). 


\section{Auswertung und Darstellung}

Die Aufnahme der Rohdaten, die Berechnungen und die graphische Umsetzung der Daten erfolgte auf die in Kapitel 4.1.1 beschriebene Weise. Die Ergebnisse der Pollenanalyse sind als Schattenrisskurven in einem Prozentwertediagramm dargestellt, dessen Grundsumme die Baumpollensumme ist (Abb. 18, Beilage).

Die Summenkurven fassen die Werte folgender Taxa zusammen:

- Eichenmischwald-Summe: Acer, Fraxinus, Quercus, Tilia cordata-Typ, Tilia platyphyllos-Typ, Ulmus.

- Baumpollen-Summe / Bäume: Abies, Acer, Alnus, Betula, Carpinus, Fagus, Fraxinus, Picea, Pinus, Quercus, Salix, Tilia cordata-Typ, Tilia platyphyllos-Typ, Ulmus.

- Sträucher: Viburnum-Typ.

- Nichtbaumpollen-Summe / Krautige Pflanzen: Alle Landpflanzenpollen-Typen, ausser Corylus und den oben genannten Baumpollen-Typen

- $\quad$ Sek. Siedlungszeiger-Summe: Alchemilla-Typ, Artemisia, Brassicaceae, Centaurea cyanus, Chenopodiaceae, Fabaceae, Plantago lanceolata, Plantago major/mediaTyp, Polygonum aviculare, Polygonum convolvulus-Typ, Pteridium, Rumex, Scleranthus, Urtica.

- Kulturpflanzen-Summe: Getreide indet., Fagopyrum esculentum, Hordeum-Typ, Secale, Triticum-Typ.

- Wasserpflanzen-Summe: Eupotamogeton, Myriophyllum spicatum-Typ, Utricularia.

Taxa mit sehr geringen Werten und/oder seltenem Auftreten sind nicht graphisch im Pollendiagramm dargestellt. Eine Liste mit den Werten dieser Taxa befindet sich im Anhang in Tabelle 48.

\subsubsection{Ergebnisse}

\section{Stratigraphie}

Tabelle 28 enthält die Stratigraphie des Kerns von Wittgerode sowie die wichtigsten Ergebnisse der geochemischen Analysen von M. Deicke (Deicke 2003). Der Kern setzt sich aus Torfen und anorganischen Lagen zusammen. Die Konnektierung der Teilkerne erfolgte weitgehend auf Basis der geochemischen Analysenergebnisse.

Tabelle 28: Stratigraphie des Kerns von Wittgerode

\begin{tabular}{|c|c|c|}
\hline & Stratigraphie & $\begin{array}{c}\text { Ergebnisse der geochemischen Analysen } \\
\text { (DEICKE 2003) }\end{array}$ \\
\hline $\begin{array}{l}0-15 \\
15-33 \\
33-50\end{array}$ & $\begin{array}{l}\text { schwach zersetzter Torf } \\
\text { Schlufflage / grau } \\
\text { stark zersetzter Torf / dunkelbraun }\end{array}$ & $\begin{array}{l}\text { 16-67 cm: deutliche Schwermetallanreicherung (Blei) } \\
\text { - Max: bei } 40-60 \mathrm{~cm} \\
\text { 16-55 cm: } 10-20 \% \text { ige Anteile schluffigen Materials, } \\
\text { vermutlich äolischer Eintrag } \\
20-31 \mathrm{~cm} \text { : hohe Anteile schluffigen Materials (Bunt- } \\
\text { sandstein) }\end{array}$ \\
\hline $\begin{array}{l}45-60 \\
60-68\end{array}$ & $\begin{array}{l}\text { stark zersetzter Torf / dunkelbraun } \\
\text { schwach zersetzter Torf / etwas heller }\end{array}$ & $\begin{array}{l}\text { 40-60 cm: Max. Schwermetalleinträge (Blei) siehe } \\
\text { oben }\end{array}$ \\
\hline $68-95$ & stark zersetzter Torf / dunkelbraun & $56-92 \mathrm{~cm}$ : Anreicherung von Kupfer (gering) \\
\hline$(81-82$ & Holz) & \\
\hline $90-99$ & mittelmäßig zersetzter Torf / & \\
\hline
\end{tabular}




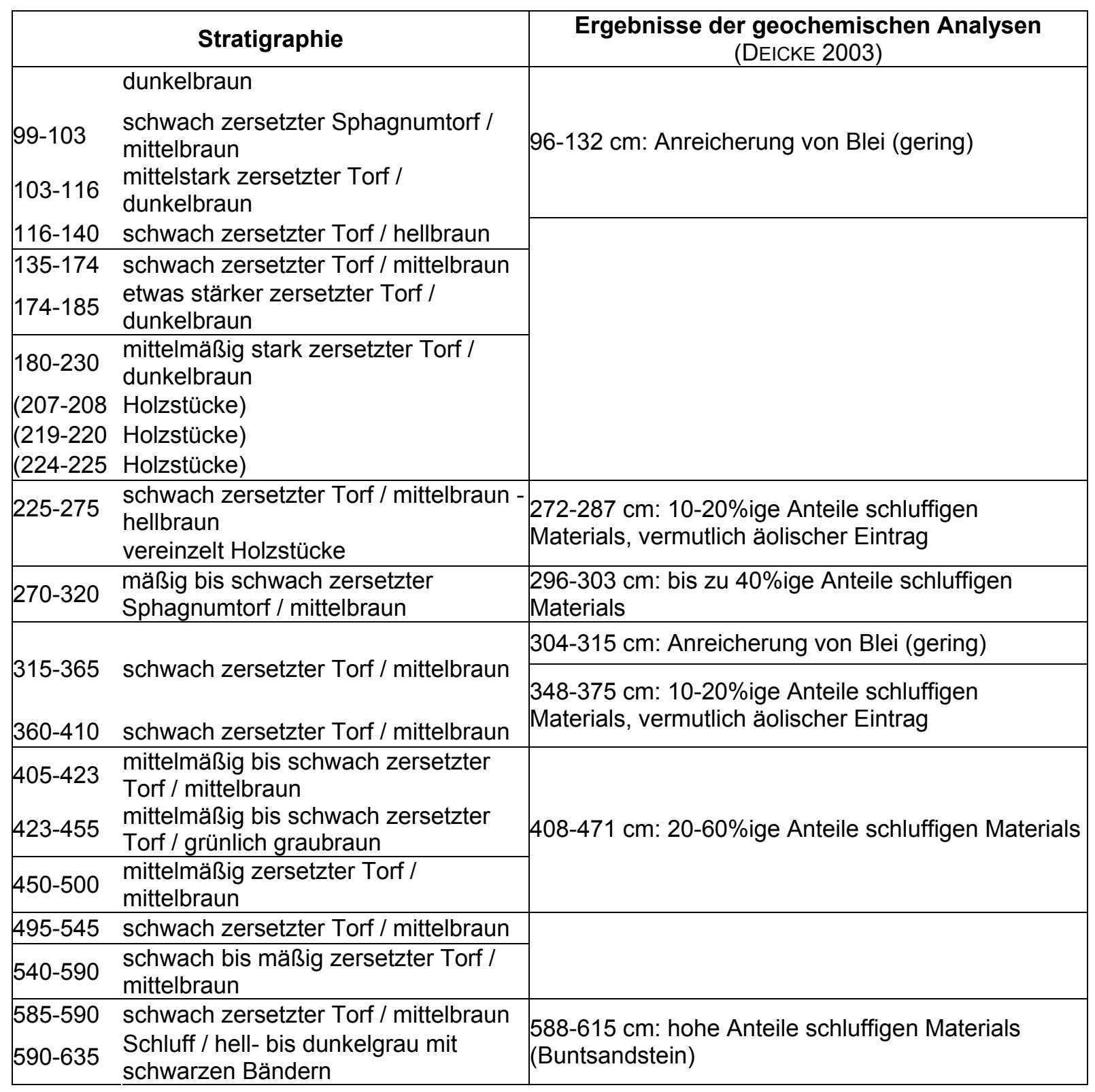

Die Anreicherung technogener Schwermetalle beschränkt sich im Kern von Wittgerode auf Blei. Darüber hinaus treten Anreicherungen von Kupfer auf, die sich jedoch nicht mit den Blei-Einträgen korrelieren lassen. Mit Ausnahme des Blei-Maximums zwischen $40-60 \mathrm{~cm}$ Tiefe zeigen alle anderen Anreicherungen vermutlich lediglich Verhüttungsvorgänge in größerer Entfernung vom Ablagerungsort im Erdfall von Wittgerode an (DEICKE 2003). 


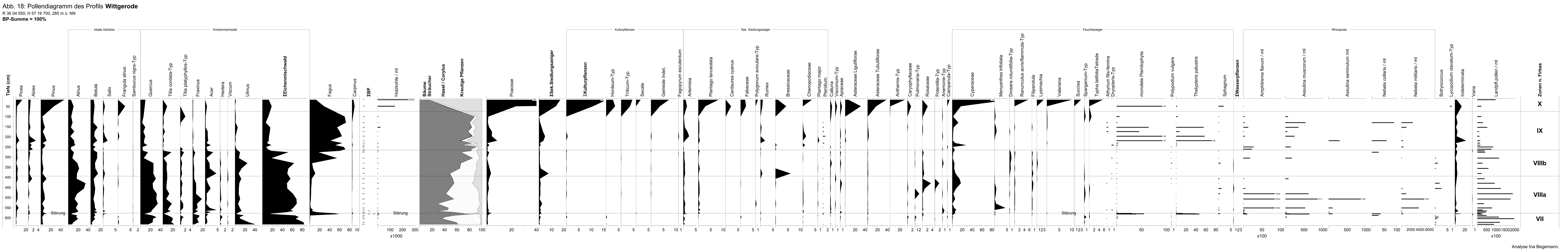




\title{
Diagrammbeschreibung und Auswertung
}

\author{
Liste der im Text beschriebenen Abbildung und der Tabellen: \\ Abbildung 18: $\quad$ Pollendiagramm des Profils von Wittgerode (BP-Summe $=100 \%$ ), Beilage \\ Tabelle 48: \\ Tabelle 32: \\ Zählwerte selten auftretender Taxa, Anhang \\ Pollenkonzentrations-Werte im Diagramm von Wittgerode (Pk/ml), S. 89
}

Die in Tabelle 23 genannten Grenzkriterien nach BEUG (1992) wurden ebenfalls zur Zonierung des Pollendiagramms von Wittgerode herangezogen. Da im folgenden Diagramm das Kriterium für die Zonengrenze IXa/IXb, der Anstieg der Carpinus-Werte nicht erfüllt wird, musste auf die Unterteilung der Zone IX verzichtet werden. Im Bereich der Zonen IXb - X besteht ein Hiatus (siehe Kapitel 4.2.3).

Der Beschreibung und Auswertung der Zonen des Pollendiagramms wird für das Diagramm von Wittgerode kein Datenkopf vorangestellt, da keine ${ }^{14} \mathrm{C}$-Datierungen vorliegen. Eine vergleichende Datierung der Diagrammabschnitte wird im darauf folgenden Unterkapitel zur Datierung vorgenommen. Da es im Diagramm von Wittgerode ungewöhnlich geringe Anzeichen für Siedlungsaktivitäten gibt, wird der Bezug zur Siedlungsgeschichte abweichend von der bisherigen Praxis dieser Arbeit hauptsächlich im Anschluss an die Auswertung diskutiert (siehe Kapitel 4.2.3, S. 87).

\section{Jüngeres Atlantikum VII}

VII $(635-577 \mathrm{~cm}=58 \mathrm{~cm})$

Die Fagus-Werte liegen in den tiefsten Proben unter 1\%. Die Dominanz des Eichenmischwaldes ist mit Werten der Summenkurve bei $80 \%$ deutlich. Die Anteile dieser Arten gehen jedoch zurück, wobei insbesondere die Ulmus-Werte rückläufig sind. Demnach gehört dieser Diagrammabschnitt nicht mehr der Zone VI sondern bereits der Zone VII an.

Der Grenzbereich zwischen den Diagrammabschnitten VII und VIIIa $(572-581 \mathrm{~cm})$ weist sehr ungewöhnliche Werte verschiedener Taxa auf (Fagus, Carpinus, Quercus), die mit großer Wahrscheinlichkeit durch eine Verlagerung von jüngeren Sedimentabschnitten hervorgerufen wurden (siehe Kapitel 4.2.3, S. 87). Da auch die Fagus-Kurve betroffen ist, konnte keine exakte Grenztiefe für die Überschreitung der 1\%-Marke ermittelt werden (vgl. Tab. 23). Angegeben ist daher der mittlere Abstand zwischen den nächsten ungestörten Proben (566 \& $588 \mathrm{~cm})$.

In der Tiefe $596 \mathrm{~cm}$ wurde ein Pollenkorn von Vitis nachgewiesen. Pollenanalytische Nachweise der Wild-Rebe sind sehr selten. Vitis sylvestris gilt heute als seltene Art der EichenUlmen-Auwälder (OBERDORFER 1994). Während des Klima-Optimums im Atlantikum (PZ VI \& VII) war die heute als submediterran beschriebene Rebe vermutlich eine begleitende Art in den relativ lichten Eichenmischwäldern in der Umgebung des Erdfalls Wittgerode. Standorte in Auwäldern gab es vor der anthropogen bedingten Auelehmablagerung kaum.

In einer Tiefe von 588-615 cm wurde mit Hilfe geochemischer Methoden eine Schüttung von Material der Buntsandsteinformation lokalisiert. 


\section{Subboreal VIII}

\section{VIIla (577-394 cm)}

Mit Beginn des Abschnitts VIIla erreicht die Fagus-Kurve Werte, die deutlich über $1 \%$ liegen. Die Rotbuche war im Gebiet anwesend. Die Anteile der Eichenmischwaldarten im Pollendiagramm sind jedoch weiterhin sehr hoch. Vermutlich stockten im Untersuchungsgebiet lichte Eichenmischwälder mit hohen Anteilen der Winterlinde (Tilia cordata) und der Hasel. Die Fagus-Anteile nehmen im Diagramm zu. Es erfolgte eine langsame Ausbreitung der Rotbuche in den Wäldern. Zeitgleich verringern sich die Prozentwerte der Eichenmischwaldarten und der Hasel. In diesem Abschnitt des Pollendiagramms beginnt die geschlossene Carpinus-Kurve.

Es gibt im gesamten Diagrammabschnitt keine Hinweise auf neolithische Siedlungsaktivitäten. Nur vereinzelt treten Pollenkörner des Getreide-Typs auf. Die Anwesenheit des Menschen in der Region wird jedoch durch die geschlossene Kurve von Plantago lanceolata belegt.

\section{VIIIb $(394-265 \mathrm{~cm})$}

Die Fagus-Kurve überschreitet die 5\%-Marke und steigt anschließend verzögert an. Die Massenausbreitung der Rotbuche ist erkennbar. Gleichzeitig gehen die Werte des Eichenmischwaldes und der Hasel weiter zurück.

Auch in diesem Abschnitt läßt sich nur ein schwacher menschlicher Einfluss erkennen. Die Funde von Pollenkörnern des Getreide-Typs sind vereinzelt und die Anteile der sekundären Siedlungszeiger und des Nichtbaumpollens sind gering. Der Anstieg der sekundären Siedlungszeiger-Kurve zu Beginn der Pollenzone auf Werte über $5 \%$ wird hauptsächlich durch die erhöhten Werte der Brassicacaeen-Kurve verursacht. Eine bronzezeitliche Siedlungsphase lässt sich daher im Diagramm von Wittgerode nicht ausweisen.

In diesem Abschnitt liegt zwischen 315-304 cm die älteste technogene Schwermetallanomalie, die sich als reine Blei-Anreicherung abzeichnet. Aufgrund der geringen Konzentrationen handelt es sich vermutlich um den Niederschlag einer Verhüttung in größerer Entfernung vom Erdfall (DEICKE 2003).

\section{Älteres Subatlantikum IX}

\section{IX (265-85,5 cm)}

Die Fagus-Kurve erreicht maximale Werte und verläuft anschließend unter Schwankungen auf sehr hohem Niveau (etwa 60\%). Im Untersuchungsgebiet stockte ein rotbuchendominierter Wald. Die Kurven der Eichenmischwaldarten und der Hasel zeigen am Übergang VIIIb/IX einen markanten Rückgang. Sie überschreiten im folgenden Diagrammteil die $20 \%$ Marke nicht mehr. Die Carpinus-Werte sind im gesamten Abschnitt gering $(<5 \%)$. Eine Ausbreitung der Hainbuche ist nicht feststellbar.

Die Anteile der sekundären Siedlungszeiger und des Nichtbaumpollens steigen an. Es treten jedoch kaum Pollenkörner des Getreide-Typs auf (vgl. Tab. 33). Im Diagramm zeichnet sich damit eine Zunahme des menschlichen Einflusses ab. Es finden sich jedoch weiterhin keine Hinweise auf Besiedlung oder Ackerbau in der Nähe des Untersuchungspunktes.

Der hohe Baumpollenanteil, vor allem die hohen Fagus-Werte und die sehr geringen Poaceae-Werte, weisen vielmehr auf einen geschlossenen und relativ dunklen Buchenwald in der Umgebung des Erdfalls Wittgerode hin.

Ungewöhnlich ist der fehlende Anstieg der Carpinus-Kurve. 
Im Bereich der PZ IXa - IXb - X konnte ein Hiatus wahrscheinlich gemacht werden (siehe Kapitel 4.2.3).

In einer Tiefe von 132-96 cm wurde eine Blei-Anreicherung nachgewiesen. Die Konzentration des Schwermetalls im Torf ist jedoch derart gering, dass eine Verhüttung in der Nähe des Erdfalls sehr unwahrscheinlich ist (DEICKE 2003).

\section{Jüngeres Subatlantikum X}

\section{$X(85,5-0 \mathrm{~cm})$}

Die Fagus-Kurve fällt infolge von Rodungen deutlich ab, während die Carpinus-Werte leicht ansteigen. Die Kurven von Pinus und Picea steigen stark an. Möglicherweise sind die Anteile dieser beiden großen Pollen-Typen durch die in diesem Abschnitt besonders schlechte Pollenerhaltung überhöht. Sie sind im Gegensatz zu anderen Pollen-Typen auch bei schlechter Erhaltung und als Bruchstücke noch gut bestimmbar. Alle anderen BaumpollenKurven reagieren dagegen kaum oder fallen leicht ab.

Die Getreide-Kurve steigt in diesem Abschnitt auf etwa 15\%. Der Anteil der SecalePollenkörner bleibt jedoch unter 5\%. Der geringe Anteil der Roggen-Pollenkörner könnte ebenfalls durch die schlechte Erhaltung bedingt sein. Secale-Pollenkörner sind in stark verfaltetem Zustand nicht von Pollenkörnern des Hordeum-Typs abgrenzbar Die RoggenKurve ist daher eine Minimum-Kurve. Die Werte der sekundären Siedlungszeiger sind erstmals ebenfalls stark erhöht. Pollenkörner von Centaurea cyanus treten auf und weisen auf einen Winterroggenanbau hin. Der Nichtbaumpollenanteil steigt auf das Fünffache des Baumpollenanteils an. Es zeichnet sich eine intensive Rodungs- und Ackerbauphase ab.

Im Bereich zwischen 16-67 cm Tiefe konnten Blei-Anreicherungen hoher Konzentration nachgewiesen werden. Ein Maximum der technogenen Blei-Einträge befindet sich im $\mathrm{Be}-$ reich 40-60 cm (DEICKE 2003). Parallel sind die Holzkohle-Konzentrationen um ein Vielfaches erhöht.

Erstmals zeichnet sich im Diagramm eine Siedlungsphase ab. Der vormals dichte Buchenwald wurde gerodet und der Anbau von Getreide wird pollenanalytisch fassbar.

\section{Datierung}

Das Profil von Wittgerode wurde nach biostratigraphischen Gesichtspunkten datiert. Die in Tabelle 29 zusammengestellten Vergleichsprofile wurden zur Datierung herangezogen. Der Aschenhütter Teich, der Jues-See und das Moosloch liegen ebenso wie der Untersuchungsort im südwestlichen Harzvorland. Sie wurden pollenanalytisch untersucht, nach den von BEUG (1992) ausgewiesenen Grenzkriterien in Zonen unterteilt und radiokarbondatiert. Die Angaben aus dem Hochharz beziehen sich auf drei ebenfalls radiokarbondatierte Profile aus den Hochmooren Bruchbergmoor, Sonnenberger Moor und aus der Ackervermoorung (BEUG et al. 1999).

Die Datierungen der Grenzen des Profils von Wittgerode wurden als Mittelwerte der in Tabelle 29 dargestellten Datierungen berechnet. Die Ergebnisse sind in Abbildung 19 graphisch dargestellt. 
Tabelle 29: Datierungen verschiedener Lokalitäten aus dem Harzvorland und dem Hochharz, sowie die daraus abgeleiteten Altersangaben für das Profil Wittgerode (Datierungen in Kalenderjahren)

\begin{tabular}{|c|c|c|c|c|c|c|}
\hline $\begin{array}{l}\text { Grenzkriterien } \\
\text { nach (BEUG 1992) }\end{array}$ & 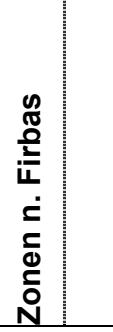 & 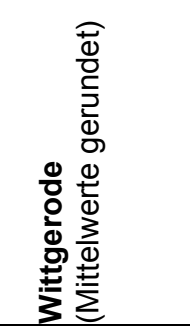 & 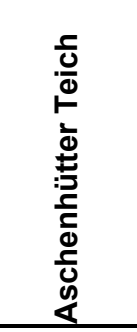 & 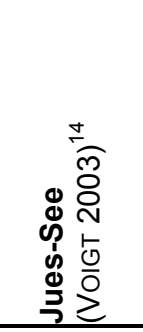 & $\begin{array}{l}\frac{1}{0} \\
\frac{0}{10} \\
\text { 을 }\end{array}$ & 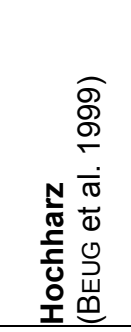 \\
\hline \multirow{2}{*}{$\begin{array}{c}\text { Getreide-Werte }>1 \% \\
\text { Rückgang Fagus-/ Carpinus-Werte }\end{array}$} & $x$ & \multirow{3}{*}{ - } & \multirow{2}{*}{$850 \mathrm{AD}$} & \multirow{2}{*}{$790 \mathrm{AD}$} & \multirow{2}{*}{$1050 \mathrm{AD}$} & \multirow{2}{*}{$900 \mathrm{AD}$} \\
\hline & $\mathrm{IXb}$ & & & & & \\
\hline Anstieg der Carpinus-Werte & \multirow{2}{*}{ IXa } & & $170 \mathrm{AD}$ & $20 \mathrm{AD}$ & $390 \mathrm{AD}$ & $540 \mathrm{AD}$ \\
\hline Fagus-Kurve (Max.werte) $>30 \%$ & & ca. 800 BC & $800 \mathrm{BC}$ & $1010 \mathrm{BC}$ & $570 \mathrm{BC}$ & $780 \mathrm{BC}$ \\
\hline Fagus-Werte $>5 \%$ & VIIIb & ca. $1600 \mathrm{BC}$ & $1540 \mathrm{BC}$ & $1670 \mathrm{BC}$ & $1500 \mathrm{BC}$ & $1710 \mathrm{BC}$ \\
\hline \multirow[t]{2}{*}{ Fagus-Werte $>1 \%$} & VIIIa & \multirow[t]{2}{*}{ ca. $4000 \mathrm{BC}$} & \multirow[t]{2}{*}{ - } & \multirow[t]{2}{*}{$3350 \mathrm{BC}$} & \multirow[t]{2}{*}{$(2440 \mathrm{BC})$} & \multirow[t]{2}{*}{$4140 \mathrm{BC}$} \\
\hline & VII & & & & & \\
\hline
\end{tabular}

Die Lokalitäten reihen sich am südwestlichen Harzrand von Nordwest nach Südost auf, wobei Wittgerode zwischen Aschenhütter Teich / Jues-See und dem Moosloch liegt.

Da sowohl der Aschenhütter Teich als auch das Moosloch geringe Oberflächendurchmesser aufweisen, ist der Anteil des Pollens der lokalen Umgebung, der sich in ihren Sedimenten ablagert, im Vergleich zum Anteil des Pollens aus der regionalen Umgebung relativ groß. Die Zonierung der Profile dieser „Kleinst-Ablagerungsstätten“ kann daher lokale Abweichungen aufweisen. Die Pollenablagerungen vom Jues-See sollten dagegen überwiegend aus der regionalen Umgebung stammen, weshalb die Datierungen der Grenzen auf das Profil von Wittgerode übertragbar sein sollten. Zur Berechnung des Alters der Grenze VII/VIIla wurde die Datierung des Profils vom Moosloch nicht herangezogen, da sie stark von den beiden anderen Datierungen abweicht (Abb. 19). Eine Diskussion der Datierungen im MooslochProfil erfolgt in Kapitel 4.3.3, S. 104.

Die Datierungen der Grenzen in den Hochharzer Profilen sind nach BEUG (1992) gut auf tiefere Lagen im Harzvorland übertragbar. Er nennt als Bedingung, dass sich die Grenzkriterien auf vegetationsgeschichtliche Ereignisse beziehen müssen, für die ein synchroner Ablauf in den fraglichen Höhenstufen angenommen werden kann. Mit Ausnahme der Grenze $\mathrm{IXb} / \mathrm{X}$ sind diese Kriterien erfüllt.

\footnotetext{
${ }^{14}$ siehe auch VoIGT et al. (2000)
} 


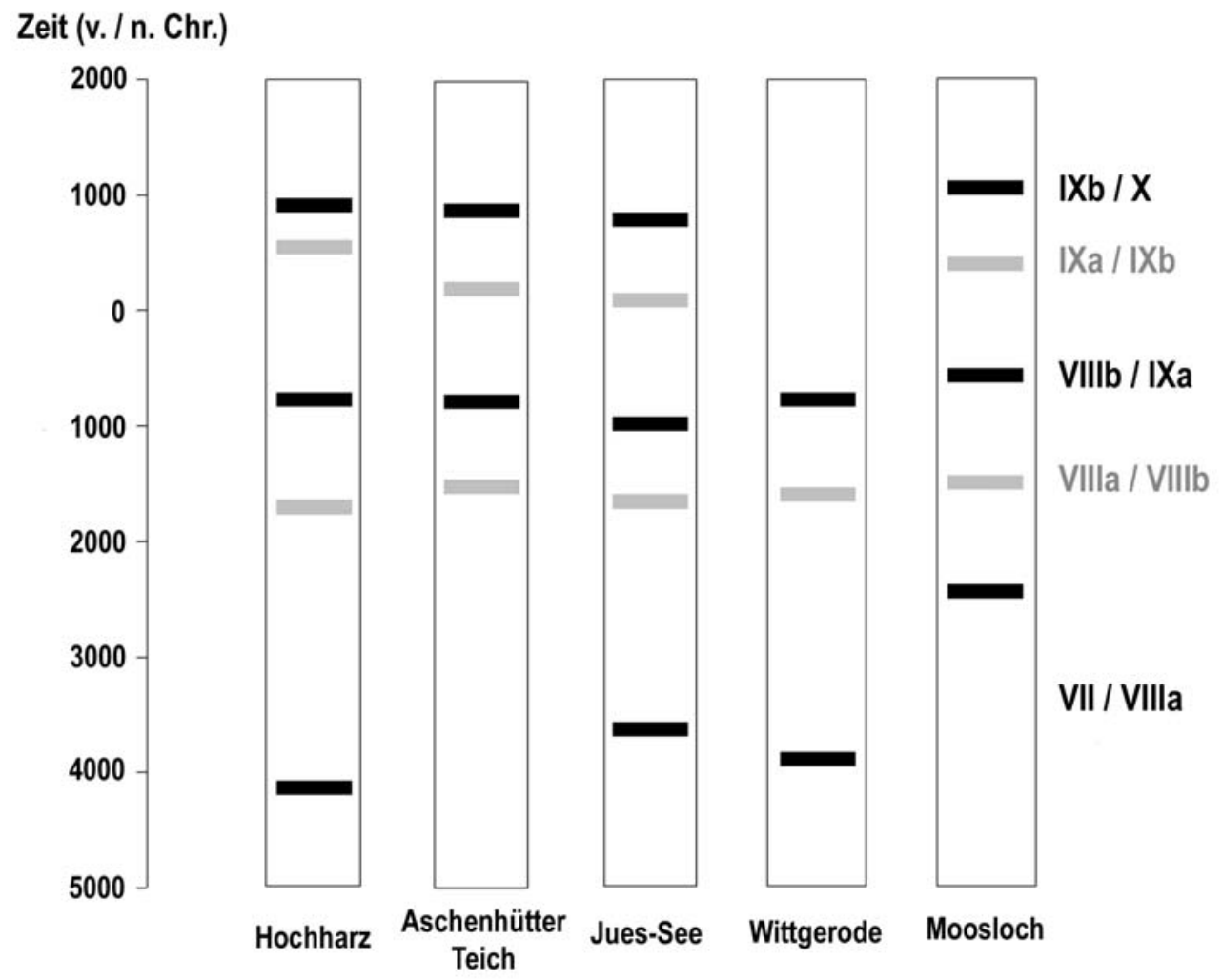

Abbildung 19: Vergleich der Pollenzonen-Datierungen. Für Wittgerode sind die Mittelwerte der dargestellten Datierungen angegeben (siehe Text). Die Grenzen IXa/IXb und XIb/X sind im Profil von Wittgerode nicht ausgeprägt, während die Grenze VII/VIIla nicht im Profil vom Aschenhütter Teich ausgeprägt ist.

\subsubsection{Diskussion}

Das Diagramm von Wittgerode zeigt im tiefsten Bereich an der Grenze der Pollenzonen VII und VIla im Bereich 572-581 cm ungewöhnliche Werte, die auf eine Störung des Sediments an dieser Stelle hinweisen. Besonders die Fagus-Werte von $>50 \%$, aber auch das Ansteigen der Carpinus-Kurve auf $2 \%$ und der auf diesen Tiefenbereich beschränkte Kurvenrückgang aller Arten des Eichenmischwaldes verweisen auf ein wesentlich jüngeres Alter des Sediments in diesem Abschnitt. Am Kern konnten jedoch in der entsprechenden Tiefe kein auffälliger Wechsel des Sediments und kein Hinweis auf eine Bioturbation festgestellt werden (siehe Stratigraphie, Kapitel 4.2.2, S. 81).

Vermutlich handelt es sich um eine Verschleppung von Material aus dem Abschnitt der Pollenzone IX in den tiefsten Bereich des erbohrten Kerns, die während des Bohrvorgangs erfolgte. Die Pollenspektren des Abschnitts 572-581 cm ähneln stark der Pollenzone IX. Die Ergebnisse der geochemischen Analysen von M. Deicke konnten zur Aufklärung dieser Frage nicht herangezogen werden, da beide Abschnitte geochemisch sehr ähnlich sind (DEICKE 2003).

Der fragliche Tiefenbereich $(572-581 \mathrm{~cm})$ wurde im Pollenprozent-Diagramm von Wittgerode (Abb. 18) als gestört ausgewiesen. Diese Pollenspektren wurden bei der Auswertung nicht berücksichtigt (siehe Kapitel 4.2.2, S. 83).

Auf das Fehlen der Carpinus-Ausbreitung in der Zone IX des Diagramms von Wittgerode wurde bereits bei der Auswertung in Kapitel 4.2.2 (S. 84) hingewiesen. In Tabelle 30 sind zum Vergleich die Carpinus-Werte verschiedener Lokalitäten aus dem Harzvorland, aus dem Hochharz und dem Eichsfeld (Luttersee) zusammengestellt. 
Tabelle 30: Vergleich der maximalen Carpinus-Werte in Prozent der BP-Summe (gerundet)

\begin{tabular}{|c|c|c|c|}
\hline Lokalität & $\mathrm{PZ}$ & Carpinus & Literatur \\
\hline \multirow{2}{*}{ Wittgerode } & $\mathrm{X}$ & $5 \%$ & \\
\hline & IX & $1 \%$ & \\
\hline Moosloch & \multirow{5}{*}{$\mathrm{IXb}$} & $50 \%$ & \\
\hline $\begin{array}{l}\text { Aschenhütter } \\
\text { Teich }\end{array}$ & & $30 \%$ & \\
\hline Jues-See & & $20 \%$ & VOIGT 2003; VOIGT et al. 2000 \\
\hline Hochharz & & $15 \%$ & BEUG et al. 1999 \\
\hline Luttersee & & $20 \%$ & BEUG 1992 \\
\hline
\end{tabular}

Bis auf Wittgerode zeigen alle Pollendiagramme einen deutlichen Anstieg der CarpinusWerte, aufgrund dessen die Grenze der PZ IXa/IXb festgelegt wurde (vgl. Tab. 23).

Die Ausbreitung der Hainbuche in den bereits stark von der Rotbuche dominierten Wäldern des Harzvorlandes erfolgte dort, wo sich zuvor vom Menschen gerodete Flächen wieder bewaldeten. In der Umgebung von Wittgerode konnten jedoch weder Rodungen noch Ackerbau pollenanalytisch nachgewiesen werden (Ausnahme PZ X).

In den Pollendiagrammen aus den Hochlagen des Harzes steigen die Carpinus-Werte bis auf $15 \%$ an. Es handelt sich ausschließlich um Polleneintrag aus dem Bereich des Harzrandes und des Harzvorlandes BEUG et al. (1999). Der Carpinus-Pollenanteil im Diagramm von Wittgerode müsste demnach in PZ IX(b) wenigstens ähnlich hohe Werte wie im Hochharz erreichen, und dies sogar, wenn aufgrund einer fehlenden Besiedlung im Umkreis des Erdfalls selbst keine Hainbuchen-Ausbreitung stattgefunden hätte.

Im Bereich des Abschnitts b der Pollenzone IX muss daher im Diagramm von Wittgerode ein Hiatus angenommen werden. Dieser erstreckt sich auf den gesamten Abschnitt b der Pollenzone IX und beginnt möglicherweise bereits in den jüngeren Bereichen des Abschnitts a der Pollenzone IX.

Tabelle 31: Mittelwerte ausgewählter Taxa für die PZ X (angegeben sind mittlere Baumpollenprozentwerte)

\begin{tabular}{|c|c|c|c|c|c|c|c|c|c|}
\hline Lokalität & $\frac{N}{N}$ & $\underset{\Sigma}{\stackrel{\infty}{\Xi}}$ & $\begin{array}{l}\mathbb{0} \\
\mathbb{1} \\
0 \\
0\end{array}$ & $\begin{array}{l}0 \\
\frac{0}{0} \\
\frac{0}{2} \\
0\end{array}$ & 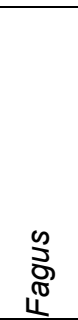 & $\frac{\mathscr{S}}{2}$ & $\begin{array}{l}\mathbb{\Phi} \\
\mathbb{J} \\
\mathbb{0} \\
\mathbb{D} \\
0 \\
0\end{array}$ & 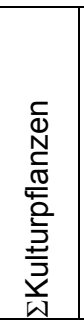 & 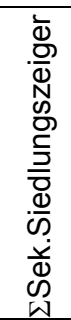 \\
\hline Wittgerode & $x$ & 36,6 & 7,4 & 9,2 & 20,6 & 3,9 & 208,2 & 13,5 & 15,3 \\
\hline \multirow{4}{*}{ Moosloch } & $x / 3 d$ & 34 & 5,2 & 26,1 & 14,3 & 3,5 & 88,6 & 57,0 & 22,7 \\
\hline & $\mathrm{X} / 3 \mathrm{c}$ & 22 & 4,5 & 30,3 & 18,6 & 10,4 & 43,1 & 23,5 & 16,9 \\
\hline & $x / 3 b$ & 13 & 1,7 & 25,1 & 29,9 & 11,0 & 70,7 & 56,9 & 36,5 \\
\hline & $\mathrm{x} / 3 a$ & 1,4 & 0,4 & 2,7 & 67,1 & 21,4 & 1,5 & 0,4 & 0,8 \\
\hline
\end{tabular}

Das Wiedereinsetzen der Überlieferung in PZ X datiert vermutlich in den jüngsten Abschnitt des Jüngeren Subatlantikums (Neuzeit). In Tabelle 31 sind zum Vergleich die mittleren Baumpollen-Prozentwerte der PZ X des Diagramms von Wittgerode und des Diagramms vom Moosloch ${ }^{15}$ aufgelistet. Die mittleren Picea-, Pinus- und Carpinus-Werte des Diagramms von Wittgerode stimmen tendenziell gut mit den entsprechenden Werten aus dem Abschnitt d der Sz 3 des Diagramms vom Moosloch überein. Dieser repräsentiert den jüngsten Abschnitt der PZX.

${ }^{15}$ Der vermoorte Erdfall, „Moosloch“ befindet sich etwa $15 \mathrm{~km}$ südöstlich von Wittgerode (siehe Kapitel 4.3.3, S. 104). 
Tabelle 32: Pollenkonzentrations-Werte im Diagramm von Wittgerode (Pk/ml)

\begin{tabular}{|c|r|r|r|}
\hline PZ n. Firbas & Mittelwert & max. & \multicolumn{1}{c|}{ min. } \\
\hline $\mathbf{X}$ & 59.579 & 97.672 & 21.485 \\
\hline $\mathbf{I X a}$ & 32.864 & 84.302 & 8.094 \\
\hline VIIIlb & 51.131 & 116.213 & 22.255 \\
\hline VIIla & 91.023 & 189.900 & 28.850 \\
\hline VII & 114.359 & 197.810 & 49.209 \\
\hline
\end{tabular}

Eine exakte Zuordnung und Datierung der PZ X des Diagramms von Wittgerode kann jedoch nicht erfolgen, da dieser Abschnitt des Profils aufgrund der extrem schlechten Pollenerhaltung und der geringen Pollenkonzentration (Tab. 32) nur mit wenigen Proben erfasst ist.

Die Ergebnisse der geochemischen Analysen bestätigen die Annahme eines Hiatus, da keine Anreicherung von Schwermetallen im Sediment festgestellt werden konnte. Durch den umfangreichen mittelalterlichen Harzbergbau ist jedoch mit einer Kontamination der Böden auch über größere Entfernungen hinweg zu rechnen. Das vollständige Fehlen eines Anreicherungshorizontes bis zur Ablagerung industrieller Schadstoffe kann daher als Hinweis auf das Fehlen mittelalterlicher Sedimente gewertet werden (DEICKE 2003).

Die Werte der siedlungszeigenden Pollen-Typen sind im gesamten Diagramm von Wittgerode ungewöhnlich gering, weshalb im Diagramm keine Siedlungszeiten ausgewiesen wurden (Ausnahme PZ X). In Tabelle 33 sind zur Veranschaulichung dieser Tatsache die Anzahlen der in einer Pollenzone gefundenen siedlungszeigenden Pollenkörner aufgeführt.

Tabelle 33: Anzahl der Pollenkörner anthropogen geförderter Taxa pro Pollenzone im Diagramm von Wittgerode

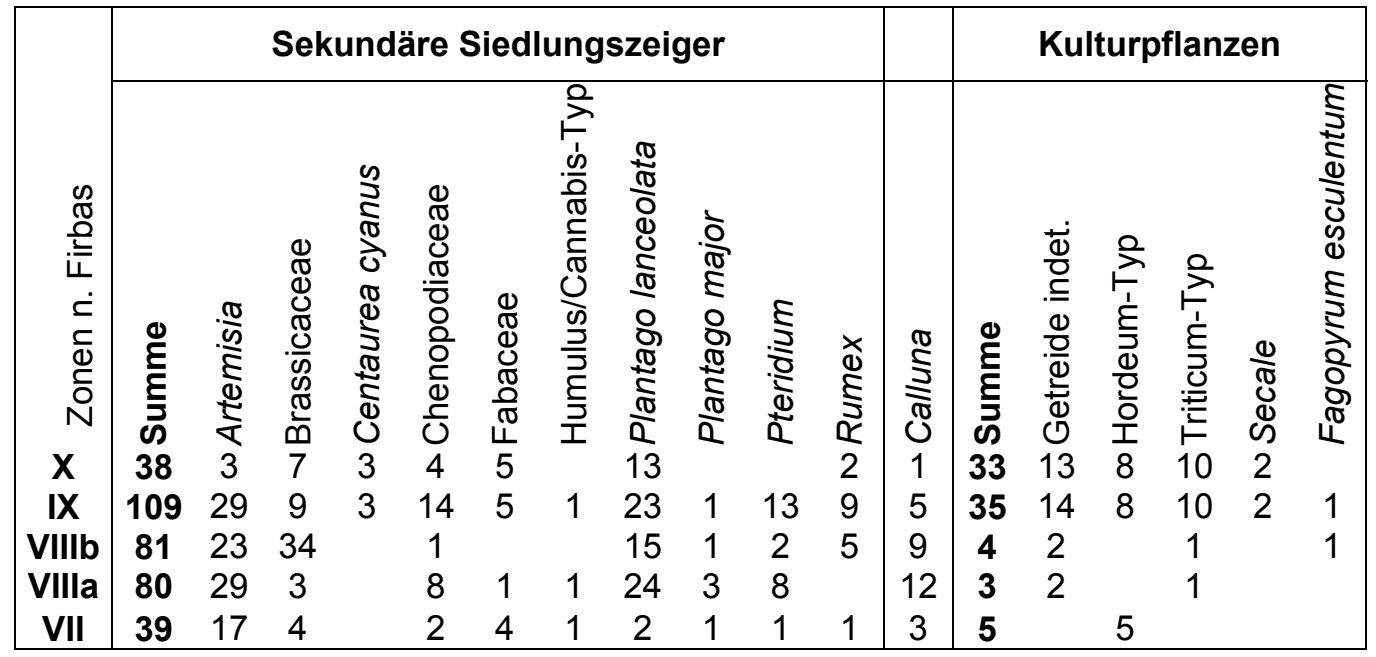

Das Auftreten von zwei Pollenkörnern des Buchweizens (Fagopyrum esculentum) erscheint verfrüht. Mit einem Anbau des Buchweizens im südlichen Niedersachsen kann frühestens ab dem Späten Mittelalter (13./14. Jh.) gerechnet werden (KÖRBER-GROHNE 1987).

Der dargestellte Hiatus sowie die schlechte Pollenerhaltung und geringe Pollenkonzentration ab einer Tiefe von $250 \mathrm{~cm}$ aufwärts, weisen auf einen Unterbrechung des Torfwachstums in der vermoorten Erdfallsenke Wittgerode hin (Abb. 20). Wahrscheinlich kam es zu einer Absenkung des Wasserspiegels und dem darauffolgenden oxidativen Abbau des Torfes sowie zur Zersetzung des abgelagerten Pollens. Tatsächlich existiert ein Entwässerungsgraben unbekannten Alters, der die Senke in östlicher Richtung zum Steina-Bach verlässt. 


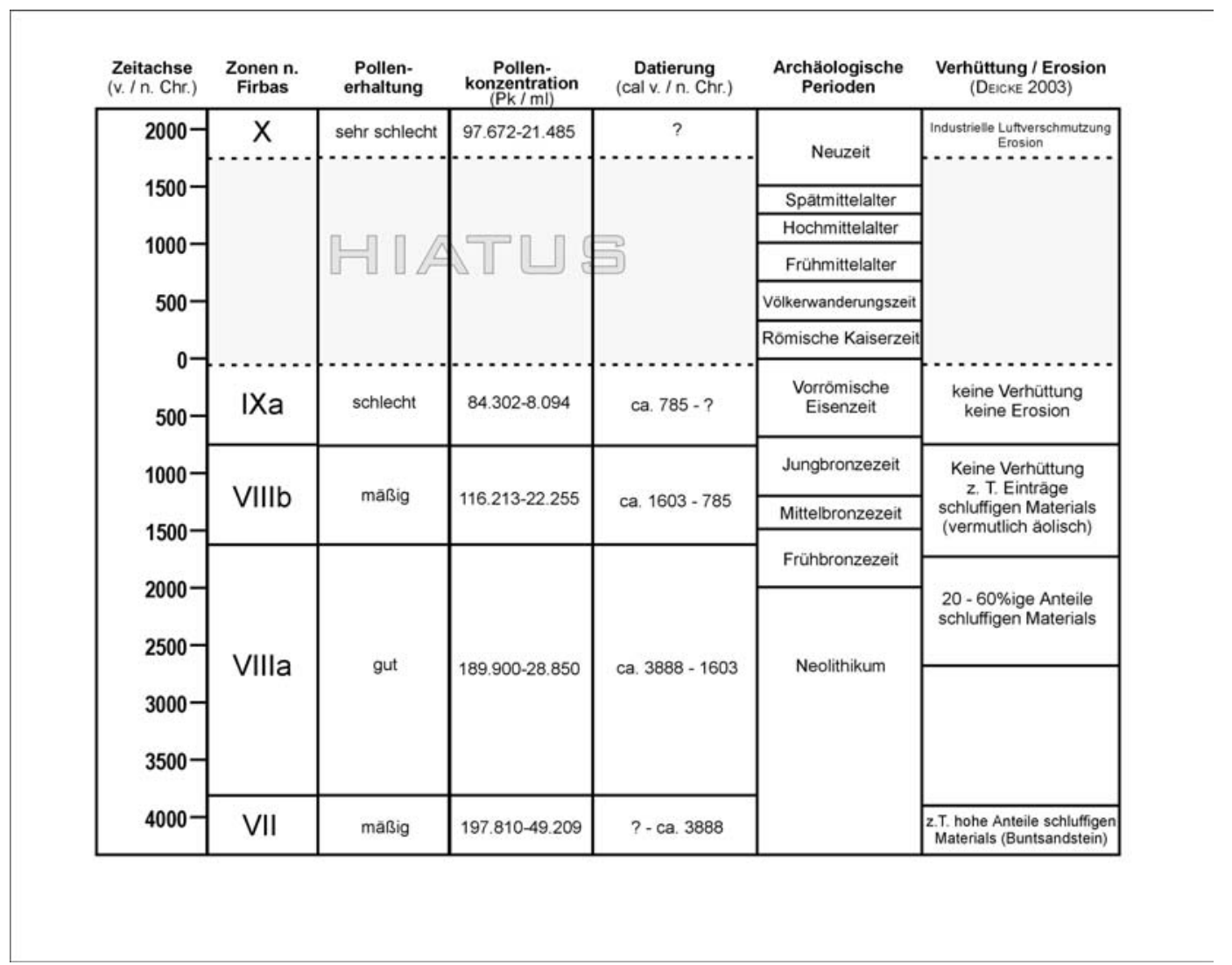

Abbildung 20: Die Datierung der Pollenzonen (biostratigraphisch) und die Dauer des Hiatus (vermutet) im Diagramm Wittgerode

Der Beginn dieser Entwässerung erfolgte vermutlich bereits während des Mittelalters. Das Kloster Walkenried, das nur etwa $7,5 \mathrm{~km}$ nordöstlich von Wittgerode lag, besaß in unmittelbarer Umgebung des Erdfalls Ländereien. Das Dorf Widagerod (Wittgerode) beispielsweise, das seit dem 15. Jh. wüst ist, lag in der Nähe des untersuchten Erdfalls und wird mehrfach in den Urkunden des Klosters Walkenried genannt (DOLLE 2002). Die älteste dieser Urkunden datiert in das Jahr 1140 und bescheinigt die Übergabe des Dorfes Widagerod an Kaiser Konrad II. Das Kloster erhielt das Dorf jedoch im Rahmen mehrerer Schenkungen innerhalb der nächsten zweihundert Jahre zurück.

Die Bestrebungen der Walkenrieder Mönche, Land urbar zu machen und agrarisch zu bewirtschaften, beinhaltete auch die Drainage vernässter Bereiche. So wurde die Urbarmachung des Helmerieths, der heutigen Goldenen Aue, durch den Konvent betrieben.

Die Entwässerung des vermoorten Erdfalls Wittgerode könnte demnach von Walkenried ausgehend bereits im 12. Jh. betrieben worden sein. Die Drainage führte jedoch vermutlich zu keiner ausreichenden Entwässerung, da keine ackerbauliche Nutzung des Kleinmoores erfolgte. Der im westlichen Teil der Vermoorung vermutete Quellhorizont verhinderte wahrscheinlich die endgültige Trockenlegung der Senke. Neuzeitlich kam es zu einer Wiedervernässung des Erdfalls, woraufhin das Torfwachstums erneut einsetzte.

Die Ergebnisse des Diagramms von Wittgerode sind zusammenfassend in Abbildung 20 dargestellt. 


\subsection{Moosloch}

(R 4409 525, H 5709 825)

Der Erdfallkessel Moosloch liegt etwa 600 m südwestlich des Ortes Hochstedt im Landkreis Nordhausen. Der Kessel ist etwa kreisrund und besitzt einen Durchmesser von ca. $70 \mathrm{~m}$ an der Geländeoberfläche und ca. $40 \mathrm{~m}$ an der Mooroberfläche. Während die Geländeoberfläche auf einer Höhe von $240 \mathrm{~m}$ ü. NN liegt, befindet sich die Mooroberfläche etwa 6-8 m tiefer. Am Übergang ist eine um etwa $20^{\circ}$ geneigte Böschung ausgebildet, die mit Eschen, Erlen, jungen Eichen, Holunder und verschiedenen anderen Sträuchern bewachsen ist.

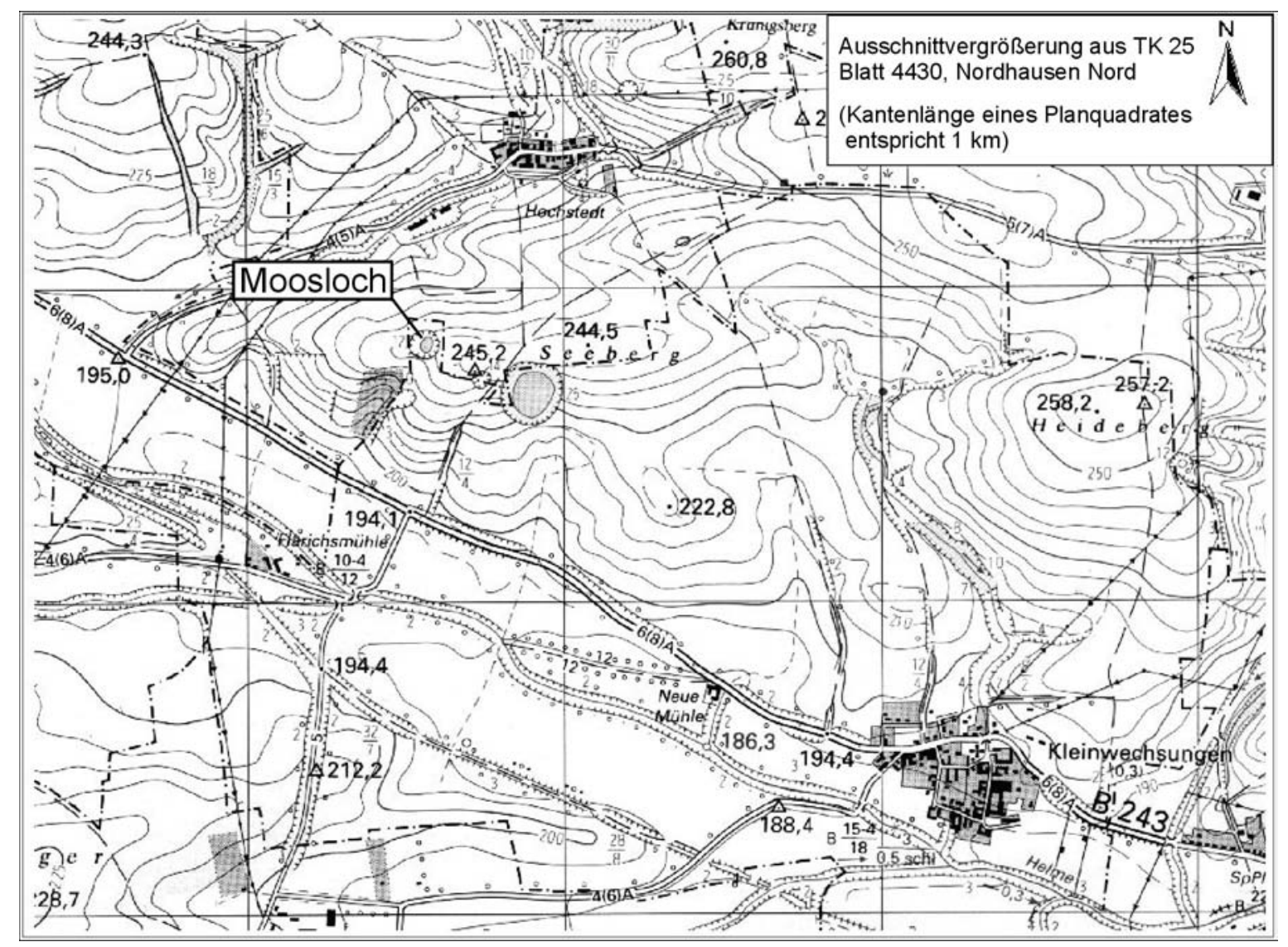

Abbildung 21: Lage des Erdfallkessels Moosloch (TK 25, Blatt 4430, Nordhausen Nord)

Die zum Zeitpunkt der Bohrung im August 2000 trockene Oberfläche des Mooslochs war mit Birken und Dornfarn bewachsen.

Auf dem Seeberg befinden sich in der Nähe des Mooslochs zwei weitere Erdfälle: das Kleine und das Grosse Seeloch. Geologisch gesehen befinden sich die Erdfälle in Sedimentgesteinen des Unteren Buntsandstein, der auf dem Seeberg eine Mächtigkeit von etwa $90 \mathrm{~m}$ erreicht. Die Entstehung der Erdfälle erklärt sich durch den Einsturz von Hohlräumen im liegenden Zechstein (TAUCHMANN 1990).

Die Umgebung des Mooslochs wird intensiv agrarwirtschaftlich genutzt, wobei die meisten Flächen als Getreideäcker bewirtschaftet werden. 


\subsubsection{Material und Methoden}

\section{Geländearbeit}

Am 11.08.2000 wurde aus dem vermoorten Erdfall Moosloch nordwestlich von Nordhausen mit Hilfe eines russischen Kammerbohrgerätes ein insgesamt $576 \mathrm{~cm}$ langer Kern erbohrt. Gebohrt wurde mit einer Überlappung von jeweils $5 \mathrm{~cm}$, wobei die Bohrlöcher in etwa $80 \mathrm{~cm}$ Abstand zueinander lagen. Die Aufbewahrung der Kernstücke erfolgte in luftdicht verpackten PVC-Halbschlalen liegend im Kühlraum des Instituts für Geologie und Dynamik der Lithosphäre (Universität Göttingen).

\section{Stratigraphie}

Die Beschreibung des Kernes erfolgte nach optischen Merkmalen und mit Hilfe der Ergebnisse aus den geochemischen Untersuchungen von M. Deicke (DEICKE 2003).

\section{Pollenanalysen}

\section{Probennahme}

Die Probennahme erfolgte nach der bereits in Kapitel 4.2.1 für den Kern von Wittgerode beschriebenen Methode.

\section{Laborarbeiten \& Datenerhebung}

Die chemische Aufbereitung der Proben aus dem Profil vom Moosloch erfolgte nach der für das Material aus dem Aschenhütter Teich beschriebenen Methode (siehe Kapitel 4.1.1). Aus dem Kern vom Moosloch wurden 63 Proben pollenanalytisch ausgewertet. Im Rahmen der Diplomarbeit von T. Pleines (PLEINES 2002) wurde der überwiegende Teil dieser Proben auf eine Baumpollensumme von mindestens 500 Pollenkörnern ausgezählt. Die Proben mit den höchsten Nichtbaumpollenanteilen im jüngsten Diagrammabschnitt wurden von der Verfasserin der vorliegenden Arbeit zusätzlich bearbeitet, um eine Baumpollensumme von 300 Pollenkörnern zu erreichen. Die Anzahl der Holzkohlepartikel mit einem Durchmesser $>20 \mu \mathrm{m}$ wurde in jeder Probe bestimmt.

\section{Auswertung und Darstellung}

Die Aufnahme und Weiterverarbeitung der Rohdaten erfolgte wie in Kapitel 4.1.1 beschrieben. Die Ergebnisse der Pollenanalyse sind als Schattenrisskurven in einem Prozentwertediagramm (Abbildung 22, Beilage) dargestellt.

Die dargestellten Werte beziehen sich auf die Summe der Baumpollen ohne Betula als Grundsumme (Baumpollensumme ohne Betula =100\%). Der Ausschluss des Birkenpollens aus der Berechnungsgrundlage wurde erforderlich, da die Betula-Kurve zum Teil sehr hohe Werte erreicht und im Verlauf des Diagramms stark schwankt. Es handelt sich vermutlich um ein lokales Vorkommen von Birken auf dem Erdfall, wie es auch rezent zu beobachten ist. Ein hoher Birken-Pollenanteil im Sediment spiegelt daher nicht unbedingt einen hohen Anteil an Birken in der Waldzusammensetzung der Umgebung wieder. 
Im Vergleich zeigt das dargestellte Summendiagramm die Anteile der Pollentaxa-Gruppen Bäume, Sträucher, Hasel und Krautige Pflanzen bezogen auf die LandpflanzenpollenSumme. Konzentrationsangaben, Sporen- und Algenwerte sind als Balkendiagramme dargestellt.

Die Summenkurven fassen die Werte folgender Taxa zusammen:

- Eichenmischwald-Summe: Acer, Fraxinus, Quercus, Tilia cordata-Typ, Tilia platyphyllos-Typ, Ulmus.

- Baumpollen-Summe / Bäume: Abies, Acer, Alnus, Carpinus, Castanea-Typ, Fagus, Fraxinus, Picea, Pinus, Quercus, Salix, Tilia cordata-Typ, Tilia platyphyllos-Typ, Ulmus.

- Sträucher: Frangula alnus, Lonicera periclymenum-Typ, Sambucus nigra-Typ, Viburnum-Typ.

- Nichtbaumpollen-Summe / Krautige Pflanzen: Alle Landpflanzenpollen-Typen, außer Corylus und den oben genannten Baumpollen-Typen.

- Sek. Siedlungszeiger-Summe: Alchemilla-Typ, Anthoceros laevis, Anthoceros punctatus, Artemisia, Brassicaceae, Centaurea cyanus, Chenopodiaceae, Convolvulus arvensis, Fabaceae, Humulus/Cannabis-Typ, Plantago lanceolata, Plantago major/media-Typ, Polygonum aviculare, Pteridium, Rumex, Urtica.

- Kulturpflanzen-Summe: Avena-Typ, Fagopyrum esculentum, Getreide indet., Hordeum-Typ, Secale, Triticum-Typ, Zea mays.

- Wasserpflanzen-Summe: Eupotamogeton, Lemna-Typ, Myriophyllum spicatum-Typ.

Taxa mit sehr geringen Werten und/oder seltenem Auftreten sind nicht graphisch im Pollendiagramm dargestellt. Eine Liste mit den Werten dieser Taxa befindet sich im Anhang in Tabelle 47. Des weiteren wurde der Pollen-Influx ausgewählter Taxa in Tabelle 50 (Anhang) sowie Auszüge der jüngeren Abschnitte in Tabelle 40 aufgelistet. Der Pollen-Influx gibt an, wie hoch die Konzentration an Pollenkörnern pro Milliliter Sediment und Jahr ist (siehe Kapitel 4.1.1).

\section{Radiokarbondatierungen}

\section{Probennahme}

Für die ${ }^{14} \mathrm{C}$-Bestimmung wurden den Kernen nach der Entnahme der Proben für die Pollenananlysen und die geochemischen Analysen in fünf Abschnitten von etwa $10 \mathrm{~cm}$ Länge Torfproben entnommen.

Diese fünf Proben wurden an das Leibniz Labor für Altersbestimmung und Isotopenforschung unter der Leitung von Prof. Dr. P.M.Grootes an der Christian-Albrechts-Universität in Kiel geschickt.

\section{Interpolation}

Altersangaben für Tiefen, die nicht direkt datiert werden konnten, wurden nach Formel 1 (siehe Kapitel 4.1.1) interpoliert.

In Tabelle 34 ist angegeben, in welchen Tiefen Material für AMS-Datierungen entnommen wurde. Es handelte sich bei allen fünf Proben um Torfproben. Die Proben $324-331 \mathrm{~cm}$ \& 400-407 cm enthielten außerdem kleinere Holzreste.

Die Kalibrierung der Radiokarbondatierungen erfolgte nach (STUIVER et al. 1998). Für die 
Interpolation wurden die Ergebnisse im $2 \sigma$-Bereich verwendet, welche die höchste Wahrscheinlichkeit besitzen.

Tabelle 34: Ergebnisse der ${ }^{14} \mathrm{C}$-Datierung des Kerns vom Moosloch

\begin{tabular}{|c|c|}
\hline KIA16307 & Probentiefe $(\mathrm{cm}):$ 95-105 \\
\hline Radiokarbon Alter & BP $330 \pm 34$ \\
\hline Kalibriertes Alter & 1522, 1573, 1627 n. Chr. (2б-Bereich: 1480-1642) \\
\hline KIA16308 & Probentiefe $(\mathrm{cm}):$ 196-206 \\
\hline Radiokarbon Alter & BP $982 \pm 26$ \\
\hline Kalibriertes Alter & 1024 n. Chr. (2б-Bereich: 998-1064) \\
\hline KIA16309 & Probentiefe $(\mathrm{cm}):$ 249-259 \\
\hline Radiokarbon Alter & BP $1747 \pm 23$ \\
\hline Kalibriertes Alter & 258, 283, 288, 299, 320 n. Chr. (2б-Bereich: 239-359) \\
\hline KIA16310 & Probentiefe $(\mathrm{cm}):$ 324-331 \\
\hline Radiokarbon Alter & BP $2417 \pm 24$ \\
\hline Kalibriertes Alter & 477, 472, 411 v. Chr. (2б-Bereich: 541-402) \\
\hline KIA16312 & Probentiefe $(\mathrm{cm}):$ :00-407 \\
\hline Radiokarbon Alter & BP $3605 \pm 29$ \\
\hline Kalibriertes Alter & 1945 v. Chr. (2б-Bereich: 1985-1883) \\
\hline
\end{tabular}

Die Standardabweichungen der interpolierten Altersangaben wurden gewonnen, indem die Mittelwerte aus den Standardabweichungen der zur Interpolation herangezogenen Datierungen berechnet wurden (Tab. 35).

Tabelle 35: Mittlere Abweichungen der durch Interpolation am Diagramm vom Moosloch gewonnenen Altersangaben (Angaben in kalibrierten Kalenderjahren)

\begin{tabular}{|c|c|c|c|c|c|c|c|c|}
\hline $\begin{array}{l}\text { Tiefen } \\
(\mathrm{cm})\end{array}$ & $\begin{array}{l}\text { Zonen n. } \\
\text { Firbas }\end{array}$ & $\begin{array}{l}\text { Interpolierte } \\
\text { Datierung }\end{array}$ & \pm & $\begin{array}{l}\text { Interpolierte } \\
\text { Strecke } \\
(\mathrm{cm}) \\
\end{array}$ & 1.Datierung & \pm & 2.Datierung & \pm \\
\hline 197,5 & $\mathrm{IXb} / \mathrm{X}$ & 1049 n. Chr. & 57 & 101 & 1031 n. Chr. & 33 & 1561 n. Chr. & 81 \\
\hline 247,5 & $\mathrm{IXa} / \mathrm{IXb}$ & 389 n. Chr. & 45 & 153 & 299 n. Chr. & 60 & 153 n. Chr. & 30 \\
\hline 332,5 & VIIIb/IXa & 568 v. Chr. & 60,5 & 76 & 472 v. Chr. & 70 & 1934 v. Chr. & 51 \\
\hline 381 & VIIIa/VIIIb & 1501 v. Chr. & 60,5 & 76 & 1934 v. Chr. & 51 & 472 v. Chr. & 70 \\
\hline 430 & VII/VIIIa & 2438 v. Chr. & & (siehe Text) & 1934 v. Chr. & 51 & & \\
\hline 496,5 & VI/VII & 3701 v. Chr. & & (siehe Text) & 1934 v. Chr. & 51 & & \\
\hline
\end{tabular}

Die Altersangaben in den Tiefen 430 und $496,5 \mathrm{~cm}$ wurden unter der Voraussetzung einer gleichbleibenden Sedimentationsrate im Bereich 327,5-403,5 cm von der tiefsten Datierung bei 403,5 cm (mittlere Tiefe) ausgehend, extrapoliert. 
Tabelle 36: Alter der Pollenzonengrenzen des Diagramms vom Moosloch

\begin{tabular}{|c|c|c|c|c|c|c|c|c|c|c|c|c|c|c|c|}
\hline \multirow[t]{2}{*}{$\frac{\mathbf{N}}{\mathbf{N}}$} & \multicolumn{2}{|c|}{ 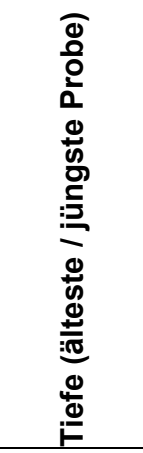 } & \multicolumn{2}{|c|}{ 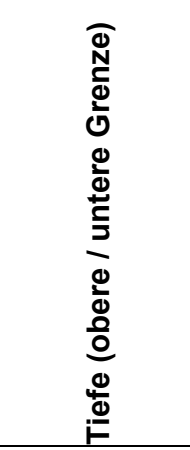 } & \multicolumn{6}{|c|}{ Datierungen der Zonengrenzen } & \multirow{3}{*}{ 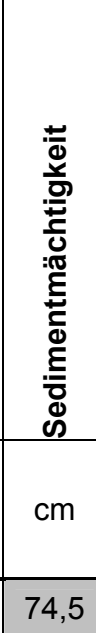 } & \multirow{3}{*}{ 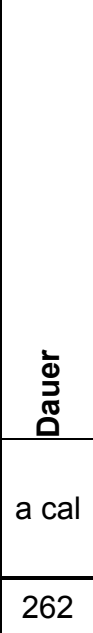 } & \multirow{3}{*}{ 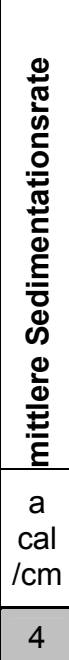 } & \multirow{3}{*}{ 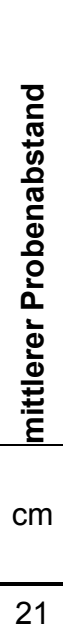 } & \multirow{3}{*}{ 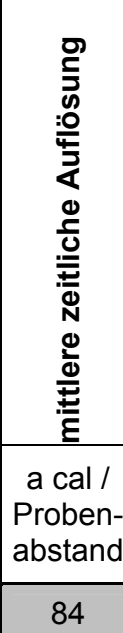 } \\
\hline & \multicolumn{2}{|c|}{$\mathrm{cm}$} & \multicolumn{2}{|c|}{$\mathrm{cm}$} & \multicolumn{2}{|c|}{ cal BP } & \multicolumn{2}{|c|}{$\mathrm{AD} / \mathrm{BC}$} & \multicolumn{2}{|c|}{ BP } & & & & & \\
\hline 3d & 64 & 26 & 74,5 & 0 & 262 & 0 & $1688 \mathrm{AD}$ & heute & 203 & 0 & & & & & \\
\hline $3 c$ & 106 & 85 & 115,5 & 74,5 & 470 & 262 & $1480 \mathrm{AD}$ & $1688 \mathrm{AD}$ & 430 & 203 & 41 & 208 & 5 & 21 & 105 \\
\hline $3 b$ & 195 & 125 & 197,5 & 115,5 & 901 & 470 & 1049 AD & $1480 \mathrm{AD}$ & 959 & 430 & 82 & 431 & 5 & 18 & 90 \\
\hline $\mathbf{x}$ & 195 & 26 & 197,5 & 0 & 901 & 0 & 1049 AD & heute & 959 & 0 & 197,5 & 901 & 5 & 20 & 100 \\
\hline $3 a$ & 210 & 200 & 212,5 & 197,5 & 1078 & 901 & 872 AD & 1049 AD & 1148 & 959 & 15 & 177 & 12 & 5 & 60 \\
\hline $\mathbf{I X b}$ & 245 & 200 & 247,5 & 197,5 & 1561 & 901 & 389 AD & 1049 AD & 1653 & 203 & 50 & 660 & 13 & 5 & 65 \\
\hline IXa & 330 & 250 & 332,5 & 247,5 & 2518 & 1561 & 568 BC & 389 AD & 2495 & 1653 & 85 & 957 & 11 & 7 & 77 \\
\hline 2 & 340 & 284 & 342 & 279 & 2701 & 1913 & $751 \mathrm{BC}$ & $37 \mathrm{AD}$ & 2964 & 2644 & 63 & 788 & 13 & 8 & 104 \\
\hline VIIIb & 377 & 335 & 381 & 332,5 & 3451 & 2518 & $1501 \mathrm{BC}$ & 568 BC & 3253 & 2495 & 48,5 & 933 & 19 & 5 & 95 \\
\hline 1 & 404 & 365 & 404,5 & 362,5 & 3903 & 3095 & 1953 BC & $1145 \mathrm{BC}$ & 3605 & 2964 & 42 & 808 & 19 & 6 & 114 \\
\hline VIIla & 427 & 385 & 430 & 381 & 4388 & 3451 & 2438 BC & $1501 \mathrm{BC}$ & 4029 & 3253 & 49 & 937 & 19 & 4 & 76 \\
\hline VII & 490 & 433 & 496,5 & 430 & 5651 & 4388 & $3701 \mathrm{BC}$ & $2438 B C$ & 5093 & 4029 & 66,5 & 1263 & 19 & 11 & 209 \\
\hline VI & 574 & 503 & 574 & 496,5 & 7124 & 5651 & $5174 \mathrm{BC}$ & $3701 \mathrm{BC}$ & 6333 & 5093 & 77,5 & 1473 & 19 & 21 & 399 \\
\hline
\end{tabular}




\subsubsection{Ergebnisse}

\section{Stratigraphie}

Der Kern setzt sich aus Torfen zusammen, die von silikatischen Zwischenlagen unterbrochen sind. Unterhalb von $265 \mathrm{~cm}$ handelt es sich größtenteils um eingeschwemmtes Buntsandsteinmaterial (vermutlich aus den Erdfallflanken). Oberhalb von $265 \mathrm{~cm}$ bildet Lösslehm die silikatische Komponente. Tabelle 37 gibt die Stratigraphie des Kerns vom Moosloch wieder. Die Karbonatgehalte im gesamten Kern sind relativ gering, die pH-Werte liegen jedoch im (sub-)neutralen Bereich (DEICKE 2003).

Tabelle 37: Stratigraphie des Kerns vom Moosloch

\begin{tabular}{|c|c|c|c|}
\hline Tiefe $(\mathbf{c m})$ & Beschreibung & Tiefe $(\mathbf{c m})$ & $\begin{array}{l}\text { Ergebnisse der geochemischen Analysen (DEICKE } \\
\text { 2003) }\end{array}$ \\
\hline $0-18$ & $\begin{array}{l}\text { Torf, stark zersetzt, } \\
\text { durchwurzelt }\end{array}$ & & $\begin{array}{l}\text { sehr hohe Schwermetallgehalte (vermutlich infolge der } \\
\text { Industrialisierung) }\end{array}$ \\
\hline \multirow{3}{*}{$18-61$} & \multirow{3}{*}{ Torf } & $0-31$ & Hinweise auf Kalium-Mangel (Bodendegradation) \\
\hline & & & \\
\hline & & $17-32$ & Eintrag minerogenen Materials (Lösslehm) \\
\hline \multirow[b]{2}{*}{$61-69$} & \multirow[b]{2}{*}{ Mudde } & $60-70$ & Eintrag minerogenen Materials (Lösslehm) \\
\hline & & $61-69$ & Verhüttung \\
\hline \multirow{5}{*}{$69-250$} & \multirow{5}{*}{ Torf } & $69-139$ & $\begin{array}{l}\text { kaum Verhüttung, Schwermetallgehalte auf } \\
\text { geringerem Niveau erhöht } \\
\text { Rückgang der minerogenen Einträge }\end{array}$ \\
\hline & & $139-206$ & Verhüttung (Max. 156 \& $185 \mathrm{~cm}$ ), \\
\hline & & $139-210$ & starke Einträge minerogenen Materials \\
\hline & & $210-246$ & $\begin{array}{l}\text { keine Hinweise auf Verhüttung } \\
\text { kaum Eintrag minerogener Stäube }\end{array}$ \\
\hline & & \multirow[t]{2}{*}{$246-252$} & \multirow[t]{2}{*}{ Eintrag minerogenen Materials (Buntsandstein) } \\
\hline $250-251$ & schluffiges Material & & \\
\hline $251-260$ & Torf & \multirow[b]{2}{*}{$256-272$} & \multirow[b]{2}{*}{ Eintrag minerogenen Materials (Buntsandstein) } \\
\hline $260-264$ & schluffig / toniges Material & & \\
\hline \multirow{2}{*}{$264-326$} & \multirow{2}{*}{ Torf } & $265-283$ & Verhüttung von Bleierzen (Silbergewinnung) \\
\hline & & $274-290$ & Eintrag minerogenen Materials (Buntsandstein) \\
\hline $326-327$ & schluffiges Material & \multirow[t]{2}{*}{$322-330$} & \multirow[t]{2}{*}{ Eintrag minerogenen Materials (Buntsandstein) } \\
\hline \multirow{2}{*}{$327-356$} & \multirow[t]{2}{*}{ Torf } & & \\
\hline & & $330-346$ & Eintrag minerogenen Materials (Lösslehm) \\
\hline $356-360$ & Mudde & & \\
\hline $360-576$ & Torf & & \\
\hline
\end{tabular}




\title{
Diagrammbeschreibung und Auswertung
}

\author{
Liste der im Text beschriebenen Abbildung und der Tabellen: \\ Abbildung 22: $\quad$ Pollendiagramm des Profils vom Moosloch (BP-Summe ohne Betula = \\ $100 \%)$, Beilage \\ Tabelle 47: \\ Tabelle 40: \\ Tabelle 50: \\ Zählwerte selten auftretender Taxa, Anhang \\ Polleninflux-Werte des Diagramms Moosloch, S. 107 \\ Pollen-Influx ausgewählter Taxa des Diagramms Moosloch, Anhang
}

Die Pollendiagramme wurden in biostratigraphische Zonen nach (FIRBAS 1949) eingeteilt. Die Kriterien für die Grenzziehungen wurden aus (BEUG 1992) übernommen (siehe Kapitel 4.1.2). Das Kriterium für die Grenze VI/VII, der Anstieg der Picea-Kurve, bezieht sich auf die Ausbreitung der Fichte im Oberharz.

Offensichtlich erreichte Fichtenpollen aus dem Oberharz das Harzvorland nur in geringen Mengen. Die Fichtenausbreitung im Harz kommt im Pollendiagramm daher nicht zum Ausdruck.

\section{VI $(574-496,5 \mathrm{~cm})$}

$5174^{16}-3701$ v. Chr. (7124-5651 cal BP, 6333-5093 BP)

Dauer: $1473 \mathrm{a}$; mittlere Sedimentationsrate: $19 \mathrm{a} / \mathrm{cm}$; mittlerer Probenabstand: $21 \mathrm{~cm}=399 \mathrm{a}$.

Sediment: Torfe

Neolithikum

Die Summenkurve des Eichenmischwaldes dominiert in der Zone VI des Pollendiagramms mit Werten über $60 \%$. Die besonders hohen Werte von Tilia cordata zeigen, dass die Winterlinde das damalige Waldbild beherrschte. Tilia ist in Pollendiagrammen gegenüber anderen Taxa wie beispielsweise Quercus und Fagus unterrepräsentiert (ANDERSEN 1973). Ihre Kurve fällt erst gegen Ende des Abschnitts auf Werte unter $20 \%$ ab. Gegenläufig steigen die Werte der Ulmus- und Quercus-Kurven an. Die Bedeutung dieser Baumarten nahm demnach in der Umgebung zu. Die Hasel verlor im Unterwuchs der Eichenmischwald-Arten zunächst an Bedeutung, wie ihre sinkende Kurve im Verlauf des Diagrammabschnitts zeigt. Synchron zu den steigenden Quercus- und Ulmus-Kurven steigen jedoch die Corylus-Werte gegen Ende der Pollenzone VI auf über $100 \%$ an. Der Pollenfernflug aus den höheren Lagen des Harzes verursachte die Picea- und die Pinus-Anteile in den Spektren des MooslochDiagramms. Die Picea-Werte liegen etwa bei $1 \%$. An der Grenze der Zonen VI/VII setzt die Kurve gänzlich aus und steigt in der folgenden Probe in Zone VII auf $>4 \%$ an.

\section{VII $(496,5-430 \mathrm{~cm})$}

3701-2438 v. Chr. (5651-4388 cal BP, 5093-4029 BP)

Dauer: 1263 a; mittlere Sedimentationsrate: $19 \mathrm{a} / \mathrm{cm}$; mittlerer Probenabstand: $11 \mathrm{~cm}=209 \mathrm{a}$

Sediment: Torfe

Neolithikum

Die Ulmus-Kurve fällt in Pollenzone VII rasch auf Werte unter $5 \%$ ab. Während die Tilia cordata-Kurve die 20\%-Marke nur noch selten überschreitet, stabilisiert sich die QuercusKurve auf hohem Niveau (etwa 40\%). Winterlinden und Eichen waren demnach im Wald zu etwa gleichen Teilen vertreten. Im Unterwuchs des Waldes wurde die Hasel häufiger, ihre

\footnotetext{
${ }^{16}$ Es handelt sich nicht um das Alter der unteren Grenze der Pollenzone VI, sondern um das Alter des untere Kernendes.
} 
Werte steigen im Diagramm auf über $100 \%$ an. In geringem Umfang konnte sich auch die Esche gegen Ende des Abschnitts VII ausbreiten. Die geschlossene Fagus-Kurve setzt in dieser Pollenzone ein und zeigt damit die erstmalige Anwesenheit vereinzelter Rotbuchen im Gebiet an. Erste Pollenkörner von Carpinus treten auf.

Die Picea-Kurve steigt am Beginn des Abschnitts singulär auf über $4 \%$ an und fällt anschließend auf unter $1 \%$ ab. Die Picea-Kurve ist aufgrund der durchgehend niedrigen Werte nur sehr beschränkt als Grenzkriterium VI/VII geeignet. Stattdessen wurde für die Abgrenzung der Rückgang der Ulmen-Werte herangezogen (vgl. VOIGT 2003).

Die Werte der sekundären Siedlungszeiger und des Nichtbaumpollens sind in beiden Abschnitten des Atlantikums sehr gering und es wurden keine Getreide-Pollenkörner gefunden. Für diesen Zeitabschnitt ist daher nicht mit einer Besiedlung in der Nähe des Untersuchungspunktes zu rechnen.

\section{Subboreal VIII}

\section{VIIla $(430-381 \mathrm{~cm})$}

2438-1501 v. Chr. (4388-3451 cal BP, 4029-3253 BP)

Dauer: 937a; mittlere Sedimentationsrate: $19 \mathrm{a} / \mathrm{cm}$; mittlerer Probenabstand: $4 \mathrm{~cm}=76 \mathrm{a}$.

Sediment: Torfe

Dieser Abschnitt umfasst den langsamen Anstieg der Fagus-Kurve von 1\% auf 5\%. Die Einwanderung und die erste Ausbreitung der Rotbuchen in den Eichenmischwaldgesellschaften zeichnen sich ab. Die Quercus-Kurve verläuft scheinbar unbeeinflusst weiterhin auf sehr hohem Niveau, während die Tilia cordata-Kurve ihren bereits im Atlantikum begonnenen Abwärtstrend fortsetzt. Lediglich der unruhigere Verlauf dieser beiden Kurven deutet möglicherweise auf das Eindringen der Rotbuche in die Eichen- und Lindenbestände hin.

\section{SZ $1(404,5-362,5 \mathrm{~cm})$}

1953-1145 v. Chr. (3903-3095 cal BP, 3605-2964 BP)

Dauer: 808 a; mittlere Sedimentationsrate: $19 \mathrm{a} / \mathrm{cm}$; mittlerer Probenabstand: $6 \mathrm{~cm}=114 \mathrm{a}$.

Sediment: Torfe

Frühe Bronzezeit - Mittere Bronzezeit

Zunächst sinkt zu Beginn der Siedlungszeit 1 der Baumpollen-Anteil parallel zur steigenden Holzkohle-Konzentration ab. Gleichzeitig setzen viele sekundäre Siedlungszeiger-Kurven ein. Die Rodung von Wald ging der Siedlung voraus, um die nötigen Flächen für Wohn- und Wirtschaftsgebäude sowie für die Äcker zu schaffen. Noch bevor Pollenkörner des GetreideTyps in einigen Proben auftreten, weisen die geschlossenen Kurven von Plantago lanceolata und Urtica sowie die erhöhten Werte der Poaceae eine Beweidung des Waldes in der Umgebung des Mooslochs hin. Der Rückgang der Ulmus- und der Fraxinus-Kurve sowie die extrem hohen Corylus-Werte wurden vermutlich durch die Rodungen verursacht.

Die pollenanalytischen Ergebnisse zeigen deutlich Siedlungstätigkeit von relativ geringer Intensität in dieser Zeit an. Vermutlich lag das Siedlungsareal nicht in unmittelbarer Nähe des Mooslochs. Die ab Probe $377 \mathrm{~cm}$ geschlossene Getreide-Typen-Kurve könnte durch eine Verlagerung der Ackerflächen zum Untersuchungspunkt hin bedingt worden sein.

Etwa $1,5 \mathrm{~km}$ südlich des Mooslochs wurden Überreste der Aunjetitzer Kultur lokalisiert. Wahrscheinlich wird im Diagramm eine Siedlung dieser frühbronzezeitlichen Kultur fassbar, die archäologisch bisher nicht bekannt ist. Funde der Aunjetitzer Kultur sind im gesamten Harzvorland häufig anzutreffen (siehe Kapitel 3.4).

Geochemisch sind in diesem Abschnitt des Kerns keine Hinweise auf Einträge minerogenen Materials oder für Verhüttung nachweisbar (DEICKE 2003). 


\section{VIIIb $(381-332,5 \mathrm{~cm})$}

1501-568 v. Chr. (3451-2518 cal BP, 3253-2495 BP)

Dauer: $933 \mathrm{a}$; mittlere Sedimentationsrate: $19 \mathrm{a} / \mathrm{cm}$; mittlerer Probenabstand: $5 \mathrm{~cm}=95 \mathrm{a}$.

Sediment: Torfe

Der steile Anstieg der Fagus-Kurve zeigt die Massenausbreitung der Rotbuche in den Wäldern an (Fagus-Werte: 5-30\%). Gleichzeitig kommt es zu einem Rückgang der Eichenmischwald- und Corylus-Werte im Pollendiagramm, da diese Arten von der konkurrenzkräftigeren Rotbuche verdrängt wurden. Besonders dramatisch gehen die Werte der Tilia cordata-Kurve zurück. Die Linden sind möglicherweise in der Siedlungszeit 2, deren Beginn in VIIlb liegt, zusätzlich anthropogen beeinträchtigt worden (siehe unten). Die CarpinusKurve ist erstmals geschlossen und zeigt die Anwesenheit von Hainbuchen im Untersuchungsgebiet an.

\section{Älteres Subatlantikum IX}

\section{IXa $(332,5-247,5 \mathrm{~cm})$}

568 v. Chr.-389 n. Chr. (2518-1561 cal BP, 2495-1653 BP)

Dauer: $957 \mathrm{a}$; mittlere Sedimentationsrate: $11 \mathrm{a} / \mathrm{cm}$; mittlerer Probenabstand: $7 \mathrm{~cm}=77 \mathrm{a}$.

Sediment: Torfe

Die Fagus-Werte erreichen mit dem Beginn der Pollenzone IXa maximale Werte (>30\%). Die Rotbuche dominierte zu dieser Zeit auf fast allen Standorten das Waldbild in der Umgebung des Mooslochs. Die Carpinus-Werte steigen ebenfalls etwas an, bleiben jedoch auf einem geringen Niveau. Starke Rückgänge lassen sich bei allen Kurven des Eichenmischwaldes feststellen. Besonders stark ist die Quercus-Kurve im ersten Abschnitt der Pollenzone betroffen. Vermutlich wurden die Arten zusätzlich zur Konkurrenz mit der Rotbuche von den Siedlungsaktivitäten während der Siedlungszeit 2 beeinträchtigt (siehe dort).

\section{SZ $2(342-279 \mathrm{~cm})$}

751 v. Chr-37 n. Chr. (2701-1913 cal BP, 2964-2644 BP)

Dauer: 788 a; mittlere Sedimentationsrate: $13 \mathrm{a} / \mathrm{cm}$; mittlerer Probenabstand: $8 \mathrm{~cm}=104 \mathrm{a}$.

Sediment: Torfe, $346-322 \mathrm{~cm}$ sowie $290-274 \mathrm{~cm}$ erhöhte silkatische Anteile

Ältere Eisenzeit - Jüngere Eisenzeit - Römische Kaiserzeit

Die Getreide-Kurve ist im gesamten Abschnitt der Siedlungszeit geschlossenen und steigt bis auf $2,5 \%$ an (Triticum- und Hordeum-Typ). Die Kurven vieler sekundärer Siedlungszeiger sind deutlich erhöht (Plantago lanceolata, Chenopodiaceae, Artemisia, Rumex, Plantago major/media-Typ). Die Werte der Nichtbaumpollen-Summe, besonders der Poaceae, steigen gleichzeitig stark an (max. 62\%).

Im Summendiagramm bleibt der Baumpollenanteil trotz dieser hohen Nichtbaumpollen-Werte auf relativ hohem Niveau und zeigt damit einen erheblichen Bewaldungsgrad an. Es zeichnet sich hier demnach keine rodungsbedingte Offenlandschaft $a b$, sondern das veränderte Artenspektrum eines Nutzwaldes. Dieser hatte vermutlich ein lichtes Kronendach und besaß daher einen reichen Unterwuchs an krautigen Arten. Ein hoher Anteil an Gräsern ist typisch für Wälder, die beweidet werden (ELLENBERG 1996). Im vorliegenden Pollendiagramm zeigen dies die hohen Werte der Poaceae-Kurve an. Die leicht erhöhten Werte der Calluna-Kurve weisen möglicherweise auf eine Beweidung des Waldes im Bereich der Böden über Buntsandstein hin.

Erfahrungsgemäß bildeten meist Eichen die Kronschicht solcher Hudewald-Gesellschaften. Sie wurden als Mastbäume geschont. Im vorliegenden Diagramm ist dies jedoch nicht erkennbar. Die Rotbuchenausbreitung in den nicht beweideten Waldgebieten und der dadurch bedingte Rückgang des Quercus-Pollens überdeckt vermutlich den Pollenanteil der 
anthropogen geförderten Eichen im Diagramm.

Darüber hinaus wurde möglicherweise nur ein geringer Teil der Eichen geschützt, während der überwiegende Baumbestand zur Bauholz- und Feuerholzgewinnung genutzt wurde. Im Pollendiagramm sinkt die Quercus-Kurve von über $40 \%$ auf Werte um $15 \%$ ab, während alle anderen Baumpollen-Kurven unbeeinflusst erscheinen.

Am Ende der Siedlungszeit 2 setzt die Kulturpflanzen-Kurve aus. Die Werte der sekundären Siedlungszeiger sind jedoch über die Siedlungszeit 2 hinaus deutlich erhöht. Möglicherweise wurde nicht die Aufgabe der Siedlung, sondern die Verlagerung der Äcker erfasst. Auch die Quercus-Kurve steigt nach dem Ende der Siedlungsphase 2 deutlich an. Der Wald wurde vermutlich nicht mehr beweidet, sondern mittelwaldartig bewirtschaftet. In einem Mittelwald bildeten hauptsächlich Eichen die Kronschicht. Im Unterwuchs stockende Haseln, Hainbuchen u.a. verhinderten das Aufkommen von Gräsern oder lichtbedürftigen Kräutern in der Bodenschicht. In einem regelmäßigen Turnus wurde dieser Holzunterwuchs abgeerntet (ELLENBERG 1996). Im Pollendiagramm steigen nach der Siedlungszeit 2 die Kurven von Quercus und Corylus an, während die Nichtbaumpollen-Werte zurückgehen.

In einer Tiefe von 283-265 cm weisen die erhöhten Anteile technogener Schwermetalle auf eine Verhüttung bleihaltiger Erze zur Silbergewinnung hin (DEICKE 2003). Damit setzt die Verhüttung gleichzeitig mit der Mittelwaldwirtschaft, gegen Ende der Siedlungsphase 2, ein und endet kurz vor Beginn der Zone IXb. Die Nutzung des Mittelwaldes diente damit wahrscheinlich der Holzproduktion für die Verhüttung.

Ein Fundplatz der Späten Latène- oder Frühen Kaiserzeit wurde etwa $2 \mathrm{~km}$ östlich des Mooslochs bei Kleinwechsungen lokalisiert. Möglicherweise handelt es sich um den Siedlungs- oder Verhüttungsplatz, der im Pollendiagramm fassbar wird. Darüber hinaus konnte ein ausgedehntes Brandgräberfeld dieser Zeitstellung am südlichen Stadtrand von Nordhausen ergraben werden (siehe Kapitel 3.6). Die dichte Besiedlung des südwestlichen Harzvorlandes während der Vorrömischen Eisenzeit setzt sich im Raum Nordhausen in der Römischen Kaiserzeit fort. Ein Abbruch der Besiedlung während des 1. Jhs. v. Chr., wie er in vielen Siedlungen im Umfeld der Pipinsburg festgestellt wurde, ist im Diagramm vom Moosloch nicht erkennbar.

Die erhöhten silikatischen Anteile in Abschnitt 346-330 cm wurden vermutlich durch eingetragenen Lösslehm ausgelöst, während es sich zwischen 330-322 cm und 290-274 cm um den Eintrag von Buntsandsteinmaterial handelt (DEICKE 2003). Die Erosion und anschließende Eintragung von Lösslehm sind direkt im Zusammenhang mit der Siedlungszeit zu deuten. Durch Rodungen und Ackerbau wurde die Vegetationsdecke geöffnet. Material des umgebenden Lössbodens wurde erodiert und gelangte in den Erdfall. Der Eintrag des Buntsandsteinmaterials wurde dagegen sehr wahrscheinlich durch Erosion im Bereich der Erdfallböschung verursacht. Diese könnte durch den natürlichen Abbruch der steilen Kanten des Erdfalls erfolgt sein und steht daher nicht in einem direkten Zusammenhang mit der anthropogenen Nutzung der Umgebung.

\section{IXb $(247,5-197,5 \mathrm{~cm})$}

389-1049 n. Chr. (1561-901 cal BP, 1653-959 BP)

Dauer: 660 a; mittlere Sedimentationsrate: $13 \mathrm{a} / \mathrm{cm}$; mittlerer Probenabstand: $5 \mathrm{~cm}=65 \mathrm{a}$.

Völkerwanderungszeit - Frühes Mittelalter

Das Jüngere Subatlantikum ist die Zeit maximaler Hainbuchen-Werte (51\%). Dementsprechend sinken die Werte von Quercus, Betula, Alnus und anderer Baumarten deutlich ab. Die Fagus-Werte bleiben jedoch unverändert hoch und steigen nach dem HainbuchenRückgang weiter an.

Alle siedlungszeigenden Kurven und die Summe des Nichtbaumpollens gehen auf minimale Werte zurück. Der Anteil des Baumpollens steigt im Summendiagramm auf maximale Werte um $80 \%$ an. Eine deutliche Zunahme der Bewaldungsdichte zeichnet sich ab. Die Bewirtschaftung des Mittelwaldes wurde im Zuge der sich verringernden Besiedlung aufgegeben. 
Hain- und Rotbuchen breiteten sich erneut sowohl in den ehemaligen Mittelwäldern als auch auf den verlassenen Ackerflächen aus.

Auf diese Weise schatteten sie zunächst die lichtbedürftigen Haselsträucher und später die Eichen aus. Im Pollendiagramm gehen daher die Kurven beider Taxa mit dem Anstieg der Carpinus-Werte stark zurück. Gleichzeitig nimmt auch der absolute Eintrag von EichenPollen in Zone IXb ab.

Das weitere Gebiet um das Moosloch war während der Pollenzone IXb vor dem Einsetzen der Sz 3a siedlungsarm, aber nicht gänzlich verlassen, wie das Auftreten von Pollenkörnern des Getreide-Typs und der Kornblume (Centaurea cyanus) zeigen.

Geochemisch gibt es im Bereich $246-210 \mathrm{~cm}$ weder Einträge minerogener Stäube noch Hinweise auf Verhüttungsaktivitäten (DEICKE 2003).

\section{SZ 3a $(212,5-197,5 \mathrm{~cm})$}

872-1049 n. Chr. (1078-901 cal BP, 1148-959 BP)

Dauer:177 a; mittlere Sedimentationsrate: $12 \mathrm{a} / \mathrm{cm}$; mittlerer Probenabstand: $5 \mathrm{~cm}=60 \mathrm{a}$.

Frühes Mittelalter

Mit dem Beginn des Abschnitts a der Siedlungszeit 3 nimmt die Besiedlung im Untersuchungsgebiet wieder zu. Die geschlossene Kulturpflanzen-Kurve und erste Pollenkörner von Secale zeigen Ackerbau und damit Siedlungsaktivitäten an. Die Kurven der Nichtbaumpollen-Summe und der Holzkohle-Konzentration sind jedoch nicht wesentlich erhöht und auch die Kurve der sekundären Siedlungszeiger verläuft auf geringem Niveau. Die Siedlungssignale sind derart gering, dass in der Nähe des Untersuchungspunktes keine Äcker gelegen haben können.

Die erhöhten Einträge technogener Schwermetalle ab einer Tiefe von $206 \mathrm{~cm}$ aufwärts lassen den Beginn einer Verhüttungsphase erkennen. Etwa zeitgleich erfolgt ein starker Eintrag minerogenen Materials (DEICKE 2003). Die Kurven der Baumpollen-Taxa erscheinen jedoch weitgehend unbeeinflusst. Da der Baumpollenanteil im Summendiagramm sogar leicht ansteigt, gibt es keine Anzeichen für Rodungen in Abschnitt a der Siedlungszeit 3.

Ungeklärt ist der Grund für einen vorübergehenden Anstieg der Quercus- und der Tilia-Kurve am Beginn der Siedlungszeit. Ein Zusammenhang mit dem Siedlungsgeschehen ist jedoch eher unwahrscheinlich.

\section{Jüngeres Subatlantikum}

\section{$X(197,5-0 \mathrm{~cm})$}

1049 n. Chr.- heute (901-0 cal BP, 959-0 BP)

Dauer: $901 \mathrm{a}$; mittlere Sedimentationsrate: $5 \mathrm{a} / \mathrm{cm}$; mittlerer Probenabstand: $20 \mathrm{~cm}=100 \mathrm{a}$.

\section{SZ 3b $(197,5-115,5 \mathrm{~cm})$}

1049-1480 n. Chr. (901-470 cal BP, 959-430 BP)

Dauer: 431 a; mittlere Sedimentationsrate: $5 \mathrm{a} / \mathrm{cm}$; mittlerer Probenabstand: $18 \mathrm{~cm}=90 \mathrm{a}$.

Hohes Mittelalter - Spätes Mittelalter

Am Beginn der Pollenzone $X$ intensiviert sich die Siedlungszeit 3 dramatisch. Die Werte der Kulturpflanzenkurve steigen sprunghaft von zuvor $0,7 \%$ auf über $20 \%$ an und erreichen bis zu $136 \%$. Die Werte aller sekundären Siedlungszeiger schnellen ebenso in die Höhe und erreichen Maximalwerte. Währenddessen geht die Fagus-Kurve stark zurück und die Werte der Nichtbaumpollen-Summe steigen auf über $200 \%$ an. Die Holzkohle-Konzentrationen sind im gesamten Abschnitt der Siedlungszeit 3 erhöht, schwanken jedoch erheblich.

Starke Rodungen, eine immense Ausweitung der Getreideanbauflächen und intensive Be- 
weidung in der Umgebung sind der Grund für diese Veränderung der Pollenspektren. Es handelt sich um den Beginn des hochmittelalterlichen Landesausbaus. Gerodet wurden bevorzugt Rot- und Hainbuchenbestände, während die Eichen als wertvolle Mastbäume geschont wurden. Gegenläufig zum Rückgang der Fagus- und der Carpinus-Werte steigt die Quercus-Kurve auf mehr als $20 \%$ an. Haselsträucher konnten sich verstärkt an Waldsäumen und auf Rodungsflächen ausbreiten, wie die deutliche Zunahme der Corylus-Werte zeigt.

Die Landschaft wurde durch einen intensiven Getreideanbau und eine starke Entwaldung geprägt. Neben Gerste und Weizen zeichnet sich erstmals deutlich der Anbau von Roggen als Wintergetreide ab. Im Pollendiagramm steigen die Secale-Werte auf bis zu $42 \%$ an. Gleichzeitig treten regelmäßig Pollenkörner der Kornblume (Centaurea cyanus) auf. Auf grund der Beweidung breiteten sich in der Umgebung Weideunkräuter wie Ampfer, Beifuss und Spitzwegerich aus, wie die deutlichen Anstiege der Rumex-, Artemisia- und Plantago lanceolata-Kurven zeigen. Diese hatten durch die Verwendung des Schollenwendpfluges ihre Standorte an Ackerunkrautgesellschaften verloren. Die bei einer Mehrfelderwirtschaft üblicherweise ein oder mehrere Jahre brachliegenden Teile der Ackerflur wurden in der Regel ebenfalls beweidet. Diese Brachen boten zusätzliche Standorte für die Ausbreitung der oben genannten Arten. Das Heidekraut (Calluna vulgaris) breitete sich verstärkt aus. Diese Ausbreitung könnte durch die Beweidung des Waldes im Bereich der ärmeren Buntsandsteinböden erfolgt sein.

In Abschnitt b der Sz 3 setzt sich die Verhüttungsphase verstärkt fort. Der Eintrag technogener Schwermetalle erreicht zwei hochmittelalterliche Maxima bei $156 \mathrm{~cm}$ und bei $185 \mathrm{~cm}$ (DEICKE 2003). Die mit Schwermetallen kontaminierten Flächen in der Umgebung von Verhüttungsplätzen können in der Regel erst nach einer gewissen Regenerationszeit erneut von Phanerogamen besiedelt werden.

Die Einträge technogener Schwermetallgehalte gehen ab einer Tiefe von $150 \mathrm{~cm}$ zurück. Vermutlich wurde nur noch in einer größeren Entfernung vom Moosloch Erz verhüttet (DEICKE 2003). Der stärkste Anstieg der Calluna-Kurve fällt mit dem Rückgang der Verhüttung zusammen. Die Ausbreitung des Heidekrautes könnte demnach mindestens teilweise auf Flächen erfolgt sein, die durch die verstärkte Verhüttungstätigkeit im Bereich des Mooslochs kontaminiert wurden.

Das Zisterzienser Kloster Walkenried betrieb einen landwirtschaftlichen Hof in der Nähe von Herreden (siehe Kapitel 3.8.1). Diese Grangie, Rotterode, lag nur etwa 2-3 km vom Moosloch entfernt und wurde bereits mindestens seit 1137 bewirtschaftet und erweitert (HEUTGER 1977). Möglicherweise spiegeln sich in Abschnitt b der Siedlungszeit 3 des Pollendiagramms der maßgeblich von Walkenrieder Mönchen betriebene, starke Landesausbau und die fortschreitende Kultivierung des Helmerieths wider. Über den Betrieb einer Verhüttungsanlage bei Rotterode durch das Kloster Walkenried ist nichts bekannt. Im Jahre 1528 wurde die Grangie Rotterode als „desolat“ (wüst gefallen) bezeichnet. Für die vermutliche Aufgabe der Bewirtschaftung oder deren starke Einschränkung wurde anhand des Pollendiagramms der Zeitraum von 1423-1537 n. Chr. errechnet.

Darüber hinaus ist $1 \mathrm{~km}$ südlich des Mooslochs am Zusammenfluss der Helme und des Hafer-Bachs die mittelalterliche Wüstung „Fladekendorf" archäologisch bekannt ${ }^{17}$. Möglicherweise hat hier die Verhüttung stattgefunden, die sich im Sediment abzeichnet. In den Dorfwüstungen des Harzvorlandes treten sehr häufig Schlackenreste auf, die auf eine Verhüttung vor Ort hinweisen (KLAPPAUF \& LINKE 1997).

Der sehr starke Anstieg der Betula-Kurve kann auf ein lokales Birkenvorkommen auf dem Erdfall zurückzuführen sein, wie es auch rezent zu beobachten ist. Eine Förderung der Birken als Pioniergehölze durch die starken Rodungen ist ebenfalls möglich.

\footnotetext{
${ }^{17}$ Freundliche Mitteilung von J. Grönke, Untere Denkmalschutzbehörde Nordhausen.
} 


\section{SZ 3c (115,5-74,5 cm)}

1480-1688 n. Chr. (470-262 cal BP, 430-203 BP)

Dauer: 208 a; mittlere Sedimentationsrate: 5 a/cm; mittlerer Probenabstand: $21 \mathrm{~cm}=105 \mathrm{a}$.

Frühe Neuzeit

Ein deutlicher Rückgang aller siedlungszeigenden Kurven charakterisiert den Abschnitt c der Siedlungszeit 3. Die Kulturpflanzen-Summe, die Sekundäre Siedlungszeiger-Summe und die Summe des Nichtbaumpollens gehen zurück. Die Kurven der anthropogen geförderten Gehölze: Corylus und Quercus sinken synchron ab. Kleine Anstiege zeigen dagegen die Kurven von Fagus, von Carpinus und die Summenkurve des Baumpollenanteils. Trotz des weiterhin beherrschenden Ackerbaus im Umfeld des Mooslochs (Getreide-Summe: ca. 20\%) lässt sich eine Zunahme der Buchen fassen, während die Hasel zurückgedrängt wurde.

Trotz des Anstiegs der Pinus-Kurve auf Werte um 20\% ist weiterhin nicht mit der Anwesenheit von Kiefern im Untersuchungsgebiet zu rechnen (siehe Diskussion).

Mit dem Rückgang der Verhüttung ab einer Tiefe von $139 \mathrm{~cm}$ verringert sich auch der Eintrag minerogener Stäube insgesamt. Eine Verhüttungstätigkeit in größerer Entfernung vom Moosloch kann jedoch nicht ausgeschlossen werden (DEICKE 2003).

\section{SZ 3d (74,5-0 cm)}

1688 n. Chr. - heute (262-0 cal BP, 203-0 BP)

Dauer: 262 a; mittlere Sedimentationsrate: 4 a/cm; mittlerer Probenabstand: $21 \mathrm{~cm}=84$ a.

Neuzeit

Ein erneuter Anstieg aller Siedlungszeiger-Kurven erfolgt in Abschnitt d der Siedlungszeit 3. Die Kurven der Kulturpflanzen steigen stark an. Die Werte des Hordeum-Typs und von Secale schwanken stark, bleiben jedoch durchgehend auf einem hohen Niveau. Die hohen Getreide-Werte zeigen einen intensiven Ackerbau in unmittelbarerer Umgebung des Mooslochs an.

Erstmals treten Pollenkörner der neuweltlichen Art Zea mays auf. Mais wurde 1492 nach Europa gebracht, sein Anbau blieb in Deutschland jedoch lange auf die Weinanbaugebiete beschränkt. Erst Hungersnöte und Kartoffelmissernten im 19. Jh. (bes. 1846/47) führten zur Züchtung unempfindlicherer Maissorten (KÖRBER-GROHNE 1987). Diese wurden offenbar auch im südlichen Harzvorland angebaut.

Das jüngste Spektrum enthält Pollenkörner des Buchweizens (Fagopyrum esculentum). Der Buchweizenanbau hatte im 17. und 18. Jh. seine größte Bedeutung als Feldfrucht bei der Kultivierung von Moorböden und auf stark degradierten Sandböden. Im 19. Jh. wurde Buchweizen auch im Harzvorland angebaut (KÖRBER-GROHNE 1987).

Das Auftreten von Sporen der Lebermoose Anthoceros punctatus und A. laevis, deren Standorte z.B. im Bereich vegetationsloser Ackerböden zu finden sind, lässt vermuten, dass diese Böden zumindest zeitweise zwischen den Vegetationsperioden stark erodiert wurden. Auch der Eintrag von Lösslehm zwischen $70-60 \mathrm{~cm}$ und $32-17 \mathrm{~cm}$ weist auf Erosionsvorgänge hin (DEICKE 2003).

Die Siedlungszeiger-Kurven steigen ebenfalls an. Die Grünland- und Brachezeiger wie Plantago lanceolata und Artemisia erreichen jedoch nicht die Maximalwerte aus Abschnitt 3b. In Folge des Übergangs von der geregelten Felderwirtschaft zum Dauerfeldbau verloren Pflanzen wie z.B. der Spitzwegerich (Plantago lanceolata) ihre Standorte auf den Brachflächen.

Besonders auffällig ist auch das im Vergleich zu Abschnitt 3b geringe Niveau der CallunaKurve. Das Heidekraut wurde durch die nachlassende Waldweide im 20. Jh. zunehmend ausgeschattet.

Der Beginn der industriellen Luftverschmutzung liegt mit einem Eintrag sehr hoher Schwermetallgehalte bei einer Tiefe von $31 \mathrm{~cm}$ (DEICKE 2003). 
Die Corylus-Kurve fällt seit dem Beginn des Abschnitts $3 c$ unverändert weiter ab und erreicht in Abschnitt 3d die geringsten Werte ihres Kurvenverlaufs.

Die neuzeitliche Forstwirtschaft beinhaltet eine Nadelholzförderung und bedingt auf diese Weise den Anstieg der Picea-Kurve.

\subsubsection{Diskussion}

Die Ergebnisse des Diagramms vom Moosloch werden im folgenden Text zusammenfassend dargestellt und diskutiert. Vergleiche mit pollenanalytischen Ergebnissen anderer Lokalitäten werden an dieser Stelle nur begrenzt gezogen. Mit Ausnahme des Diagramms von Wittgerode befinden sich alle Untersuchungsorte in mehr als $20 \mathrm{~km}$ Entfernung vom Moosloch und damit im Bereich des sogenannten Pollenfernfluges (Tab. 38).

Tabelle 38: Entfernungen verschiedener pollenanalytisch untersuchter Lokalitäten vom vermoorten Erdfall Moosloch.

\begin{tabular}{|l|l|l|}
\hline Lokalität & Entfernung & Literatur \\
\hline Wittgerode & $15 \mathrm{~km}$ & \\
\hline Jues-See & $30 \mathrm{~km}$ & GRÜGER 2003; HERKING 1998; VOIGT 2003 \\
\hline Aschenhütter Teich & $34 \mathrm{~km}$ & \\
\hline Luttersee & $40 \mathrm{~km}$ & BEUG 1992 \\
\hline Süsser / Salziger See & $45 \mathrm{~km}$ & MÜLLER 1953 \\
\hline Alperstedter Ried & ca. $70 \mathrm{~km}$ & LANGE 1965 \\
\hline
\end{tabular}

Im Moosloch wurde und wird jedoch aufgrund des geringen Durchmessers der Mooroberfläche von etwa $40 \mathrm{~m}$ hauptsächlich Pollen der direkten Umgebung abgelagert (LANG 1994). Das Diagramm vom Moosloch reflektiert daher überwiegend Veränderungen dieser lokalen Vegetation und dementsprechend Veränderungen aufgrund lokaler Siedlungsaktivitäten, die im folgenden diskutiert werden sollen.

In Hinblick auf Fragestellungen zur regionalen Vegetations- und Siedlungsgeschichte des südwestlichen Harzvorlandes werden die Ergebnisse des Diagramms vom Moosloch in Kapitel 5 diskutiert.

In Tabelle 39 wurde die Intensität der Siedlungszeiten im Diagramm vom Moosloch bewertet (siehe auch Abb. 23). Während des Neolithikums konnte im Moosloch-Diagramm keine Siedlungsintensität festgestellt werden. Die archäologisch vermutete linienbandkeramische Siedlung bei Kleinwechsungen (siehe Kapitel 3.3) zeichnet sich im Pollendiagramm nicht ab, obwohl dieser Fundort nur etwa $1 \mathrm{~km}$ südöstlich des Mooslochs liegt. Die Linienbandkeramik war zwischen 5500-4900 v. Chr. in Mitteleuropa verbreitet. Dieser Zeitabschnitt ist im Moosloch-Diagramm in den tiefsten Pollenspektren (PZ VI) erfasst. Aufgrund der geringen zeitlichen Auflösung in diesem Abschnitt des Diagramms konnte der meist schwach ausgeprägte Siedlungseinfluss früher Ackerbauern möglicherweise nicht detektiert werden. 
Tabelle 39: Die Intensität der Siedlungszeiten im Diagramm vom Moosloch (mittlere Baumpollenprozentwerte, $\mathrm{x}=$ Präsenz. Die Mittelwerte der PZ beziehen sich nur auf Tiefen, die außerhalb der Sz liegen)

\begin{tabular}{|c|c|c|c|c|c|c|c|c|c|c|c|c|c|c|c|c|c|c|}
\hline $\begin{array}{l}\text { N } \\
\text { N } \\
\Omega\end{array}$ & 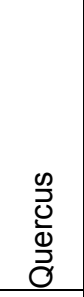 & 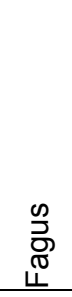 & $\begin{array}{l}\frac{\infty}{2} \\
\frac{\mathrm{C}}{\overline{2}} \\
\frac{0}{0} \\
0\end{array}$ & $\begin{array}{l}\mathbb{D} \\
\mathbb{J} \\
\mathbb{J} \\
\mathbb{D} \\
0 \\
\end{array}$ & 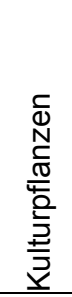 & 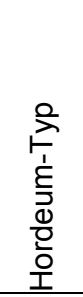 & 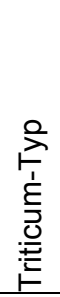 & $\begin{array}{l}\frac{1}{\pi} \\
\mathbb{J} \\
\mathbb{D} \\
\text { C) }\end{array}$ & $\begin{array}{l}\stackrel{0}{\frac{1}{1}} \\
\frac{1}{2} \\
\frac{2}{2} \\
\frac{2}{2}\end{array}$ & 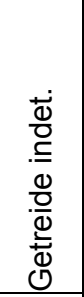 & 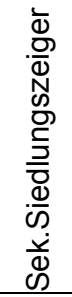 & $\begin{array}{l}\frac{\pi}{\pi} \\
\frac{\pi}{0} \\
\mathbb{0} \\
\frac{0}{\pi} \\
\frac{\pi}{0} \\
\frac{\pi}{\pi} \\
\frac{\pi}{2} \\
\frac{\pi}{\alpha}\end{array}$ & $\begin{array}{l}\stackrel{\times}{\circlearrowright} \\
\stackrel{\text { E}}{\vec{\partial}} \\
\underline{\alpha}\end{array}$ & 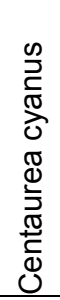 & $\frac{\mathbb{N}}{\stackrel{0}{*}}$ & $\begin{array}{l}\frac{\mathbb{N}}{5} \\
\frac{\bar{J}}{\widetilde{N}}\end{array}$ & 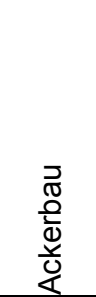 & 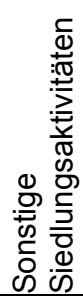 \\
\hline $3 d$ & 26,1 & 14,3 & 3,5 & 88,6 & 57,0 & 11,2 & 3,1 & 32,4 & 1,4 & 8,6 & 22,7 & 1,9 & 8,4 & 0,3 & 0,2 & 1,7 & +++ & ++ \\
\hline $3 c$ & 30,3 & 18,6 & 10,4 & 43,1 & 23,5 & 9,3 & 1,6 & 8,6 & 0,3 & 3,7 & 16,9 & 4,2 & 7,1 & 0,2 & 0,5 & 10,9 & $(+)++$ & +++ \\
\hline $3 b$ & 25,1 & 29,9 & 11,0 & 70,7 & 56,9 & 17,7 & 4,5 & 22,4 & 0,5 & 11,8 & 36,5 & 8,8 & 14,6 & 1,0 & 0,5 & 3,7 & +++ & +++ \\
\hline $3 a$ & 2,7 & 67,1 & 21,4 & 1,5 & 0,4 & & 0,1 & 0,1 & & 0,2 & 0,8 & 0,1 & 0,1 & & & 0,1 & + & - \\
\hline $\mathbf{I X b}$ & 7,5 & 39,0 & 35,1 & 1,4 & 0,1 & $x$ & & & & 0,1 & 0,6 & 0,1 & 0,2 & $x$ & $x$ & & $(+)$ & - \\
\hline $\mathrm{IXa}$ & 31,3 & 34,8 & 4,8 & 6,7 & 0,2 & 0,1 & & & $x$ & 0,1 & 2,8 & 0,6 & 0,7 & & 0,2 & 0,1 & $(+)$ & +++ \\
\hline 2 & 24,3 & 35,7 & 2,2 & 34,5 & 0,9 & 0,2 & 0,2 & & & 0,4 & 8,7 & 2,0 & 0,8 & & 0,1 & 0,7 & ++ & +++ \\
\hline VIIIb & 46,6 & 15,7 & 1,2 & 8,0 & & & & & & & 3,9 & 0,7 & 0,3 & & 0,2 & 0,8 & - & + \\
\hline 1 & 47,8 & 3,5 & 0,3 & 10,1 & 0,4 & $x$ & $x$ & $x$ & $x$ & 0,3 & 3,4 & 0,9 & 0,3 & & 0,3 & 0,2 & + & + \\
\hline VIIIa & 38,7 & 1,4 & 0,1 & 2,5 & & & & & & & 1,5 & 0,2 & $x$ & & 0,2 & $x$ & - & $(+)$ \\
\hline VII & 39,4 & 0,4 & 0,1 & 2,1 & & & & & & & 0,8 & $x$ & 0,1 & & & $x$ & - & - \\
\hline VI & 21,9 & & & 2,3 & & & & & & & 0,5 & & & & & & - & - \\
\hline
\end{tabular}

Während der Frühen und Mittleren Bronzezeit (Sz 1) lässt sich erstmalig eine geringe Siedlungsintensität ablesen. Die archäologische Fundkonzentration der Aunjetitzer Kultur $1,5 \mathrm{~km}$ südlich des Mooslochs könnte zu dem bronzezeitlichen Siedlungsplatz gehören, der sich in Sz 1 abzeichnet. Während der anschließenden Siedlungslücke, die in die Jungbronzezeit datiert, treten im Pollendiagramm keine Pollenkörner des Getreide-Typs auf. Die Werte einiger Sekundärer Siedlungszeiger bleiben jedoch auf einem erhöhten Niveau.

Ein deutlicher Anstieg der Siedlungsintensität lässt sich für die Vorrömische Eisenzeit und die Römische Kaiserzeit nachweisen ( $\mathrm{Sz} 2$ und $\mathrm{IXa}$ ). Rodungen und Ackerbau führten besonders zu Beginn der Siedlungszeit zur Erosion des fruchtbaren Lösslehms. Das später eingetragene Buntsandsteinmaterial stammt dagegen wahrscheinlich aus den Flanken des Erdfalls. Es handelt sich in diesem Fall vermutlich um suspendiertes Feinmaterial aus Rutschungen im Bereich der Böschungen. Möglich ist auch die anthropogene Förderung dieser Erdbewegungen durch starken Tritt (z.B. Vieh) und die Verringerung der Pflanzendecke im Bereich des Erdfallrandes während der Besiedlung.

Der umgebende Wald entwickelte sich von einem durch Beweidung geprägten lichten Hudewald (Sz 2) zu einem auf Holzproduktion ausgerichteten Mittelwald (IXa im Anschluss an Sz 2). Mit Beginn der Römischen Kaiserzeit wurde erstmals in der Nähe des Mooslochs Verhüttung betrieben. Es wurden bleihaltige Erze zur Silbergewinnung verarbeitet. Ein etwa 2 km östlich des Mooslochs lokalisierter Fundplatz der Oder/Warthe-Gruppe (Späte Latène- I Frühe Kaiserzeit) könnte der konstatierte Siedlungs- und Verhüttungsplatz sein. 


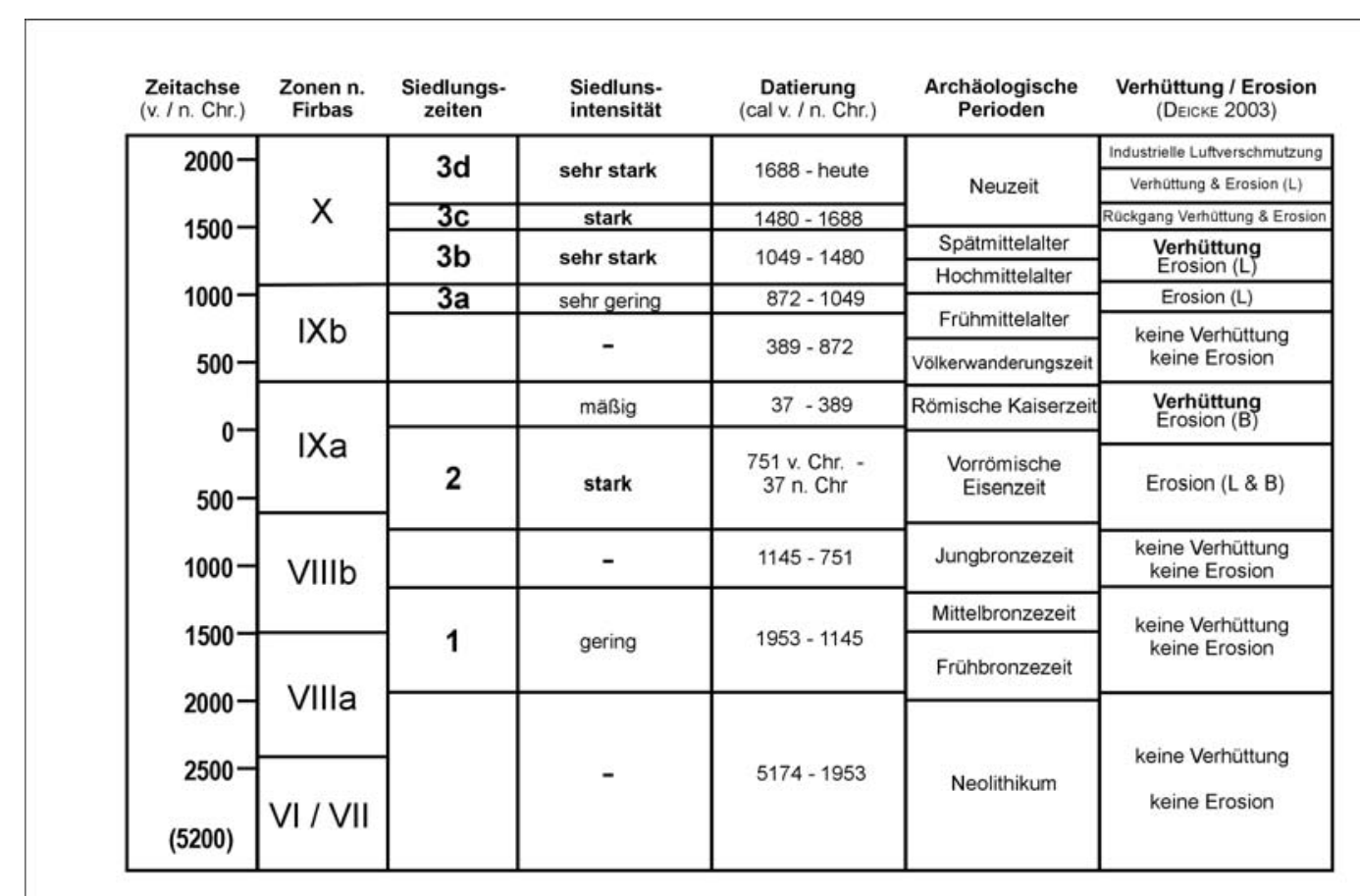

Abbildung 23: Intensität und Datierung der Siedlungszeiten, Verhüttungsaktivitäten und Bodenerosion im Diagramm vom Moosloch ( $\mathrm{L}=$ überwiegend Lösslehm, $\mathrm{B}$ = überwiegend Buntsandstein-Material).

Während der Völkerwanderungszeit (IXb) scheint die Umgebung des Mooslochs vom Menschen weitgehend unbeinflusst gewesen zu sein. Der Nachweis von Centaurea cyanus zeigt jedoch, dass die mittelalterliche Besiedlung und der Ackerbau in der weiteren Umgebung früher einsetzten, als dies im direkten Umfeld des Mooslochs der Fall war.

Die Ende des 9. Jhs. einsetzende frühmittelalterliche Besiedlung war über einen Zeitraum von etwa 200 Jahren von sehr geringer Intensität. Mit dem Beginn der Besiedlung begann jedoch unmittelbar die Erosion von Lösslehm, obwohl in der Umgebung des Erdfalls vermutlich keine umfangreicheren Rodungen stattfanden. Am Übergang zum Hochmittelalter setzte erneut eine Verhüttungsphase ein. Während des gesamten Hohen und Späten Mittelalters (2b) muss die Siedlungsintensität als sehr stark bewertet werden. Vermutlich wurde in direkter Umgebung des Mooslochs Getreide (u.a. Roggen) angebaut. Während der Buchenwald stark gerodet wurde, wurden Eichen(hude)wälder geschützt und gefördert. Die bis zum Ende des Späten Mittelalters unvermindert anhaltende Siedlungsintensität spiegelt höchstwahrscheinlich das Wirtschaften des klösterlichen Eigenbetriebs Rotterode bei Herreden (seit 1137 Grangie des Klosters Walkenried) wider. Das Ende der intensiven Siedlungsphase fällt in die Zeit zwischen 1423-1537 n. Chr.

Die Verhüttung könnte $1 \mathrm{~km}$ südlich des Mooslochs im Bereich der mittelalterlichen Wüstung "Fladekendorf" stattgefunden haben.

Frühneuzeitlich (3c) verringerte sich die Intensität der Siedlungsaktivitäten. Der Waldanteil nahm in der Umgebung des Mooslochs wieder zu (die Mittelwerte in Tab. 39 geben diesen Trend im Gegensatz zum Pollenprozentdiagramm nicht wieder!).

Etwa seit dem 17. Jh. wurde der Ackerbau im Umfeld des Erdfalls erneut ausgeweitet. Die Mehrfelderwirtschaft wurde zugunsten eines Dauerfeldbaus aufgegeben und das Kulturpflanzenspektrum um Mais und Buchweizen erweitert.

Die Ergebnisse zur Siedlungsintensität und zu Verhüttungs- und Bodenerosionsvorgängen am Moosloch sind in Abbildung 23 zusammenfassend dargestellt. 
Die in Tabelle 40 aufgeführten Influx-Werte zeigen einen starken Anstieg der absoluten Pollengehalte aller Taxa an der Grenze 3a/b (Tiefen 200-195 cm) im Sediment an.

Dieser Anstieg kann durch die Rodung des Waldes in der Umgebung des Erdfalls hervorgerufen worden sein, da ein Waldgürtel die Bewegung der Luftschichten erheblich abbremst und auf diese Weise den Ablagerungsort, das Moosloch, von einem Teil des in der Luft transportierten Pollens abgeschirmt haben kann. Nach der Rodung dieses benachbarten Waldes kam es zu einer Zunahme der absoluten Menge abgelagerten Pollens, auch des Baumpollens, und gleichzeitig zur Abnahme des relativen Baumpollenanteils.

Tabelle 40: Polleninflux-Werte des Diagramms vom Moosloch

\begin{tabular}{|c|c|c|c|c|c|c|c|c|c|c|c|c|}
\hline $\mathbf{P Z}$ & Sz & $\begin{array}{l}\text { Tiefe } \\
\text { (cm) }\end{array}$ & Picea & Pinus & Alnus & Betula & Quercus & Fagus & Carpinus & $\Sigma \mathrm{BP}$ & $\Sigma N B P$ & Poaceae \\
\hline \multirow{10}{*}{$x$} & \multirow{3}{*}{ 3d } & 26 & 2187 & 50296 & 14214 & 42642 & 12027 & 7654 & 6560 & 138861 & 198998 & 98406 \\
\hline & & 45 & 59043 & 183691 & 39362 & 3608208 & 78725 & 52483 & 19681 & 4113357 & 806926 & 518270 \\
\hline & & 64 & 39588 & 182107 & 23753 & 87095 & 356296 & 190025 & 31671 & 926371 & 1258914 & 380049 \\
\hline & \multirow{2}{*}{$3 c$} & 85 & 20410 & 61230 & 37418 & 115657 & 91845 & 40820 & 47623 & 415005 & 187092 & 81640 \\
\hline & & 106 & 1781 & 28500 & 12469 & 80157 & 24938 & 33844 & 7125 & 197719 & 147844 & 53438 \\
\hline & \multirow{5}{*}{$3 b$} & 125 & 266 & 666 & 2130 & 4926 & 4527 & 799 & 932 & 15311 & 40075 & 15178 \\
\hline & & 145 & 940 & 7993 & 4232 & 52660 & 8933 & 5172 & 1411 & 83222 & 48899 & 22098 \\
\hline & & 164 & 149 & 2088 & 1492 & 2237 & 1939 & 5966 & 1939 & 17004 & 19838 & 10441 \\
\hline & & 184 & 498 & 13944 & 19919 & 22409 & 23405 & 34361 & 10956 & 130970 & 286840 & 37349 \\
\hline & & 195 & 25992 & 77975 & 127596 & 134685 & 129959 & 623803 & 238652 & 1431912 & 810472 & 328442 \\
\hline \multirow{5}{*}{$\mathbf{I X b}$} & \multirow{3}{*}{$3 a$} & 200 & 2824 & 5648 & 6589 & 19768 & 4707 & 530901 & 135549 & 722929 & 19768 & 4707 \\
\hline & & 204 & 7699 & 33360 & 76985 & 38493 & 51324 & 1131685 & 307941 & 1729604 & 71853 & 35926 \\
\hline & & 210 & 5442 & 14511 & 41719 & 25394 & 50789 & 663884 & 301106 & 1168146 & 56231 & 18139 \\
\hline & & 215 & & 37423 & 310080 & 16039 & 315426 & 1160126 & 1197550 & 3207723 & 42770 & 37423 \\
\hline & & 220 & 3150 & 17323 & 103940 & 9449 & 15749 & 376389 & 348042 & 900815 & 29922 & 12599 \\
\hline
\end{tabular}

Diesen deutlichen Rückgang des relativen Baumpollenanteils zeigt sowohl das Prozentwerte-Diagramm als auch der unterschiedliche Faktor der absoluten Anstiege: Während die Menge des pro Fläche $\left(\mathrm{cm}^{2}\right)$ und Jahr (a) eingetragenen Baumpollens zwischen den Tiefen 200-195 cm um das ungefähr Zweifache zunimmt, steigt die Menge des Nichtbaumpollens ungefähr um das Vierzigfache an (Tab. 40).

Der Eintrag ferntransportierten Pollens in das Moosloch nimmt aufgrund der Rodungen ebenfalls zu, wie die Influx-Werte der Taxa Picea und Pinus zeigen. In dem auf die Baumpollensumme bezogenen Prozentwerte-Diagramm steigen die relativen Anteile dieser Arten durch den Rückgang der Hauptbaumarten Fagus und Carpinus (erkennbar an dem geringeren absoluten Zuwachs) verstärkt an. Die Pinus-Kurve steigt in der Siedlungszeit 3 im Prozent-Diagramm von etwa 5\% (3a) auf $>20 \%$ (3b) an. Diese Zunahme der relativen und absoluten Pinus-Pollenanteile spiegelt aufgrund der genannten Faktoren (erhöhter Polleneintrag und Rückgang der Hauptbaumarten) vermutlich kein häufigeres Auftreten von Kiefern wider.

Darüber hinaus sind die vorliegenden Pinus-Werte von $20-30 \%$ bei einem gleichzeitig geringen Baumpollenanteil zu gering, um auf die Anwesenheit von Kiefern im Harzvorland schließen zu können. Die Untersuchung von Oberflächenproben im Bereich des Süßen Sees (ca. $45 \mathrm{~km}$ östlich des Mooslochs) ergab Pinus-Anteile von $50 \%$ bezogen auf die Baumpollensumme, obwohl die Kiefer weniger als $1 \%$ der sehr geringen Waldfläche in der Region einnimmt und Kiefernwälder erst etwa 50 km weiter östlich auftreten (MüLLER 1953). 


\section{Datierungsergebnisse}

Die in Tabelle 41 angegebenen interpolierten Altersangaben der Pollenzonengrenzen des Diagramms vom Moosloch weisen zum Teil größere Abweichungen von den Altersangaben des Jues-Sees und des Hochharzes auf.

Tabelle 41: Datierungen der Pollenzonen in kalibrierten Kalenderjahren

\begin{tabular}{|c|r|r|r|r|}
\hline & $\begin{array}{c}\text { Aschenhütter } \\
\text { Teich }\end{array}$ & $\begin{array}{c}\text { Jues-See } \\
\text { (VOIGT 2003) }\end{array}$ & Moosloch & $\begin{array}{c}\text { Hochharz } \\
\text { (BEUG et al. } \\
\text { 1999) }\end{array}$ \\
\hline IXb/X & 857 n. Chr. & 790 n. Chr. & 1049 n. Chr. & $900 \mathrm{n}$. Chr. \\
\hline IXa/IXb & 174 n. Chr. & 20 n. Chr. & 389 n. Chr. & 540 n. Chr. \\
\hline VIIIb/IXa & 799 v. Chr. & 1010 v. Chr. & 568 v. Chr. & 780 v. Chr. \\
\hline VIIIa/VIIIb & 1543 v. Chr. & 1670 v. Chr. & 1501 v. Chr. & 1710 v. Chr. \\
\hline VII /VIIIa & & 3350 v. Chr. & 2438 v. Chr. & 4140 v. Chr. \\
\hline VI/VII & & 3960 v. Chr. & 3701 v. Chr. & 4830 v. Chr. \\
\hline Vb/VI & & 7210 v. Chr. & & 6570 v. Chr. \\
\hline
\end{tabular}

\section{Dem können mehrere Ursachen zu Grunde liegen:}

Es wurden unterschiedliche Materialien datiert (z.B. Moosloch: Torfabschnitte, Aschenhütter Teich und Jues-See: Makroreste von Landpflanzen). Den kalibrierten Altersangaben liegen bei verschiedenen Autoren abweichende Standardabweichungen zugrunde. Die Berechnung der interpolierten Daten stützt sich auf eine unterschiedliche Anzahl von Datierungen, die unterschiedlich große Sedimentabschnitte überspannen. Die zur Berechnung der interpolierten Daten nötigen Mittelwerte werden in der Regel ohne Berücksichtigung des Schwankungsbereichs verwendet.

Die Grenzkriterien weichen z.T. voneinander ab. So wurde die Grenze VI/VII in den Hochharzer Diagrammen aufgrund des Beginns der Picea-Ausbreitung gezogen, während in den Diagrammen von Jues-See und Moosloch der Rückgang der Ulmen-Werte herangezogen wurde. Am Diagramm vom Moosloch weisen die interpolierten Datierungen der Grenzen VII/VIIla und VI/VII zudem große Abweichungen auf, da die Sedimentationsrate aus einem jüngeren Abschnitt abgeleitet wurde (siehe Kapitel 4.3.1). Die Grenze VII/VIIIa wurde aufgrund des dauerhaften Anstiegs der Fagus-Werte auf $>1 \%$ festgelegt. An den Diagrammen des Hochharzes wurde jedoch zum Teil der Rückgang der Ulmen-Werte als Kriterium verwendet. Wird dagegen der Fagus-Anstieg datiert, zeigen die Werte eine große Übereinstimmung mit der Datierung der Grenze VII/VIIIa vom Jues-See (Hochharz: 3441 v. Chr. (WILLUTZKI 1962 zitiert nach VOIGT 2003).

Die Kriterien die den Grenzen IXb/X und IXa/IXb zugrunde liegen, sind stark abhängig von der Stärke des anthropogenen Einflusses auf die Vegetation. Die Datierungen dieser Grenzen können daher auch über geringe Distanzen stark variieren. 


\section{Zusammenfassende Diskussion der Ergebnisse}

Im folgenden Kapitel werden die Ergebnisse der pollenanalytischen Untersuchungen an den Sedimenten vom Aschenhütter Teich, von Wittgerode und vom Moosloch mit den Untersuchungsergebnissen des ebenfalls im südwestlichen Harzvorland gelegenen Jues-Sees in Herzberg (VOIGT 2003) und des Luttersees im Unteren Eichsfeld (BEUG 1992) verglichen.

Die genannten Ablagerungsstätten unterscheiden sich vor allem in Bezug auf die Größe ihrer Oberflächen. Der Aschenhütter Teich (ca. $4712 \mathrm{~m}^{2}$ ), Wittgerode (ca. $314 \mathrm{~m}^{2}$ ) und das Moosloch (ca. $126 \mathrm{~m}^{2}$ ) besitzen eine relativ kleine Oberfläche. Der hier abgelagerte Pollen stammt daher zu einem großen Teil aus der lokalen Umgebung der Erdfälle. Der Luttersee (ca. $\left.95000 \mathrm{~m}^{2}\right)$ und der Jues-See $\left(68800 \mathrm{~m}^{2}\right)$ dagegen besitzen wesentlich größere Oberflächen. Dementsprechend überwiegt in ihren Ablagerungen vermutlich der regionale Polleneintrag.

Nach Untersuchungen von BEHRE \& KUČAN (1986) wird der überwiegende Anteil des Pollens von Siedlungszeigern (insbesondere Getreide-Pollen) bereits in unmittelbarer Nähe des Wuchsortes abgelagert. Bei kleinen Ablagerungsstätten ist demnach die Lage in der Siedlungslandschaft ein entscheidendes Kriterium für die Abzeichnung der Siedlungsintensität in den Pollendiagrammen ihrer Sedimente. Die siedlungsgeschichtlichen Ergebnisse der Diagramme vom Aschenhütter Teich und vom Moosloch tragen daher überwiegend zur Klärung der lokalen Abläufe bei. Bei der Bewertung der regionalen Besiedlungsintensität verschiedener Zeiträume im südwestlichen Harzvorland wird dagegen den Ergebnissen vom Jues-See ein größeres Gewicht gegeben.

In Abbildung 24 sind die Ergebnisse der Diagramme vom Aschenhütter Teich, vom Jues$\mathrm{See}^{18}$, von Wittgerode und vom Moosloch einander gegenübergestellt.

In der Zeit des Atlantikums herrschten Eichenmischwälder im gesamten Harzvorland und dem angrenzenden Unteren Eichsfeld vor. Im Lüderholz bei Aschenhütte und in der Umgebung des Mooslochs dominierte die Winterlinde (Tilia cordata) den Wald, während am Jues-See ein Eichen-Ulmen-Linden-Mischwald mit recht ausgewogenen Anteilen stockte (BEUG 1992; CHEN 1982; VOIGT 2003). Im älteren Subboreal erreichte die Rotbuche das Untersuchungsgebiet. An der Zusammensetzung der zuvor beschriebenen Laubmischwälder änderte sich dadurch jedoch zunächst nichts.

Die im Diagramm vom Aschenhütter Teich seit Beginn der Sedimentation (ca. 3500 v. Chr.) nahezu geschlossene Kurve von Plantago lanceolata und die regelmäßigen Funde von Pollenkörnern des Getreide-Typs in PZ VIlla des Diagramms vom Lüderholz (CHEN 1982) verweisen auf eine anthropogene Beeinflussung der Vegetation. Die ältesten Funde von Pollenkörnern des Spitzwegerichs wurden am Jues-See im jüngeren Abschnitt der Sz 3 erfasst (ab 3600 v. Chr.). Im Diagramm vom Luttersee im Unteren Eichsfeld konnte Plantago lanceolata dagegen bereits mehr als 1000 Jahre früher nachgewiesen werden (BEUG 1992). In den Diagrammen vom Aschenhütter Teich, vom Moosloch und von Wittgerode konnten keine neolithischen Siedlungsphasen ausgewiesen werden. Die neolithische Wirtschaftsweise ist jedoch pollenanalytisch schwer fassbar, da sie meist mit geringen Eingriffen in die natürliche Vegetation verbunden war (kleine Äcker, geringe Rodungen).

Für die Zeit des Neolithikums konnten am Jues-See drei Siedlungszeiten mit geringer Siedlungsintensität unterschieden werden (Sz 1: 5650-5375 v. Chr.; Sz 2: 4870-4430 v. Chr.; Sz 3: 4050-2900 v. Chr.). Während der frühesten Siedlungszeit wurde kein Anbau von Getreide nachgewiesen. VOIGT (2003) führt jedoch den Anstieg der Fraxinus-Werte auf eine vermehrte Blühfähigkeit der Eschen durch Schneitelung zurück. In den jüngeren Siedlungsphasen konnte neben Laubfuttergewinnung auch Waldweide und Getreideanbau nachgewiesen werden. Aus der Zeit der Linienbandkeramik wurden im Harzvorland mehrere archäologische Funde nachgewiesen (z.B. Siedlungen bei Schwiegershausen und bei Klein Wechsungen, siehe Kapitel 3.3).

${ }^{18}$ Ergebnisse des Jues-Sees, zitiert nach: (VOIGT in Vorbereitung; VOIGT 2003, VOIGT et al. 2000) 


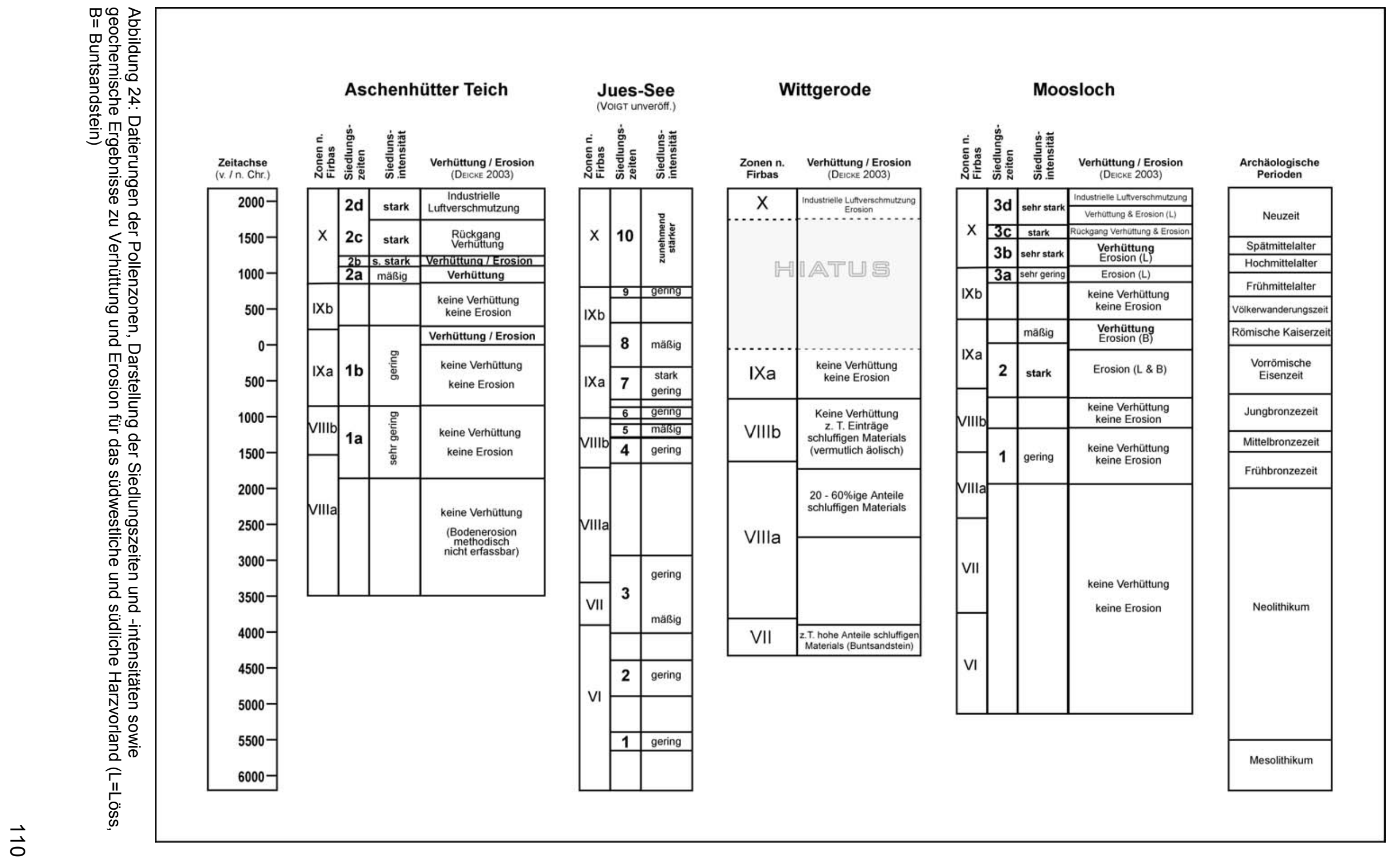


Am Jues-See lässt sich zwischen den neolithischen Siedlungsphasen 1 und 2 kein menschlicher Einfluss nachweisen (VOIGT 2003), während die Umgebung des Luttersees im Unteren Eichsfeld zur Zeit der Linienbandkeramik relativ dicht besiedelt war (BEUG 1992). Vergleichbar geringe Besiedlungsdichten herrschten dagegen an beiden Seen während des Mittelneolithikums. Im anschließenden Jungneolithikum war die Umgebung des Luttersees erneut wesentlich dichter besiedelt als die des Jues-Sees. Während des Endneolithikums kam es anschließend an beiden Lokalitäten zu einem Rückgang der Besiedlungsdichte (Jues-See nach Sz 3), der vermutlich klimatisch bedingt war (BEUG 1992; VOIGT 2003).

Im Jüngeren Subboreal breitete sich die Rotbuche stark auf Kosten der Eichenmischwaldarten aus. Sie dominierte spätestens mit Beginn des Jüngeren Subatlantikums auf allen grundwasserfernen Standorten. Infolgedessen änderte sich die Zusammensetzung der Wälder drastisch und viele Arten verloren durch die Buchenbeschattung ihre Standorte im Unterwuchs der Wälder (z.B. die Hasel).

In den Diagrammen vom Aschenhütter Teich, vom Jues-See und vom Moosloch sind deutliche Siedlungsphasen ausgeprägt, die der Bronzezeit zuzuordnen sind. Lediglich im Diagramm von Wittgerode konnte keine Siedlungszeit ausgewiesen werden. Zur Zeit der Frühen und Mittleren Bronzezeit scheint die Besiedlung im Harzvorland eher schwach ausgeprägt gewesen zu sein. Die Siedlungszeit $1 \mathrm{im}$ Diagramm vom Moosloch erfasst vermutlich eine Siedlung der Aunjetitzer Kultur, die der frühen Bronzezeit zuzurechnen ist. Das Untere Eichsfeld war während der Frühen und Mittleren Bronzezeit wesentlich dichter besiedelt. Dies geht aus den zahlreichen archäologischen Befunden ebenso wie aus den Ergebnissen des Diagramms vom Luttersee hervor (BEUG 1992).

Tabelle 42: Siedlungsintensitäten während der bronzezeitlichen Siedlungsphasen (mittlere Baumpollenprozentwerte, $x=$ Präsenz)

\begin{tabular}{|c|c|c|c|c|c|c|c|c|c|c|c|c|c|c|c|c|c|}
\hline & N & $\begin{array}{l}\stackrel{0}{0} \\
\frac{0}{0} \\
\frac{0}{0}\end{array}$ & 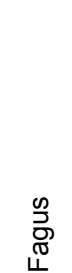 & 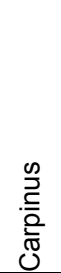 & $\begin{array}{l}\mathbb{0} \\
\mathbb{\Xi} \\
\mathbb{0} \\
\mathbb{0} \\
0 \\
0\end{array}$ & 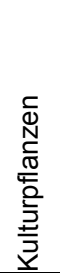 & 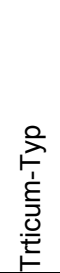 & $\frac{\substack{\frac{1}{\infty} \\
\frac{2}{\infty}}}{\frac{2}{\alpha}}$ & 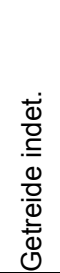 & 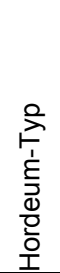 & 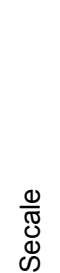 & 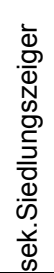 & $\begin{array}{l}\frac{\pi}{\pi} \\
\frac{\pi}{0} \\
\frac{d}{0} \\
0 \\
\frac{\pi}{0} \\
\frac{\pi}{0} \\
\frac{\pi}{\pi} \\
\frac{\pi}{2} \\
\frac{\pi}{\alpha}\end{array}$ & 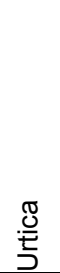 & 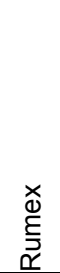 & 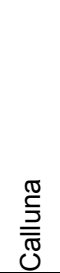 & 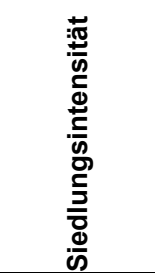 \\
\hline Aschenhütter Teich & $1 \mathrm{a}$ & 16,9 & 8,6 & 0,5 & 2,5 & 0,1 & $x$ & 0,0 & $x$ & $x$ & 0,0 & 1,8 & 0,6 & $x$ & 0,2 & 0,3 & sehr gering \\
\hline Moosloch & 1 & 47,8 & 3,5 & 0,3 & 10,1 & 0,4 & $x$ & $x$ & 0,3 & $x$ & $x$ & 3,4 & 0,9 & 0,3 & 0,3 & 0,2 & gering \\
\hline \multirow{3}{*}{$\begin{array}{l}\text { Jues-See } \\
\text { (VOIGT 2003) }\end{array}$} & 6 & 9,3 & 37,2 & 0,5 & 2,7 & 0,6 & 0,2 & $x$ & 0,2 & 0,2 & 0,0 & 1,0 & 0,6 & 0,0 & 0,1 & 0,2 & gering \\
\hline & 5 & 14,6 & 15,6 & 0,4 & 3,5 & 3,3 & 0,8 & 0,0 & $x$ & 2,3 & 0,1 & 1,5 & 0,6 & 0,0 & 0,2 & 0,1 & mäßig \\
\hline & 4 & 14,1 & 6,7 & 0,4 & 3,2 & 0,2 & 0,1 & 0,0 & 0,0 & 0,1 & $x$ & 1,2 & 0,6 & 0,0 & 0,1 & $x$ & gering \\
\hline
\end{tabular}

Die archäologischen Befunde belegen, dass die Besiedlungsdichte während der Jüngeren Bronzezeit im Harzvorland zunahm. So datiert beispielsweise die unbefestigte Höhensiedlung im Bereich der Pipinsburg (siehe Kapitel 3.4) in diese Zeit. Am Jues-See wurde während der Jüngeren Bronzezeit (Sz 5) eine Phase mit mäßigem anthropogenem Einfluss erfasst (Tab. 42).

Sowohl im Diagramm vom Luttersee als auch im Diagramm vom Jues-See geht die Siedlungsintensität am Ende der Bronzezeit deutlich zurück (BEUG 1992; VOIGT 2003). Dem gegenüber nimmt die Siedlungsintensität im Diagramm vom Aschenhütter Teich am Übergang von der Bronze- zur Eisenzeit etwas zu (Sz 1b). Im Diagramm vom Moosloch setzt in diesem Zeitraum die Siedlungszeit 2 ein, die von einer relativ starken Siedlungsintensität geprägt wird (Tab. 43). 
Tabelle 43: Siedlungsintensitäten während der eisenzeitlichen Siedlungsphasen (mittlere Baumpollenprozentwerte, $x=$ Präsenz)

\begin{tabular}{|c|c|c|c|c|c|c|c|c|c|c|c|c|c|c|c|c|c|}
\hline & $\frac{N}{N}$ & $\begin{array}{l}\stackrel{0}{J} \\
0 \\
\stackrel{0}{0} \\
0 \\
\end{array}$ & $\begin{array}{l}\mathscr{\infty} \\
\stackrel{5}{\mathscr{D}} \\
\stackrel{\mathbb{L}}{ }\end{array}$ & 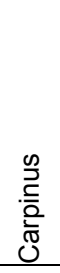 & $\begin{array}{l}\mathbb{0} \\
\mathbb{\Phi} \\
\mathbb{0} \\
\mathbb{0} \\
0 \\
\end{array}$ & 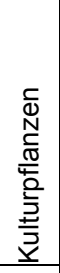 & 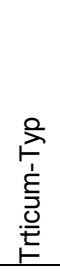 & $\begin{array}{l}\stackrel{2}{\frac{1}{2}} \\
\frac{1}{0} \\
\frac{0}{0} \\
\frac{1}{2}\end{array}$ & 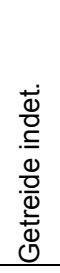 & 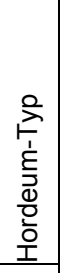 & $\begin{array}{l}\frac{1}{\pi ల} \\
\mathbb{D} \\
\infty\end{array}$ & 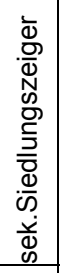 & 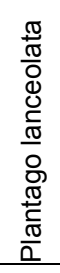 & 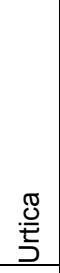 & $\begin{array}{l}\stackrel{\times}{\Phi} \\
\stackrel{E}{J} \\
\underline{\underline{\Psi}}\end{array}$ & 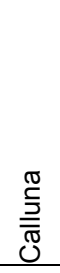 & 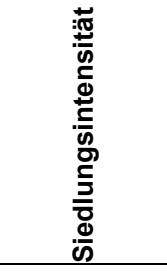 \\
\hline Aschenhütter Teich & $1 \mathrm{~b}$ & 11,5 & 35,6 & 1,3 & 6,7 & 0,2 & 0,1 & & & 0,1 & & 2,8 & 1,1 & $x$ & 0,5 & 0,1 & gering \\
\hline \multirow{2}{*}{ Moosloch } & IXa & 31,3 & 34,8 & 4,8 & 6,7 & 0,2 & & $x$ & 0,1 & 0,1 & & 2,8 & 0,6 & 0,2 & 0,7 & 0,1 & mäßig \\
\hline & 2 & 24,3 & 35,7 & 2,2 & 34,5 & 0,9 & 0,2 & & 0,4 & 0,2 & & 8,7 & 2,0 & 0,1 & 0,8 & 0,7 & stark \\
\hline \multirow{2}{*}{ Jues-See } & 8 & 9,8 & 36,7 & 8,2 & 2,0 & 0,2 & 0,1 & & $x$ & 0,1 & $x$ & 0,7 & 0,4 & $x$ & 0,1 & 0,1 & mäßig \\
\hline & 7 & 7,7 & 39,3 & 0,6 & 5,2 & 1,2 & 0,8 & $x$ & 0,1 & 0,2 & $x$ & 2,2 & 0,8 & $x$ & 0,7 & 0,2 & gering-stark \\
\hline
\end{tabular}

Während der Eisenzeit war das Harzvorland dicht besiedelt. Diese Tatsache wird durch die zahlreichen archäologischen Funde (z.B. die befestigte Siedlung Pipinsburg siehe Kapitel 3.5) ebenso bestätigt wie durch die palynologischen Ergebnisse zur Siedlungsgeschichte am Jues-See, am Aschenhütter Teich und am Moosloch. Im Unteren Eichsfeld herrschte während der Vorrömischen Eisenzeit eine ähnlich hohe Besiedlungsdichte wie im Harzvorland. Im Diagramm des Luttersees ist jedoch keine deutliche Zunahme der Siedlungsintensität gegenüber der vorherigen Siedlungsphase erkennbar (BEUG 1992).

Während der eisenzeitlichen Sz 7 am Jues-See wurden erstmals starke Rodungen im Bereich der Buchenwälder sowie anthropogen geschaffenes Grasland erfasst (VOIGT 2003). Die Entwicklung von Sensen während der Eisenzeit ermöglichte vermutlich erstmals eine Nutzung von Grünland zur Gras- und Heugewinnung (siehe Kapitel 3.5). Während der Siedlungszeit 2 konnten im Diagramm vom Moosloch dagegen keine größeren Rodungen erfasst werden. Der Wald wurde hier vermutlich durch eine intensive Beweidung stark aufgelichtet.

Kurz vor dem Ende der Sz 2 setzt am Moosloch eine Verhüttungsphase ein. Die Verhüttung hält über das Ende der Siedlungszeit hinaus an, das durch ein Aussetzen der KulturpflanzenWerte gekennzeichnet ist. Während der Römischen Kaiserzeit zeichnet sich pollenanalytisch im Diagramm vom Moosloch ein Mittelwald ab (Tab. 43 Sz IXa). Im gleichen Zeitraum lässt sich im Diagramm vom Aschenhütter Teich (Sz 1b) eine Verhüttungsphase feststellen. Am Jues-See wurden während der Siedlungszeit 8 lediglich Siedlungsaktivitäten in größerer Entfernung vom See festgestellt.

Trotz der Aufgabe der Pipinsburg und weiterer Siedlungsplätze während des 1. Jhs. v. Chr. ist weder archäologisch noch pollenanalytisch mit einem starken Siedlungsrückgang im Harzvorland während der Römischen Kaiserzeit zu rechnen. Untersuchungen der Siedlung bei Düna im südwestlichen Harzvorland zeigten eine Siedlungskonstanz vom Beginn der Römischen Kaiserzeit bis ins Späte Mittelalter. Im südlichen Harzvorland sind ebenfalls mehrere germanische Gräberfelder und Siedlungsplätze archäologisch bekannt (siehe Kapitel 3.6).

Mit dem Beginn der PZ IXb (Völkerwanderungszeit) kam es im Harzvorland und im Unteren Eichsfeld zu einem deutlichen Rückgang der Besiedlung und einer Zunahme der Bewaldung. Erstmals breitete sich neben der Rotbuche auch die Hainbuche verstärkt aus (BEUG 1992; VOIGT 2003). 
Tabelle 44: Siedlungsintensitäten von der Völkerwanderungszeit bis zur Neuzeit (mittlere Baumpollenprozentwerte, $x=$ Präsenz, PZ IXb excl. Sz)

\begin{tabular}{|c|c|c|c|c|c|c|c|c|c|c|c|c|c|c|c|c|c|}
\hline & $\frac{N}{N}$ & $\begin{array}{l}0 \\
0 \\
0 \\
0 \\
\partial \\
0\end{array}$ & $\begin{array}{l}\stackrel{0}{5} \\
\text { D } \\
\stackrel{\pi}{\leftarrow} \\
\end{array}$ & $\begin{array}{l}\stackrel{0}{D} \\
\stackrel{\frac{D}{2}}{\frac{2}{\pi}} \\
0 \\
\end{array}$ & $\begin{array}{l}\mathbb{0} \\
\mathbb{J} \\
\mathbb{0} \\
\mathbb{0} \\
0 \\
0\end{array}$ & $\begin{array}{l}\frac{c}{0} \\
\stackrel{N}{N} \\
\frac{\pi}{0} \\
\frac{0}{2} \\
\frac{2}{3} \\
\frac{2}{2} \\
\underline{1} \\
\end{array}$ & 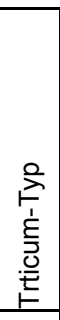 & 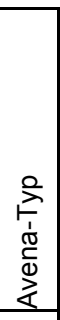 & 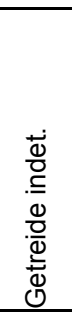 & 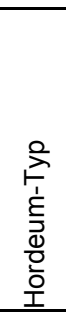 & $\begin{array}{l}\frac{0}{\sqrt[N]{N}} \\
\mathbb{\Phi} \\
\infty\end{array}$ & 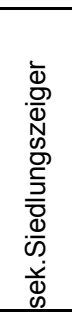 & $\begin{array}{l}\frac{\pi}{\pi} \\
\frac{\pi}{0} \\
d \\
0 \\
\frac{\pi}{\pi} \\
0 \\
0 \\
\frac{\pi}{\pi} \\
\frac{\pi}{0} \\
\frac{\pi}{\alpha} \\
\end{array}$ & 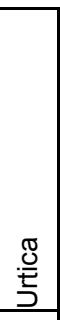 & 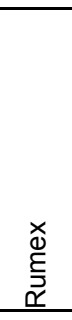 & $\begin{array}{l}\stackrel{\mathbb{N}}{5} \\
\overline{\bar{J}} \\
0 \\
\end{array}$ & 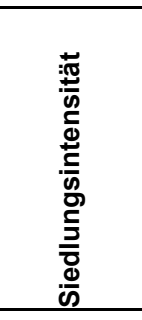 \\
\hline \multirow{5}{*}{ 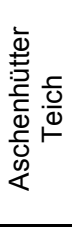 } & $2 d$ & 25,1 & 20,8 & 8,1 & 43,3 & 17,3 & & 0,7 & 2,3 & 6,8 & 7,5 & 14,3 & 3,6 & 0,0 & 7,2 & 0,7 & stark \\
\hline & $2 c$ & 41,1 & 20,7 & 10,1 & 13,7 & 13,1 & 0,5 & 0,1 & 0,9 & 3,8 & 7,7 & 4,6 & 1,6 & 0,0 & 1,3 & 0,6 & stark \\
\hline & $2 \mathrm{~b}$ & 14,7 & 30,1 & 13,4 & 25,6 & 22,5 & 2,2 & 0,2 & 2,4 & 6,1 & 11,6 & 12,3 & 2,7 & $x$ & 6,4 & 1,6 & sehr stark \\
\hline & $2 a$ & 6,2 & 43,5 & 27,5 & 4,1 & 2,5 & 0,4 & $x$ & 0,1 & 0,4 & 1,5 & 2,6 & 0,5 & $x$ & 1,1 & 0,4 & mäßig \\
\hline & $\mathrm{IXb}$ & 5,4 & 39,9 & 23,5 & 1,4 & 0,1 & & $x$ & 0,0 & $x$ & $x$ & 0,7 & 0,2 & 0,0 & 0,1 & 0,2 & \\
\hline \multirow{5}{*}{$\begin{array}{l}\frac{}{0} \\
\frac{0}{0} \\
0 \\
\sum \\
\sum\end{array}$} & $3 d$ & 26,1 & 14,3 & 3,5 & 88,6 & 57,0 & 3,1 & 1,4 & 8,6 & 11,2 & 32,4 & 22,7 & 1,9 & 0,2 & 8,4 & 1,7 & sehr stark \\
\hline & $3 c$ & 30,3 & 18,6 & 10,4 & 43,1 & 23,5 & 1,6 & 0,3 & 3,7 & 9,3 & 8,6 & 16,9 & 4,2 & 0,5 & 7,1 & 10,9 & stark \\
\hline & $3 b$ & 25,1 & 29,9 & 11,0 & 70,7 & 56,9 & 4,5 & 0,5 & 11,8 & 17,7 & 22,4 & 36,5 & 8,8 & 0,5 & 14,6 & 3,7 & sehr stark \\
\hline & $3 a$ & 2,7 & 67,1 & 21,4 & 1,5 & 0,4 & 0,1 & & 0,2 & & 0,1 & 0,8 & 0,1 & & 0,1 & 0,1 & sehr gering \\
\hline & $\mathrm{IXb}$ & 7,5 & 39,0 & 35,1 & 1,4 & 0,1 & & & 0,1 & $x$ & & 0,6 & 0,1 & $x$ & 0,2 & & \\
\hline \multirow{5}{*}{ 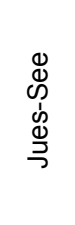 } & Neuzeit (10) & 25,7 & 19,9 & 4,0 & 38,8 & 15,4 & 3,2 & 0,3 & 8,2 & 0,6 & 3,1 & 15,8 & 4,1 & 0,0 & 3,0 & 1,0 & stark \\
\hline & Spätes Ma / Früh. Nz (10) & 42,8 & 18,3 & 4,8 & 15,1 & 4,3 & 0,4 & $x$ & 1,6 & 0,4 & 1,9 & 6,0 & 2,0 & $x$ & 1,7 & 0,6 & mäßig \\
\hline & Hohes Ma (10) & 7,2 & 36,8 & 11,2 & 12,6 & 4,4 & 0,5 & 0,1 & 1,2 & 0,9 & 1,7 & 7,0 & 1,3 & 0,2 & 3,9 & 0,4 & mäßig \\
\hline & Frühes $\mathrm{Ma}(\mathrm{Sz} 9+10)$ & 16,8 & 36,2 & 11,2 & 15,2 & 6,1 & 1,0 & 0,1 & 2,5 & 0,8 & 1,7 & 6,9 & 1,7 & 0,1 & 2,2 & 0,5 & mäßig \\
\hline & $\mathrm{IXb}$ & 4,1 & 46,1 & 15,0 & 0,9 & 0,1 & $x$ & $x$ & $\mathrm{x}$ & $x$ & $x$ & 0,3 & 0,1 & $x$ & 0,1 & 0,1 & \\
\hline
\end{tabular}

Das erneute Einsetzen der Siedlungstätigkeiten datiert in das Frühe Mittelalter. Der Anbau von Getreide und besonders von Roggen als Wintergetreide zeichnet sich jetzt im Harzvorland und im Unteren Eichsfeld klar ab (BEUG 1992; VOIGT 2003). Trotz der gleichzeitig einsetzenden Verhüttung im Harzvorland (Aschenhütter Teich) kam es weder hier noch im Unteren Eichsfeld zu umfangreicheren Rodungen (vgl. BEUG 1992). Während des anschließenden hochmittelalterlichen Landesausbaus kam es dagegen in beiden Räumen zu starken Rodungen und einer Intensivierung des Getreideanbaus.

Wie die mittleren Prozentwerte der siedlungszeigenden Taxa in Tabelle 44 zeigen, unterschied sich die Intensität der Nutzung während des Mittelalters und der Neuzeit erheblich. Während es am Aschenhütter Teich und am Moosloch zu einer starken Ausweitung des Getreideanbaus während des Hochmittelalters kam, wurde im Bereich des Jues-Sees erst mit Beginn der Neuzeit vermehrt Getreide angebaut (VOIGT 2003). Im Diagramm vom Moosloch wurde vermutlich mit dem Abschnitt b der Sz 3, der eine sehr starke Siedlungsintensität aufweist, die hochmittelalterliche Urbarmachung der Helmeniederung erfasst. Im Hochmittelalter nahm die Verhüttung am Moosloch und am Aschenhütter Teich stark zu.

Die Auswirkungen der Verhüttung auf die Vegetation lassen sich pollenanalytisch insbesondere durch den Rückgang der Baumpollenanteile in Folge der Rodungen nur indirekt fassen. Die Anlage von Verhüttungsplätzen, die kleinflächige Ausbreitung einer Schwermetallvegetation auf kontaminierten Böden oder die Schädigung der Vegetation durch die Rauchentwicklung kann dagegen mit den Mitteln der Pollenanalyse kaum oder gar nicht nachgewiesen werden.

Während des Hochmittelalters kam es sowohl am Aschenhütter Teich als auch am Moosloch zu Bodenerosion. 
Trotz der erheblichen Rodungen, die im gesamten Harzvorland während des Hochmittelalters erfolgten, gibt es Hinweise für eine Schonung der Eichen. Die starken spätmittelalterlichen bis frühneuzeitlichen Anstiege der Quercus-Werte in den Diagrammen vom Aschenhütter Teich und vom Jues-See lassen sich mit historisch überlieferten Eichenmastwäldern in Zusammenhang bringen. Im Lüderholz bei Aschenhütte und „östlich des JuesSees" stockten nach Aussage historischer Quellen aus der Zeit von 1596-1732 Masteichen (siehe Kapitel 3.8.4). Während des Spätmittelalters und der Frühen Neuzeit kam es in Folge der Wüstungsprozesse zu einem Rückgang der Siedlungsintensität und der Verhüttung im Harzvorland. Das Ausmaß und die Datierung dieser Siedlungsrückgänge variiert jedoch stark zwischen den unterschiedlichen Lokalitäten.

Im Diagramm vom Moosloch steigt die Siedlungsintensität neuzeitlich besonders stark an. Auch aktuell wird in der direkten Umgebung des Mooslochs ein intensiver Getreideanbau betrieben.

Die vorliegenden Pollendiagramme enthalten keine Hinweise auf ein vorneuzeitliches Auftreten der Fichte oder der Kiefer im Harzvorland. Die von SCHUBART (1978) ausgewiesenen Fichtenkerngebiete im nordwestlichen Harzvorland (Abb. 13) können anhand der vorliegenden Ergebnisse weder bestätigt noch dementiert werden. 


\section{Literatur}

ANDERSEN, S.T., 1973. The differential pollen productivity of trees and its significance for the interpretation of a pollen diagram from a forested region. In: H. J. B. BIRKS \& R.G. WEST (Hrsg.), Quaternary Plant Ecology, Oxford, S.109-115.

ANDRAE, C. \& WILLERDING, U., 1989. Zur Entwicklung der Landnutzung bei Düna. Denkmalpflege in Niedersachsen, 9: S.74-79.

Bauer, L., 1962a. Helme-Unstrutniederung. In: Meynen, E.; Schmidthüsen, J.; Gellert, I; Neef, E.; MÜLLER-MINY, H.; SCHULTZE, I.H. (Hrsg.), Handbuch der naturrämlichen Gliederung Deutschlands. Bundesanstalt für Landeskunde und Raumforschung Selbstverlag, Bad Godesberg, S.750-752.

BAUeR, L., 1962b. Nordthüringisches Hügelland. In: Meynen, E.; SChmidthüsen, J.; Gellert, I; Neef, E.; MÜLLER-MINY, H.; SCHULTZE, I.H. (Hrsg.), Handbuch der naturrämlichen Gliederung Deutschlands. Bundesanstalt für Landeskunde und Raumforschung Selbstverlag, Bad Godesberg, S.745-747.

BAUER, L., 1962c. Südharzer Zechsteingürtel. In: MeYnen, E.; SchmidthüSEn, J.; Gellert, I; Neef, E.; MüLLER-MINY, H.; SCHULTZE, I.H. (Hrsg.), Handbuch der naturrämlichen Gliederung Deutschlands. Bundesanstalt für Landeskunde und Raumforschung Selbstverlag, Bad Godesberg, S.747-748.

BeHRE, K.-E., 1998. Mensch und Umwelt in der Bronzezeit Europas. In: BeRnHARD HünSEL (Hrsg.), Die Bronzezeit: Das erste goldene Zeitalter Europas, Kiel, S.91-110.

BEHRE, K.-E. \& KUČAN , D., 1986. Die Reflektion archäologisch bekannter Siedlungen in Pollendiagrammen verschiedener Entfernung - Beispiele aus der Siedlungskammer Flögeln, Nordwestdeutschland. In: KARL-ERNST BEHRE (Hrsg.), Anthropogenic Indicators in Pollen Diagrams, Rotterdam, Boston, S.95-114.

BEUG, H.-J., 1957. Untersuchungen zur spät- und postglazialen Florengeschichte einiger Mittelgebirge. Flora, 145: S.167-211.

BEUG, H.-J., 1961. Leitfaden der Pollenbestimmung für Mitteleuropa und angrenzende Gebiete, Lieferung 1, Stuttgart, S.63.

BEUG, H.-J., 1992. Vegetationsgeschichtliche Untersuchungen über die Besiedlung im Unteren Eichsfeld, Landkreis Göttingen, vom frühen Neolithikum bis zum Mittelalter. Neue Ausgrabungen und Forschungen in Niedersachsen, 20: S.261-339.

Beug, H.-J., HenRION, I. \& SCHMÜsER, A., 1999. Landschaftsgeschichte im Hochharz: Die Entwicklung der Wälder und Moore seit dem Ende der letzten Eiszeit. Papierflieger, Clausthal-Zellerfeld, S.454.

BINDING, G., 1996. Deutsche Königspfalzen - Von Karl dem Großen bis Friedrich II. (765-1240). Wissenschaftliche Buchgesellschaft, Darmstadt, S.398.

BORNHARDT, W., 1931. Geschichte des Rammelsberger Bergbaus von seiner Aufnahme bis zur Neuzeit. Archiv für Lagerstättenforschung, 52, S.366.

BORNHARDT, W., 1943. Der Oberharzer Bergbau im Mittelalter. Archiv für Landeskunde Niedersachsen, 2: S.449-502.

Вотн, F., 1987. Neue latènezeitliche Funde aus der Kleinen Jettenhöhle bei Düna, Stadt Osterode am Harz (Ldkr. Osterode am Harz). Nachrichten aus Niedersachsens Urgeschichte, 56: S.129154.

BrachmanN, H., 1994. [Rezension zu Claus 1992]. Die Kunde N.F., 45: S.287-292.

BRINKMANN, R., 1976. Abriß der Geologie - Band II: Historische Geologie. Enke Verlag, Stuttgart, S.131f.

BROCKNER, W., 1992. Vor- und frühgeschichtliche Metallgewinnung und Metallverarbeitung in der Harzregion. Mitteilungsblatt TU Clausthal, 74: S.21-24.

BROCKNER, W., 2000. Archäometrische Untersuchungen an ausgewählten Grabungsfunden zur Erhellung der frühen Silbergewinnung in der Harzregion. In: CHRISTIANE SEGERS-GLOCKE (Hrsg.), Auf den Spuren einer frühen Industrielandschaft. Naturraum - Mensch - Umwelt im Harz. Niemeyer, Hameln, S.39-41.

BROCKNER, W. \& KOLB, H.E., 1986. Archäometrische Untersuchungen an Erz- und Schlackenfunden der Grabung Düna. In: HANS-HERBERT MöLleR (Hrsg.), Düna/Osterode - ein Herrensitz des frühen Mittelalters. Arbeitshefte zur Demkmalpflege in Niedersachsen, Hannover, S.74-77.

BRÜNING, K., 1928. Alte und neue Wasserwirtschaft im Harz und ihre natürlichen Grundlagen, eine wirtschaftsgeographische Skizze. Jahrbuch der geographischen Gesellschaft Hannover 1928: S.113-140.

BRÜNNING, K. \& SCHMIDT, H. (Hrsg.), 1969. Niedersachsen und Bremen. Handbuch historischer Stätten Deutschlands, 2. Kröner, Stuttgart, S.602. 
CHEN, S.-H., 1982. Neue Untersuchungen über die Spät- und Postglaziale Vegetationsgeschichte im Gebiet zwischen Harz und Leine, Dissertation Universität Göttingen, S.102.

Claus, M., 1958. Die Pipinsburg bei Osterode am Harz. In: RömISCH-GeRmanische Kommission DES DEUTSCHEN ARCHÄOLOGISCHEN INSTITUTES (Hrsg.), Neue Ausgrabungen in Deutschland. Mann, Berlin, S.161-174.

ClaUs, M., 1973. Ein frühbronzezeitlicher Grabhügel auf dem Rotenberg bei Pöhlde, Kr. Osterode am Harz. Nachrichten aus Niedersachsens Urgeschichte, 42: S.239-244.

CLAUS, M., 1978. Archäologie im südwestlichen Harzvorland. Wegweiser zur Vor- und Frühgeschichte Niedersachsens, 10, Hildesheim, S.192.

CLAUS, M., 1992. Palithi. Die Ausgrabungen an der Wallburg König Heinrichs Vogelherd bei Pöhlde (Stadt Herzberg am Harz / Landkreis Osterode am Harz). Materialhefte zur Ur- und Frühgeschichte Niedersachsens, 23. Theiss, Stuttgart, S.138.

Claus, M. \& FANSA, M., 1983. Palithi. Die Keramik der jüngeren Eisenzeit, römischen Kaiserzeit und des Mittelalters aus dem Pfalzbereich von Pöhlde (Stadt Herzberg am Harz / Landkreis Osterode am Harz). Materialhefte zur Ur- und Frühgeschichte Niedersachsens, 18. Lax, Hildesheim, S.102.

Claus, M. \& SCHLÜTER, W., 1975. Die Pipinsburg bei Osterode am Harz. Ausgrabungen in Deutschland, 1: S.253-272.

DEICKE, M., 2003. Erdfallablagerungen des südlichen Harzvorlandes - Archive der Umweltgeschichte der letzten Jahrtausende. Dissertation der geowissenschaftlichen Fakultät der Universität Göttingen, S.105.

DENECKE, D., 1969. Methodische Untersuchungen zur historisch-geographischen Wegenetzforschung im Raum zwischen Solling und Harz. Ein Beitrag zur Rekonstruktion der mittelalterlichen Kulturlandschaft. Göttinger Geographische Abhandlungen, 54, S.423.

DENECKE, D., 1978. Erzgewinnung und Hüttenwesen des Mittelalters im Oberharz und im Harzvorland. Archäologisches Korrespondenzblatt, 8: S.77-84.

DIERSCHKE, H., 1969. Pflanzensoziologische Exkursionen im Harz. Mitteilungen der FloristischSoziologischen Arbeitsgemeinschaft N.F., 14: S.459-479.

DiERSCHKE, H., 1986. Pflanzensoziologische und ökologische Untersuchungen in Wäldern SüdNiedersachsens. Tuexenia, 6: S.299-323.

DierschKe, H., OtTE, A. \& NordMAnN, H., 1983. Die Ufervegetation der Fliessgewässer des Westharzes und seines Vorlandes. Naturschutz und Landschaftspflege in Niedersachsen, 4: S.1-83.

DoLLE, J., 2002. Urkundenbuch des Klosters Walkenried. Quellen und Forschungen zur braunschweigischen Landesgeschichte, mehrere Bände. Hahn, Hannover.

DöRFLER, W., 1989. Pollenanalytische Untersuchungen zur Vegetations- und Siedlungsgeschichte im Süden des Landkreises Cuxhaven, Niedersachsen. Probleme der Küstenforschung im südlichen Nordseegebiet, 17: S.1-75.

DRACHENFELS, O.V., 1990. Naturraum Harz - Grundlagen für ein Biotopschutzprogramm. Naturschutz und Landschaftspflege in Niedersachsen, 19: S.1-100.

DUŠEK, S. (Hrsg.), 1999. Ur- und Frühgeschichte Thüringens. Konrad Theiss, Weimar, S.202.

ElLeNBERG, H., 1996. Vegetation Mitteleuropas mit den Alpen in ökologischer, dynamischer und historischer Sicht, 5. Ulmer, Stuttgart, S.1095.

FAEGRI, K. \& IVERSEN, J., 1989. Textbook of pollenanalysis, Cichester, New York, Brisbane, Toronto, Singapore, S.328.

FIRBAS, F., 1949. Allgemeine Waldgeschichte - Spät- und nacheiszeitliche Waldgeschichte nördlich der Alpen, 1. Fischer, Jena, S.480.

FIRBAS, F., LOSERT, H. \& BROIHAN, F., 1939. Untersuchungen zur jüngeren Vegetationsgeschichte im Oberharz. Planta, 30: S.422-456.

FLINDT, S., 1996. Die Lichtensteinhöhle bei Osterode, Landkreis Osterode am Harz. Eine Opferhöhle der jüngeren Bronzezeit im Gipskarst des südwestlichen Harzrandes. Forschungsgeschichte und erste Grabungsergebnisse. Die Kunde N.F., 47: S.435-466.

FLINDT, S. \& GESCHWINDE, M., 1997. Ein Haus aus der Steinzeit - archäologische Entdeckungen auf den Spuren früher Ackerbauern in Südniedersachsen. Wegweiser zur Vor- und Frühgeschichte Niedersachsens, 19: S.1-64.

FLINDT, S. \& LEIBER, C., 1998. Kulthöhlen und Menschenopfer im Harz, Ith und Kyffhäuser. Archäologische Schriften des Landkreises Osterode am Harz, 2, Holzminden, S.128.

GLÄSSER, R., 1994. Das Klima des Harzes. Kovac, Hamburg, S.341. 
GOCKEL, M., 2000. Thüringen. Die Deutschen Königspfalzen - Repertorium der Pfalzen, Königshöfe und übrigen Aufenthaltsorte der Könige im deutschen Reich des Mittelalters, 2. Vandenhoeck \& Ruprecht, Göttingen, S.750.

GRÜGER, E., 2003. Palynologische Beiträge zum Wandel von Biodiversität und Klima. In: STEPHAN RobBert GRADSTEIN, RAINER WILLMANN \& GEORg ZIZKA (Hrsg.), Biodiversitätsforschung - Die Entschlüsselung der Artenvielfalt in Raum und Zeit. Kleine Senckenberg-Reihe, S.217-223.

HÄßLER, H.-J. (Hrsg.), 1991. Ur- und Frühgeschichte in Niedersachsen. Theiss, Stuttgart, S.592.

HAUPTMEYER, C.-H., 1992. Bergbau und Hüttenwesen im Harz während des Mittelalters. In: KARL HEINRICH KAUFHOLD (Hrsg.), Bergbau und Hüttenwesen im und am Harz. Veröffentlichungen der Historischen Kommission für Niedersachsen und Bremen / Quellen und Untersuchungen zur Wirtschafts- und Sozialgeschichte Niedersachsens in der Neuzeit. Hahn, Hannover, S.1120.

HEINE, H.-W., 1991a. Burgen der salischen Zeit in Niedersachsen - Ein Überblick -. In: HORST WOLFGANG BÖHME (Hrsg.), Burgen der Salierzeit - Teil 1: In den nördlichen Landschaften des Reiches. Jan Thorbecke Verlag, Sigmaringen, S.342.

HEINE, H.-W., 1991b. Frühe Burgen und Pfalzen in Niedersachsen von den Anfängen bis zum Mittelalter. Wegweiser zur Vor- und Frühgeschichte, 17. Lax, Hildesheim, S.88.

HEINE, H.-W., 1997. Archäologische Burgenforschung in Südniedersachsen. Nachrichten aus Niedersachsens Urgeschichte, 66(1): S.259-276.

HenNING, F.-W. (Hrsg.), 1994. Deutsche Agrargeschichte des Mittelalters. 9. - 15. Jahrhundert. Ulmer, Stuttgart, S.368.

HeNNING, F.-W. (Hrsg.), 1997. Deutsche Agrargeschichte. Vor- und Frühgeschichte. Ulmer, Stuttgart, S.479.

HENNINGSEN, D., 1981. Einführung in die Geologie der Bundesrepublik Deutschland. Enke Verlag, Stuttgart, S.34f.

HERKING, C., 1998. Vegetationsgeschichtliche Untersuchungen zur frühen Siedlungsgeschichte im Umkreis des Jues-Sees (Herzberg am Harz). Unveröffentlichte Diplomarbeit der Biologischen Fakultät der Universität Göttingen, S.73.

Herrmann, A., 1981. Abriß der Geologie - Band II: Historische Geologie. Ber. naturhist. Ges. Hannover, 124: S.35-45.

HerRmann, B., 1988. Erste anthropologische Befunde aus der Lichtenstein-Höhle bei Dorste. Heimatblätter für den Süd-Westlichen Harzrand, 44: S.13-15.

HeTTWER, K., 1999. Stoffbestand und Schwermetall-Anomalien eines Moorprofiles der Erdfallsenke "Silberhohl" bei Seesen (Westharz), unveröff. Diplomarbeit, Universität Göttingen.

HEUtger, N., 1977. 850 Jahre Kloster Walkenried. Lax, HIldesheim, S.163.

HILLEBRECHT, M.-L., 1982. Die Relikte der Holzkohlewirtschaft als Indikatoren für Waldnutzung und Waldentwicklung - Untersuchungen an Beispielen aus Südniedersachsen. Göttinger Geographische Abhandlungen, 79: S.1-158.

HöVermanN, J., 1962. Harz. In: E. MeYnen; Schmidthüsen, J.; GelleRt, I; NeEf, E.; MülleR-Miny, H.

SCHULTZE, I.H. (Hrsg.), Handbuch der naturrämlichen Gliederung Deutschlands. Bundesanstalt für Landeskunde und Raumforschung Selbstverlag, Bad Godesberg, S.601-603.

HöVERMANN, J., 1963. Die naturräumlichen Einheiten auf Blatt 99 Göttingen. In: INSTITUT_FÜR_LANDESKUNDE (Hrsg.), Geographische Landesaufnahme 1:200000 Naturräumliche Gliederung Deutschlands. Bundesanstalt für Landeskunde und Raumforschung Selbstverlag, Bad Godesberg.

JANDT, U., 1999. Kalkmagerrasen am Südharzrand und im Kyffhäuser. Dissertationes Botanicae, 322. Cramer, Berlin, Stuttgart, S.246.

JANSSEN, W., 1963. Die Ausgrabungen auf der mittelalterlichen Wüstung Königshagen, Gem. Barbis, Kr. Osterode (Harz). Göttinger Jahrbuch, 11: S.59-68.

JANSSEN, W., 1987. Die Wüstung Königshagen. In: LANDKREIS OSTERODE AM HARZ (Hrsg.), Damit die Jahrtausende nicht spurlos vergehen... Archäologische Denkmalpflege im Landkreis Osterode am Harz 1986/87, Osterode am Harz, S.101-112.

JoCKENHÖVEL, A. \& KUBACH, W. (Hrsg.), 1994. Bronzezeit in Deutschland. Archäologie in Deutschland, Sonderheft. Theiss, Stuttgart, S.110.

JUNG, W., BEUG, H.-J. \& DeHM, R., 1972. Das Riß/Würm-Interglazial von Zeifen, Landkreis Laufen an der Salzach. Bayrische Akademie der Wissenschaften Math.-Naturwiss. Klasse Abhandlungen Neue Folge, 151: S.1-131.

Kaltofen, A., 1998. Am Ende war das Feuer - Die linienbandkeramische Siedlung bei Schwiegershausen. Archäologie in Niedersachsen, 1: S.21-24.

KEYSER, E. (Hrsg.), 1952. Nordwest-Deutschland: I. Niedersachsen und Bremen. Deutsches Städtebuch - Handbuch Städtischer Geschichte, 3. Kohlhammer, Stuttgart. 
KLAMM, M., 1987. Die eisenzeitliche Siedlung am "Steinbühl" bei Nörten-Hardejnberg, Ldkr. Northeim bodenkundliche Untersuchungen. Nachrichten aus Niedersachsens Urgeschichte, 56: S.121127.

KLAPPAUF, L., 1983. Prospektion, Befunde und Funde in Düna / Osterode. Resümee des Kolloquiums am 9./10. September 1983. Berichte zur Denkmalpflege in Niedersachsen, 3: S.133-136.

KLAPPAUF, L., 1986. Archäologische Prospektion, Befunde und Funde des frühmittelalterlichen Herrensitzes zu Düna. In: HANS-HERBERT MöLlER (Hrsg.), Düna/Osterode - ein Herrensitz des frühen Mittelalters. Arbeitshefte zur Demkmalpflege in Niedersachsen, Hannover, S.47-59.

KLAPPAUF, L., 2000. Spuren deuten - Frühe Montanwirtschaft im Harz. In: CHRISTIANE SEGERS-GLOCKE (Hrsg.), Auf den Spuren einer frühen Industrielandschaft. Naturraum - Mensch - Umwelt im Harz. Niemeyer, Hameln, S.19-27.

KLAPPAUF, L. \& LINKE, F.-A., 1990. Düna - I. Das Bachbett vor Errichtung des repräsentativen Steingebäudes. Materialhefte zur Ur- und Frühgeschichte Niedersachsens, 22: S.1-221.

KLAPPAUF, L. \& LINKE, F.-A., 1996. Düna - II. Untersuchungen zur Keramik des 1. bis 14. nachchristlichen Jahrhunderts. Materialhefte zur Ur- und Frühgeschichte Niedersachsens, 24: S.1-188.

KLAPPAUF, L. \& LINKE, F.-A., 1997. Montanarchäologie im westlichen Harz. Nachrichten aus Niedersachsens Urgeschichte, 66(1): S.21-53.

KÖRBER-GROHNE, U., 1987. Nutzpflanzen in Deutschland. Theiss, Stuttgart, S.490.

KRECKMANN, I., 1999. Von der Burg Lichtenstein im Sösetal und ihrer Umgebung. Heimatblätter für den Süd-Westlichen Harzrand, 55: S.52-65.

KREMSER, W., 1984. Die Frühgeschichte des Eichenanbaus in Niedersachsen. Rotenburger Schriften, 61: S.7-88.

KüHLHORN, E. (Hrsg.), 1970. Blatt Osterode - Erläuterungsheft. Historisch-Landeskundliche Exkursionskarte von Niedersachsen - Massstab 1:50 000, 2,2. Kommissionsverlag August Lax, Hildesheim, S.125.

LANG, G., 1994. Quartäre Vegetationsgeschichte Europas - Methoden und Ergebnisse. Fischer, Jena, Stuttgart, New York, S.462.

LANGE, E., 1965. Zur Vegetationsgeschichte des zentralen Thüringer Beckens. Drudea, 5(1): S.3-58.

LINKE, F.-A., 2000. Die Spur des "Alten Mannes". In: CHRISTIANE SEGERS-GLOCKE (Hrsg.), Auf den Spuren einer frühen Industrielandschaft. Naturraum - Mensch - Umwelt im Harz. Niemeyer, Hameln, S.7-11.

LUND, A.A., 1988. P. Cornelius Tacitus, Germania / interpretiert, hrsg., übertr., kommentiert u. mit einer Bibliographie versehen von Allan A. Lund. Wissenschaftliche Kommentare zu griechischen und lateinischen Schriftstellern. Winter, Heidelberg, S.282.

MENSCHING, H., 1950. Schotterfluren und Talauen im niedersächsischen Bergland. Geographie. Universität Göttingen, Göttingen, S. 51.

MeYnen, E.; Schmidthüsen, J.; Gellert, I; NeEF, E.; Müller-Miny, H.; SchultZe, I.H. (Hrsg.), 1962. Handbuch der naturrämlichen Gliederung Deutschlands, I \& II. Bundesanstalt für Landeskunde und Raumforschung Selbstverlag, Bad Godesberg, S. 1339.

MOHR, K., 1982. Harzvorland westlicher Teil. In: MANFRED P. GWINNER (Hrsg.), Sammlung Geologischer Führer. Gebrüder Borntraeger, Berlin, Stuttgart, S.155.

MöLLER, J., 1998. Fundchronik Niedersachsen 1997. Nachrichten aus Niedersachsens Urgeschichte, Beiheft 1. Konrad Theiss Verlag, Stuttgart, S.280.

MöLLER, J., 1999. Fundchronik Niedersachsen 1998. Nachrichten aus Niedersachsens Urgeschichte, Beiheft 2. Konrad Theiss Verlag, Stuttgart, S.404.

MoORE, P.D., WebB, J.A. \& Collinson, M.E., 1991. Pollenanalysis, Heft 2, Oxford, S.216.

MÜLLER, H., 1953. Zur spät- und nacheiszeitlichen Vegetationsgeschichte des mitteldeutschen Trockengebietes. Nova Acta Leopoldina N. F., 110(16): S.1-67.

NiemanN, H.-W., 1991. Die Geschichte des Bergbaus in St. Andreasberg. Pieper, Clausthal-Zellerfeld, S.154.

NITZ, H.-J., 1983. Feudal woodland colonization as a strategy of the carolingian empire in the conquest of saxony; reconstruction of the spatial patterns of expansion and colonist settlement morphology in the Leine-Weser-region. In: B.K. ROBERTS \& R.E. GLASSCOCK (Hrsg.), Villages, Fields and Frontiers - Studies in European rural settlement in the medieval and early modern periods. BAR International Series 185, S.171-184.

OBERDORFER, E., 1994. Pflanzensoziologische Exkursionsflora. Ulmer, Stuttgart, S.1050.

PESCHEL, K., 1994. Thüringen in ur- und frühgeschichtlicher Zeit. Beier \& Beran. Archäologische Fachliteratur, Wilkau-Haßlau, S.107.

Pflume, S., 1999. Laubwaldgesellschaften im Harz - Gliederung, Ökologie, Verbreitung. Archiv naturwissenschaftlicher Dissertationen, 9: S.238. 
PLEINES, T., 2002. Vegetationsgeschichtliche Untersuchungen an den Sedimenten des Mooslochs westlich von Nordhausen / Thüringen. unveröffentlichte Diplomarbeit der Biologischen Fakultät der Universität Göttingen, S.47.

PunT, W. (Hrsg.), 1976. The Northwest European Pollenflora I, Amsterdam, S.145.

PunT, W., BLACKMORE, S. \& CLARK, G.C.S. (Hrsg.), 1988. The Northwest European Pollenflora V, Amsterdam, S.154.

PUNT, W., BLACKMORE, S. \& CLARK, G.C.S. (Hrsg.), 1991. The Northwest European Pollenflora VI, Amsterdam, S.275.

PUNT, W. \& CLARK, G.C.S. (Hrsg.), 1980. The Northwest European Pollenflora II, Amsterdam, S.265.

PUNT, W. \& ClARK, G.C.S. (Hrsg.), 1981. The Northwest European Pollenflora III, Amsterdam, S.138.

PUNT, W. \& CLARK, G.C.S. (Hrsg.), 1984. The Northwest European Pollenflora IV, Amsterdam, S.369.

Punt, W. \& MATOTEAUX, M., 1984. Cannabaceae, Moraceae and Urticaceae. In: W. PUNT \& G.C.S. CLARK (Hrsg.), The Northwest European Pollenflora IV, Amsterdam, S.369.

REINBOTH, F. \& REINBOTH, W., 1989. Walkenrieder Zeittafel - Abriss der Orts- und Klostergeschichte. Schriftenreihe des Vereins für Heimatgeschichte Walkenried und Umgebung e. V., 16. Selbstverlag, S.84.

RICKEN, W., 1980. Quartäre fluviatile und äolische Sedimentation am Süd-West-Harz und ihre Beeinflussung durch die Subrosion. Unveröffentlichte Diplomarbeit, Universität Göttingen, S.138.

RICKEN, W., 1982. Quartäre Klimaphasen und Subrosion als Faktoren der Bildung von Kies-Terrassen im südwestlichen Harzvorland. Eiszeitalter Gegenwart, 32: S.109-136.

SCHLÜTER, W., 1975a. Die vorgeschichtlichen Funde der Pipinsburg bei Osterode/Harz. Göttinger Schriften zur Vor- und Frühgeschichte, 17. Karl Wacholtz Verlag, Neumünster, S.137.

SCHLÜTER, W., 1975b. Untersuchungen in der Kleinen Jettenhöhle bei Düna, Gem. Hörden, Kr. Osterode am Harz - II. Latenezeitliche Siedlungsspuren in der Kleinen Jettenhöhle. Nachrichten aus Niedersachsens Urgeschichte, 44: S.95-104.

SCHLÜTER, W., 1987. Die Pipinsburg bei Osterode am Harz. In: LANDKREIS OSTEROdE AM HARZ (Hrsg.), Damit die Jahrtausende nicht spurlos vergehen... Archäologische Denkmalpflege im Landkreis Osterode am Harz 1986/87, Osterode am Harz, S.37-46.

SCHÖNFELDER, P., 1978. Vegetationsverhältnisse auf Gips im südwestlichen Harzvorland - Eine vergleichende Untersuchung unter besonderer Berücksichtigung der Naturschutzprobleme . Naturschutz und Landschaftspflege in Niedersachsen, 8: S.1-110.

SCHUBART, W., 1978. Die Verbreitung der Fichte im und am Harz vom hohen Mittelalter bis in die Neuzeit. Aus dem Walde, 28.

SCHULTES, T., 2000. Typisierung alter DNA zur Rekonstruktion von Verwandtschaft in einem bronzezeitlichen Skelettkollektiv, Göttingen, S.168.

SCHULTZE-MOTEL, J. \& GALL, W., 1994. Archäologische Kulturpflanzenreste aus Thüringen. Weimarer Monographien zur Ur- und Frühgeschichte, 32. Theiss, Stuttgart, S.49.

SEIDENSTICKER, A., 1896. Rechts- und Wirthschaftsgeschichte norddeutscher Forsten besonders im Lande Hannover, 2. Dieterich, Göttingen, S.588.

SPÖNEMANN, J., 1970. Die naturräumlichen Einheiten auf Blatt 100 Halberstadt. In: INSTITUT FÜR LANDESKUNDE (Hrsg.), Geographische Landesaufnahme 1:200 000 Naturräumliche Gliederung Deutschlands. Bundesanstalt für Landeskunde und Raumforschung Selbstverlag, Bad Godesberg.

STEINAU, N., 1986. Historische-Geographische Aspekte zur Erforschung der mittelalterlichen Siedlung Düna. In: HANS-HERBERT MölLER (Hrsg.), Düna/Osterode - ein Herrensitz des frühen Mittelalters. Arbeitshefte zur Demkmalpflege in Niedersachsen, Hannover, S.11-15.

SteUeR, H., 2000. Die Ursprünge des Silber-Bergbaus im Mittelalter: Wirtschaft und Münzgeld. In: CHRISTIANE SEGERS-GLOCKE (Hrsg.), Auf den Spuren einer frühen Industrielandschaft. Naturraum - Mensch - Umwelt im Harz. Arbeitshefte zur Denkmalpflege in Niedersachsen. Niemeyer, Hameln, S.112-118.

StOCKMARR, J., 1971. Tablets with spores used in absolute pollen analysis. Pollen and Spores, 13: S.615-621.

StRICKHAUSEN, G., 1998. Burgen der Ludolwinger in Thüringen, Hessen und dem Rheinland. Quellen und Forschungen zur hessischen Geschichte, 109, Marburg, S.398.

Stuiver, M.; Reimer, P.J.; BARD, E.; Beck, J.W.; BuRR, G.S.; Hughen, K.A.; KROMer, B.; McCormac, F.G.; V.D. PFLICHT, J.; SPURK, M., 1998. References for calibration datasets. Radiocarbon, 40: S.1041-1083.

TAUCHMANN, J., 1990. Die beiden Seelöcher und das Moosloch. Interessante Erdfälle zwischen Kleinwechsungen und Hochstedt. Beiträge zur Heimatkunde, 15: 54-67. 
VEIL, S., 1988. Die jungpaläolithischen und mesolithischen Funde und Befunde aus der "Steinkirche" bei Scharzfeld, Ldkr. Osterode am Harz. Die Kunde N.F., 39: S.209-222.

VoIGT, R., 2003. Der Juess-See in Herzberg am Harz, unveröff. Abschlussbericht, Deutsche Forschungsgemeinschaft.

VOIGT, R., in Vorbereitung. Lake Jues in Herzberg / Harz Mountains: sedimentology, geochemistry, palynology and diatomology of laminated muds.

Voigt, R., BAier, J., HeRking, C., Grüger, E. \& Meischner, D., 2000. Lake Jues in Herzberg, Harz mountains. Sedimentology, geochemistry, palynology and diatomology of laminated limnic muds. In: W. ANDRES (Hrsg.), Final Colloquium of the DFG priority program "Changes of the Geo-Biosphere during the last 15,000 years" http://www.unifrankfurt.de/fb11/ipg/spp/postergallery/Postergif/Poster_Voigt_ctal.gif.

WACHENDORF, H., 1986. Der Harz - variszischer Bau und geodynamische Entwicklung. Geol. Jb., 91: S.71.

WALTER, D., 1990. Eine befestigte Siedlung der Bernburger Kultur mit Brunnen bei Sundhausen, Kr. Nordhausen. Ausgrabungen und Funde, 35: S.223-233.

WILLERDING, U., 1974. Latènezeitliche Pflanzenreste von der Pipinsburg, Kr. Osterode/Harz. Nachrichten aus Niedersachsens Urgeschichte, 43: S.134-137.

WILLERDING, U., 1975. Untersuchungen in der Kleinen Jettenhöhle bei Düna, Gem. Hörden, Kr. Osterode am Harz - IV. Eisenzeitliche Pflanzenreste aus der Kleinen Jettenhöhle. Nachrichten aus Niedersachsens Urgeschichte, 44: S.107-112.

WILLERDING, U., 1979. Zum Ackerbau in der jüngeren vorrömischen Eisenzeit. In: UDELGARD KöRBERGROHNE (Hrsg.), Festschrift Maria Hopf. Archaeo-Physika. Rheinland-Verlag, Köln, S.309-330.

WILLERDING, U., 1980. Anbaufrüchte der Eisenzeit und des frühen Mittelalters, ihre Anbauformen, Standortverhältnisse und Erntemethoden. Abhandlungen der Akademie der Wissenschaften in Göttingen, Phil.-Hist. Klasse, 3. Folge, 116(Teil 2): S.129-196.

WILLERDING, U., 1986. Erste paläoethnobotanische Ergebnisse über die mittelalterliche Siedlungsanlage von Düna. In: HANS-HERBERT MÖLLER (Hrsg.), Düna/Osterode - ein Herrensitz des frühen Mittelalters. Arbeitshefte zur Denkmalpflege in Niedersachsen, Hannover, S.67-73.

WILLERDING, U. \& WolF, G., 1990. Paläo-ethnobotanische Befunde aus einer Siedlung der jüngeren Vorrömischen Eisenzeit am Steinbühl bei Nörten-Hardenberg, Ldkr. Northeim. Nachrichten aus Niedersachsens Urgeschichte, 59: S.111-140.

WILLUTZKI, H., 1962. Zur Waldgeschichte und Vermoorung sowie über Rekurrenzflächen im Oberharz. Nova Acta Leopoldina N. F., 160(25): S.1-25.

ZotZ, T., 1993. Goslar. Silberbergbau und frühe Pfalz. In: M. BRANDT \& A. EgGEBRECHT (Hrsg.), Das Zeitalter der Ottonen. Katalog der Ausstellung Hildesheim 1993, Mainz, S.241-247. 


\section{Anhang}

Tabelle 45: Zählwerte selten auftretender Taxa, 1. Teil (aus zeichnerischen Gründen nicht im Pollendiagramm des Profils Aschenhütter Teich dargestellt)

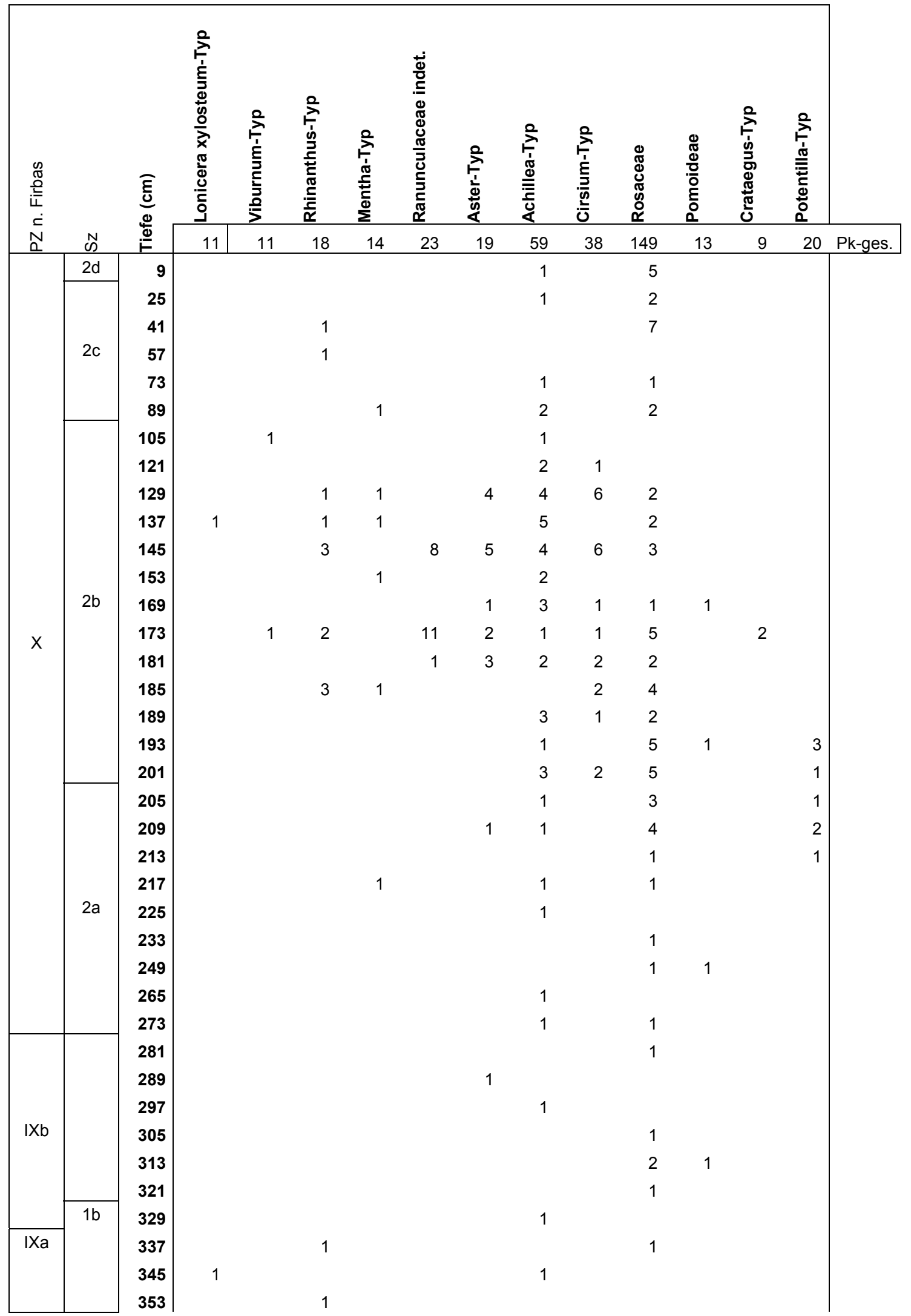




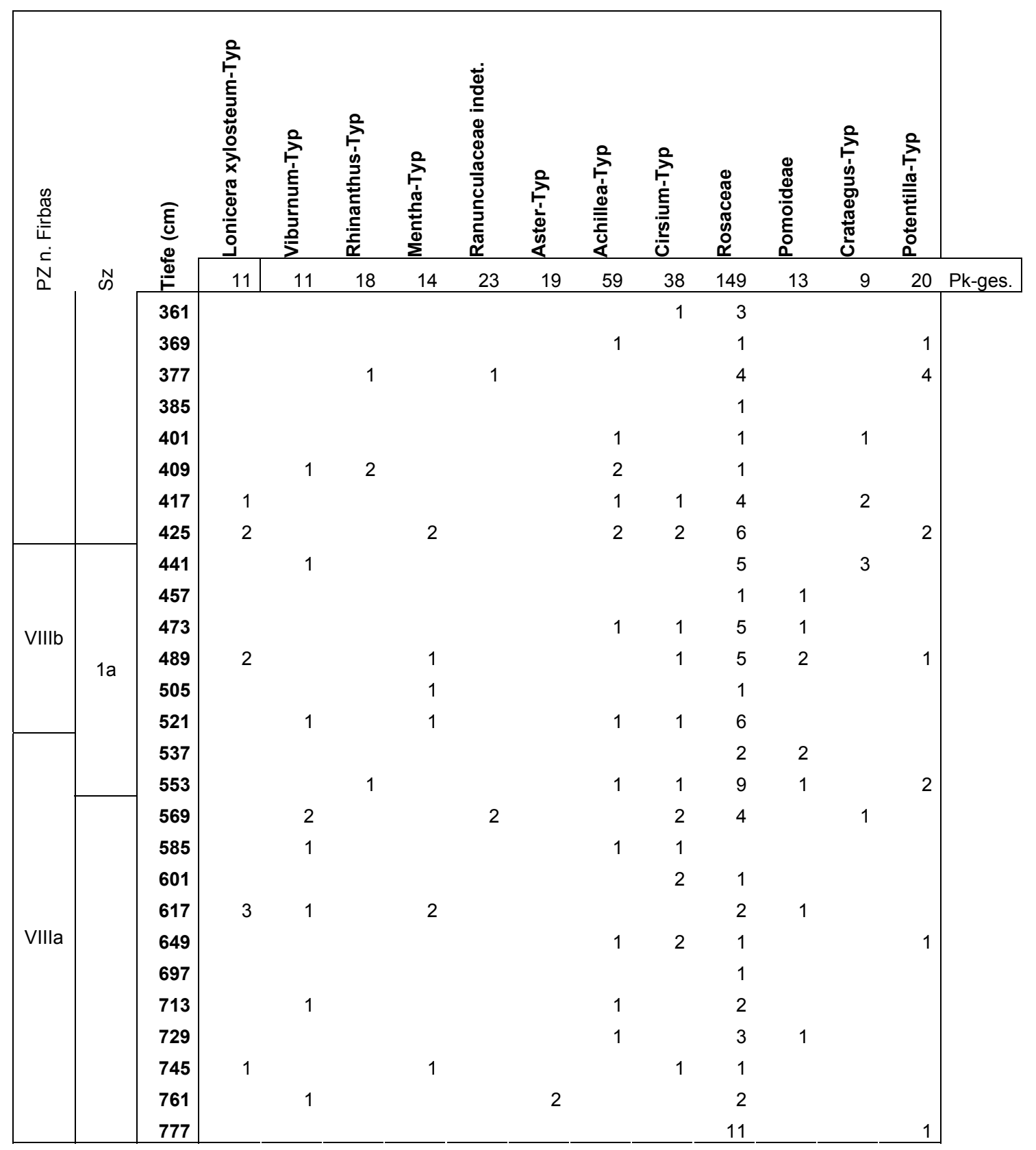

Tabelle 46: Zählwerte selten auftretender Taxa, 2. Teil (aus zeichnerischen Gründen nicht im Pollendiagramm des Profils Aschenhütter Teich dargestellt)

\begin{tabular}{|c|c|c|c|}
\hline & Taxa & Pk-ges. & Tiefen (Anzahl der $\mathrm{Pk}>1$ ) \\
\hline & Viscum & 6 & $457 / 553(2) / 601 / 617(2)$ \\
\hline & Rhamnus carthaticus & 3 & $9 / 585 / 745$ \\
\hline & Sambucus ebulus & 1 & 489 \\
\hline & Cornus mas-Typ & 1 & 777 \\
\hline & Lonicera periclymenum-Typ & 1 & 201 \\
\hline \multirow{4}{*}{ Sek. Siedlungszeiger } & Polygonum aviculare-Typ & 1 & 105 \\
\hline & Agrostemma githago & 1 & 553 \\
\hline & Alchemilla-Typ & 1 & 521 \\
\hline & Anthoceros punctatus & 2 & $145 / 185$ \\
\hline & Ilex aquifolium & 1 & 189 \\
\hline & Papaver rhoeas-Typ & 1 & 777 \\
\hline & Melampyrum & 2 & $181 / 189$ \\
\hline & Jasione-Typ & 2 & $105 / 289$ \\
\hline
\end{tabular}




\begin{tabular}{|c|c|c|c|}
\hline & Taxa & Pk-ges. & Tiefen (Anzahl der Pk>1) \\
\hline & Helianthemum & 3 & $173 / 649(2)$ \\
\hline & Mercurialis perennis & 6 & $409 / 537(2) / 569(2) / 697$ \\
\hline & Pulmonaria-Typ & 1 & 553 \\
\hline & Stachys-Typ & 2 & $417 / 553$ \\
\hline & Valeriana & 3 & $129 / 205 / 377$ \\
\hline & Succisa & 3 & $225(2) / 649$ \\
\hline & Chamaenerion angustifolium-Typ & 2 & $189 / 205$ \\
\hline & Geranium & 1 & 137 \\
\hline & Prunella-Typ & 1 & 393 \\
\hline & Saxifraga granulata- $T$ & 1 & 761 \\
\hline & Centaurea jacea & 1 & 121 \\
\hline & Bidens-Typ & 3 & $169(2) / 601$ \\
\hline & Centaurea nigra-Typ & 3 & $121 / 417 / 489 /$ \\
\hline & Vaccinium-Typ & 8 & $73 / 145 / 313(2) / 409 / 569(2) / 713$ \\
\hline & Andromeda & 1 & 777 \\
\hline & Empetrum & 1 & 189 \\
\hline & Medicago lupulina-Typ & 3 & $369(3)$ \\
\hline & Astragalus-Typ & 7 & $409(4) / 425$ / $601 / 761$ \\
\hline & Lathyrus-Typ & 1 & 425 \\
\hline & Vicia-Typ s.str. & 6 & $9 / 1 / 409(2) / 425(2)$ \\
\hline & Gentianaceae & 1 & 777 \\
\hline & Gentianella campestris-Typ & 1 & 777 \\
\hline & Malus sylvestris & 2 & $473(2)$ \\
\hline & Menyanthes trifoliata & 9 & $353(2) / 393 / 409 / 521(2) / 729 / 745(2)$ \\
\hline \multirow{5}{*}{ Wasserpflanzen } & Eupotamogeton & 7 & $441(2) / 521 / 553(4)$ \\
\hline & Utricularia & 2 & $185(2)$ \\
\hline & Nymphaea alba-Typ & 2 & 505 \\
\hline & Botrychium lunaria-Typ & 1 & 173 \\
\hline & Lycopodium annotinum & 1 & 353 \\
\hline \multirow{4}{*}{ Rhizopoda } & Amphitrema flavum & 1 & 745 \\
\hline & Assulina muscorum & 4 & $265 / 313 / 409$ / 553 \\
\hline & Nebela militaris & 3 & $169 / 393 / 505$ \\
\hline & Assulina seminulum & 1 & 385 \\
\hline
\end{tabular}

Tabelle 47: Zählwerte selten auftretender Taxa (aus zeichnerischen Gründen nicht im Pollendiagramm des Profils Moosloch dargestellt)

\begin{tabular}{|lcl|}
\hline Taxa & Pk-ges. & Tiefen (Anzahl Pk>1) \\
\hline Rhamnus carthaticus & 4 & $295 / 390(3)$ \\
Viburnum-Typ & 1 & 85 \\
Euonymus & 1 & 250 \\
Hippophae rhamnoides & 1 & 164 \\
Lonicera xylosteum-Typ & 1 & 427 \\
Alchemilla-Typ & 1 & 335 \\
Pomoideae & 1 & 45 \\
Succisa & 2 & 340 / 370 \\
Valeriana & 4 & 240 / 344 / 395 / 406 \\
Linum catharticum-Typ & 1 & 335 \\
Parnassia palustris & 1 & 340 \\
Rhinanthus-Typ & 1 & 164 \\
\hline
\end{tabular}

Tabelle 48: Zählwerte selten auftretender Taxa (aus zeichnerischen Gründen nicht im Pollendiagramm des Profils Wittgerode dargestellt)

\begin{tabular}{|lcl|}
\hline Taxa & Pk-ges. & Tiefe (Anzahl Pk>1) \\
\hline Alchemilla-Typ & 1 & 561 \\
Humulus/Cannabis-Typ & 5 & 174 / 407 / 572(2) / 632 \\
\hline
\end{tabular}




\begin{tabular}{|c|c|c|}
\hline Taxa & Pk-ges. & Tiefe (Anzahl Pk>1) \\
\hline Polygonum convolvulus-Typ & 1 & 153 \\
\hline Scleranthus annuus & 5 & $596(5)$ \\
\hline Urtica & 1 & 596 \\
\hline Centaurea scabiosa & 1 & 596 \\
\hline Sanguisorba minor & 1 & 356 \\
\hline Eupotamogeton & 4 & 330 / 455 / 604 / 622 \\
\hline Myriophyllum spicatum-Typ & 3 & $65 / 356$ \\
\hline Utricularia & 3 & $455(2) / 561$ \\
\hline Blechnum spicant & 6 & $71(2) / 100 / 356 / 580(2)$ \\
\hline Aster-Typ & 4 & $17(4)$ \\
\hline Chamaenerion angustifolium-Typ & 2 & $407(2)$ \\
\hline Circea & 2 & $241 / 622$ \\
\hline Cirsium-Typ & 9 & $17(3) / 49(6)$ \\
\hline Euphorbia & 2 & $231 / 632$ \\
\hline Galium-Typ & 6 & $219 / 330 / 455(4)$ \\
\hline Geranium & 3 & $429(2) 572$ \\
\hline Jasione-Typ & 1 & 596 \\
\hline Lathyrus-Typ & 2 & 17 / 596 \\
\hline Lonicera & 2 & $330 / 596$ \\
\hline Lythrum & 7 & $455 / 596(5) / 1$ \\
\hline Melampyrum & 1 & 481 \\
\hline Mentha-Typ & 2 & $330 / 455$ \\
\hline Mercurialis perennis & 6 & $407(2) / 596 / 622(3)$ \\
\hline Pomoideae & 1 & 429 \\
\hline Ranunculaceae indet. & 2 & $182 / 276$ \\
\hline Sanguisorba officinalis & 1 & 578 \\
\hline Saxifraga stellaris-Typ & 1 & 153 \\
\hline Spergula-Typ & 1 & 153 \\
\hline Stachys-Typ & 4 & $174(2) / 429 / 507$ \\
\hline Thalictrum & 6 & 455 / 561 / 596 / 632(3) \\
\hline Trifolium-Typ & 1 & 49 \\
\hline Viburnum-Typ & 3 & $551 / 596(2)$ \\
\hline Vicia-Typ & 2 & $429 / 596$ \\
\hline Vitis & 1 & 596 \\
\hline
\end{tabular}

Tabelle 49: Pollen-Influx ausgewählter Taxa des Diagramms Aschenhütter Teich (gerundet)

\begin{tabular}{|c|c|c|c|c|c|c|c|c|c|c|c|c|}
\hline $\mathbf{P Z}$ & Sz & $\mathrm{cm}$ & Picea & Pinus & Alnus & Betula & Quercus & Ulmus & Fagus & Carpinus & BP-Summe & NBP-Summe \\
\hline \multirow[t]{20}{*}{$x$} & $2 d$ & 9 & 394 & 334 & 249 & 163 & 660 & 43 & 549 & 214 & 2631 & 2211 \\
\hline & \multirow{5}{*}{$2 c$} & 25 & 141 & 201 & 312 & 322 & 1459 & 20 & 563 & 161 & 3239 & 1449 \\
\hline & & 41 & 116 & 155 & 361 & 284 & 1935 & 142 & 606 & 426 & 4089 & 1393 \\
\hline & & 57 & 124 & 223 & 273 & 273 & 3822 & 99 & 1278 & 397 & 6576 & 1216 \\
\hline & & 73 & 489 & 760 & 1846 & 706 & 6406 & 380 & 2877 & 2280 & 16231 & 4886 \\
\hline & & 89 & 88 & 229 & 493 & 951 & 898 & 123 & 1937 & 845 & 5704 & 2782 \\
\hline & \multirow{13}{*}{$2 b$} & 105 & 1707 & 3201 & 6828 & 14296 & 5761 & 640 & 18564 & 10029 & 62093 & 53771 \\
\hline & & 121 & 874 & 2185 & 1858 & 3278 & 5026 & 1093 & 12238 & 6665 & 33982 & 29830 \\
\hline & & 129 & 617 & 864 & 1605 & 3642 & 3148 & 247 & 6050 & 3025 & 19445 & 19569 \\
\hline & & 137 & 448 & 1386 & 978 & 978 & 1997 & 285 & 4564 & 856 & 11981 & 7621 \\
\hline & & 145 & 408 & 1704 & 2223 & 3483 & 2112 & 222 & 5335 & 1741 & 17672 & 17265 \\
\hline & & 153 & 478 & 1513 & 2787 & 3345 & 4460 & 398 & 6451 & 2947 & 23016 & 23733 \\
\hline & & 169 & 937 & 4283 & 5755 & 7629 & 5621 & 535 & 9904 & 3614 & 39080 & 34529 \\
\hline & & 173 & 607 & 1822 & 2783 & 4807 & 4048 & 304 & 7185 & 3036 & 25300 & 20746 \\
\hline & & 181 & 464 & 1904 & 2880 & 3669 & 3901 & 46 & 6131 & 3158 & 22572 & 16255 \\
\hline & & 185 & 477 & 1165 & 3019 & 5721 & 3443 & 212 & 9005 & 2437 & 26167 & 15096 \\
\hline & & 189 & 300 & 900 & 4500 & 6299 & 4740 & 540 & 8939 & 3480 & 30477 & 14699 \\
\hline & & 193 & 149 & 3125 & 15922 & 13244 & 9821 & 744 & 18600 & 8779 & 71723 & 25594 \\
\hline & & 201 & 127 & 1108 & 2058 & 1583 & 2027 & 253 & 4211 & 3958 & 15611 & 4496 \\
\hline & $2 a$ & 205 & 51 & 565 & 3545 & 2055 & 2826 & 668 & 7296 & 9659 & 27334 & 4521 \\
\hline
\end{tabular}




\begin{tabular}{|c|c|c|c|c|c|c|c|c|c|c|c|c|}
\hline $\mathbf{P Z}$ & Sz & $\mathrm{cm}$ & Picea & Pinus & Alnus & Betula & Quercus & Ulmus & Fagus & Carpinus & BP-Summe & NBP-Summe \\
\hline & & 209 & 340 & 1225 & 3812 & 2791 & 1974 & 817 & 12254 & 13071 & 36558 & 4561 \\
\hline & & 213 & 119 & 1423 & 8182 & 3913 & 3913 & 1304 & 18736 & 20159 & 58937 & 7589 \\
\hline & & 217 & 144 & 939 & 3250 & 1733 & 2456 & 867 & 15963 & 12207 & 37992 & 3178 \\
\hline & & 225 & 251 & 1171 & 5102 & 2342 & 2342 & 502 & 19068 & 11541 & 42988 & 6189 \\
\hline & & 233 & 178 & 462 & 1386 & 675 & 1244 & 373 & 8372 & 5652 & 18574 & 2222 \\
\hline & & 241 & 741 & 1010 & 3299 & 2289 & 1751 & 404 & 18584 & 4781 & 33599 & 3569 \\
\hline & & 249 & 251 & 920 & 1673 & 711 & 1547 & 335 & 12503 & 5771 & 24170 & 1714 \\
\hline & & 265 & 187 & 671 & 1716 & 1082 & 821 & 522 & 11900 & 4626 & 21822 & 1567 \\
\hline & & 273 & 170 & 1787 & 5021 & 511 & 2553 & 766 & 21700 & 9020 & 43230 & 3574 \\
\hline \multirow{7}{*}{$\mathrm{IX} b$} & & 281 & 573 & 430 & 12756 & 1290 & 3440 & 3010 & 39987 & 26801 & 91440 & 3153 \\
\hline & & 289 & 111 & 155 & 1910 & 511 & 689 & 422 & 7263 & 2910 & 14394 & 333 \\
\hline & & 297 & 93 & 278 & 4119 & 879 & 972 & 1018 & 11893 & 6108 & 26423 & 602 \\
\hline & & 305 & 111 & 888 & 7219 & 1555 & 2888 & 1333 & 21990 & 19214 & 57197 & 888 \\
\hline & & 313 & 63 & 105 & 2797 & 314 & 828 & 210 & 4474 & 2735 & 12007 & 377 \\
\hline & & 321 & & 384 & 11661 & 2114 & 2179 & 384 & 10893 & 7881 & 37099 & 705 \\
\hline & & 329 & 86 & 144 & 2398 & 431 & 589 & 57 & 2671 & 1063 & 7640 & 488 \\
\hline \multirow{12}{*}{ IX a } & & 337 & 36 & 427 & 6621 & 2599 & 1922 & 320 & 8472 & 1103 & 21856 & 2029 \\
\hline & & 345 & 21 & 185 & 3026 & 2120 & 1400 & 185 & 4344 & 371 & 12063 & 597 \\
\hline & & 353 & 159 & 874 & 6397 & 4530 & 3894 & 477 & 8662 & 358 & 26106 & 3815 \\
\hline & & 361 & 43 & 174 & 2685 & 1956 & 880 & 239 & 4511 & 130 & 10967 & 1174 \\
\hline & & 369 & 84 & 227 & 1685 & 1016 & 824 & 108 & 2187 & 96 & 6763 & 1099 \\
\hline & $1 b$ & 377 & 32 & 195 & 2087 & 1103 & 719 & 57 & 2591 & 13 & 7207 & 700 \\
\hline & & 385 & 167 & 216 & 905 & 256 & 698 & 154 & 1801 & 25 & 4771 & 238 \\
\hline & & 393 & 123 & 339 & 2017 & 985 & 1124 & 216 & 3032 & 46 & 8328 & 954 \\
\hline & & 401 & 25 & 305 & 2211 & 1932 & 2542 & 280 & 5211 & 153 & 13548 & 2643 \\
\hline & & 409 & 126 & 300 & 2211 & 607 & 614 & 105 & 2308 & 7 & 7030 & 788 \\
\hline & & 417 & 63 & 398 & 7093 & 2375 & 1506 & 314 & 4843 & 31 & 18035 & 1245 \\
\hline & & 425 & 256 & 476 & 4092 & 879 & 1199 & 357 & 5446 & 119 & 14554 & 2114 \\
\hline \multirow{6}{*}{ VIII b } & & 441 & 317 & 297 & 1829 & 594 & 737 & 103 & 1499 & 26 & 6629 & 330 \\
\hline & & 457 & 69 & 60 & 1151 & 145 & 353 & 242 & 414 & 6 & 3106 & 154 \\
\hline & & 473 & 175 & 363 & 5964 & 1100 & 1700 & 500 & 1700 & 50 & 13252 & 763 \\
\hline & 1a & 489 & 119 & 159 & 2741 & 172 & 819 & 252 & 179 & 33 & 5200 & 447 \\
\hline & & 505 & 194 & 171 & 1806 & 343 & 892 & 857 & 286 & 46 & 5785 & 320 \\
\hline & & 521 & 444 & 256 & 3685 & 234 & 1515 & 501 & 484 & 46 & 8948 & 678 \\
\hline \multirow{13}{*}{ VIII a } & & 537 & 395 & 374 & 2259 & 277 & 2038 & 547 & 326 & 28 & 7540 & 312 \\
\hline & & 553 & 26 & 148 & 2062 & 270 & 1758 & 1014 & 157 & 30 & 7018 & 370 \\
\hline & & 569 & 266 & 161 & 1805 & 179 & 2650 & 785 & 135 & 9 & 6909 & 262 \\
\hline & & 585 & 123 & 168 & 1555 & 280 & 1991 & 638 & 246 & & 5829 & 190 \\
\hline & & 601 & 233 & 336 & 2627 & 277 & 2408 & 627 & 292 & & 7924 & 496 \\
\hline & & 617 & 150 & 123 & 573 & 123 & 1131 & 207 & 75 & & 3151 & 153 \\
\hline & & 649 & 194 & 188 & 305 & 61 & 604 & 222 & 55 & & 2804 & 94 \\
\hline & & 697 & 22 & 43 & 496 & 42 & 432 & 92 & 33 & 3 & 1462 & 46 \\
\hline & & 713 & 41 & 69 & 239 & 54 & 427 & 69 & 13 & & 1104 & 35 \\
\hline & & 729 & 16 & 49 & 399 & 140 & 647 & 161 & 65 & 9 & 2397 & 86 \\
\hline & & 745 & 9 & 29 & 35 & 10 & 75 & 15 & 6 & & 243 & 18 \\
\hline & & 761 & 53 & 87 & 205 & 57 & 269 & 57 & 34 & & 1034 & 57 \\
\hline & & 777 & 11 & 40 & 17 & 8 & 23 & 4 & & & 172 & 20 \\
\hline
\end{tabular}


Tabelle 50: Pollen-Influx ausgewählter Taxa des Diagramms Moosloch (gerundet)

\begin{tabular}{|c|c|c|c|c|c|c|c|c|c|c|c|c|}
\hline $\mathbf{P Z}$ & $\mathrm{Sz}$ & $\mathbf{c m}$ & Picea & Pinus & Alnus & Betula & Quercus & Fagus & Carpinus & BP-Summe & NBP-Summe & Poaceae \\
\hline \multirow{10}{*}{$\mathbf{x}$} & \multirow{3}{*}{$3 d$} & 26 & 2187 & 50296 & 14214 & 42642 & 12027 & 7654 & 6560 & 138861 & 198998 & 98406 \\
\hline & & 45 & 59043 & 183691 & 39362 & 3608208 & 78725 & 52483 & 19681 & 4113357 & 806926 & 518270 \\
\hline & & 64 & 39588 & 182107 & 23753 & 87095 & 356296 & 190025 & 31671 & 926371 & 1258914 & 380049 \\
\hline & \multirow{2}{*}{$3 c$} & 85 & 20410 & 61230 & 37418 & 115657 & 91845 & 40820 & 47623 & 415005 & 187092 & 81640 \\
\hline & & 106 & 1781 & 28500 & 12469 & 80157 & 24938 & 33844 & 7125 & 197719 & 147844 & 53438 \\
\hline & \multirow{5}{*}{$3 b$} & 125 & 266 & 666 & 2130 & 4926 & 4527 & 799 & 932 & 15311 & 40075 & 15178 \\
\hline & & 145 & 940 & 7993 & 4232 & 52660 & 8933 & 5172 & 1411 & 83222 & 48899 & 22098 \\
\hline & & 164 & 149 & 2088 & 1492 & 2237 & 1939 & 5966 & 1939 & 17004 & 19838 & 10441 \\
\hline & & 184 & 498 & 13944 & 19919 & 22409 & 23405 & 34361 & 10956 & 130970 & 286840 & 37349 \\
\hline & & 195 & 25992 & 77975 & 127596 & 134685 & 129959 & 623803 & 238652 & 1431912 & 810472 & 328442 \\
\hline \multirow{10}{*}{$\mathbf{I X b}$} & \multirow{3}{*}{$3 a$} & 200 & 2824 & 5648 & 6589 & 19768 & 4707 & 530901 & 135549 & 722929 & 19768 & 4707 \\
\hline & & 204 & 7699 & 33360 & 76985 & 38493 & 51324 & 1131685 & 307941 & 1729604 & 71853 & 35926 \\
\hline & & 210 & 5442 & 14511 & 41719 & 25394 & 50789 & 663884 & 301106 & 1168146 & 56231 & 18139 \\
\hline & & 215 & & 37423 & 310080 & 16039 & 315426 & 1160126 & 1197550 & 3207723 & 42770 & 37423 \\
\hline & & 220 & 3150 & 17323 & 103940 & 9449 & 15749 & 376389 & 348042 & 900815 & 29922 & 12599 \\
\hline & & 225 & 25752 & 34336 & 244645 & 85840 & 68672 & 1085882 & 1656721 & 3317734 & 72964 & 34336 \\
\hline & & 230 & & 34216 & 196740 & 82688 & 54175 & 789813 & 752746 & 2007322 & 54175 & 19959 \\
\hline & & 235 & 43689 & 148544 & 865050 & 384467 & 244661 & 2953404 & 1939810 & 7016520 & 157282 & 78641 \\
\hline & & 240 & 3150 & 3150 & 132287 & 50395 & 135437 & 400012 & 338593 & 1154366 & 36222 & 15749 \\
\hline & & 245 & 31255 & 52091 & 447985 & 333384 & 614676 & 1192889 & 573003 & 3432812 & 109392 & 67719 \\
\hline \multirow{12}{*}{$\mathrm{IXa}$} & & 250 & & 8691 & 154992 & 305639 & 233213 & 276668 & 73875 & 1126953 & 57941 & 26073 \\
\hline & & 255 & 22190 & 103554 & 414216 & 636117 & 1124300 & 1220457 & 170124 & 3846289 & 295868 & 147934 \\
\hline & & 260 & 1114 & 1671 & 44002 & 57369 & 76863 & 128663 & 15595 & 340872 & 25064 & 12811 \\
\hline & & 265 & 46229 & 123278 & 685737 & 1594916 & 1017048 & 855245 & 107869 & 4622944 & 439180 & 154098 \\
\hline & & 270 & 5360 & 32160 & 124618 & 304176 & 123278 & 147398 & 17420 & 797290 & 76379 & 34840 \\
\hline & & 274 & 8651 & 21628 & 103813 & 532044 & 201139 & 173022 & 8651 & 1085716 & 125441 & 84348 \\
\hline & \multirow{12}{*}{2} & 284 & 9190 & 11159 & 58423 & 111594 & 91901 & 119471 & 6564 & 437842 & 70895 & 42668 \\
\hline & & 295 & 9154 & 68658 & 219704 & 359308 & 141892 & 290650 & 38906 & 1212951 & 173933 & 73235 \\
\hline & & 304 & 5292 & 5292 & 33310 & 44517 & 23660 & 47319 & 3424 & 182427 & 81563 & 46385 \\
\hline & & 314 & 16951 & 55475 & 194164 & 198787 & 134065 & 414524 & 26197 & 1095638 & 442262 & 245016 \\
\hline & & 324 & 1608 & 15276 & 69947 & 317576 & 34572 & 87635 & 3216 & 548321 & 92459 & 47435 \\
\hline & & 330 & 10811 & 57144 & 122011 & 105022 & 210044 & 233210 & 12356 & 795386 & 730520 & 427810 \\
\hline \multirow{9}{*}{ VIIIb } & & 335 & 44319 & 293611 & 393328 & 476426 & 781117 & 720179 & 27699 & 2869635 & 1883544 & 1312941 \\
\hline & & 340 & 31968 & 205510 & 365351 & 493224 & 844875 & 616530 & 13701 & 2767535 & 1548176 & 1196525 \\
\hline & & 344 & 8014 & 18317 & 64109 & 70978 & 416707 & 112190 & 3434 & 733817 & 114480 & 41213 \\
\hline & & 349 & 21236 & 238905 & 392867 & 185815 & 1014021 & 387558 & 42472 & 2882792 & 828206 & 260141 \\
\hline & & 354 & 22753 & 96700 & 392488 & 1092139 & 511940 & 426617 & 17065 & 3816799 & 517628 & 193400 \\
\hline & & 360 & 21968 & 153778 & 1098416 & 2365255 & 2299350 & 205038 & 73228 & 6912697 & 336848 & 168424 \\
\hline & \multirow{8}{*}{1} & 365 & 289582 & 308888 & 2297353 & 1389995 & 4054153 & 405415 & 57916 & 10560103 & 1081107 & 521248 \\
\hline & & 370 & 167879 & 426156 & 2647331 & 7490008 & 3396331 & 439069 & 38741 & 15987294 & 981449 & 477811 \\
\hline & & 377 & 155491 & 252673 & 1211534 & 239715 & 1788146 & 298024 & 19436 & 4599942 & 1710401 & 1166182 \\
\hline \multirow[t]{10}{*}{ VIIIa } & & 385 & 12170 & 38943 & 251912 & 66933 & 293289 & 27990 & & 866479 & 54763 & 25556 \\
\hline & & 390 & 5643 & 15519 & 72424 & 36212 & 58786 & 6584 & 1411 & 253484 & 92176 & 40445 \\
\hline & & 395 & 74326 & 488429 & 1497141 & 265450 & 3514564 & 127416 & 10618 & 6838005 & 1836917 & 913150 \\
\hline & & 403 & 11410 & 22821 & 350870 & 57052 & 1075431 & 25673 & & 1757203 & 94136 & 48494 \\
\hline & & 404 & 29018 & 47484 & 342942 & 195213 & 1464100 & 23742 & & 2342559 & 160919 & 52760 \\
\hline & & 405 & 17336 & 121349 & 832106 & 1386843 & 1551531 & 60674 & & 4446567 & 329375 & 112681 \\
\hline & & 406 & 69500 & 312749 & 5976980 & 13795703 & 5177732 & 139000 & & 28147404 & 2050243 & 486498 \\
\hline & & 407 & 28315 & 141574 & 3256193 & 9372172 & 1840457 & 141574 & & 16224334 & 821127 & 283147 \\
\hline & & 409 & 135911 & 322788 & 2888101 & 1800816 & 1936727 & 67955 & 16989 & 8885159 & 305799 & 135911 \\
\hline & & 415 & 23440 & 52289 & 311929 & 37864 & 369627 & 19834 & 1803 & 1404584 & 54092 & 25243 \\
\hline
\end{tabular}




\begin{tabular}{|c|c|c|c|c|c|c|c|c|c|c|c|c|}
\hline PZ & Sz & $\mathrm{cm}$ & Picea & Pinus & Alnus & Betula & Quercus & Fagus & Carpinus & BP-Summe & NBP-Summe & Poaceae \\
\hline & & 421 & 21781 & 38116 & 315818 & 38116 & 1056357 & 21781 & \multirow{12}{*}{13652} & 3032942 & 87122 & 27226 \\
\hline & & 427 & 33181 & 86271 & 583991 & 192452 & 1526340 & 46454 & & 3503946 & 79635 & 39818 \\
\hline \multirow{6}{*}{ VII } & & 433 & 69248 & 120030 & 406255 & 73864 & 1292628 & 4617 & & 2562174 & 184661 & 23083 \\
\hline & & 440 & 64097 & 151501 & 565215 & 46616 & 640966 & 29135 & & 2400708 & 244732 & 58270 \\
\hline & & 453 & 38008 & 130312 & 705857 & 152031 & 988200 & 16289 & & 2655108 & 97734 & 32578 \\
\hline & & 465 & 21843 & 98293 & 928318 & 387709 & 972004 & 5461 & & 2926933 & 147439 & 49146 \\
\hline & & 477 & 27303 & 150169 & 1310567 & 1174050 & 1597253 & & & 5324178 & 204776 & 109214 \\
\hline & & 490 & 103057 & 257643 & 332594 & 721401 & 861933 & & & 2904341 & 299803 & 65582 \\
\hline \multirow{4}{*}{ VI } & & 503 & & 163821 & 427754 & 591575 & 901015 & & & 3331024 & 200226 & 54607 \\
\hline & & 515 & 4605 & 52962 & 59870 & 59870 & 87503 & & & 421395 & 23027 & 4605 \\
\hline & & 540 & 21236 & 148652 & 155731 & 99102 & 254832 & & & 1840457 & 63708 & 35393 \\
\hline & & 574 & 152899 & 3057990 & 840947 & 1146746 & 2140593 & & & 15137049 & 1070296 & 535148 \\
\hline
\end{tabular}




\section{Lebenslauf}

Persönliche Daten

Name

Staatsangehörigkeit geboren

Schulbildung

Allgemeine Hochschulreife

Auslandsaufenthalt

\section{Studium}

Titel der Diplomarbeit

Promotion
Ina Begemann

deutsch

4.3.1972 in Rinteln

$1978-1991$

5.6.1991 Gymnasium Adolfinum in Bückeburg

Juli 1991 - Juli 1992

Als Praktikantin in Südafrika an der „Deutschen Schule Hermannsburg"(Natal).

1992 - 2000 Georg-August-Universität Göttingen, Biologie Diplomstudiengang

„Untersuchungen zur Vegetations- und Siedlungsgeschichte im Bereich des Tagebaus Cottbus Nord (Niederlausitz)." Durchgeführt am Albrecht-von-Haller-Institut für Pflanzenwissenschaften, Abteilung für Palynologie und Quartärwissenschaften.

1.4.2000 - 31.3.2002 Wissenschaftliche Mitarbeiterin am Institut für Geologie und Dynamik der Lithosphäre an der Universität Göttingen im Rahmen des durch die DFG geförderten Projektes:

"Erdfallsedimente des südwestlichen Harzvorlandes als Zeugen der Umweltgeschichte der letzten 3000 Jahre unter besonderer Berücksichtigung der frühen Metallgewinnung." Anfertigung der vorliegenden. 6.11.2003 Rigorosum in den Fächern Botanik, Anthropologie und Umweltgeschichte. 